\title{
CONTRIBUICÃO AO ESTUDO DAS RESPOSTAS NUMÉRICAS NÃO-LINEARES ESTÁTICA E DINÂMICA DE ESTRUTURAS RETICULADAS PLANAS
}

\section{Cristina Ferreira de Paula}

Tese apresentada à Escola de Engenharia de São Carlos da Universidade de São Paulo, como parte dos requisitos para obtenção do título de Doutor em Engenharia de Estruturas.

Orientador: Prof. Dr. Sergio Persival Baroncini Proença

São Carlos

2001 
Aos meus pais Francisco e Guilhermina, dedico este trabalho. 
"Se o Senhor não constrói a casa,

em vão trabalham os seus construtores

se o Senhor não guarda a cidade,

em vão vigiam os sentinelas.

\section{É inútil que madrugueis \\ e que atraseis o vosso deitar}

para comer o pão com duros trabalhos;

ao seu amado Ele o dá enquanto dorme!

Sim os filhos são a herança do Senhor,

é um salário o fruto do ventre!

Como flechas na mão de um guerreiro

são os filhos da juventude.

Feliz o homem

que encheu sua aljava com tais flechas

não ficará envergonhado frente às portas

ao lutar com seus inimigos. “

Salmo 127 


\section{AGRADECIMENTOS}

A Deus por mais esta oportunidade e pela força em todos os instantes de minha vida.

Ao Prof. Dr. Sérgio P. B. Proença pela excelente orientação, amizade e incentivo durante a realização deste trabalho. Uma pessoa que, com certeza, sempre guardarei na lembrança como a figura de um grande orientador.

A toda a minha família, eterna gratidão pelo apoio, amor e carinho em todos os momentos. Pessoas que sempre partilharam comigo alegrias, tristezas, dores, sucessos e fracassos.

Aos amigos, tesouros, que conquistei no convívio destes anos, de modo especial Priscila, Cristiane, Karla, Carlos, Mário, Maria Cristina, Aline, Ana Rita, Suzana, Ana Cláudia, Larissa, Ana Elizabete, Rejane e Felício.

Aos irmãos neocatecúmenos da comunidade 1 do São Rafael, pela convivência durante todos estes anos.

Aos colegas e funcionários do Departamento de Estruturas da Escola de Engenharia de São Carlos.

A Maria Nadir Minatel, pelo auxílio no trabalho de referências bibliográficas.

A todas as pessoas que direta ou indiretamente contribuíram para a realização deste trabalho.

Ao CNPq, pelo apoio financeiro. 


\section{SUMÁRIO}

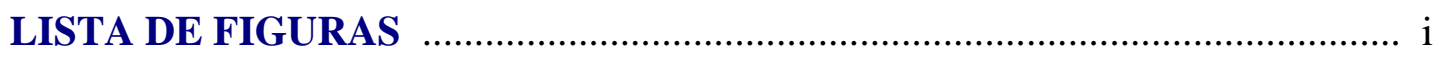

LISTA DE TABELAS E QUADROS …................................................. vi

LISTAS DE SÍMBOLOS E ABREVIATURAS ........................................ vii

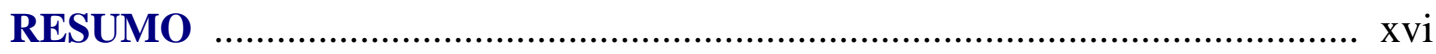

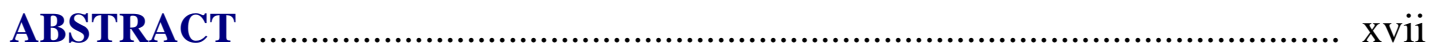

\section{INTRODUÇÃO}

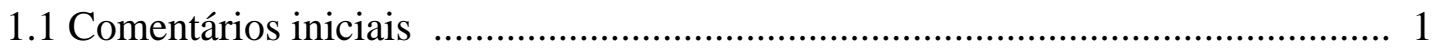

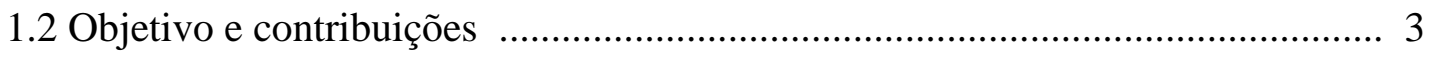

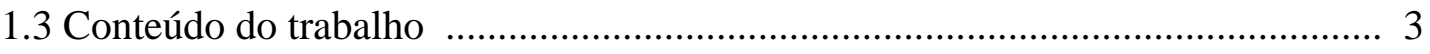

2 CONSIDERAÇÃO DA NÃO-LINEARIDADE GEOMÉTRICA EM ESTRUTURAS RETICULADAS PLANAS: TRELIÇAS E PÓRTICOS

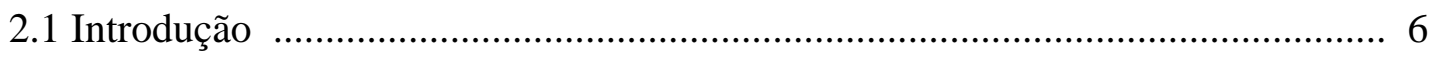

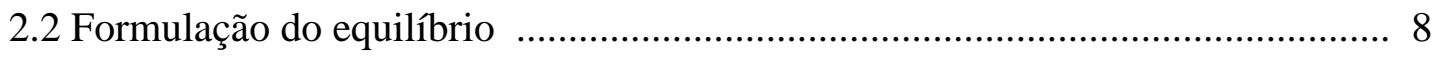

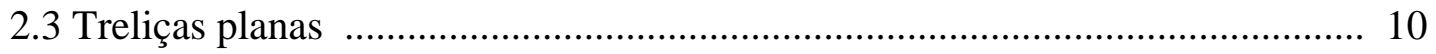

2.3.1 Considerações sobre tensão e deformação ................................................ 10

2.3.2 Aplicação do método dos elementos finitos: matriz de rigidez tangente e vetor

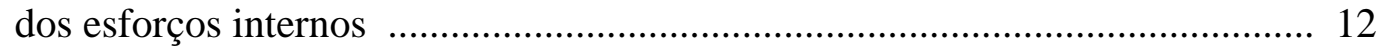


2.4.1 Descrição do campo de deslocamento do regime de flexão: análise plana ... 20

2.4.2 Relação deformação-deslocamento

2.4.3 Relação entre os tensores de tensão e de deformação

2.4.4 Aplicação do método dos elementos finitos: matriz de rigidez tangente e vetor dos esforços internos

2.4.5 Implementação numérica das formulações lagrangianas total e atualizada

2.4.6.2 Exemplo 2 - Viga em balanço com carga aplicada na extremidade livre .. 34

2.4.6.3 Exemplo 3- Viga em balanço com momento aplicado na extremidade livre

\section{CONSIDERAÇÃO DAS NÃO-LINEARIDADES FÍSICA E GEOMÉTRICA EM PÓRTICOS PLANOS DE CONCRETO ARMADO}

3.1 Introdução

3.2 Elementos da mecânica do dano contínuo 
3.4 Modelo constitutivo de La Borderie ............................................................. 51

3.4.1 Implementação do Modelo de La Borderie para o caso unidimensional 55

3.5 Combinação dos modelos de dano com a não-linearidade geométrica 60

3.5.1 Modelo de Mazars combinado com não-linearidade geométrica 60

3.5.2 Modelo de La Borderie combinado com não-linearidade geométrica 62

3.6 Modelo constitutivo para o aço 63

3.7 Discretização da seção de concreto armado e integração numérica 64

3.8 Exemplos numéricos 66

3.8.1 Exemplo 1 - Vigas bi-apoiadas 66

3.8.2 Exemplo 2 - Viga simplesmente apoiada carregada por força axial excêntrica 69

3.8.3 Exemplo 3 - Pórtico simples em concreto armado 71

\section{CONSIDERAÇÃO DO EFEITO DINÂMICO}

4.1 Introdução 74

4.2 Equação de movimento via Princípio dos Trabalhos Virtuais 75

4.3 Matriz de massa 80

4.4 Matriz de amortecimento 80

4.5 Método de integração numérica no domínio do tempo 82

4.5.1 Procedimento implícito de Newmark 83 
4.5.2 Método de Newmark combinado com o procedimento incremental iterativo de Newton-Raphson

4.6 Exemplos numéricos

4.6.1 Viga biengastada de material homogêneo com massa concentrada no meio do vão

4.6.2 Pórtico em concreto armado 90

4.6.3 Viga bi-apoiada em concreto armado 93

\section{SÍNTESE DO TRABALHO E CONCLUSÕES}

5.1 Considerações finais e conclusões

5.2 Sugestões para trabalhos futuros

REFERÊNCIAS BIBLIOGRÁFICAS

BIBLIOGRAFIA CONSULTADA

ANEXO A 


\section{LISTA DE FIGURAS}

\section{Capítulo 2}

Figura 2.1- Deformação de uma fibra genérica - SILVA (1996)

Figura 2.2- Elemento finito de treliça plana no sistema de coordenadas globais e locais

Figura 2.3- Treliça simples

Figura 2.4- Gráficos carga-deslocamento 18

Figura 2.5- Gráficos carga-deslocamento 18

Figura 2.6- Deslocamentos de pontos da barra 20

Figura 2.7- Elemento diferencial do eixo da barra antes e depois da deformação

Figura 2.8- Elemento finito de pórtico plano no sistema de coordenadas globais e locais

Figura 2.9- Pórtico simples - adaptado de ELIAS (1986) 33

Figura 2.10- Curva carga-deslocamento

Figura 2.11- Tempo de processamento

Figura 2.12- Viga em balanço 35

Figura 2.13- Curva carga paramétrica-deslocamento adimensional $\mathrm{u} / \mathrm{L}$ 35

Figura 2.14- Curva carga paramétrica-deslocamento adimensional v/L 36

Figura 2.15- Curva carga paramétrica-rotação (rad) 36

Figura 2.16- Tempo de processamento 
Figura 2.17- Viga em balanço

Figura 2.18- Tempo de processamento

\section{Capítulo 3}

Figura 3.1- Elemento de volume representativo

Figura 3.2- Dano de uma barra com tração uniaxial - adaptada de KATTAN \& VOYIADJIS (1990)

Figura 3.3- Curva tensão/deformação para ensaio de tração uniaxial 46

Figura 3.4- Espaço das deformações principais 47

Figura 3.5- Diagrama tensão/deformação - MAZARS et al (2000) 60

Figura 3.6- Diagrama tensão/deformação para aço com encruamento linear 63

Figura 3.7- Discretização da seção de concreto armado 64

Figura 3.8- Divisão da seção transversal de concreto em estratos 65

Figura 3.9- Geometria e armação das vigas, dimensões em cm 67

Figura 3.10- Curva carga/deslocamento - Viga $3 \phi 10 \mathrm{~mm}$ 68

Figura 3.11- Curva carga/deslocamento - Viga 5 ф $10 \mathrm{~mm}$ 68

Figura 3.12- Curva carga/deslocamento - Viga $7 \phi 10 \mathrm{~mm}$ 69

Figura 3.13- Viga biapoiada 69

Figura 3.14- Curva carga/deslocamento 70

Figura 3.15- Pórtico de concreto armado 72

Figura 3.16- Curva carga horizontal/deslocamento horizontal 72 


\section{Capítulo 4}

Figura 4.1- Viga biengastada com massa concentrada no meio do vão 88

Figura 4.2- Curva deslocamento vertical do ponto B versus tempo 89

Figura 4.3- Curva deslocamento vertical do ponto B versus tempo 89

Figura 4.4- Pórtico simples de concreto armado 90

Figura 4.5- Variação da força $\mathrm{F}(\mathrm{t})$ com o tempo 91

Figura 4.6- Geometria da viga e armação da seção transversal - dimensões $\mathrm{em} \mathrm{cm}$

Figura 4.7- Curva deslocamento versus tempo - vibração forçada não amortecida

Figura 4.8- Curva deslocamento versus tempo - vibração forçada não amortecida 96

Figura 4.9- Curva deslocamento versus tempo - vibração forçada não amortecida 97

Figura 4.10- Curva deslocamento versus tempo - vibração forçada amortecida 97

Figura 4.11- Curva deslocamento versus tempo - vibração forçada amortecida 98

Figura 4.12- Curva deslocamento versus tempo - vibração forçada amortecida 98

Figura 4.13- Curva deslocamento versus tempo - vibração forçada amortecida 99

Figura 4.14- Curva deslocamento versus tempo - vibração livre não amortecida 
Figura 4.15- Curva deslocamento versus tempo - vibração livre não amortecida 100

Figura 4.16- Curva deslocamento versus tempo - vibração livre não amortecida 101

Figura 4.17- Curva deslocamento versus tempo - vibração livre não amortecida 101

Figura 4.18- Curva deslocamento versus tempo - vibração livre amortecida 102

Figura 4.19- Curva deslocamento versus tempo - vibração livre amortecida 103

Figura 4.20- Curva deslocamento versus tempo - vibração livre amortecida 103

Figura 4.21- Curva deslocamento versus tempo - vibração livre amortecida 104

Figura 4.22- Curva deslocamento versus tempo - vibração livre amortecida 105

Figura 4.23- Curva deslocamento versus tempo - vibração livre amortecida 105

Figura 4.23a- Curva deslocamento versus tempo - vibração livre amortecida 106

Figura 4.24- Curva velocidade do meio da viga versus tempo - vibração livre amortecida 107

Figura 4.25- Curva aceleração do meio da viga versus tempo - vibração livre amortecida 107 
Figura 4.26- Curva primeiro modo de vibração livre versus tempo - vibração forçada 108

Figura 4.27- Curva primeiro modo de vibração livre versus tempo - vibração livre 109

Figura 4.28- Curva primeiro modo de vibração livre versus tempo - vibração livre 109

Figura 4.29- Variação da força $P(t)=10 \cos \left(\omega_{\mathrm{e}} \mathrm{t}\right)$ com o tempo $-\omega_{\mathrm{e}}=62.83$ 110

Figura 4.30- Curva deslocamento versus tempo - vibração forçada não amortecida 111

Figura 4.31- Curva deslocamento versus tempo - vibração forçada não amortecida 111

Figura 4.32- Curva deslocamento versus tempo - vibração forçada não amortecida

Figura 4.33- Variação da força $P(t)=10 \operatorname{sen}\left(\omega_{\mathrm{e}} \mathrm{t}\right)$ com o tempo $-\omega_{\mathrm{e}}=62.83$

Figura 4.34- Curva deslocamento versus tempo - vibração forçada não amortecida 113

Figura 4.35- Curva deslocamento versus tempo - vibração forçada não amortecida 114

Figura 4.36- Curva deslocamento versus tempo - vibração forçada não amortecida 114 


\section{LISTA DE TABELAS E QUADROS}

\section{Capítulo 2}

Tabelas 2.1- Coordenadas (x,y) e rotação $(\theta)$ da extremidade livre 38

\section{Capítulo 3}

Tabelas 3.1- Expressões das tensões, módulo de rigidez e deformações anelásticas LA BORDERIE (1991)

\section{Capítulo 4}

Tabelas 4.1- Deslocamentos máximos, em cm, obtidos no nó '5' na direção global x, para $0 \leq t \leq 0.064 s$

Tabela 4.2- Valores do deslocamento vertical do meio do vão - análise estática ... 95

Quadro 4.1- Solicitação constante ao longo do tempo 78

Quadro 4.2- Solicitação linearmente variável num certo intervalo inicial de tempo

Quadro 4.3- Solicitação incremental constante no tempo 79

Quadro 4.4- Solicitação em forma de pulso 79

Quadro 4.5- Solicitações harmônicas 80

Quadro 4.6- Algoritmo de Newmark combinado com o método de NewtonRaphson 


\section{LISTA DE SÍMBOLOS}

$A_{o}=$ área na configuração indeformada sem dano

$\tilde{A}=$ área efetiva resistente

$A_{D}=$ área danificada

$\mathrm{a}=$ projeção horizontal da treliça

$A_{T}, B_{T}=$ parâmetros característicos do material na tração uniaxial

$A_{C}, B_{C}=$ parâmetros característicos do material na compressão uniaxial

$A, B, \underline{B}_{L}, \underline{B}_{N L}, C=$ matrizes auxiliares

$A_{i}, B_{i}$ e $Y_{0 i}=$ parâmetros a serem identificados no modelo de dano de La Borderie

$\underline{B}, \underline{B}_{a}=$ matrizes que relacionam a deformação axial com os deslocamentos

$b_{o}=$ forças por unidade de volume na configuração inicial

$\dot{b}_{o}=$ taxa da força por unidade de volume na configuração inicial

$b s=$ largura da seção transversal

$\underline{C}=$ matriz de amortecimento do sistema

$\underline{\underline{D}}_{0}=$ matriz constitutiva do material íntegro

$D_{11}=$ módulo de rigidez tangente

$D_{1}=$ variável de dano na tração para o modelo de La Borderie

$D_{2}=$ variável de dano na compressão para o modelo de La Borderie 
$D_{c}=$ variável de dano na compressão para o modelo de Mazars

$d S, d X=$ comprimentos final e inicial de uma fibra genérica

$D_{T}=$ variável de dano na tração para o modelo de Mazars

$\dot{D}=$ taxa de dano

$d A_{o}=$ diferencial de área na configuração indeformada

$d V_{o}=$ diferencial de volume na configuração indeformada

$\bar{d}_{i}=$ deslocamento prescrito na coordenada $\mathrm{i}$

$d_{0}=$ vetor deslocamento do eixo da barra

$\dot{d}=$ derivada do vetor de deslocamento em relação ao tempo (velocidade)

$\ddot{d}=$ vetor aceleração

$E=$ módulo elástico de rigidez do material íntegro

$E_{D}, \widetilde{E}=$ módulos de rigidez do material danificado

$E_{G}=$ módulo elástico de rigidez que relaciona $S$ e $\varepsilon_{G}$

$E_{X 0}=$ deformação linear de um segmento do eixo da barra

$F=$ tensor gradiente de deformação

$F(\widetilde{\varepsilon})=$ função que governa a evolução do dano no modelo de Mazars

$f_{c}=$ resistência à compressão do concreto

$f_{d}=$ forças dissipativas

$f_{m}=$ forças inerciais 
$f_{t}=$ resistência à tração do concreto

$f_{y}=$ tensão de escoamento do aço

$f(\underline{\sigma})=$ função que leva em conta a abertura e o fechamento de fissuras

$f^{\prime}(\underline{\sigma})=$ derivada da função $f(\underline{\sigma})$ com relação a $\underline{\sigma}$

$\underline{G}, \underline{G}_{a}=$ matrizes que relacionam a taxa de deformação virtual com os deslocamentos

$G_{l}\left(z_{1}\right), G_{2}\left(z_{2}\right)=$ funções de encruamento no modelo de dano de La Borderie

$h=$ altura da treliça com relação à horizontal

$h_{e}=$ altura dos estratos

$h s=$ altura da seção transversal

$I=$ tensor identidade ou momento de inércia

$k$ = curvatura do eixo da barra

$\underline{K}_{L}=$ matriz de rigidez de correção das coordenadas

$\underline{K}_{0}=$ matriz de rigidez elástica linear inicial

$\underline{K}_{\sigma}=$ matriz de rigidez geométrica

$\underline{K}_{T}=$ matriz de rigidez tangente

$L=$ comprimento atual da barra

$L_{0}=$ comprimento inicial da barra

$M=$ massa concentrada

$\underline{M}=$ matriz de massa do sistema 
$N=$ força normal

$\bar{N}=$ razão entre a força normal e o estiramento $\lambda$

$n=$ versor normal à superfície do elemento representativo de volume

$n c=$ número de coordenadas nodais

$n_{e}=$ número de estratos na altura da seção transversal

$N_{i}=$ funções interpoladoras

$P=$ carga genérica aplicada

$q=$ vetor dos deslocamentos nodais

$q_{i}=$ deslocamento nodal correspondente ao grau de liberdade $\mathrm{i}$

$r_{0}=$ resíduo de forças

$\underline{R}=$ tensor ortogonal próprio

$\underline{S}=$ tensor de tensão de Piola-Kirchhoff de $2^{\mathrm{a}}$ espécie

$\underline{S}_{0}=$ tensor de tensão de Piola-Kirchhoff de $2^{\underline{a}}$ espécie na configuração anterior

$s(D)=$ máximo da deformação equivalente a partir do instante que $\widetilde{\varepsilon}>\varepsilon_{d 0}$

$t=$ tempo

$\bar{t}_{o}=$ força por unidade de área na configuração inicial

$\dot{\bar{t}}_{o}=$ taxa da força por unidade de área na configuração inicial

$\operatorname{Tr}(\underline{\sigma})=$ primeiro invariante do tensor de tensão

$u^{\prime}=$ derivada primeira do deslocamento axial com relação a x

$u^{\prime \prime}=$ derivada segunda do deslocamento axial com relação a $\mathrm{x}$ 
$U=$ tensor simétrico definido positivo

$u(x)=$ deslocamento axial de pontos do eixo da barra

$v(x)=$ deslocamento transversal de pontos do eixo da barra

$u_{p}(x, y)=$ componente axial do deslocamento de pontos genéricos da barra

$v_{p}(x, y)=$ componente transversal do deslocamento de pontos do eixo da barra

$v^{\prime}=$ derivada primeira do deslocamento transversal com relação a $\mathrm{X}$

$v^{\prime \prime}=$ derivada segunda do deslocamento transversal com relação a $\mathrm{X}$

$V_{o}=$ volume na configuração inicial

$\{x\}=$ vetor das posições nodais na configuração atualizada

$\left\{X_{0}\right\}=$ vetor das posições nodais na configuração anterior

$\underline{X}=$ vetor posição

$z_{1}$ e $z_{2}=$ medidas de dano acumulado

$Z_{1}$ e $Z_{2}=$ variáveis associadas a $z_{1}$ e $z_{2}$, respectivamente

$Y_{1}$ e $Y_{2}=$ taxas de energia liberada durante o processo de evolução do dano

$\alpha=$ giro da seção transversal

$\alpha_{1}, \alpha_{2}=$ coeficientes relacionados com as medidas de $D_{1}$ e $D_{2}$

$\alpha_{c}=$ coeficiente do dano na compressão no modelo de Mazars

$\alpha_{T}=$ coeficiente do dano na tração no modelo de Mazars

$\beta$ e $\gamma=$ parâmetros de Newmark 
$\beta_{1}$ e $\beta_{2}=$ parâmetros relacionados ao aparecimento de deformações anelásticas

$\underline{\phi}(x)=$ matriz que contém as funções de forma

$\underline{\phi}_{M}(x)=$ matriz que interpola o vetor deslocamento de um ponto genérico do elemento finito de pórtico plano

$\psi=$ vetor resíduo de forças

$\varepsilon_{L}=$ medida de deformação linear

$\varepsilon_{G}, \varepsilon=$ medidas de deformação de Green

$\dot{\varepsilon}=$ taxa da deformação de Green

$\underline{\dot{\varepsilon}}=$ tensor taxa de deformação de Green

$\underline{\varepsilon}=$ tensor de deformação de Green

$\varepsilon_{x}=$ deformação longitudinal de Green aproximada

$\varepsilon_{x x}=$ deformação longitudinal de Green completa

$\varepsilon_{x 0}=$ deformação longitudinal de Green completa no eixo da barra

$\varepsilon_{d 0}=$ deformação elástica limite

$\widetilde{\varepsilon}=$ deformação equivalente

$\underline{\varepsilon}_{e}=$ tensor de deformação elástica

$\underline{\varepsilon}_{a n}=$ tensor de deformação anelástica

$\delta U=$ energia de deformação virtual

$\Delta t=$ incremento de tempo 
$\delta \dot{\varepsilon}=$ taxa de deformação virtual de Green

$\delta \varepsilon=$ deformação virtual de Green

$\delta \underline{\dot{\varepsilon}}=$ tensor taxa de deformação virtual de Green

$\delta \underline{\varepsilon}=$ tensor de deformação virtual de Green na configuração inicial

$\delta W_{e}=$ trabalho virtual externo

$\delta W=$ trabalho virtual total

$\delta q=$ vetor dos deslocamentos virtuais nodais

$\nabla u=$ gradiente dos deslocamentos na configuração inicial

$\lambda=$ estiramento

$\lambda_{k}=$ constante de amortecimento proporcional à rigidez da estrutura

$\lambda_{m}=$ constante de amortecimento proporcional à massa da estrutura

$\Lambda=$ autovalores

$v=$ coeficiente de Poisson

$\eta=$ coeficiente relativo à evolução do dano de Mazars na matriz de rigidez tangente

$\mu$ = parâmetro de amortecimento viscoso do material

$\xi_{i}=$ frações de amortecimento crítico

$\sigma=$ tensão de Cauchy

$\underline{\sigma}=$ tensor de tensão de Cauchy

$\sigma_{N}=$ tensão nominal 
$\tilde{\sigma}=$ tensão efetiva

$\sigma_{f}=$ tensão de fechamento de fissuras

$\underline{\dot{S}}=$ tensor taxa de tensão de Piola-Kirchhoff de $2^{\mathrm{a}}$ espécie na configuração de referência

$\dot{q}=$ vetor das velocidades nodais

$\ddot{q}=$ vetor das acelerações nodais

$\{\Delta u\}=$ vetor dos deslocamentos incrementais

$\Delta \underline{S}=$ incremento do tensor de tensão

$\left\langle\varepsilon_{i}\right\rangle_{+}=$i-ésima componente positiva do vetor de deformações principais

$\rho=$ densidade específica do material

$\omega_{1}=$ menor freqüência natural de vibração da estrutura

$\omega_{2}=$ freqüência relacionada ao carregamento externo ou a subsequente à $\omega_{1}$

$\langle\sigma\rangle_{+} \mathrm{e}\langle\sigma\rangle_{-}=$partes positiva e negativa do tensor de tensões principais fictício

$\tau=$ tempo auxiliar

$\nabla()=$. operador gradiente com relação às coordenadas iniciais 


\section{ABREVIATURAS}

$\mathrm{CG}=$ centro geométrico da seção transversal da barra

$\mathrm{EVR}=$ elemento de volume representativo

$\mathrm{F}^{\mathrm{ext}}=$ vetor das forças externas

$\mathrm{F}^{\mathrm{int}}=$ vetor das forças internas

PTV = Princípio dos Trabalhos Virtuais

P-K = Piola-Kirchhoff

NLF = não-linear físico, não-linearidade física

NLG = não-linear geométrico, não-linearidade geométrica

$\mathrm{TOL}=$ tolerância 


\section{RESUMO}

PAULA, C.F. (2001). Contribuição ao estudo das respostas numéricas não-lineares estática e dinâmica de estruturas reticuladas planas. São Carlos. 128p. Tese (Doutorado) - Escola de Engenharia de São Carlos, Universidade de São Paulo.

O trabalho trata da formulação e implementação numérica de modelos matemáticos do comportamento de estruturas considerando-se as não-linearidades física e geométrica. O equilíbrio na posição deslocada é formulado via Princípio dos Trabalhos Virtuais, empregando-se o método dos elementos finitos para a discretização espacial das estruturas e busca de soluções aproximadas. Inicialmente destaca-se com base no caso de treliças planas o emprego de medidas de deformação e tensão conjugadas energeticamente. Particularizando-se a formulação geral do equilíbrio para os pórticos planos apresenta-se uma análise crítica das formulações lagrangiana total e atualizada. Em seguida, tendo-se em vista aplicações às estruturas em concreto armado, aborda-se o comportamento não-linear físico pela mecânica do dano em meios contínuos, empregando-se os modelos de dano para o concreto propostos por Mazars e La Borderie. Estendem-se os estudos do comportamento estrutural não-linear físico (dano) e geométrico incorporando-se a análise dinâmica. Utiliza-se para integração no domínio do tempo o método implícito de Newmark combinado com o procedimento incremental e iterativo de Newton-Raphson. O amortecimento é levado em conta por meio da regra de Rayleigh. Exemplos consistindo de análises não-lineares estática e dinâmica de estruturas reticulares planas compõem as aplicações numéricas. Os resultados obtidos ilustram o desempenho e as potencialidades das formulações empregadas.

Palavras-chave: Análise não-linear, não-linearidade geométrica, não-linearidade física, Mecânica do Dano, análise dinâmica não-linear. 


\section{ABSTRACT}

PAULA, C.F. (2001). Contribution to the study of static and dynamic numerical nonlinear responses of plane frames. São Carlos. 128p. Tese (Doutorado) - Escola de Engenharia de São Carlos, Universidade de São Paulo.

The formulation and numerical implementation of mathematical models of the structural behavior of plane frames considering material and geometrical nonlinearities are treated in this work. The Principle of Virtual Work is presented in order to characterize the equilibrium in the displaced position. The structure is discretized by the finite element method. Plane trusses analysis is performed in order to show how important it is to take into account the strain and stress tensors energetically conjugated. Being particularized, the general equilibrium formulation for the plane frames a critical analysis of the total and updated lagrangian formulations is presented. The material nonlinear behavior is modeled by continuum damage mechanics by using both Mazars and La Boderie's damage models. The nonlinear analysis is extended including the dynamic response of the reinforced concrete plane frames. The usual iterative Newton-Raphson technique is used combined with implicit Newmark method in order to carry out the integration at time. The damping is introduced by means of the Rayleigh's rule. Numerical analysis by a suitable computer program show the theoretical results considering static and dynamic response of plane frames.

Keywords: Nonlinear analysis, geometrical nonlinearity, material nonlinearity, damage mechanic, nonlinear dynamic. 


\section{1}

INTRODUÇÃO

"A sabedoria não se transmite por si mesma, é preciso que nós a encontremos depois de uma caminhada que ninguém pode fazer por nós e que ninguém nos pode evitar. Porque a sabedoria é uma maneira própria de ver as coisas."

Maral Proust

\subsection{COMENTÁRIOS INICIAIS}

Recentemente o estudo das respostas estruturais em regimes não-lineares estático e dinâmico tem sido intensamente desenvolvido por vários pesquisadores, sendo que a literatura sobre o assunto tem-se tornado rapidamente muito vasta do ponto de vista geral. Deste modo, optou-se por não compor um capítulo que pudesse se constituir num estado da arte sobre o assunto e sim destacar algumas das principais referências bibliográficas empregadas no desenvolvimento deste trabalho. De maneira resumida e objetiva, pode-se afirmar que tais referências abordam, com maior ênfase, aspectos numéricos e de formulação referentes às análises não-lineares estática e dinâmica de estruturas reticuladas planas, aqui conduzidas.

Dentre inúmeros trabalhos publicados, podem ser destacados alguns relacionados à formulação teórica da resposta não-linear geométrica e que foram mais detalhadamente estudados: HINTON (1993), BATHE (1996), CRISFIELD (1991), SOUZA LIMA \& VENÂNCIO FILHO (1982), GARCIA \& VILLAÇA (1999), PAULA (1997), PIMENTA (1988). Quanto às questões relativas à implementação numérica 
estudaram-se com maior profundidade: PIMENTA (1996), SILVA (1996), CORREA (1991), BATHE (1996), CRISFIELD (1991) e MAZZILLI (1988).

Por sua vez, os estudos sobre a resposta não-linear do material têm se desenvolvido a cada dia pela busca de modelos mecânico-matemáticos que sejam capazes de simular com melhor precisão tal comportamento. Nesse campo, também de maior interesse para este trabalho, destacam-se alguns estudos que tratam da aplicação da teoria da plasticidade e da mecânica do dano em meios contínuos: LEMAITRE \& CHABOCHE (1990), LEMAITRE (1992), MAZARS (1984), KATTAN \& VOYADJIS (1990), PEREGO (1990), LA BORDERIE (1991), ALTENBACH et al (1997), MAZARS et al (2000) e LEMAITRE (2000).

No âmbito da EESC-USP, alguns trabalhos têm sido desenvolvidos com relação ao emprego dos modelos de dano, destacando-se: ÁLVARES (1993), DRIEMEIER (1995), BOTTA (1998), PITUBA (1998), BALBO (1998), DRIEMEIER (1999), ÁLVARES (1999) e NEVES (2000).

Diante do aperfeiçoamento alcançado pelos modelos mecânico-matemáticos que permitem simular numericamente o comportamento estrutural estático não-linear físico e geométrico, nos dias de hoje a atenção na análise estrutural tem se voltado progressivamente para a extensão do estudo para a simulação da resposta dinâmica em campo não-linear.

Com relação à resposta linear dinâmica podem-se citar algumas referências clássicas tais como: WARBURTON (1976), HUGHES (1987), COOK (1989), ARGYRIS \& MLEJNEK (1991), PAZ (1991), CLOUGH \& PENZIEN (1993) e BATHE (1996). Dentre os trabalhos relacionados à análise dinâmica não-linear geométrica podem-se citar os seguintes: BRASIL (1990) e BRASIL \& MAZZILLI (1993). Já quanto à análise dinâmica não-linear física destacam-se: LA BORDERIE(1991), VEIZAGA (1993), RIOS(1994), MAZARS et al (2000) e HATZIGEORGIOU \& BESKOS (2000); e, finalmente quanto às análises dinâmicas não-lineares física e geométrica estudouse, particularmente: RODRIGUES (1997). 
Vale ressaltar que os trabalhos consultados, embora não diretamente referenciados no texto, foram de grande importância na realização do trabalho.

\subsection{OBJETIVO E CONTRIBUIÇÕES}

Este trabalho tem como principal objetivo oferecer contribuições para a simulação numérica dos comportamentos não-lineares físico e geométrico de estruturas reticulares planas nos regimes de respostas estática e dinâmica.

Pelo lado da não-linearidade geométrica apresenta-se um estudo comparativo relativo à implementação numérica das formulações lagrangiana total e atualizada aplicada à análise de pórticos planos.

Relativamente à análise não-linear física, no campo numérico destaca-se o emprego das quadraturas de Gauss e Gauss-Lobatto nas integrações numéricas das tensões na seção transversal do elemento estrutural. Também merece ser ressaltada a combinação de uma formulação não-linear geométrica com a não-linearidade física decorrente de um processo de danificação progressiva.

A extensão dos modelos estudados para a dinâmica não-linear é outra contribuição que deve ser destacada.

\subsection{CONTEÚDO DO TRABALHO}

Como resultado de uma atividade de estudos 'incremental e iterativa', o conteúdo deste trabalho se encontra organizado como se segue.

No capítulo 2 apresenta-se a formulação não-linear geométrica com aplicação a estruturas reticulares planas: treliças e pórticos. A formulação do equilíbrio na posição deslocada é apresentada via Princípio dos Trabalhos Virtuais. Aproveitandose a aplicação às treliças planas, destaca-se o emprego de medidas de deformação e tensão conjugadas energeticamente . Com aplicação aos pórticos planos desenvolvese uma discussão sobre as formulações lagrangianas total e atualizada do equilíbrio. 
Nessa aplicação, emprega-se a medida de deformação de Green, nas formas completa e aproximada, e a tensão de Piola-Kirchhoff de segunda espécie, considerando-se um regime de pequenas deformações. Os exemplos ilustram numericamente respostas não-lineares geométricas de treliças e pórticos planos.

No capítulo 3 apresenta-se uma abordagem para a análise do comportamento nãolinear físico e geométrico de estruturas reticuladas planas de concreto armado, em especial vigas e pórticos. Coloca-se em destaque o comportamento não-linear físico modelado pela mecânica do dano em meios contínuos. Empregam-se os modelos constitutivos de Mazars e de La Borderie, porém outros modelos poderiam ter sido empregados. Os exemplos ilustram numericamente as respostas obtidas verificandose que em certos casos a combinação das não-linearidades física e geométrica é absolutamente necessária para a realização de uma simulação numérica de boa qualidade.

No capítulo 4 estende-se o tratamento anterior para a análise dinâmica de estruturas reticulares planas, considerando-se os comportamentos não-lineares físico e geométrico. Para integração numérica no domínio do tempo utiliza-se o método implícito de Newmark combinado com o procedimento incremental e iterativo de Newton-Raphson. Os exemplos considerando-se as vibrações forçada e livre, com e sem amortecimento, ilustram particularmente a influência da danificação sobre a resposta dinâmica de estruturas aporticadas planas em concreto armado.

No capítulo 5 são apresentadas as considerações finais e conclusões observadas a partir do conjunto de resultados obtidos nos capítulos anteriores. Algumas sugestões para posteriores investigações complementam o capítulo.

No anexo A apresenta-se um breve estudo sobre o procedimento de análise incremental com deslocamentos controlados utilizado neste trabalho.

No anexo B são apresentados gráficos que ilustram as respostas obtidas empregandose diferentes métodos para a integração das tensões ao longo da altura da seção transversal do elemento finito de pórtico plano. Esse estudo permitiu definir o 
número de pontos de integração numérica, utilizado neste trabalho, para o emprego das regras de quadratura. 


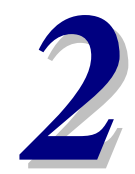

\title{
CONSIDERAÇÃO DA NÃO-LINEARIDADE GEOMÉTRICA EM ESTRUTURAS RETICULADAS PLANAS: TRELIÇAS E PÓRTICOS
}

\author{
"O verdadeiro significado das coisas é encontrado \\ ao se dizer as mesmas coisas com outras palavras." \\ Charles Chaplin
}

\subsection{INTRODUÇ̃̃O}

A análise estrutural linear clássica pressupõe proporcionalidade entre carga e deslocamento. As condições para que essa proporcionalidade se verifique são: resposta elástica linear do material e pequenos deslocamentos.

A condição de resposta linear do material pode ser garantida limitando-se os níveis de tensão e deformação. Entretanto, a de pequenos deslocamentos pode ter implicações que vão além do sentido puramente geométrico.

De forma mais completa entende-se por 'pequenos deslocamentos' aqueles que não influem na condição de equilíbrio, isto é, sem erro significativo as equações de equilíbrio podem ser escritas referindo-se à estrutura na posição indeslocada.

Essa forma mais completa, juntamente com a linearidade de resposta do material, garante a proporcionalidade entre carga e deslocamentos globais. Em muitos 
problemas, porém, mesmo que o campo de deslocamentos do sistema possa ser considerado pequeno, é necessário escrever as equações de equilíbrio na posição deslocada, sob pena de serem desprezadas parcelas importantes, como às referentes às deformações axiais, ao se referir à posição indeslocada.

As análises resultantes de uma abordagem na qual a verificação do equilíbrio é feita na posição deslocada, mas o material se mantém num regime de resposta linear elástica, são aqui denominadas análises geometricamente não-lineares.

Decorrem de um tratamento estático não-linear geométrico: a determinação da trajetória de equilíbrio apresentada pela estrutura sob ação de um determinado carregamento e o estudo da instabilidade do equilíbrio, pelo aparecimento de ponto limite ou ponto de bifurcação.

Neste capítulo, trata-se da não-linearidade geométrica de estruturas reticuladas planas, utilizando-se o Princípio dos Trabalhos Virtuais segundo a formulação abordada por HINTON (1993). Considera-se a linearidade física e, portanto, supõe-se válida a lei de Hooke.

Apesar da análise aqui apresentada restringir-se a elementos finitos de treliças e pórticos planos, os conceitos discutidos são gerais e podem ser aplicados a outras estruturas reticuladas, bem como às placas e às cascas.

Nas análises estruturais empregando-se o método dos elementos finitos a maioria dos programas que permitem considerar a não-linearidade geométrica baseia-se em alguma forma de descrição lagrangiana do equilíbrio.

Numa formulação lagrangiana total, o equilíbrio na posição deslocada é referenciado a uma configuração inicial indeformada, isto é, todas as integrais são calculadas tomando-se áreas e volumes da estrutura no tempo $t=0$.

Alternativamente, uma configuração deformada conhecida pode ser tomada como referência e atualizada continuamente ao longo da análise e, neste caso, a formulação é denominada lagrangiana atualizada. 
Existem na literatura algumas divergências quanto à denominação formulação lagrangiana atualizada. Por exemplo, segundo WONG \& TIN-LOI (1990) e BATHE (1996), a formulação lagrangiana atualizada é aquela em que a configuração de referência é a imediatamente anterior à atual, enquanto CRISFIELD (1997) considera a correspondente ao passo de carga anterior equilibrado. PETERSON \& PETERSON (1985) e WONG\&TIN-LOI (1990), definem uma variante da formulação lagrangiana atualizada como lagrangiana parcialmente atualizada cuja configuração de referência é a do passo de carga imediatamente anterior.

Consideram-se, neste capítulo, as formulações lagrangianas total e atualizada, sendo que no segundo caso a atualização da configuração de referência é feita após a convergência de cada incremento de carga, conforme CRISFIELD (1997).

\subsection{FORMULAÇÃO DO EQUILÍBRIO}

Pode-se impor a condição de equilíbrio estático da estrutura utilizando-se o Princípio dos Trabalhos Virtuais, PAULA (1997). Adotando-se uma descrição lagrangiana total, a também chamada forma fraca do equilíbrio representa-se do seguinte modo:

$$
\int_{V_{0}} r_{0} . \delta d d V_{o}=\int_{V_{0}} \underline{S} . \delta \underline{\varepsilon} d V_{0}-\int_{V_{0}} b_{0} . \delta d d V_{0}-\int_{A_{0}} \bar{t}_{0} . \delta d d A_{0}=0
$$

$\mathrm{Na}$ equação (2.1), a primeira parcela da soma de integrais refere-se à energia virtual interna e as duas últimas ao trabalho virtual das cargas externas; $b_{0}$ e $\bar{t}_{0}$ são, respectivamente, forças externas distribuídas por unidade de volume e de superfície da configuração de referência e $\underline{S}$ é o tensor de Piola-Kirchhoff de $2^{\mathrm{a}}$ espécie. Ainda na (2.1), $\delta d$ é o vetor de deslocamentos virtuais cinematicamente admissíveis, $\delta \underline{\varepsilon}$ o tensor de deformações virtuais compatíveis e $r_{0}$ indica o vetor resíduo de forças.

Devido ao fato de que a equação do PTV é essencialmente não-linear nos deslocamentos, sua linearização é normalmente empregada como uma estratégia eficiente para encontrar, de modo iterativo, uma solução que a satisfaça. Deste modo, o método de Newton-Raphson surge da linearização da equação (2.1), obtida a partir 
do truncamento em $1^{\underline{a}}$ ordem do seu desenvolvimento em série em torno do instante $t$, tal como:

$$
\left(\int_{V_{0}} r_{0} . \delta d d V_{0}\right)_{t+\Delta t}=\left(\int_{V_{0}} r_{0} . \delta d d V_{0}\right)_{t}+\frac{d}{d t}\left(\int_{V_{0}} r_{0} . \delta d d V_{0}\right)_{t} \Delta t=0
$$

Neste trabalho optou-se pela estratégia tradicional de Newton-Raphson por ser suficiente para as análises numéricas realizadas. Entretanto, estratégias mais robustas como aquelas derivadas do método de arco poderiam ter sido implementadas. Nas aplicações numéricas, por outro lado, observou-se uma taxa de convergência quadrática com a estratégia de Newton-Raphson.

É importante observar que em análises puramente estáticas a variável tempo que aparece na (2.2) é interpretada apenas como um parâmetro implícito de ordenação de eventos, como passos de carregamento externo aplicado ou de deslocamento imposto.

Para melhor identificação da matriz de rigidez na linearização da equação de equilíbrio, pode-se reescrever, após algumas operações, a equação (2.2) da seguinte forma:

$$
(r)_{t}+\left(\underline{K}_{T} \dot{d}-\dot{f}_{b}-\dot{f}_{t}\right) \Delta t=0
$$

Restringindo-se a análise à consideração somente de forças conservativas, as quais não dependem da deformação, torna-se possível escrever a derivada que aparece na relação (2.2) como:

$$
\frac{d}{d t} \int_{V_{0}} r_{0} . \delta d d V_{o}=\int_{V_{0}} \underline{\dot{S}} . \delta \underline{\varepsilon} d V_{0}+\int_{V_{0}} \underline{S} . \delta \underline{\dot{\varepsilon}} d V_{0}
$$

Dessa relação decorre a rigidez tangente da estrutura. 


\subsection{TRELICGAS PLANAS}

Apresenta-se nesta seção, um estudo do comportamento não-linear geométrico em estruturas treliçadas planas, utilizando-se uma formulação lagrangiana total. As medidas de deformação empregadas são a linear e a de Green, com o objetivo de mostrar a importância de se utilizar uma formulação onde as medidas de deformação e tensão empregadas sejam conjugadas energeticamente. Utiliza-se o conceito de matriz de rigidez tangente, por ser mais adequado para o procedimento incremental iterativo de Newton-Raphson para obtenção da solução numérica; neste caso emprega-se a força ou o deslocamento como parâmetro controlador.

\subsubsection{Considerações sobre tensão e deformação}

Segundo PIMENTA (1986) pode-se definir medidas de deformação baseadas no conceito de estiramento, sendo este definido pela relação entre o comprimento final e o inicial do elemento. Deste modo, para uma fibra genérica de um segmento infinitesimal de barra, conforme apresentado na Figura 2.1, tem-se:

$$
\lambda=\frac{d s}{d x}=\frac{\sqrt{(d x+d u)^{2}+d v^{2}}}{d x}=\sqrt{\left(\frac{d x+d u}{d x}\right)^{2}+\left(\frac{d v}{d x}\right)^{2}}
$$

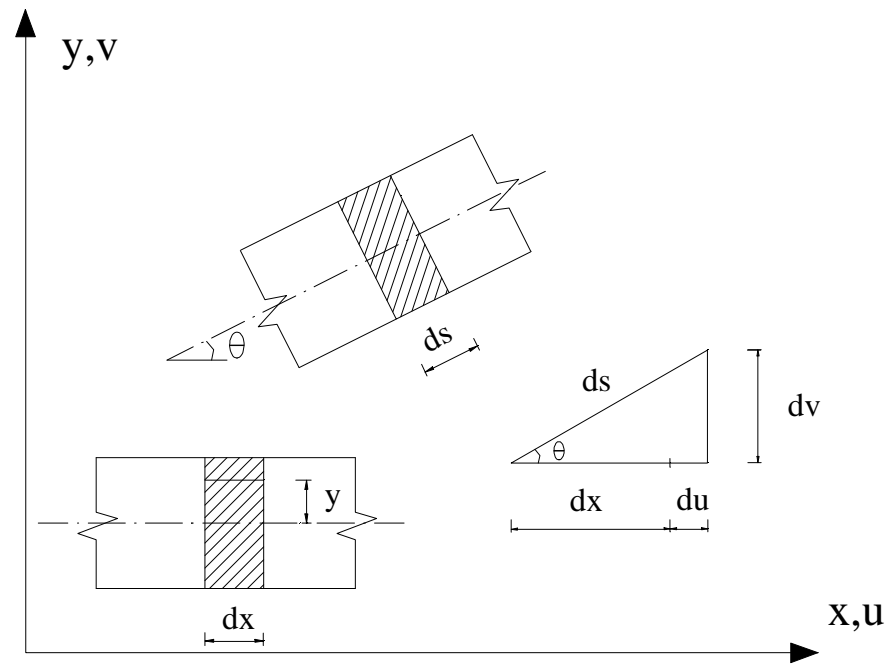

Figura 2.1 - Deformação de uma fibra genérica - SILVA (1996) 
Embora existam, na literatura, várias medidas de deformação, foram utilizadas, neste trabalho, as medidas de deformação quadrática ou de Green, e linear ou de engenharia, respectivamente dadas pelas equações (2.6) e (2.7):

$$
\begin{gathered}
\varepsilon_{G}=\frac{\lambda^{2}-1}{2}=\frac{d u}{d x}+\frac{1}{2}\left[\left(\frac{d u}{d x}\right)^{2}+\left(\frac{d v}{d x}\right)^{2}\right] \\
\varepsilon_{L}=\lambda-1=\sqrt{1+2 \frac{d u}{d x}+\left(\frac{d u}{d x}\right)^{2}+\left(\frac{d v}{d x}\right)^{2}}-1
\end{gathered}
$$

Os tensores de tensão conjugados com os tensores de deformações de Green e linear são o segundo tensor de Piola-Kirchhoff, expresso em campo unidimensional pela equação (2.8) e o tensor de Biot, que em campo unidimensional se confunde com a tensão nominal, dada pela equação (2.9):

$$
\begin{gathered}
S=\frac{\sigma_{N}}{\lambda} \\
\sigma_{N}=\frac{N}{A_{0}}
\end{gathered}
$$

sendo $N$ a força normal e $A_{o}$ a área inicial da seção transversal da barra. Note-se, neste caso, que:

$$
S=\lambda^{-1} \sigma_{N}
$$

Para um modelo elástico-linear, a relação tensão-deformação é dada pela Lei de Hooke. Portanto, considerando-se a deformação linear, tem-se:

$$
\sigma_{N}=E \varepsilon_{L}
$$

e utilizando-se a deformação de Green, resulta:

$$
\sigma_{N}=\lambda E_{G} \varepsilon_{G}
$$


onde $E$ é o módulo de elasticidade longitudinal e $E_{G}$ o módulo correspondente que relaciona $S$ e $\varepsilon_{G}$. Assim, igualando-se as expressões (2.11) e (2.12) e tendo-se em vista as equações (2.6) e (2.7), obtém-se:

$$
E_{G}=\frac{2 E}{\lambda(1+\lambda)}
$$

Deste modo, pode-se escrever a tensão de Piola-Kirchhoff de segunda espécie, segundo a equação (2.14).

$$
S=E_{G} \varepsilon_{G}
$$

Nos casos em que as deformações são pequenas, pode-se admitir $\lambda \cong 1$, portanto $E_{G}=E$ e com isto: $S=E \varepsilon_{G}$.

\subsubsection{Aplicação do método dos elementos finitos: matriz de rigidez tangente e vetor dos esforços internos}

Seja o elemento de barra de treliça plana no sistema local, mostrado na Figura 2.2, com quatro graus de liberdade, sendo dois por nó, correspondentes aos deslocamentos na direção do eixo da barra e transversal a ele. Na configuração inicial o elemento possui área de seção transversal $A_{o}$ e comprimento $L_{o}$.

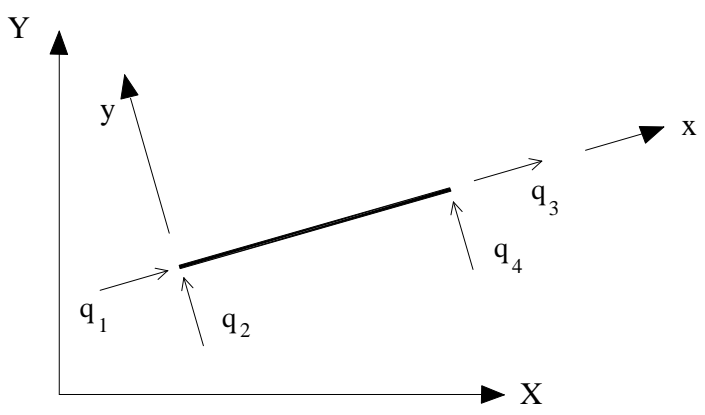

Figura 2.2- Elemento finito de treliça plana no sistema de coordenadas globais e locais

Para o elemento finito mostrado na Figura 2.2, os deslocamentos são interpolados de maneira usual, segundo as coordenadas nodais locais, por: 


$$
d=\left\{\begin{array}{l}
u(x) \\
v(x)
\end{array}\right\}=\underline{\phi}(x) q
$$

Sendo:

$u(x)$ - componente axial do deslocamento do eixo da barra;

$v(x)$ - componente transversal do deslocamento do eixo da barra;

$\underline{\phi}(x)$ - matriz que contém as funções interpoladoras, representada por:

$$
\underline{\phi}(x)=\left[\begin{array}{cccc}
N_{1}(x) & 0 & N_{3}(x) & 0 \\
0 & N_{2}(x) & 0 & N_{4}(x)
\end{array}\right]
$$

As funções interpoladoras e o vetor dos deslocamentos nodais são:

$$
\begin{gathered}
N_{1}(x)=N_{2}(x)=\left(1-\frac{x}{L_{o}}\right) \\
N_{3}(x)=N_{4}(x)=\frac{x}{L_{o}} \\
q^{T}=\left\{\begin{array}{llll}
q_{1} & q_{2} & q_{3} & q_{4}
\end{array}\right\}
\end{gathered}
$$

Utilizando-se as equações (2.6), (2.7) e (2.15), obtém-se respectivamente, as deformações axiais de Green $\varepsilon_{G}$ e linear $\varepsilon_{L}$, representadas por:

$$
\begin{gathered}
\varepsilon_{G}=\left(\underline{B}_{L}+\frac{1}{2} \underline{B}_{N L}\right) q \\
\varepsilon_{L}=\sqrt{1+\left(2 \underline{B}_{L}+\underline{B}_{N L}\right) q}-1
\end{gathered}
$$

sendo:

$$
\underline{B}_{L}=\frac{1}{L_{o}}\left[\begin{array}{llll}
-1 & 0 & 1 & 0
\end{array}\right]
$$




$$
\underline{B}_{N L}=\frac{1}{L_{o}^{2}}\left[\begin{array}{llll}
-\hat{U}_{1} & -\hat{U}_{2} & \hat{U}_{1} & \hat{U}_{2}
\end{array}\right]
$$

$\operatorname{com} \hat{U}_{1}=q_{3}-q_{1}$ e $\hat{U}_{2}=q_{4}-q_{2}$.

Por outro lado, pode-se escrever a equação (2.1), de equilíbrio, na forma:

$$
\psi=F^{i n t}-F^{e x t}
$$

onde o vetor resíduo $\psi=\int_{V_{0}} r_{0} . \delta d d V_{0}$, na situação de equilíbrio, deve, com uma certa tolerância, ser muito próximo de zero. Na expressão (2.24) $F^{i n t}=\int_{V_{0}} \underline{S} . \delta \underline{\varepsilon} d V_{0}$ é o vetor dos esforços internos e $F^{e x t}=\int_{V_{0}} b . \delta d d V_{0}+\int_{A_{0}} \bar{t}_{0} . \delta d d A_{0} \quad$ o vetor das cargas externas aplicadas à estrutura.

Numa forma matricial, o vetor dos esforços internos, para o elemento de treliça plana, passa ser expresso por:

$$
F^{i n t}=\int_{V_{0}} \underline{B}^{T} S d V_{0}
$$

sendo $\underline{B}=\underline{B}_{L}+\underline{B}_{N L}$.

Utilizando-se as equações (2.8), (2.14), (2.22) e (2.23) e realizando-se a integral dada pela equação (2.25), tem-se:

$$
F^{i n t}=\bar{N}\left\{\begin{array}{c}
-1 \\
0 \\
1 \\
0
\end{array}\right\}+\frac{\bar{N}}{L_{0}}\left\{\begin{array}{c}
-\hat{U}_{1} \\
-\hat{U}_{2} \\
\hat{U}_{1} \\
\hat{U}_{2}
\end{array}\right\}
$$

$\operatorname{com} \bar{N}=E_{G} \varepsilon_{G} A_{0}$ ou com as relações (2.8) e (2.9): $\bar{N}=\frac{E \varepsilon_{L} A_{0}}{\lambda}$. 
É possível mostrar que a taxa da tensão de Piola-Kirchhoff de segunda espécie pode ser escrita na forma:

$$
\dot{S}=\frac{E}{\lambda^{3}} \dot{\varepsilon_{G}}
$$

Por sua vez, as taxas da deformação de Green e da deformação virtual de Green são dadas respectivamente, por:

$$
\begin{gathered}
\dot{\varepsilon}_{G}=\underline{B} \dot{q} \\
\delta \dot{\varepsilon}_{G}=\delta q^{T} \underline{G}^{T} G \dot{q}
\end{gathered}
$$

onde:

$$
\underline{G}=\frac{1}{L_{o}}\left[\begin{array}{cccc}
-1 & 0 & 1 & 0 \\
0 & -1 & 0 & 1
\end{array}\right]
$$

Deste modo, do desenvolvimento da expressão (2.4), considerando-se as relações (2.27), (2.28), (2.29) e colocando-se $\dot{q}$ em evidência, tem-se a matriz de rigidez tangente para o elemento finito de treliça plana:

$$
\underline{K}_{T}=\int_{V o} \underline{B}^{T} \frac{D_{11}}{\lambda^{3}} \underline{B} d V_{o}+\int_{V o} \underline{G}^{T} S \underline{G} d V_{o}
$$

a qual pode ser também escrita, na forma aditiva:

$$
\underline{K}_{T}=\underline{K}_{o}+\underline{K}_{L}+\underline{K}_{\sigma}
$$

onde, cada parcela é dada por:

$$
\begin{gathered}
\underline{K}_{o}=\int_{V o} \underline{B}_{L}^{T} \frac{D_{11}}{\lambda^{3}} \underline{B}_{L} d V_{o} \\
\underline{K}_{L}=\int_{V o}\left(\underline{B}_{L}^{T} \frac{D_{11}}{\lambda^{3}} \underline{B}_{N L}+\underline{B}_{N L}^{T} \frac{D_{11}}{\lambda^{3}} \underline{B}_{L}+\underline{B}_{N L}^{T} \frac{D_{11}}{\lambda^{3}} \underline{B}_{N L}\right) d V_{o}
\end{gathered}
$$




$$
\underline{K}_{\sigma}=\int_{V o} \underline{G}^{T} S \underline{G} d V_{o}
$$

sendo:

$D_{11}$ - o módulo de rigidez tangente, que no caso elástico linear é igual ao módulo de elasticidade longitudinal $E$;

$\underline{K}_{0}$ - matriz de rigidez da barra na sua configuração inicial;

$\underline{K}_{L}$ - parcela de rigidez decorrente da mudança de posição da barra;

$\underline{K}_{\sigma}$ - parcela de rigidez geométrica, função do nível de solicitação axial nas barras.

Realizando-se as operações indicadas em cada parcela da matriz de rigidez tangente, chega-se às seguintes matrizes:

$$
\begin{aligned}
& \underline{K}_{o}=\frac{1}{\lambda^{3}} \frac{E A_{o}}{L_{o}}\left[\begin{array}{cccc}
1 & 0 & -1 & 0 \\
0 & 0 & 0 & 0 \\
-1 & 0 & 1 & 0 \\
0 & 0 & 0 & 0
\end{array}\right] \quad \underline{K}_{\sigma}=\frac{\bar{N}}{L_{o}}\left[\begin{array}{cccc}
1 & 0 & -1 & 0 \\
0 & 1 & 0 & -1 \\
-1 & 0 & 1 & 0 \\
0 & -1 & 0 & 1
\end{array}\right] \\
& \underline{K}_{L}=\frac{1}{\lambda^{3}} \frac{E A_{o}}{L_{o}^{2}}\left[\begin{array}{cccc}
2 \hat{U}_{1} & \hat{U}_{2} & -2 \hat{U}_{1} & -\hat{U}_{2} \\
\hat{U}_{2} & 0 & -\hat{U}_{2} & 0 \\
-2 \hat{U}_{1} & -\hat{U}_{2} & 2 \hat{U}_{1} & \hat{U}_{2} \\
-\hat{U}_{2} & 0 & \hat{U}_{2} & 0
\end{array}\right]+ \\
& +\frac{1}{\lambda^{3}} \frac{E A_{o}}{L_{o}^{3}}\left[\begin{array}{cccc}
\left(\hat{U}_{1}\right)^{2} & \hat{U}_{1} \hat{U}_{2} & -\left(\hat{U}_{1}\right)^{2} & -\hat{U}_{1} \hat{U}_{2} \\
\hat{U}_{1} \hat{U}_{2} & \left(\hat{U}_{2}\right)^{2} & -\hat{U}_{1} \hat{U}_{2} & -\left(\hat{U}_{2}\right)^{2} \\
-\left(\hat{U}_{1}\right)^{2} & -\hat{U}_{1} \hat{U}_{2} & \left(\hat{U}_{1}\right)^{2} & \hat{U}_{1} \hat{U}_{2} \\
-\hat{U}_{1} \hat{U}_{2} & -\left(\hat{U}_{2}\right)^{2} & \hat{U}_{1} \hat{U}_{2} & \left(\hat{U}_{2}\right)^{2}
\end{array}\right]
\end{aligned}
$$

É importante salientar que devido à facilidade algébrica todo o desenvolvimento foi feito utilizando-se a tensão de Piola-Kirchhoff e a deformação de Green. No entanto, na implementação numérica na equação (2.37) $\bar{N}$ pode opcionalmente ser calculado em função da medida de deformação linear conforme indicado na equação (2.26). 


\subsubsection{Exemplos numéricos}

O exemplo trata de uma treliça simples de comportamento elástico linear, e é ilustrativo de uma instabilidade que se manifesta somente ao atingir o ponto limite. Analisam-se duas situações diferentes, variando-se o ângulo de inclinação inicial das barras da treliça com o objetivo de avaliar a aproximação resultante ao se considerar as deformações pequenas.

No critério de convergência utilizam-se as normas euclidianas em deslocamentos e em forças residuais, fixando-se a tolerância em $10^{-6}$.

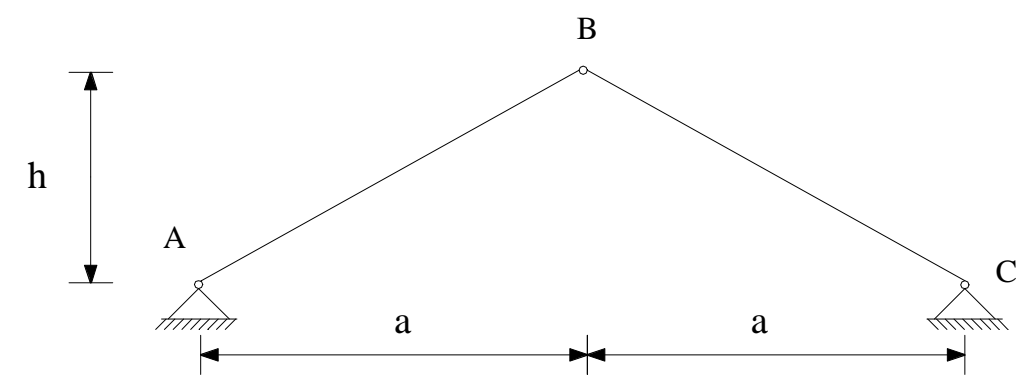

Figura 2.3 - Treliça simples

\subsubsection{Caso 1}

Este caso foi analisado considerando-se o método incremental de Newton-Raphson com controle de forças e o mesmo método com controle de deslocamentos (ver anexo A1). Os dados de interesse são: $\mathrm{h}=10 \mathrm{~cm}, \mathrm{a}=150 \mathrm{~cm}$, área da seção transversal das barras $A=6,53 \mathrm{~cm}^{2}$ e módulo de elasticidade longitudinal $E=20500 \mathrm{kN} / \mathrm{cm}^{2}$. A Figura 2.4 apresenta os resultados obtidos utilizando-se as diferentes medidas de deformação estudadas. Ilustra-se também a solução analítica apresentada por HINTON (1993), ressaltando que a mesma emprega o módulo de elasticidade $E$ e a deformação de Green, isto é considera-se 'a priori' $\lambda \cong 1$. 


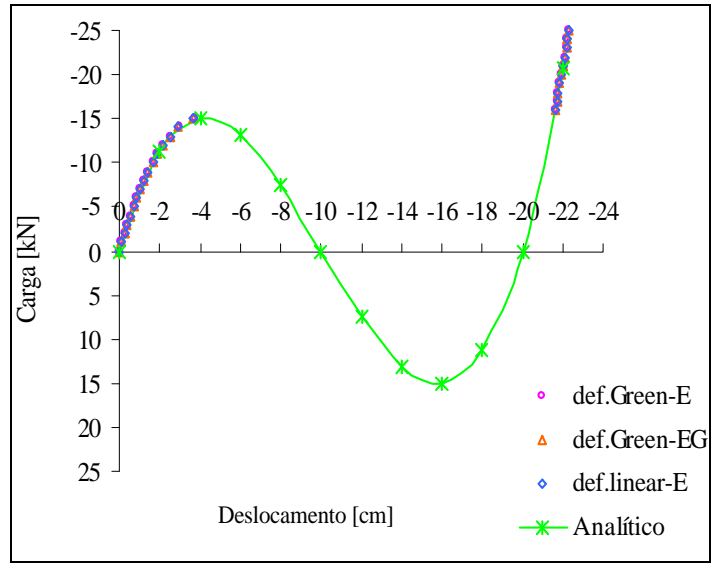

controle de força

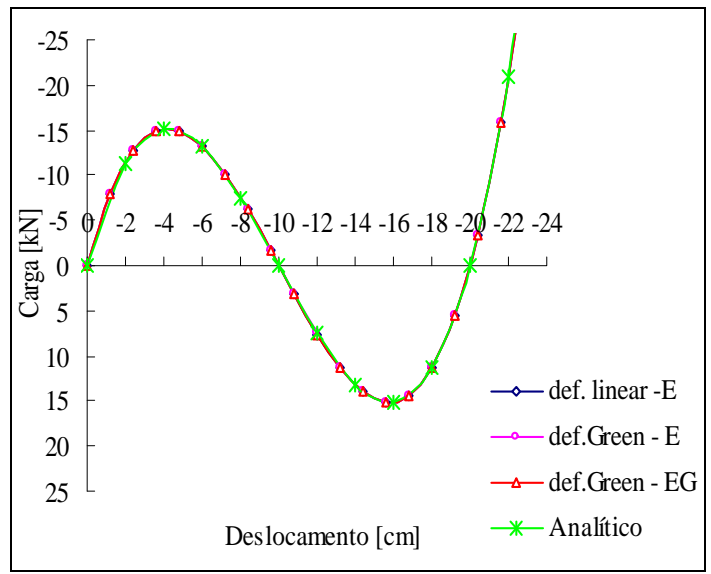

controle de deslocamento

Figura 2.4 - Gráficos carga-deslocamento vertical do nó B

\subsubsection{Caso 2}

Neste caso, a fim de comparar a resposta não-linear do modelo com a obtida por RUBERT (1993), considera-se $\mathrm{h}=127 \mathrm{~cm}$ e $\mathrm{a}=219,97 \mathrm{~cm}$, a área $\mathrm{A}=6,4516 \mathrm{~cm}^{2} \mathrm{e}$ $\mathrm{E}=20685 \mathrm{kN} / \mathrm{cm}^{2}$.

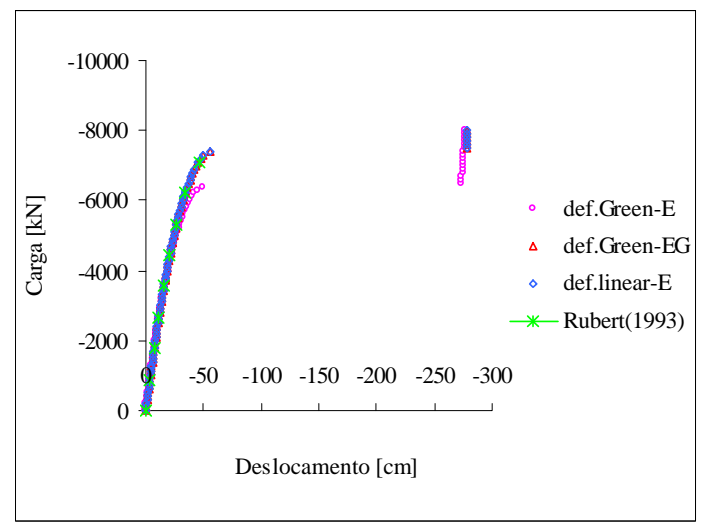

controle de força

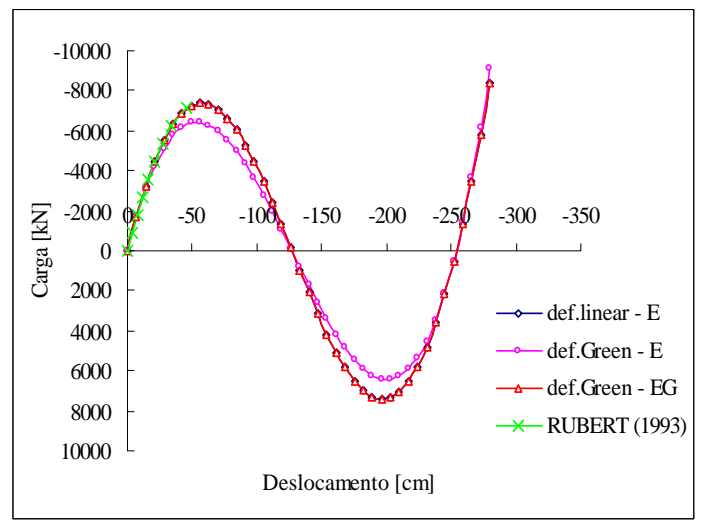

controle de deslocamento

Figura 2.5 - Gráficos carga-deslocamento vertical do nó B

As mesmas considerações feitas para o gráfico apresentado na Figura 2.4 são válidas para a Figura 2.5. Porém, nesta última, verificam-se resultados diferentes para as duas medidas de deformação utilizadas.

Nota-se que na Figura 2.5, com controle de carga, está ilustrado o fenômeno de perda de estabilidade por aparecimento de ponto limite chamado "snap through". 
No caso 1, todas as curvas apresentadas na Figura 2.4 são coincidentes. Segundo SOUZA LIMA \& VENÂNCIO FILHO (1992), quando a elevação $h$ apresentada na Figura 2.3 é suficientemente pequena, ou seja, tal que o ângulo de inclinação inicial das barras da treliça seja inferior a 5 graus, as deformações permanecem pequenas para todo o carregamento, verificando-se, portanto, $\lambda \cong 1$. Assim, as medidas de deformação se confundem.

Para treliças com inclinações superiores a cinco graus, como apresentado no caso 2, observa-se, na Figura 2.5, que os resultados obtidos são coincidentes enquanto as deformações são ainda pequenas. Assim, tomar 'a priori' $\lambda \cong 1$ pode constituir uma aproximação significativa, particularmente quanto à determinação da carga limite. Vale observar que para essas inclinações pode ocorrer bifurcação do equilíbrio antes de atingir o ponto limite, tal possibilidade não foi incluída na análise apresentada em função do objetivo exclusivo de se confrontar o uso de diferentes medidas de deformações. Um resultado análogo é apresentado por CRISFIELD (1997). Pode-se observar também que a resposta obtida utilizando-se a deformação de Green e o módulo de elasticidade longitudinal $E$, não compatíveis para valores de $\lambda$ diferente de 1 , é mais flexível que a obtida considerando-se a deformação de Green e $E_{G}$ ou a deformação linear e $E$.

Verifica-se, portanto, que uma modelagem coerente deve tratar de forma consistente as medidas de deformação e tensão, que deverão ser conjugadas. Além disso, pode-se observar que quando esta consistência é verificada os resultados devem ser independentes da escolha sobre os pares de tensão e deformação.

\subsection{PÓRTICOS PLANOS}

Nesta seção apresenta-se um estudo do comportamento não-linear geométrico em estruturas aporticadas planas, utilizando-se as formulações lagrangianas total e atualizada. A medida de deformação empregada é a de Green e a tensão correspondente é a de Piola-Kirchhoff de $2^{2}$ espécie. Considera-se um regime de pequenas deformações. 


\subsubsection{Descrição do campo de deslocamento do regime de flexão: análise plana}

Objetivando-se a construção de um modelo do comportamento de elementos de barra, limitando-se a consideração da não-linearidade àquela decorrente do campo de deslocamentos, admitem-se, como hipóteses básicas, que as deformações sejam pequenas e que o material tenha resposta linear elástica com isotropia.

Com relação ao campo de deslocamentos vale a hipótese cinemática de EulerNavier-Bernoulli: seções transversais planas e ortogonais ao eixo antes da deformação permanecem planas, indeformadas e normais ao eixo após a deformação.

$\mathrm{Na}$ configuração inicial, indeformada, a barra prismática possui comprimento $L_{o}$, seção transversal com área $A_{o}$ e, por conveniência, um plano de simetria longitudinal coincidente com o plano de carregamento, embora essa não seja uma condição imposta pelo modelo. Adotando-se uma das extremidades da barra para a origem de um referencial, ao qual se associa um sistema de coordenadas cartesiano, considerase que os eixos x e y definam o plano longitudinal de simetria, que contém o eixo da barra. Seja sobre esse plano o traço de uma seção posicionada a uma distância genérica $\mathrm{x}$ da origem, e nele dois pontos, $\mathrm{P}$ e G, conforme ilustra a Figura 2.6.

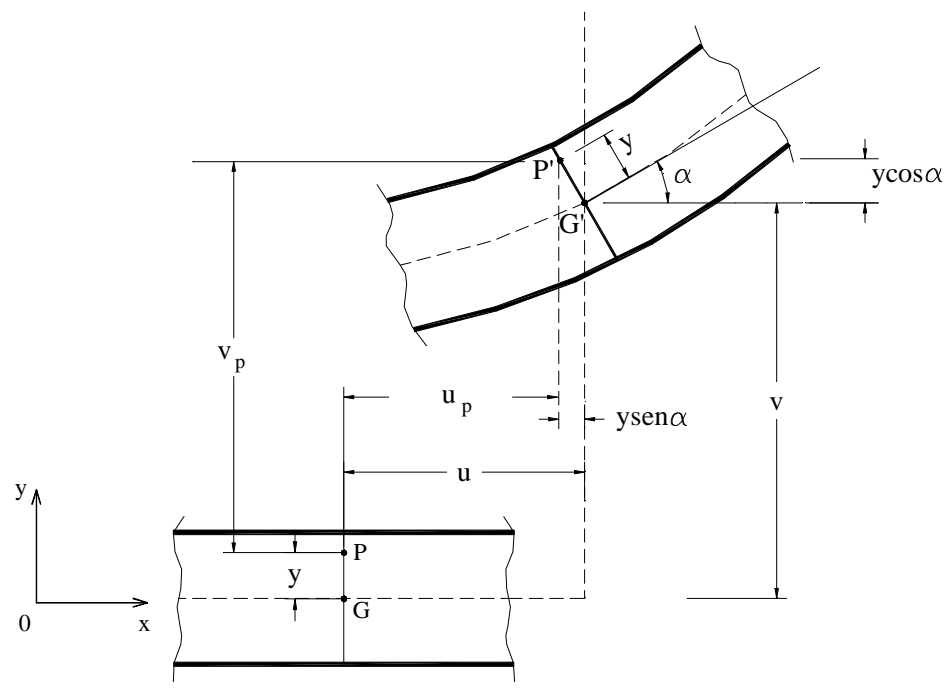

Figura 2.6- Deslocamentos de pontos da barra

Tendo-se em vista a hipótese cinemática, o deslocamento arbitrário do ponto genérico $\mathrm{P}(\mathrm{x}, \mathrm{y})$, descrito por suas componentes $u_{p} \mathrm{e} v_{p}$, segundo as direções dos eixos 
coordenados x e y, respectivamente, pode ser expresso em função das componentes $u$ e $v$ do deslocamento do ponto $\mathrm{G}(\mathrm{x}, 0)$, situado sobre o eixo, na forma:

$$
\begin{gathered}
u_{p}(x, y)=u(x)-y \operatorname{sen} \alpha \\
v_{p}(x, y)=v(x)-y(1-\cos \alpha)
\end{gathered}
$$

sendo $\alpha=\alpha(x)$ o giro da seção.

As expressões (2.39) e (2.40) podem ser interpretadas na Figura 2.6, na qual se mostra o segmento GP, normal ao eixo na geometria inicial, que passa a ser o segmento G'P', também normal ao eixo na configuração deformada. Nota-se que em ambas as situações aquele segmento tem comprimento $y$, em virtude da hipótese de que a seção transversal permanece indeformada no seu plano.

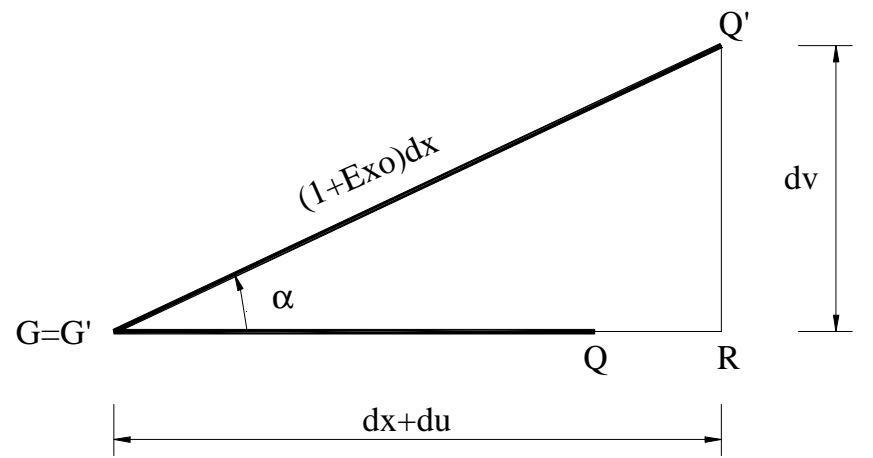

Figura 2.7- Elemento diferencial do eixo da barra antes e depois da deformação

Com o auxílio da Figura 2.7, onde se representa um elemento infinitesimal do eixo da barra antes e depois da deformação, identificado respectivamente por GQ e G'Q', e considerando-se a hipótese de que a medida de deformação linear $E_{X 0}$ é pequena com relação à unidade, tem-se que a rotação $\alpha$ relaciona-se com os deslocamentos $u$ e $v$ da seguinte forma:

$$
\begin{gathered}
\operatorname{sen} \alpha=\frac{d v}{\left(1+E_{X 0}\right) d x} \cong \frac{d v}{d x} \\
\cos \alpha=\frac{d x+d u}{\left(1+E_{X 0}\right) d x} \cong 1+\frac{d u}{d x}
\end{gathered}
$$




$$
\operatorname{tg} \alpha=\frac{\frac{d v}{d x}}{1+\frac{d u}{d x}}
$$

\subsubsection{Relação deformação-deslocamento}

Conhecendo-se o campo de deslocamentos, passa-se à definição do tensor de deformações a ser associado a um certo ponto da barra. Como a formulação utilizada neste trabalho é a lagrangiana, por motivos de simplificação algébrica na descrição do equilíbrio na posição deslocada, o tensor de deformação de Green torna-se mais interessante do que o tensor de deformação linear, sendo dado por:

$$
\underline{\varepsilon}=\frac{1}{2}\left(\nabla d+\nabla d^{T}+\nabla d^{T} \nabla d\right)
$$

sendo $d$ o vetor deslocamento, cujas componentes são apresentadas nas expressões (2.39) e (2.40), e $\nabla($.$) o operador gradiente com relação às coordenadas iniciais.$

Coerentemente com a hipótese feita sobre o campo de deslocamentos, a única componente não nula do tensor de deformação de Green é $\varepsilon_{X X}$, como se pode observar pela substituição das expressões (2.39) e (2.40) em (2.44), com posterior consideração das expressões (2.41) e (2.42). Para $\varepsilon_{X X}$ resulta a seguinte expressão:

$$
\varepsilon_{X X}=\frac{d u}{d x}-y \cos \alpha \frac{d \alpha}{d x}+\frac{1}{2}\left[\left(\frac{d u}{d x}-y \cos \alpha \frac{d \alpha}{d x}\right)^{2}+\left(\frac{d v}{d x}-y \operatorname{sen} \alpha \frac{d \alpha}{d x}\right)^{2}\right]
$$

Desenvolvendo-se a expressão acima, resulta:

$$
\begin{aligned}
\varepsilon_{X X}= & u^{\prime}+\frac{1}{2}\left(u^{\prime}\right)^{2}+\frac{1}{2}\left(v^{\prime}\right)^{2}-y \cos \alpha \alpha^{\prime}-y \cos \alpha u^{\prime} \alpha^{\prime}+ \\
& -y \operatorname{sen} \alpha v^{\prime} \alpha^{\prime}+\frac{1}{2} y^{2}\left(\alpha^{\prime}\right)^{2}
\end{aligned}
$$


De acordo com GARCIA \& VILLAÇA (1999) a curvatura do eixo da barra pode ser aproximada por $k=\frac{d \alpha}{\left(1+E_{x 0}\right) d x} \cong \frac{d \alpha}{d x}$, que em termos dos deslocamentos $u$ e $v$, pode ser obtida a partir da derivação em relação a $x$ de ambos os membros da expressão exata apresentada em (2.43), como se segue:

$$
\frac{1}{(\cos \alpha)^{2}} \alpha^{\prime}=\frac{v^{\prime \prime}\left(1+u^{\prime}\right)-v^{\prime} u^{\prime \prime}}{\left(1+u^{\prime}\right)^{2}}
$$

Considerando-se a expressão (2.42), tem-se que:

$$
k \cong \alpha^{\prime}=v^{\prime \prime}\left(1+u^{\prime}\right)-v^{\prime} u^{\prime \prime}
$$

A deformação dada pela expressão (2.46) é completa, mas segundo GARCIA \& VILLAÇA (1999), pode ser aproximada pela seguinte forma:

$$
\varepsilon_{X}=\varepsilon_{X 0}-y k
$$

sendo: $\varepsilon_{X o}\left(=\left.\varepsilon_{X X}\right|_{Y=0}\right)$ e $k$, a deformação e a curvatura do eixo da barra, respectivamente.

De fato, a expressão (2.46) pode ser escrita como:

$$
\varepsilon_{X X}=\varepsilon_{X 0}-y \alpha^{\prime}\left(1+2 u^{\prime}+\left(u^{\prime}\right)^{2}+\left(v^{\prime}\right)^{2}\right)+\frac{1}{2} y^{2}\left(\alpha^{\prime}\right)^{2}
$$

Reconhecendo-se na expressão anterior a soma que aparece na parcela entre parênteses como sendo igual a $\left(1+2 \varepsilon_{X 0}\right)$ tem-se:

$$
\varepsilon_{X X}=\varepsilon_{X 0}-y \alpha^{\prime}\left(1+2 \varepsilon_{X 0}\right)+\frac{1}{2} y^{2}\left(\alpha^{\prime}\right)^{2}
$$

ou ainda, em função de $\varepsilon_{X 0}<1$ :

$$
\varepsilon_{X X}=\varepsilon_{X 0}-y \alpha^{\prime}+\frac{1}{2} y^{2}\left(\alpha^{\prime}\right)^{2}
$$


assim, desprezando-se o termo $\frac{1}{2} y^{2}\left(\alpha^{\prime}\right)^{2}$ em presença de $y \alpha^{\prime}$ obtém-se a expressão (2.49).

\subsubsection{Relação entre os tensores de tensão e de deformação}

Sendo válida a hipótese de pequenas deformações, tem-se que as equações constitutivas nas formas secante e tangente, para um meio elástico linear, podem ser dadas por:

$$
\underline{S}=\underline{D}_{0} \underline{\varepsilon} \quad \underline{\dot{S}}=\underline{D}_{0} \underline{\dot{\varepsilon}}
$$

sendo $\underline{\underline{D}}_{0}$ o tensor constitutivo do material íntegro, que no caso unidimensional se reduz ao módulo de rigidez do material, $E$.

\subsubsection{Aplicação do método dos elementos finitos: matriz de rigidez tangente e vetor dos esforços internos}

Seja o elemento de barra de pórtico plano (ou viga-coluna) e um referencial cartesiano local, tal que o eixo x coincida com o eixo do elemento, como mostra a Figura 2.8. Definem-se nas extremidades do elemento um conjunto de seis graus de liberdade, três por nó, correspondentes ao deslocamento na direção do eixo, deslocamento transversal a ele e rotação em torno do eixo perpendicular ao plano xy.

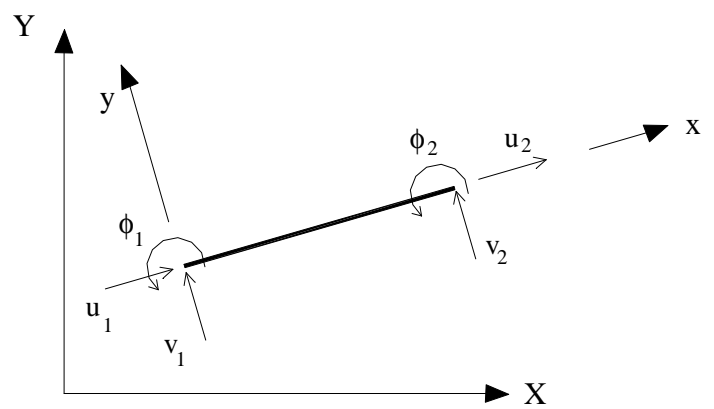

Figura 2.8- Elemento finito de pórtico plano no sistema de coordenadas globais e locais

Com o objetivo de calcular as integrais que aparecem nas equações que levam às expressões do vetor dos esforços internos e da matriz de rigidez tangente do elemento de pórtico plano, adotam-se funções que aproximam as componentes $u$ e $v$ 
dos deslocamentos de pontos do eixo. Tais deslocamentos constituem interpolações sobre os graus de liberdade nodais. A representação matricial da interpolação é dada por:

$$
d_{0}=\underline{\phi}(x) q
$$

onde $d_{0}=\left\{\begin{array}{l}u(x) \\ v(x)\end{array}\right\} \quad$ é vetor deslocamento do eixo e $\underline{\phi}(x)=\left[\begin{array}{cccccc}N_{1}(x) & 0 & 0 & N_{4}(x) & 0 & 0 \\ 0 & N_{2}(x) & N_{3}(x) & 0 & N_{5}(x) & N_{6}(x)\end{array}\right]$ é a matriz que contém as funções de interpolação.

O vetor de deslocamentos nodais pode ser representado por:

$$
q^{T}=\left\{\begin{array}{llllll}
u_{1} & v_{1} & \phi_{1} & u_{2} & v_{2} & \phi_{2}
\end{array}\right\}=\left\{\begin{array}{llllll}
q_{1} & q_{2} & q_{3} & q_{4} & q_{5} & q_{6}
\end{array}\right\}
$$

Para funções de interpolação, utilizam-se as mesmas formas usuais apresentadas, por exemplo, no trabalho de MAZZILLI (1988), onde o deslocamento axial $u$ possui variação linear, o deslocamento transversal $v$ tem variação cúbica e a rotação da seção é obtida derivando-se o deslocamento transversal uma vez em relação a x:

$$
\begin{gathered}
N_{1}(x)=\left(1-\frac{x}{L_{o}}\right) \\
N_{2}(x)=1-3\left(\frac{x}{L_{o}}\right)^{2}+2\left(\frac{x}{L_{o}}\right)^{3} \\
N_{3}(x)=L_{o}\left[\left(\frac{x}{L_{o}}\right)-2\left(\frac{x}{L_{o}}\right)^{2}+\left(\frac{x}{L_{o}}\right)^{3}\right] \\
N_{4}(x)=\frac{x}{L_{o}}
\end{gathered}
$$




$$
\begin{gathered}
N_{5}(x)=3\left(\frac{x}{L_{o}}\right)^{2}-2\left(\frac{x}{L_{o}}\right)^{3} \\
N_{6}(x)=L\left[-\left(\frac{x}{L_{o}}\right)^{2}+\left(\frac{x}{L_{o}}\right)^{3}\right]
\end{gathered}
$$

Utilizando-se as funções de interpolação descritas acima e o vetor de deslocamentos nodais, pode-se escrever os deslocamentos axial e transversal do eixo da barra, $u(x)$ e $v(x)$, nas formas:

$$
\begin{gathered}
u(x)=\left[\begin{array}{llllll}
N_{1}(x) & 0 & 0 & N_{4}(x) & 0 & 0
\end{array}\right] q \\
v(x)=\left[\begin{array}{llllll}
0 & N_{2}(x) & N_{3}(x) & 0 & N_{5}(x) & N_{6}(x)
\end{array}\right] q
\end{gathered}
$$

Por outro lado, levando-se as expressões (2.41) e (2.42) em (2.46) e sendo, neste caso, a segunda derivada de u com x igual a zero, a deformação de Green $\varepsilon_{X X}$ passa a ser escrita como:

$$
\begin{aligned}
\varepsilon_{X X}= & u^{\prime}+\frac{1}{2}\left(u^{\prime}\right)^{2}+\frac{1}{2}\left(v^{\prime}\right)^{2}-y v^{\prime \prime}\left(1+u^{\prime}\right)^{2}-y u^{\prime} v^{\prime \prime}\left(1+u^{\prime}\right)^{2}+ \\
& -y\left(v^{\prime}\right)^{2} v^{\prime \prime}\left(1+u^{\prime}\right)+\frac{1}{2} y^{2}\left(v^{\prime \prime}\right)^{2}\left(1+u^{\prime}\right)^{2}
\end{aligned}
$$

ou na sua forma aproximada, apresentada na relação (2.49), por:

$$
\varepsilon_{X}=u^{\prime}+\frac{1}{2}\left(u^{\prime}\right)^{2}+\frac{1}{2}\left(v^{\prime}\right)^{2}-y v^{\prime \prime}\left(1+u^{\prime}\right)
$$

Para escrever as relações (2.64) e (2.65) em forma matricial empregam-se inicialmente as (2.62) e (2.63), de onde se obtém:

$$
\begin{gathered}
u^{\prime}=\left[\begin{array}{llllll}
N_{1}^{\prime}(x) & 0 & 0 & N_{4}^{\prime}(x) & 0 & 0
\end{array}\right] q=A^{T} q \\
v^{\prime}=\left[\begin{array}{llllll}
0 & N_{2}^{\prime}(x) & N_{3}^{\prime}(x) & 0 & N_{5}^{\prime}(x) & N_{6}^{\prime}(x)
\end{array}\right] q=B^{T} q
\end{gathered}
$$




$$
v^{\prime \prime}=\left[\begin{array}{llllll}
0 & N_{2}^{\prime \prime}(x) & N_{3}^{\prime \prime}(x) & 0 & N^{\prime \prime}(x)_{5} & N_{6}^{\prime \prime}(x)
\end{array}\right] q=C^{T} q
$$

Observa-se que apesar de $A, B$ e $C$ serem, no caso, vetores, mantém-se a notação de letra maiúscula para eles, de modo a contemplar a notação usual em desenvolvimentos semelhantes com modelos mais complexos.

Portanto, utilizando-se as expressões (2.66) a (2.68) pode-se escrever as deformações $\varepsilon_{X X}$ e $\varepsilon_{X}$ respectivamente por:

$$
\begin{aligned}
& \varepsilon_{X X}=A^{T} q+\frac{1}{2}\left(A^{T} q\right)\left(A^{T} q\right)+\frac{1}{2}\left(B^{T} q\right)\left(B^{T} q\right)-y\left(C^{T} q\right)-3 y\left(A^{T} q\right)\left(C^{T} q\right)+ \\
& -3 y\left(A^{T} q\right)\left(A^{T} q\right)\left(C^{T} q\right)-y\left(A^{T} q\right)\left(A^{T} q\right)\left(A^{T} q\right)\left(C^{T} q\right)-y\left(B^{T} q\right)\left(B^{T} q\right)\left(C^{T} q\right)+ \\
& -y\left(A^{T} q\right)\left(B^{T} q\right)\left(B^{T}\right)\left(C^{T} q\right)+\frac{1}{2} y^{2}\left(C^{T} q\right)\left(C^{T} q\right)+y^{2}\left(A^{T} q\right)\left(C^{T} q\right)\left(C^{T} q\right)+ \\
& +\frac{1}{2} y^{2}\left(A^{T} q\right)\left(A^{T} q\right)\left(C^{T} q\right)\left(C^{T} q\right) \\
& \varepsilon_{X}=A^{T} q+\frac{1}{2}\left(A^{T} q\right)\left(A^{T} q\right)+\frac{1}{2}\left(B^{T} q\right)\left(B^{T} q\right)-y\left(C^{T} q\right)-y\left(A^{T} q\right)\left(C^{T} q\right)
\end{aligned}
$$

As respectivas deformações virtuais de Green são dadas por:

$$
\begin{gathered}
\delta \varepsilon_{X X}=\underline{B} \delta q \\
\delta \varepsilon_{X}=\underline{B}_{a} \delta q
\end{gathered}
$$

com

$$
\begin{aligned}
\underline{B}= & A^{T}+\left(A^{T} q\right) A^{T}+\left(B^{T} q\right) B^{T}-y C^{T}-3 y\left(A^{T} q\right) C^{T}-3 y\left(C^{T} q\right) A^{T}+ \\
& -6 y\left(A^{T} q\right)\left(C^{T} q\right) A^{T}-3 y\left(A^{T} q\right)^{2} C^{T}-3 y\left(A^{T} q\right)^{2}\left(C^{T} q\right) A^{T}-y\left(A^{T} q\right)^{3} C^{T}+ \\
& -2 y\left(B^{T} q\right)\left(C^{T} q\right) B^{T}-y\left(B^{T} q\right)^{2} C^{T}-y\left(B^{T} q\right)^{2}\left(C^{T} q\right) A^{T}+y^{2}\left(C^{T} q\right) C^{T}+ \\
& -y\left(A^{T} q\right)\left(B^{T} q\right)^{2} C^{T}-2 y\left(A^{T} q\right)\left(B^{T} q\right)\left(C^{T} q\right) B^{T}+y^{2}\left(C^{T} q\right)^{2} A^{T}+ \\
& +2 y^{2}\left(A^{T} q\right)\left(C^{T} q\right) C^{T}+y^{2}\left(A^{T} q\right)\left(C^{T} q\right)^{2} A^{T}+y^{2}\left(A^{T} q\right)^{2}\left(C^{T} q\right) C^{T}
\end{aligned}
$$




$$
\underline{B}_{a}=A^{T}+\left(A^{T} q\right) A^{T}+\left(B^{T} q\right) B^{T}-y C^{T}-y\left(C^{T} q\right) A^{T}-y\left(A^{T} q\right) C^{T}
$$

De modo análogo, as taxas da deformação e da deformação virtual de Green são dadas, respectivamente, por:

$$
\begin{gathered}
\dot{\varepsilon}_{X X}=\underline{B} \dot{q} \\
\dot{\varepsilon}_{X}=\underline{B}_{a} \dot{q} \\
\delta \dot{\varepsilon}_{X X}=\delta q^{T} \underline{G} \dot{q} \\
\delta \dot{\varepsilon}_{X}=\delta q^{T} \underline{G}_{a} \dot{q}
\end{gathered}
$$

com

$$
\begin{aligned}
& \underline{G}=A A^{T}+B B^{T}-3 y C A^{T}-3 y A C^{T}-6 y A\left(C^{T} q\right) A^{T}-6 y A\left(A^{T} q\right) C^{T}+ \\
&-6 y C\left(A^{T} q\right) A^{T}-6 y A\left(A^{T} q\right)\left(C^{T} q\right) A^{T}-3 y A\left(A^{T} q\right)^{2} C^{T}+ \\
&-3 y C\left(A^{T} q\right)^{2} A^{T}-2 y B\left(C^{T} q\right) B^{T}-2 y B\left(B^{T} q\right) C^{T}-2 y C\left(B^{T} q\right) B^{T}+ \\
&-2 y A\left(B^{T} q\right)\left(C^{T} q\right) B^{T}-y A\left(B^{T} q\right)^{2} C^{T}-2 y B\left(B^{T} q\right)\left(C^{T} q\right) A^{T}+ \\
&-2 y B\left(A^{T} q\right)\left(C^{T} q\right) B^{T}-y C\left(B^{T} q\right)^{2} A^{T}-2 y B\left(A^{T} q\right)\left(B^{T} q\right) C^{T}+ \\
&-2 y C\left(A^{T} q\right)\left(B^{T} q\right) B^{T}+y^{2} C C^{T}+2 y^{2} A\left(A^{T} q\right) C^{T}+ \\
&+2 y^{2} C\left(C^{T} q\right) A^{T}+2 y^{2} C\left(A^{T} q\right) C^{T}+y^{2} A\left(C^{T} q\right)^{2} A^{T}+ \\
&+2 y^{2} A\left(A^{T} q\right)\left(C^{T} q\right) C^{T}+2 y^{2} C\left(A^{T} q\right)\left(C^{T} q\right) A^{T}+ \\
&+y^{2} C\left(A^{T} q\right)^{2} C^{T} \\
& \\
& \underline{G}_{a}=A A^{T}+B B^{T}-y A C^{T}-y C A^{T}
\end{aligned}
$$

Com os elementos definidos acima, pode-se obter as expressões do vetor dos esforços internos e da matriz de rigidez tangente para o elemento finito de pórtico plano. 
Nesse sentido, utilizando-se a expressão (2.1), na sua forma matricial, e colocando-se em evidência o vetor de deslocamentos virtuais, tem-se que os vetores dos esforços internos ficam definidos por:

$$
\begin{aligned}
& F^{i n t}=\int_{V_{0}} \underline{B}^{T} S d V_{0} \\
& F^{i n t}=\int_{V_{0}} \underline{B}_{a}^{T} S d V_{0}
\end{aligned}
$$

de acordo com uma ou outra definição do campo virtual de deformações empregado.

Por sua vez, do desenvolvimento da expressão (2.4), considerando-se as relações (2.53b), (2.71), (2.72), (2.75), (2.76), (2.77), (2.78), (2.79) e (2.80) e colocando-se $\dot{q}$ em evidência, segue que as matrizes de rigidez tangente para o elemento finito de pórtico plano ficam dadas por:

$$
\begin{gathered}
\underline{K}_{T}=\int_{V_{0}} \underline{B}^{T} E \underline{B} d V_{0}+\int_{V_{0}} \underline{G} S d V_{0} \\
\underline{K}_{T}=\int_{V_{0}} \underline{B}_{a}{ }^{T} E \underline{B}_{a} d V_{0}+\int_{V_{0}} \underline{G}_{a} S d V_{0}
\end{gathered}
$$

\subsubsection{Implementação numérica das formulações lagrangianas total e atualizada}

$\mathrm{Na}$ implementação da formulação lagrangiana total a configuração de referência é sempre a inicial e com relação a ela são calculadas as integrais (2.81) a (2.84).

Como por conveniência, assim como neste trabalho, normalmente se adotam aproximações sobre os giros (relações (2.41), (2.42) e (2.48)), nos casos onde ocorrem grandes deslocamentos e rotações a formulação lagrangiana total pode levar a uma descrição imprecisa do equilíbrio, na medida em que configuração atual se afasta da configuração de referência (ver exemplo 2, item 2.4.6.2). Daí a atualização da configuração constituir-se em alternativa interessante, pois permite que se mantenham as aproximações sobre os giros sem perda de precisão da resposta numérica. 
Conforme observado anteriormente, na formulação lagrangiana atualizada empregada neste trabalho todas as integrais são calculadas com relação à última situação equilibrada, o que a torna mais adequada para casos de grandes deslocamentos e rotações. De acordo com CRISFIELD (1997) sua implementação numérica exige duas operações distintas:

a) atualização das coordenadas

As novas posições dos nós são determinadas adicionando-se o vetor dos deslocamentos incrementais $\{\Delta u\}$ ao vetor das coordenadas cartesianas nodais referentes à última configuração equilibrada, $\left\{X_{0}\right\}$, ou seja:

$$
\{x\}=\left\{X_{0}\right\}+\{\Delta u\}
$$

sendo $\{x\}$ o vetor das novas posições nodais que reúne as componentes $\mathrm{X}$ e $\mathrm{Y}$.

b) atualização da descrição do tensor de tensão da configuração anterior para a atual de referência

Na descrição atualizada há uma mudança contínua de referencial ou região de observação. Assim sendo, o tensor de tensão de Piola-Kirchhoff de $2^{\text {a }}$ espécie deve ser transformado para a nova configuração que está rotacionada com relação à anterior, da seguinte forma:

$$
\underline{S}=\underline{R}^{T} \underline{S}_{0} \underline{R}
$$

sendo $\underline{S}_{0}$ o tensor de tensão de P-K de $2^{\mathrm{a}}$ espécie referido à configuração anterior e $\underline{R}$ o tensor ortogonal próprio de rotação.

Porém na nova configuração, o princípio variacional empregado para imposição do equilíbrio segundo a descrição lagrangiana atualizada envolve o tensor de Cauchy. Assim sendo, o tensor de tensão de Piola-Kirchhoff de $2^{\underline{a}}$ espécie associado à configuração atual deve ser transformado no tensor de tensão de Cauchy através da seguinte relação: 


$$
\underline{\sigma}=\frac{1}{\operatorname{det} \underline{F}} \underline{F} \underline{S} \underline{F}^{T}
$$

com:

$$
\underline{F}=I+\frac{\partial \Delta u}{\partial X_{0}}
$$

É possível mostrar, entretanto, que no caso de pequenas deformações essa sequência de transformações é imediata. De fato, neste caso, utilizando-se o teorema da decomposição polar, pode-se escrever o tensor gradiente de deformação, $\underline{F}$, da seguinte forma:

$$
\underline{F} \cong \underline{R}
$$

sendo $\operatorname{det} \underline{F}=1$.

Substituindo-se (2.89) na expressão (2.87), tem-se que o tensor de tensão de Cauchy na nova configuração é dado por:

$$
\underline{\sigma}=\underline{R} \underline{S}^{T}=\underline{R}^{T} \underline{S}_{0} \underline{R}^{T}=\underline{S}_{0}
$$

Portanto, no caso de pequenas deformações tensor de tensão de Piola-Kirchhoff de $2^{\text {a }}$ espécie da configuração anterior é igual ao tensor de tensão de Cauchy na configuração atualizada.

Assim, no passo de carga seguinte, gera-se um incremento de tensão $\Delta \underline{S}$ que simplesmente se soma à tensão $\underline{S}_{0}$ :

$$
\underline{S}=\underline{S}_{0}+\Delta \underline{S}
$$

Um outro aspecto relativo à implementação numérica, diz respeito ao cálculo das integrais que aparecem nos princípios variacionais de equilíbrio. Entretanto, neste trabalho tais integrais são calculadas numericamente utilizando-se as quadraturas de Gauss ou de Gauss-Lobatto, HUGHES (1987). Para a integração ao longo do 
comprimento deve-se considerar um número de pontos superior ou igual a 6. Para a integração ao longo da altura além das quadraturas de Gauss e Gauss-Lobatto podese empregar a estratificação da seção em camadas de igual espessura; neste caso, deve-se considerar um número de pontos de integração superior a 3 quando se empregam as quadraturas de Gauss e Gauss-Lobatto ou no mínimo 10 camadas para o método da estratificação. No anexo B justificam-se as sugestões quanto ao número de pontos de integração numérica, quando se considera a não-linearidade física do material. Conforme sugere PIMENTA (1996), desde que se adote uma deformação média associada ao esforço normal constante para toda a barra, as integrais (2.82) e (2.84) podem ser calculadas de forma analítica.

\subsubsection{Exemplos numéricos}

Nesta seção apresentam-se três exemplos procurando-se ilustrar, em particular, o emprego das duas matrizes de rigidez tangente desenvolvidas. O primeiro exemplo apresenta em destaque uma comparação entre as formulações lagrangianas utilizadas. Os outros dois exemplos envolvem um confronto entre os valores numéricos obtidos com a formulação lagrangiana atualizada e os valores analíticos encontrados na literatura. Em todos os casos, mostra-se o tempo de processamento despendido empregando-se as diferentes matrizes de rigidez tangente.

\subsubsection{Exemplo 1- Pórtico simples}

Neste exemplo, Figura 2.9, é analisado um pórtico simples, biengastado, sujeito a cargas concentradas verticais e horizontais, proposto por ELIAS (1986). Para cargas vertical e horizontal adotam-se, respectivamente: $\mathrm{P}=350$ kips, $\mathrm{H}=1 \mathrm{kip}$. Todas as barras possuem as mesmas propriedades elásticas e de geometria: área $\mathrm{A}=10 \mathrm{in}^{2}$, momento de inércia $\mathrm{I}=100 \mathrm{in}^{4}$, módulo de elasticidade E=30000 ksi e comprimento $\mathrm{L}=240$ in. É importante destacar que, em ELIAS (1986) a barra horizontal é considerada inextensível. A simulação numérica é conduzida de modo que a carga horizontal é mantida constante durante toda resolução. Em termos de discretização cada uma das barras foi dividida em 6 elementos iguais, num total de 18 elementos. 
$\mathrm{Na}$ análise não-linear foram utilizados 10 incrementos iguais de carga vertical e as tolerâncias sobres as normas em deslocamentos e forças foram fixadas em $10^{-6}$.

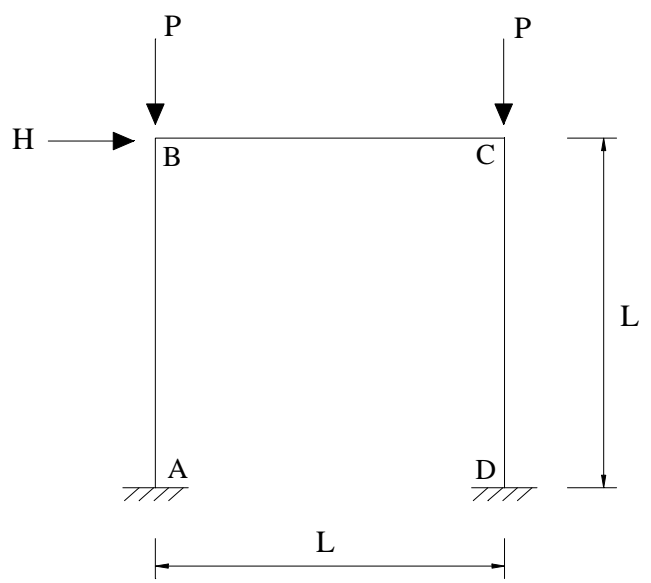

Figura 2.9- Pórtico simples - adaptado de ELIAS (1986)

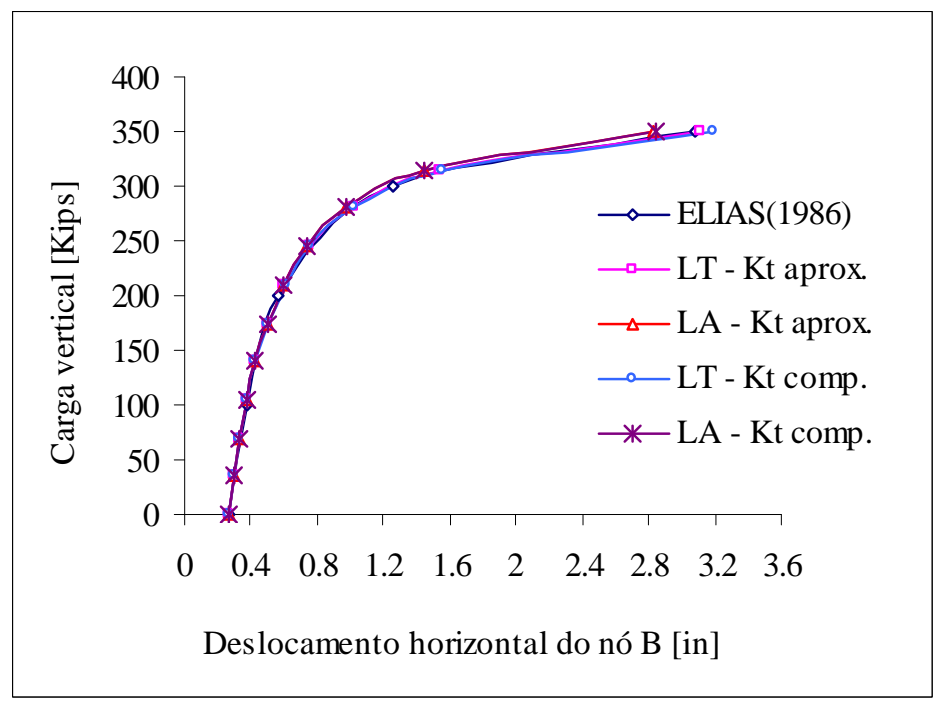

Figura 2.10- Curva carga-deslocamento

Na Figura 2.10 são mostradas as curvas carga-deslocamento obtidas utilizando-se as formulações lagrangianas total (LT) e atualizada (LA) com as duas matrizes de rigidez tangente desenvolvidas, completa e aproximada, assim como os resultados apresentados por ELIAS (1986).

Pode-se observar na Figura 2.10 que no final do processo de carregamento os resultados em termos do deslocamento do nó B obtidos com as formulação lagrangiana total combinada com a matriz de rigidez aproximada coincidem com os 
apresentados por ELIAS (1986), porém, para a formulação atualizada o valor do deslocamento final é um pouco menor. Já os resultados obtidos com a matriz completa em qualquer umas das formulações lagrangianas diferem um pouco daquele apresentado por ELIAS (1986), ou seja, um pouco menor para o caso da total e um pouco menor para a atualizada.

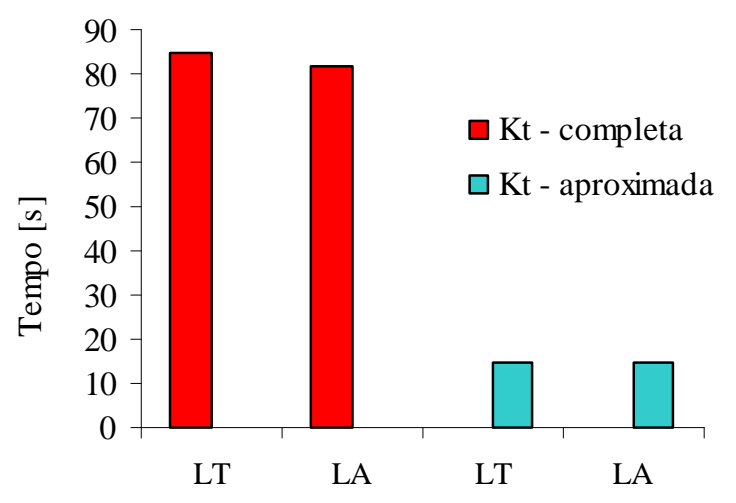

Figura 2.11- Tempo de processamento

A Figura 2.11 ilustra o tempo gasto no processamento desta estrutura utilizando-se a matriz de rigidez tangente completa e aproximada nas formulações lagrangiana total e atualizada.

\subsubsection{Exemplo 2 - Viga em balanço com carga aplicada na extremidade livre}

Este exemplo tem como objetivo ilustrar a eficiência da descrição lagrangiana atualizada. Trata-se de uma viga em balanço sujeita a uma carga vertical concentrada na extremidade livre, cuja solução analítica encontra-se no trabalho de MATTIASSON (1981). Os dados sugeridos para obtenção da solução numérica são: $\mathrm{P}=10 \mathrm{kN}$, área transversal $\mathrm{A}=120 \mathrm{~cm}^{2}$, momento de inércia $\mathrm{I}=10 \mathrm{~cm}^{4}$, módulo de elasticidade $\mathrm{E}=1000 \mathrm{kN} / \mathrm{cm}^{2}$ e comprimento $\mathrm{L}=100 \mathrm{~cm}$. 


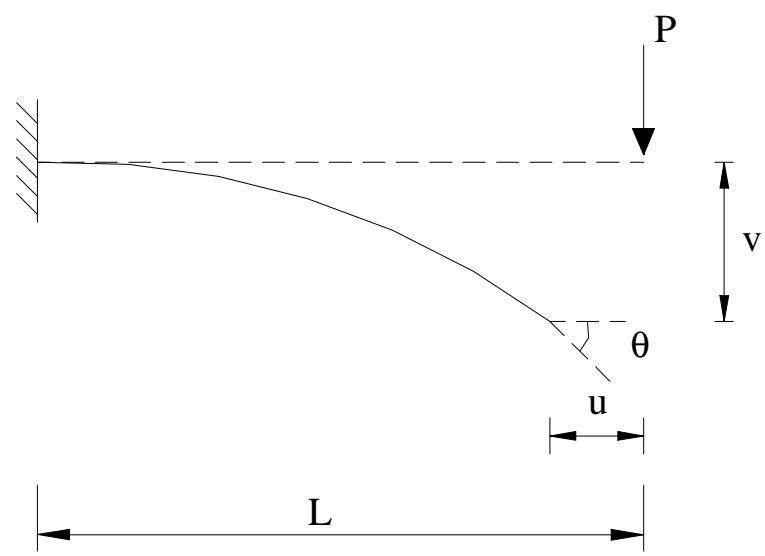

Figura 2.12- Viga em balanço

A barra é discretizada em 20 elementos iguais. Para a integração por Gauss utilizamse 3 pontos ao longo da altura da seção transversal e 6 pontos distribuídos ao longo do eixo de cada elemento.

O carregamento é aplicado em 100 incrementos iguais e a tolerância com a qual se comparam as normas euclidianas em deslocamentos e em forças (ambas são verificadas, por opção) é fixada em $10^{-6}$.

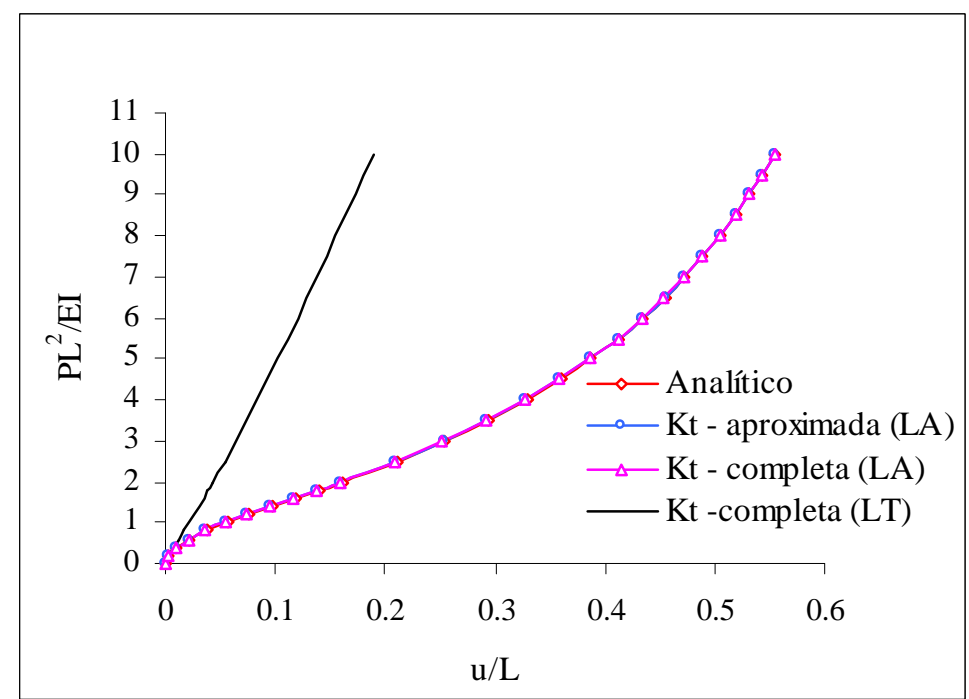

Figura 2.13- Curva carga paramétrica x deslocamento adimensional u/L 


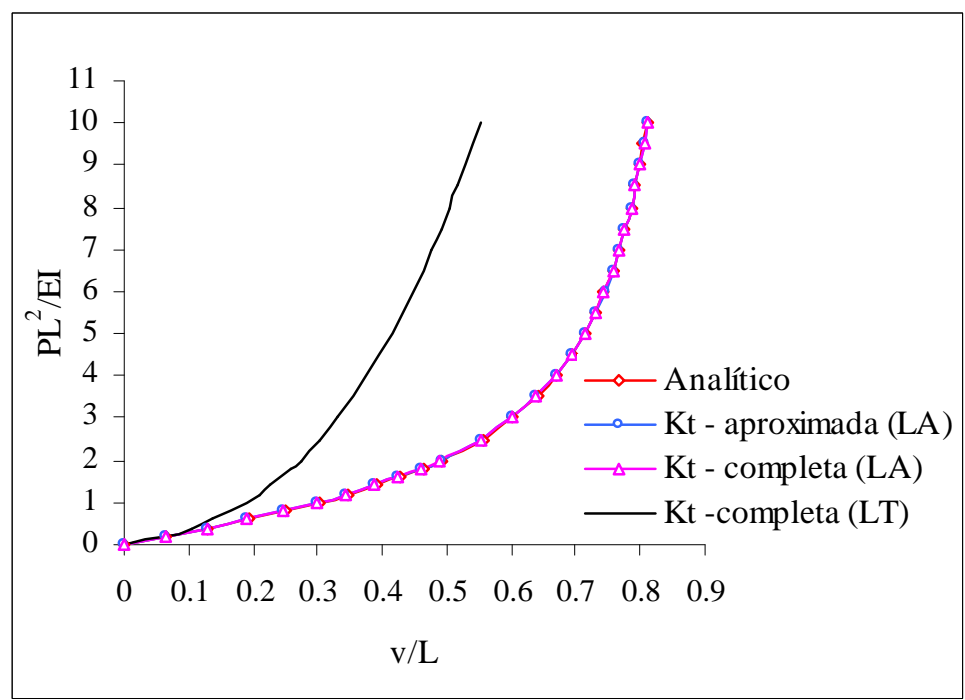

Figura 2.14- Curva carga paramétrica $x$ deslocamento adimensional v/L

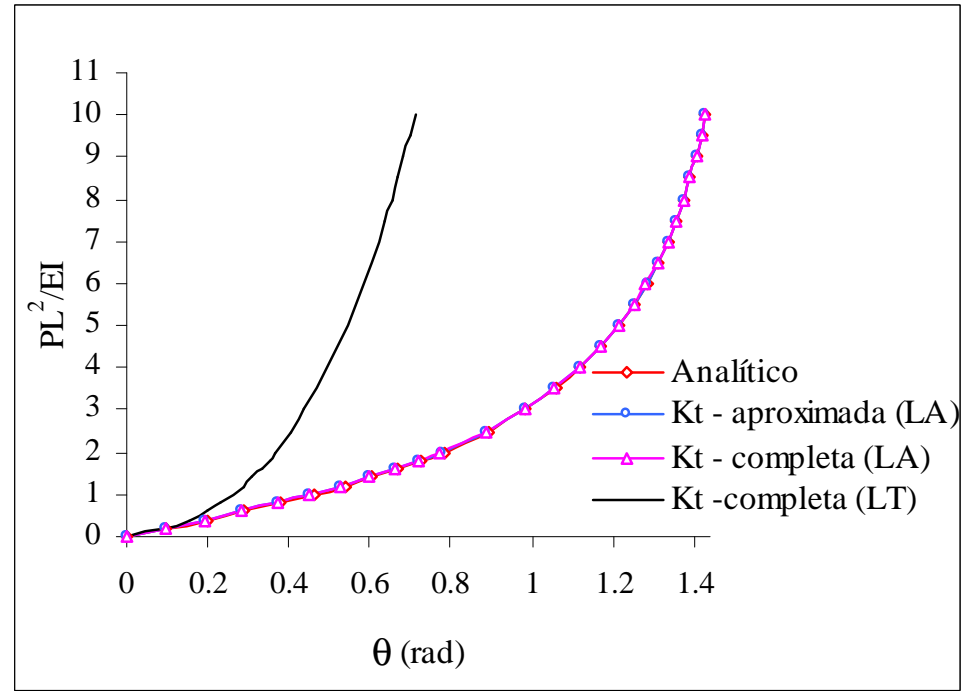

Figura 2.15- Curva carga paramétrica x rotação (rad)

Nas Figuras 2.13, 2.14, 2.15 estão apresentadas as curvas adimensionais cargadeslocamentos longitudinais e transversais de pontos do eixo e carga-rotações das seções, obtidas utilizando-se a formulação lagrangiana atualizada e as duas matrizes de rigidez tangente desenvolvidas bem como as obtidas com a matriz completa na formulação lagrangiana total. Os resultados são confrontados com a solução analítica, observando-se que os mesmos são coincidentes quando se emprega a formulação lagrangiana atualizada, isso devido às aproximações feitas nas expressões (2.41) e (2.42). 


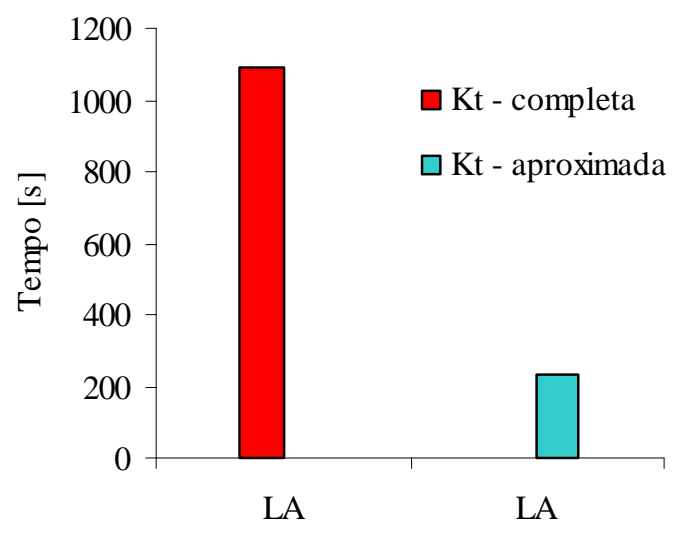

Figura 2.16- Tempo de processamento

A Figura 2.16 mostra o tempo gasto no processamento desta estrutura utilizando-se as matrizes de rigidez tangente completa e aproximada na formulação lagrangiana atualizada.

\subsubsection{Exemplo 3- Viga em balanço com momento aplicado na extremidade livre}

Neste exemplo é analisada uma viga em balanço submetida a um momento fletor concentrado na extremidade livre.

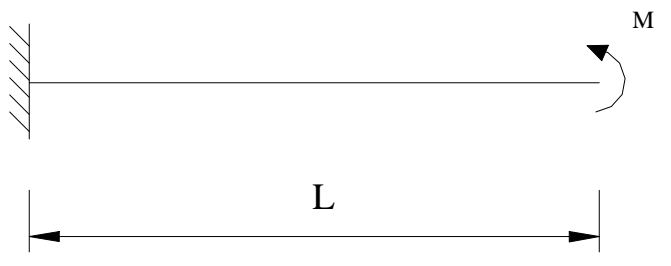

Figura 2.17- Viga em balanço

Os valores adotados na solução numérica são: momento concentrado $M=50265480$ Kgf.cm, comprimento $\mathrm{L}=500 \mathrm{~cm}$, área $\mathrm{A}=20 \mathrm{~cm}^{2}$, momento de inércia $\mathrm{I}=2.0 \times 10^{3} \mathrm{~cm}^{4}$ e módulo de elasticidade $\mathrm{E}=2.0 \times 10^{6} \mathrm{Kgf} / \mathrm{cm}^{2}$. A estrutura foi discretizada em 10 elementos iguais.

Foram utilizados 200 incrementos iguais de carga na análise incremental iterativa e normas em deslocamentos e forças iguais a $10^{-6}$. 
Na Tabela 2.1 estão apresentados os resultados obtidos para as coordenadas (x,y) e a rotação $\theta$ da extremidade livre utilizando-se a formulação lagrangiana atualizada com as diferentes matrizes de rigidez tangente, assim como os resultados exatos e numéricos apresentados no trabalho de LAVALL (1996). Nota-se que os resultados de solução exata implica em que por efeito do momento a extremidade livre sobre um giro de $360^{\circ}$ passa a coincidir com a origem na seção do engaste fixo.

Tabela 2.1- Coordenadas (x,y) e rotação $(\theta)$ da extremidade livre

\begin{tabular}{|c|c|c|c|c|}
\hline \multicolumn{2}{|c|}{$M=50265480 \mathrm{kgf.cm}$} & $\mathrm{x}(\mathrm{cm})$ & $\mathrm{y}(\mathrm{cm})$ & $\theta(\mathrm{rad})$ \\
\hline \multicolumn{2}{|c|}{ Solução exata } & 0.0 & 0.0 & 6.283 \\
\hline \multicolumn{2}{|c|}{ LAVALL (1996) } & 2.846 & 2.381 & 6.34611 \\
\hline \multirow{2}{*}{$\begin{array}{c}\text { Presente } \\
\text { trabalho }\end{array}$} & $\mathrm{K}_{\mathrm{T}}$ completa & -0.787 & -0.230 & 6.272 \\
\cline { 2 - 5 } & $\mathrm{K}_{\mathrm{T}}$ aproximada & -0.316 & -0.00255 & 6.278 \\
\hline
\end{tabular}

A Figura 2.18 mostra o tempo gasto no processamento desta estrutura utilizando-se as matrizes de rigidez tangente completa e aproximada.

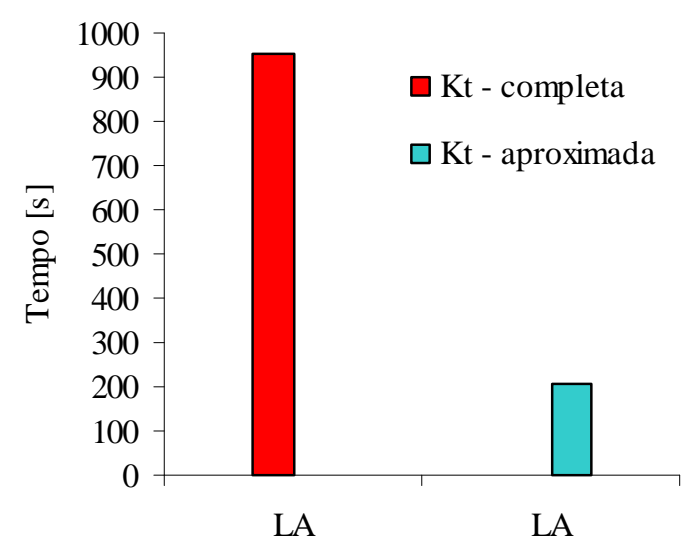

Figura 2.18- Tempo de processamento

A Tabela 2.1 mostra que os resultados obtidos com a formulação lagrangiana atualizada são satisfatórios considerando que se trata de um problema envolvendo 
grandes rotações. Uma solução mais próxima da exata é conseguida aumentando-se o número de incrementos.

Nas Figuras 2.11, 2.16 e 2.18 observa-se que o tempo de processamento gasto é indiscutivelmente menor quando se utiliza a matriz de rigidez tangente aproximada.

Finalmente, observando-se os resultados apresentados em cada exemplo, pode-se concluir que a matriz de rigidez tangente aproximada é mais vantajosa em função do tempo de processamento e simplicidade de implementação, uma vez que os resultados são praticamente os mesmos que os obtidos com a matriz completa. Diante dessa conclusão, na análise dinâmica realizada no capítulo 4, deste trabalho, emprega-se somente a matriz de rigidez aproximada. 


\section{CONSIDERAÇÃO DAS NÃO-LINEARIDADES FÍSICA E GEOMÉTRICA DE PÓRTICOS PLANOS EM CONCRETO ARMADO}

"O que sabemos é uma gota, o que ignoramos é um oceano."

Isaac Newton

\subsection{INTRODUÇ̃̃O}

Neste capítulo trata-se da análise não-linear física e geométrica de estruturas reticuladas planas em concreto armado, em especial vigas e pórticos. No entanto, como a não-linearidade geométrica teve sua formulação apresentada anteriormente, capítulo 2, o estudo teórico aqui abordado será quase que exclusivamente dedicado à não-linearidade do material, modelada pela mecânica do dano em meios contínuos.

A mecânica do dano no contínuo foi introduzida por KACHANOV em 1958 e vem, desde então, estendendo seu campo de aplicação no âmbito da engenharia. Segundo essa teoria, as equações constitutivas são escritas incluindo-se uma variável que quantifica o processo de deterioração ou microfissuração difusa do material numa etapa preliminar à formação das macrofissuras. A variável de dano, baseada no conceito de tensão efetiva, LEMAITRE (1992), relaciona-se, portanto, com a degradação média do material em nível de microescala. 
Um grande número de modelos matemáticos baseados na mecânica do dano no continuo têm sido propostos para simular o comportamento não-linear físico apresentado pelas estruturas em concreto armado. Neste estudo, utilizam-se particularmente os modelos de dano de Mazars $^{1}$ e de La Borderie ${ }^{2}$ para modelagem do comportamento não-linear físico do concreto, enquanto que as armaduras são consideradas como meios elastoplásticos, empregando-se um modelo elastoplástico com encruamento linear cinemático ou misto.

\subsection{ELEMENTOS DA MECÂNICA DO DANO CONTÍNUO}

Fisicamente a danificação do material é caracterizada pela formação e evolução de micro-defeitos que se espalham por sua estrutura interna, conduzindo a uma deterioração de suas propriedades mecânicas macroscópicas. Na mecânica dos meios contínuos para que se possa levar em conta a danificação do material real, utilizamse, variáveis de estado cuja ordem tensorial matemática depende das hipóteses adotadas para representar o dano.

Apresentam-se, aqui, modelos que empregam variáveis escalares de dano. Estudos mais completos relativos à mecânica do dano podem ser encontrados na literatura, como por exemplo em LEMAITRE (1992).

\subsubsection{Definição da variável dano}

Considere-se inicialmente um elemento de volume representativo, EVR, do meio danificado apresentado na Figura 3.1, grande o suficiente para admitir-se a hipótese de continuidade e pequeno o bastante para evitar grandes gradientes das variáveis mecânicas de interesse, LEMAITRE (1992).

${ }^{1}$ MAZARS (1984)

2 LA BO RDERIE (1991) 


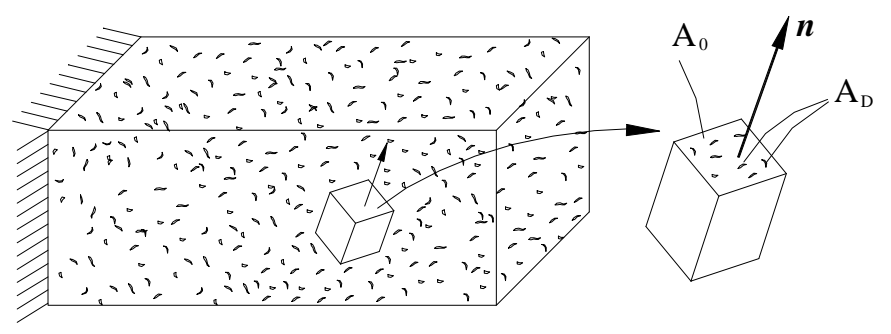

Figura 3.1- Elemento de Volume Representativo, com dano

A orientação dada ao elemento é definida pelo versor $\boldsymbol{n}$. Admitindo-se que esse elemento venha a sofrer tração uniaxial na direção de $\boldsymbol{n}$ e que a distribuição de defeitos seja homogênea, o estado de deterioração pode ser definido pela variável $D_{n}$, através da razão:

$$
D_{n}=\frac{A_{D}}{A_{0}}
$$

sendo $A_{o}$ a área de uma seção transversal tomada sobre o EVR. Como a área total apresenta microfissuras e microdefeitos de distribuição aleatória que constituem o dano, $A_{D}$ é a parcela de $A_{o}$ constituída pelos defeitos e que não resiste às solicitações internas.

Por outro lado, sendo a área efetivamente resistente dada por:

$$
\tilde{A}=A_{0}-A_{D}
$$

tem-se, alternativamente, que:

$$
D_{n}=\frac{A_{0}-\tilde{A}}{A_{0}}
$$

Desse modo:

$D_{n}=0 \Rightarrow$ corresponde ao estado sem deterioração do material, estado íntegro ou de referência. 
$D_{n}=1 \Rightarrow$ corresponde ao estado de deterioração total, isto é a ruptura do elemento de volume representativo do material.

Utilizando-se a equação (3.3), tem-se que área que efetivamente resiste à solicitação interna pode ser escrita por:

$$
\tilde{A}=\left(1-D_{n}\right) A_{0}
$$

Em princípio, o valor de $D_{n}$ depende da orientação definida pela normal $\boldsymbol{n}$; essa situação configura o que se pode definir como dano anisótropo. No entanto, é possível admitir uma situação teórica em que todos os microdefeitos tenham uma distribuição uniforme em todas as direções, ou seja, independente da orientação da normal $\boldsymbol{n}$. Nesse caso, o dano, dito isótropo, passa a ser caracterizado por uma variável de natureza escalar, independente de $\boldsymbol{n}$, que caracteriza completamente o estado local de dano.

\subsubsection{Conceito de tensão efetiva e deformação equivalente}

A tensão efetiva é definida dividindo-se a força de tração sobre o EVR, considerada no item anterior, pela parte da seção que efetivamente resiste à solicitação.
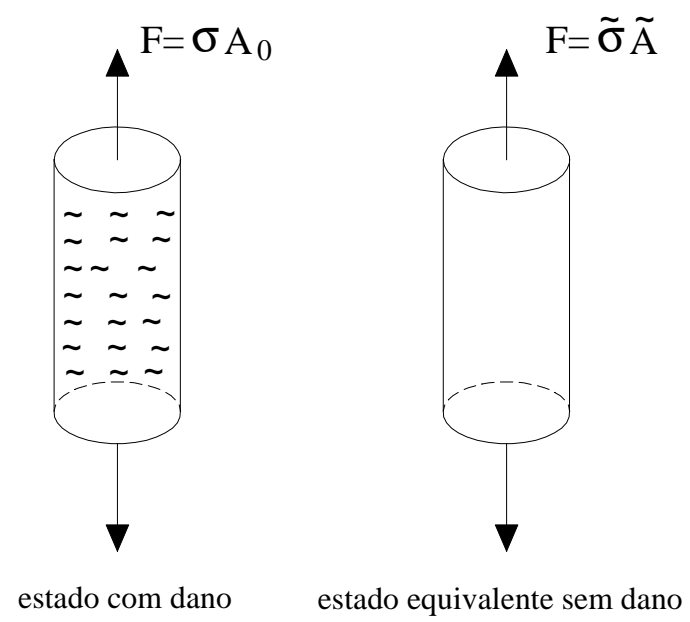

Figura 3.2- Dano de uma barra com tração uniaxial - adaptada de KATTAN \& VOYIADJIS(1990) Assim sendo, considerando-se o caso unidimensional mostrado na Figura 3.2, no qual o EVR está solicitado por uma força $F$, a tensão normal nominal é dada por: 


$$
\sigma=\frac{F}{A_{0}}
$$

Porém, se no lugar de $A_{0}$ for usada a área que efetivamente resiste à solicitação, $\tilde{A}$, obtém-se a tensão efetiva correspondente:

$$
\tilde{\sigma}=\frac{F}{\tilde{A}}=\frac{\sigma}{(1-D)}
$$

Em particular, $\widetilde{\sigma}=\sigma$ quando $D=0$ e $\widetilde{\sigma} \rightarrow \infty$ para $D=1$.

Considerando-se que o meio danificado permaneça com resposta elástica linear, a relação constitutiva para o caso uniaxial decorre da aplicação do princípio da equivalência de deformação. Segundo LEMAITRE \& CHABOCHE (1992), tal princípio estabelece que:

O estado de deformação de um ponto em um meio danificado pode ser obtido pela relação constitutiva do meio íntegro, onde se envolve a tensão efetiva.

Deste modo, a deformação elástica unidimensional de um meio com dano pode ser escrita da seguinte forma:

$$
\varepsilon=\frac{\tilde{\sigma}}{E}=\frac{\sigma}{(1-D) E}
$$

sendo $E$ o módulo de elasticidade do material sem dano.

Por outro lado, a mesma deformação pode ser expressa em função do módulo de elasticidade do material com dano, levando-se em conta a tensão nominal:

$$
\varepsilon=\frac{\sigma}{\widetilde{E}}
$$

Comparando-se as equações (3.7) e (3.8), tem-se a relação entre os módulos de elasticidade do material com e sem danificação: 


$$
\widetilde{E}=(1-D) E
$$

A relação (3.9) evidencia a degradação das características mecânicas do material causada pelo dano.

Ainda da relação (3.9), tem-se que:

$$
D=1-\frac{\tilde{E}}{E}
$$

A relação (3.10) é de grande interesse para a identificação paramétrica, pois sugere a determinação do valor atual da variável dano a partir da medida do valor do módulo de elasticidade atual, relativo a um estado deteriorado. Tal medida pode ser feita em laboratório conduzindo-se a um ensaio de tração uniaxial com deformação controlada, e operando-se um ciclo de descarregamento em correspondência ao nível de deformação de interesse.

\subsection{MODELO CONSTITUTIVO DE MAZARS}

Entre os diversos modelos constitutivos dedicados ao concreto e baseados na mecânica do dano, o modelo constitutivo de Mazars, apresentado originalmente em MAZARS (1984), além de envolver um número pequeno de parâmetros a identificar, permite representar adequadamente algumas evidências experimentais do concreto. Esse modelo introduz uma variável escalar $D$ que representa e quantifica o estado local de deterioração do material.

Destacam-se as seguintes hipóteses gerais: as deformações permanentes são desprezadas, sejam elas de natureza plástica, viscosa, ou induzidas pelo próprio processo de danificação e o carregamento é proporcionalmente crescente (radial). Além disso, admite-se que o aparecimento e a evolução do dano decorram exclusivamente da existência de alongamentos. Nesse sentido, define-se a deformação equivalente como uma variável escalar representativa do estado local de extensão. 
A deformação equivalente é calculada em função da parte positiva das componentes principais da deformação por:

$$
\tilde{\varepsilon}=\sqrt{\left\langle\varepsilon_{1}\right\rangle_{+}^{2}+\left\langle\varepsilon_{2}\right\rangle_{+}^{2}+\left\langle\varepsilon_{3}\right\rangle_{+}^{2}}=\sqrt{\sum_{1}^{3}\left\langle\varepsilon_{i}\right\rangle_{+}^{2}}
$$

sendo $\langle\bullet\rangle_{+}=\frac{1}{2}(\bullet+|\bullet|)$ e $\langle\bullet\rangle_{-}=\frac{1}{2}(\bullet-|\bullet|)$.

Deste modo, $\left\langle\varepsilon_{i}\right\rangle_{+}$a i-ésima componente positiva do vetor de deformações principais é dada por:

$$
\left\langle\varepsilon_{i}\right\rangle_{+}=\frac{1}{2}\left[\varepsilon_{i}+\left|\varepsilon_{i}\right|\right]
$$

Portanto, $\left\langle\varepsilon_{i}\right\rangle_{+}=\varepsilon_{i}$ se $\varepsilon_{i}>0$ e $\left\langle\varepsilon_{i}\right\rangle_{+}=0$ se $\varepsilon_{i} \leq 0$.

No modelo de Mazars, o dano se inicia quando a deformação equivalente atinge um valor de referência igual à deformação $\varepsilon_{d 0}$, à qual corresponde a resistência máxima em ensaios de tração uniaxial, conforme ilustrado na Figura 3.3.

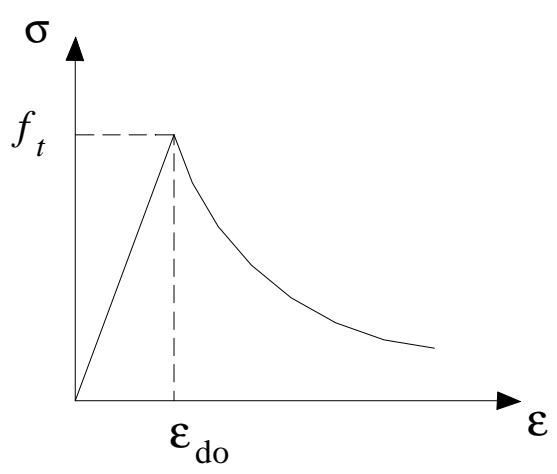

Figura 3.3- Curva tensão/deformação - ensaio de tração uniaxial

Para o caso unidimensional, tem-se:

$$
\varepsilon_{d 0}=\frac{f_{t}}{E}
$$

onde $f_{t}$ é a resistência à tração do concreto. 
O critério da danificação, que permite identificar situações de evolução do dano, é dado pela seguinte função:

$$
f(\tilde{\varepsilon}, D)=\tilde{\varepsilon}-s(D) \leq 0 \quad \text { com } \quad s(0)=\varepsilon_{d 0}
$$

onde $D$ é a variável escalar que representa o dano e $s(D)$ assume o valor máximo de $\tilde{\varepsilon}$ a partir do instante em que $\tilde{\varepsilon}>\varepsilon_{d 0}$.

Para o caso em que $f(\tilde{\varepsilon}, D)=0$ tem-se:

$$
\tilde{\varepsilon}=s(D)=\sqrt{\left\langle\varepsilon_{1}\right\rangle_{+}^{2}+\left\langle\varepsilon_{2}\right\rangle_{+}^{2}+\left\langle\varepsilon_{3}\right\rangle_{+}^{2}}
$$

A equação (3.15) caracteriza, no espaço das deformações principais, uma superfície de um quarto de esfera de raio $s(D)$, como mostrado na Figura 3.4, que limita estados de deformação que não se tem evolução de dano.

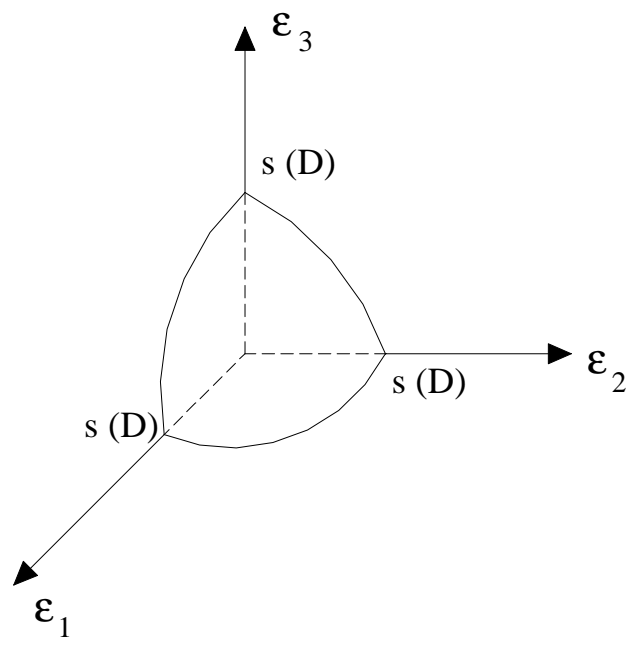

Figura 3.4- Espaço das deformações principais

A lei de evolução da variável $D$, atendendo ao princípio da irreversibilidade do processo de danificação, decorrente da segunda lei da termodinâmica, é expressa pelas seguintes relações:

$$
\dot{D}=0 \text { se } f<0 \text { ou } f=0 \text { e } \dot{f}<0
$$




$$
\dot{D}=F(\tilde{\varepsilon})\langle\dot{\tilde{\varepsilon}}\rangle_{+} \text {se } f=0 \text { e } \dot{f}=0
$$

sendo $F(\tilde{\varepsilon})$ uma função contínua e positiva da deformação equivalente, de modo que $\dot{D} \geq 0$ para qualquer $\dot{\tilde{\varepsilon}} \geq 0$.

Segundo PEREGO (1990), a função $F(\widetilde{\varepsilon})$ que governa a evolução do dano, deve ser capaz de reproduzir as curvas experimentais obtidas nos ensaios uniaxiais, biaxiais e triaxiais.

Uma característica particular do modelo de Mazars é a forma como a relação (3.17) é explicitada, tomando-se por base casos mais simples de solicitação. De início, tendose em vista somente as situações uniaxiais de tração e de compressão e procurandose capturar a não simetria do comportamento do concreto, definem-se duas variáveis escalares independentes, $D_{T}$ e $D_{C}$, que representam o dano na tração e compressão, respectivamente, e cujas leis de evolução são:

$$
\begin{gathered}
\dot{D}_{T}=F_{T}(\tilde{\varepsilon})\langle\dot{\tilde{\varepsilon}}\rangle_{+} \quad \text { para tração } \\
\dot{D}_{C}=F_{C}(\tilde{\varepsilon})\langle\dot{\tilde{\varepsilon}}\rangle_{+} \quad \text { para compressão }
\end{gathered}
$$

sendo:

$$
\begin{aligned}
& F_{T}(\tilde{\varepsilon})=\frac{\varepsilon_{d 0}\left(1-A_{T}\right)}{\tilde{\varepsilon}^{2}}+\frac{A_{T} B_{T}}{\exp \left[B_{T}\left(\tilde{\varepsilon}-\varepsilon_{d 0}\right)\right]} \\
& F_{C}(\tilde{\varepsilon})=\frac{\varepsilon_{d 0}\left(1-A_{C}\right)}{\tilde{\varepsilon}^{2}}+\frac{A_{C} B_{C}}{\exp \left[B_{C}\left(\tilde{\varepsilon}-\varepsilon_{d 0}\right)\right]}
\end{aligned}
$$

Nos casos de carregamento radial as expressões (3.18) e (3.19) são integráveis, resultando em:

$$
D_{T}(\tilde{\varepsilon})=1-\frac{\varepsilon_{d 0}\left(1-A_{T}\right)}{\tilde{\varepsilon}}-\frac{A_{T}}{\exp \left[B_{T}\left(\tilde{\varepsilon}-\varepsilon_{d 0}\right)\right]}
$$




$$
D_{C}(\widetilde{\varepsilon})=1-\frac{\varepsilon_{d 0}\left(1-A_{C}\right)}{\widetilde{\varepsilon}}-\frac{A_{C}}{\exp \left[B_{C}\left(\tilde{\varepsilon}-\varepsilon_{d 0}\right)\right]}
$$

Nas expressões acima $A_{T}, B_{T}$ e $\varepsilon_{d 0}$ são parâmetros característicos do material que podem ser identificados com base em resultados de ensaios de tração uniaxial com deformação controlada; $A_{C}$ e $B_{C}$ podem ser identificados com resultados de ensaios de compressão uniaxial com deformação controlada, ÁLVARES (1993).

Em geral, Mazars propõe os seguintes intervalos de variação para os parâmetros $A_{T}$, $B_{T}, A_{C}, B_{C}$ e $\varepsilon_{d 0}$, nos quais se podem enquadrar os concretos usuais: $0.7 \leq A_{T} \leq 1$; $10^{4} \leq B_{T} \leq 10^{5} ; 1 \leq A_{C} \leq 1.5 ; 10^{3} \leq B_{C} \leq 2.10^{3}$ e $10^{-5} \leq \varepsilon_{d 0} \leq 10^{-4}$. Em ÁLVARES (1993) estes intervalos foram reavaliados, em particular foram alterados os limites inferiores $\operatorname{de} \varepsilon_{d 0}$ e $B_{T}$.

Para incluir estados de tensão mais complexos, mas preservando-se as características dos casos uniaxiais, a variável de dano $D$ correspondente é então definida como uma combinação linear de $D_{T}$ e $D_{C}$ na forma:

$$
D=\alpha_{T} D_{T}+\alpha_{C} D_{T}
$$

respeitando-se sempre $\alpha_{T}+\alpha_{C}=1$; naturalmente $\alpha_{T}=1$ para tração uniaxial e $\alpha_{C}=1$ para compressão uniaxial.

A forma em taxas da expressão (3.24), de interesse para as aplicações que seguem, assumindo-se a hipótese de $\alpha_{T}$ e $\alpha_{C}$ serem constantes, o que é verdade no caso de carregamento radial, resulta:

$$
\dot{D}=\alpha_{T} \dot{D}_{T}+\alpha_{C} \dot{D}_{C}
$$

Neste trabalho, para a determinação dos coeficientes $\alpha_{T}$ e $\alpha_{C}$ em casos gerais de solicitação é adotada a proposta de PEREGO (1990): 


$$
\begin{array}{r}
\alpha_{T}=\frac{\sum_{i}\left\langle\varepsilon_{T_{i}}\right\rangle_{+}}{\varepsilon_{V}^{+}} \\
\alpha_{C}=\frac{\sum_{i}\left\langle\varepsilon_{C_{i}}\right\rangle_{+}}{\varepsilon_{V}^{+}}
\end{array}
$$

sendo $\varepsilon_{V}^{+}$uma variável cinemática representativa do estado local de extensão, definida por:

$$
\varepsilon_{V}^{+}=\sum_{i}\left\langle\varepsilon_{T_{i}}\right\rangle_{+}+\sum_{i}\left\langle\varepsilon_{C_{i}}\right\rangle_{+}
$$

Observa-se que nas relações (3.26) e (3.27), são consideradas somente as componentes positivas de $\underline{\varepsilon}_{T}$ e $\underline{\varepsilon}_{C}$, respeitando assim a hipótese assumida pelo modelo que atribui o aparecimento do dano à presença de alongamentos, isto é para $\varepsilon_{i}>0$. Por sua vez, as expressões propostas por MAZARS (1984), para $\underline{\varepsilon}_{T}$ e $\underline{\varepsilon}_{C}$ são:

$$
\begin{aligned}
& \underline{\varepsilon}_{T}=\frac{1+v}{E}\langle\underline{\sigma}\rangle_{+}-\frac{v}{E} \sum_{i}\left\langle\sigma_{i}\right\rangle_{+} I \\
& \underline{\varepsilon}_{c}=\frac{1+v}{E}\langle\underline{\sigma}\rangle_{-}-\frac{v}{E} \sum_{i}\left\langle\sigma_{i}\right\rangle_{-} I
\end{aligned}
$$

onde $I$ é o tensor identidade e, $\langle\underline{\sigma}\rangle_{+}$e $\langle\underline{\sigma}\rangle_{-}$são as partes positiva e negativa do tensor de tensões de um estado de tensão principal fictícia, calculado com o estado de deformações atual aplicando-se a relação elástica isótropa.

Finalmente, em termos de relação tensão-deformação, pode-se afirmar que o dano escalar penaliza diretamente todas as componentes do tensor de rigidez elástica. Assim sendo, a relação constitutiva do modelo, nas formas secante e tangente, é expressa, respectivamente, por:

$$
\underline{\sigma}=\underline{D}_{0}(1-D) \underline{\varepsilon}
$$




$$
\underline{\sigma}=\underline{\underline{D}}_{0}(1-D) \dot{\varepsilon}-\underline{\underline{D}}_{0} \dot{D} \underline{\varepsilon}
$$

\subsection{MODELO CONSTITUTIVO DE LA BORDERIE}

Este modelo aplica-se principalmente a situações de solicitações cíclicas com inversão de sinal. Na sua formulação permite-se levar em conta o aspecto unilateral da resposta do material, fenômeno inerente ao comportamento mecânico do concreto que consiste na independência dos processos de danificação de estados de tração e de compressão. Definem-se, então, duas variáveis escalares representativas do dano em tração $\left(D_{1}\right)$ e do dano em compressão $\left(D_{2}\right)$. A ativação de um ou outro processo de danificação, por efeito do fechamento ou abertura de fissuras, quando da inversão do processo de carregamento, é feita através de um controle sobre o sinal das tensões principais. Ao contrário do modelo de Mazars, em estados mais complexo de tensão as duas variáveis não se combinam numa única variável de dano. Consideram-se, também, deformações anelásticas ou residuais devidas exclusivamente ao dano.

O modelo de dano proposto por LA BORDERIE (1991) é apresentado originalmente segundo o formalismo termodinâmico do método do estado local, LEMAITRE \& CHABOCHE (1990). Aquela forma de apresentação será mantida no texto. Nesse sentido definem-se variáveis de estado ditas primária $(\underline{\sigma})$ e internas $\left(D_{1}, D_{2}, z_{1}, z_{2}\right)$, bem como suas correspondentes variáveis associadas $\left(\underline{\varepsilon}, Y_{1}, Y_{2}, Z_{1}, Z_{2}\right)$. Em particular, $Y_{1}$ e $Y_{2}$ são variáveis associadas a $D_{1}$ e $D_{2}$, respectivamente e, interpretadas como taxas de energia liberadas durante o processo de evolução do dano. Por sua vez, $Z_{1}$ e $Z_{2}$ são associadas, respectivamente, a $z_{1}$ e $z_{2}$ (medidas de dano acumulado) e controlam o processo de encruamento, estando inseridas nas funções representativas dos critérios de danificação.

As relações entre as variáveis de estado e as suas variáveis associadas podem ser deduzidas a partir de um potencial de estado. No modelo constitutivo de La Borderie sugere-se o potencial de energia livre de Gibbs $(\chi)$ como potencial de estado, sendo dado pela seguinte expressão: 


$$
\begin{gathered}
\chi\left(\underline{\sigma}, D_{1}, D_{2}, z_{1}, z_{2}\right)=\frac{\langle\underline{\sigma}\rangle_{+}:\langle\underline{\sigma}\rangle_{+}}{2 E\left(1-D_{1}\right)}+\frac{\langle\underline{\sigma}\rangle_{-}:\langle\underline{\sigma}\rangle_{-}}{2 E\left(1-D_{2}\right)}+\frac{v}{2 E}\left(\underline{\sigma}: \underline{\sigma}-\operatorname{Tr}^{2}(\underline{\sigma})\right)+ \\
+\frac{\beta_{1} D_{1}}{E\left(1-D_{1}\right)} f(\operatorname{Tr}(\underline{\sigma}))+\frac{\beta_{2} D_{2}}{E\left(1-D_{2}\right)} \operatorname{Tr}(\underline{\sigma})+G_{1}\left(z_{1}\right)+G_{2}\left(z_{2}\right)
\end{gathered}
$$

onde $\langle\underline{\sigma}\rangle_{+}$e $\langle\underline{\sigma}\rangle_{-}$são, respectivamente, as partes positiva e negativa do tensor de tensões, $\operatorname{Tr}(\underline{\sigma})$ é o primeiro invariante do tensor de tensões, $v$ é o coeficiente de Poisson do material virgem, $E$ é o módulo de elasticidade do material íntegro, $\beta_{l}$ e $\beta_{2}$ são os parâmetros a serem identificados, relacionados ao aparecimento de deformações anelásticas; $G_{1}\left(z_{1}\right)$ e $G_{2}\left(z_{2}\right)$ são funções de encruamento. Além disso, a função $f(\operatorname{Tr}(\underline{\sigma}))$ que procura levar em conta a abertura e o fechamento de fissuras assumem diferentes formas tendo-se como referência a tensão de fechamento de fissuras, $\sigma_{f}$, considerada um parâmetro do material a ser identificado.

As expressões propostas são:

$$
\begin{gathered}
f(\operatorname{Tr}(\underline{\sigma}))=\operatorname{Tr}(\underline{\sigma}) \quad \text { quando } \quad \operatorname{Tr}(\underline{\sigma}) \in[0, \infty[ \\
\left.f(\operatorname{Tr}(\underline{\sigma}))=\left(1+\frac{\operatorname{Tr}(\underline{\sigma})}{2 \sigma_{f}}\right) \operatorname{Tr}(\underline{\sigma}) \quad \text { quando } \quad \operatorname{Tr}(\underline{\sigma}) \in\right\rfloor-\sigma_{f}, 0[ \\
\left.\left.f(\operatorname{Tr}(\underline{\sigma}))=-\frac{\sigma_{f}}{2} \quad \text { quando } \quad \operatorname{Tr}(\underline{\sigma}) \in\right\rfloor-\infty,-\sigma_{f}\right\rfloor
\end{gathered}
$$

Das expressões anteriores seguem ainda:

$$
\begin{gathered}
\left.\frac{\partial f(\operatorname{Tr}(\underline{\sigma})}{\partial \underline{\sigma}}\right|_{[0,+\infty[}=I \\
\left.\frac{\partial f(\operatorname{Tr}(\underline{\sigma})}{\partial \underline{\sigma}}\right|_{]_{-\infty,-\sigma_{f}}\right]}=0
\end{gathered}
$$




$$
\left.\frac{\partial f(\operatorname{Tr}(\underline{\sigma})}{\partial \underline{\sigma}}\right|_{]_{-\sigma_{f}, 0}}=\left(1+\frac{\operatorname{Tr}(\underline{\sigma})}{\sigma_{f}}\right) I
$$

As leis de estado derivam do potencial de estado, dado pela expressão (3.33) e definem as variáveis associadas às variáveis de estado mediante derivadas parciais. Assim, o tensor de deformações resulta de:

$$
\underline{\varepsilon}=\frac{\partial \chi}{\partial \underline{\sigma}}=\underline{\varepsilon}_{e}+\underline{\varepsilon}_{a n}
$$

sendo $\underline{\varepsilon}_{e}$ a parcela de deformações elásticas e $\underline{\varepsilon}_{a n}$ o tensor de deformações anelásticas. Tais componentes são dadas, respectivamente, por:

$$
\begin{gathered}
\underline{\varepsilon}_{e}=\frac{\langle\underline{\sigma}\rangle_{+}}{E\left(1-D_{1}\right)}+\frac{\langle\underline{\sigma}\rangle_{-}}{E\left(1-D_{2}\right)}+\frac{v}{E}(\underline{\sigma}-\operatorname{Tr}(\underline{\sigma}) I) \\
\underline{\varepsilon}_{a n}=\frac{\beta_{1} D_{1}}{E\left(1-D_{1}\right)} \frac{\partial f}{\partial \underline{\sigma}}+\frac{\beta_{2} D_{2}}{E\left(1-D_{2}\right)} I
\end{gathered}
$$

Por sua vez, as variáveis associadas às variáveis de dano resultam de:

$$
\begin{gathered}
Y_{1}=\frac{\partial \chi}{\partial D_{1}}=\frac{\langle\underline{\sigma}\rangle_{+}:\langle\underline{\sigma}\rangle_{+}+2 \beta_{1} f(\underline{\sigma})}{2 E\left(1-D_{1}\right)^{2}} \\
Y_{2}=\frac{\partial \chi}{\partial D_{2}}=\frac{\langle\underline{\sigma}\rangle_{-}:\langle\underline{\sigma}\rangle_{-}+2 \beta_{2} \operatorname{Tr}(\underline{\sigma})}{2 E\left(1-D_{2}\right)^{2}}
\end{gathered}
$$

As variáveis $Z_{i}$ poderiam ser definidas de forma análoga. Entretanto, em lugar de explicitar as $G_{i}$ que aparecem na relação (3.33) e a partir delas, por derivação, obter aquelas variáveis, sugere-se empregar diretamente expressões para $Z_{i}$ resultantes de ajustes sobre resultados experimentais. A forma geral dessas expressões é a seguinte: 


$$
Z_{i}=\frac{\partial G_{i}\left(z_{i}\right)}{\partial z_{i}}=\left[Y_{0 i}+\frac{1}{A_{i}}\left(\frac{D_{i}}{1-D_{i}}\right)^{1 / B_{i}}\right] \quad(i=1,2)
$$

onde $A_{i}, B_{i}$ e $Y_{0 i}$ são parâmetros a serem identificados.

Nota-se que as variáveis $Z_{i}$ tem valores iniciais dados por $Z_{i}\left(D_{i}=0\right)=Y_{0 i}$. As expressões (3.45) aparecem, na verdade, nas funções critério de danificação $F_{i}=Y_{i}-Z_{i}$, as quais caracterizam condições para a evolução ou não do dano em tração ou em compressão. Tais condições são:

Se $Y_{i}<Z_{i}$ então $\dot{D}_{i}=0$ e a resposta imediata é elástica linear

$$
\text { Se } Y_{i}=Z_{i} \text { e } \dot{Y}_{i}>0 \text {, então } \dot{Y}_{i}=\dot{Z}_{i} \text { e } \dot{D}_{i} \neq 0
$$

Havendo evolução de dano pode-se determinar $D_{i}$ a partir da expressão (3.45):

$$
D_{i}=1-\frac{1}{1+\left[A_{i}\left(Y_{i}-Y_{0 i}\right)\right]^{B_{i}}}
$$

Deve-se observar que nas equações (3.43) e (3.44) originalmente propostas por $L A$ BORDERIE (1991), as taxas de energia liberada durante o processo de evolução do dano $\left(Y_{i}\right)$ dependem continuamente dos parâmetros anelásticos $\beta_{i}$, estritamente relacionados às deformações residuais, mesmo antes de ocorrer qualquer processo de danificação $\left(D_{i}>0\right)$. Tal fato contradiz uma das hipóteses do modelo: deformações residuais devidas apenas ao dano. As equações mencionadas são, a rigor, consistentes somente no caso de $Y_{0 i}$ nulo, o que implicaria em admitir que o material apresenta danificação desde o início da análise.

Diante desta observação, e de modo a recuperar coerência com a hipótese relacionada às deformações residuais, PITUBA et al (1999) propõem as seguintes formas para o cálculo das taxas de energia liberada durante o processo de evolução do dano $\left(Y_{i}\right)$ : 


$$
\begin{gathered}
Y_{1}=\frac{\partial \chi}{\partial D_{1}}=\frac{\langle\underline{\sigma}\rangle_{+}:\langle\underline{\sigma}\rangle_{+}+2 \beta_{1} f(\underline{\sigma}) \alpha_{1}}{2 E\left(1-D_{1}\right)^{2}} \\
Y_{2}=\frac{\partial \chi}{\partial D_{2}}=\frac{\langle\underline{\sigma}\rangle_{-}:\langle\underline{\sigma}\rangle_{-}+2 \beta_{2} \operatorname{Tr}(\underline{\sigma}) \alpha_{2}}{2 E\left(1-D_{2}\right)^{2}}
\end{gathered}
$$

Os coeficientes $\alpha_{i}(i=1,2)$ assumem o valor unitário quando a variável de dano $D_{i}$ for diferente de zero, caso contrário são nulos.

\subsubsection{Implementação do Modelo de La Borderie para o caso unidimensional}

Conforme LA BORDERIE (1991) apresentam-se, nesta seção, as principais etapas necessárias para a implementação numérica do modelo constitutivo de La Borderie para o caso unidimensional.

Inicialmente, a equação que expressa a deformação total pode ser escrita na forma:

$$
\varepsilon=\frac{\langle\sigma\rangle_{+}}{E\left(1-D_{1}\right)}+\frac{\langle\sigma\rangle_{-}}{E\left(1-D_{2}\right)}+\frac{\beta_{1} D_{1}}{E\left(1-D_{1}\right)} f^{\prime}(\sigma)+\frac{\beta_{2} D_{2}}{E\left(1-D_{2}\right)}
$$

onde $f^{\prime}(\sigma)$ é a derivada da função que leva em conta o fechamento de fissuras com relação à tensão $\sigma$.

As taxas de energia liberada nos processos de evolução do dano são dadas por:

$$
\begin{aligned}
& Y_{1}=\frac{\langle\sigma\rangle_{+}^{2}}{2 E\left(1-D_{1}\right)^{2}}+\frac{\beta_{1} f(\sigma) \alpha_{1}}{E\left(1-D_{1}\right)^{2}} \\
& Y_{2}=\frac{\langle\sigma\rangle_{-}^{2}}{2 E\left(1-D_{2}\right)^{2}}+\frac{\beta_{2} \sigma \alpha_{2}}{E\left(1-D_{2}\right)^{2}}
\end{aligned}
$$

As expressões para o cálculo das variáveis de dano são: 


$$
\begin{aligned}
& D_{1}=1-\frac{1}{1+A_{1}\left(Y_{1}-Y_{01}\right)^{B_{1}}} \text { se } Y_{1}>Z_{1} \operatorname{com} Z_{1}=\max \left(Y_{1}, Y_{01}\right) \\
& D_{2}=1-\frac{1}{1+A_{2}\left(Y_{2}-Y_{02}\right)^{B_{2}}} \text { se } Y_{2}>Z_{2} \operatorname{com} Z_{2}=\max \left(Y_{2}, Y_{02}\right)
\end{aligned}
$$

A função que leva em conta o fechamento de fissuras e suas derivadas em relação à tensão $\sigma$ são:

$$
\text { Se } \sigma \geq 0 \quad f(\sigma)=\sigma \quad f^{\prime}(\sigma)=1 \quad \rightarrow \text { caso } 1
$$

Se $0>\sigma>-\sigma_{f} \quad f(\sigma)=\sigma\left(1+\frac{\sigma}{2 \sigma_{f}}\right) \quad f^{\prime}(\sigma)=1+\frac{\sigma}{\sigma_{f}} \rightarrow$ caso 2

$$
\text { Se } \sigma \leq-\sigma_{f} \quad f(\sigma)=\frac{-\sigma_{f}}{2} \quad f^{\prime}(\sigma)=0 \rightarrow \text { caso } 3
$$

Segundo LA BORDERIE (1991) os valores do módulo secante e das deformações anelásticas devem ser calculados em termos da deformação total.

A grande dificuldade na implementação numérica deste modelo é a determinação do sinal da tensão, que permite identificar se as fissuras estão fechando ou não, e qual é a função a ser adotada para $f(\sigma)$, equações (3.55) a (3.57). A solução deste problema é indicada no diagrama que segue. 


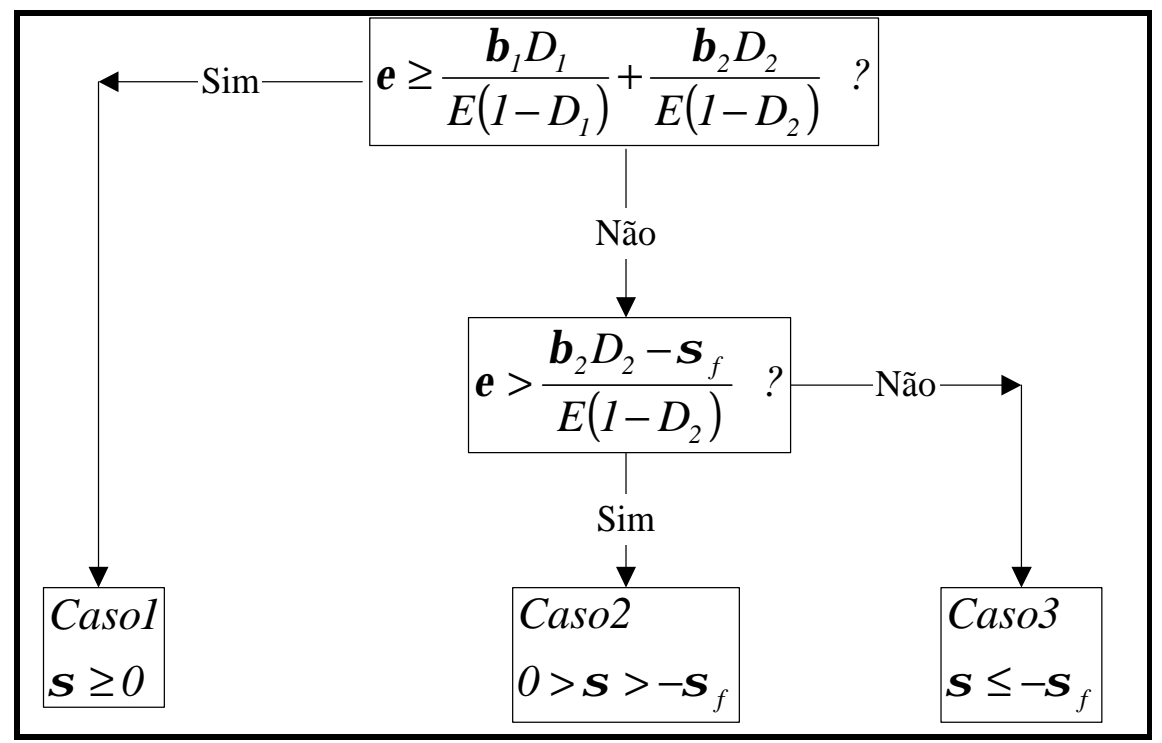

A verificação em questão é feita em cada ponto de Gauss e os valores de dano são calculados a partir de diferentes expressões dependendo do caso identificado. Deste modo, tem-se que:

\section{Caso $1($ tração $\sigma \geq 0)$}

Neste caso, $D_{1}$ e $Y_{1}$ aumentam e a outra variável de dano, $D_{2}$, permanece constante, não aparecendo explicitamente na relação constitutiva. Uma primeira estimativa de $Y_{1}$ deve ser efetuada para testar o critério adotado para a evolução do dano, equação (3.51).

$$
Y_{1}=\frac{1}{2 E}\left[\left(E \varepsilon+\beta_{l} \alpha_{1}-\frac{\beta_{2} \alpha_{2}}{1-D_{2}}\right)^{2}-\frac{\left(\beta_{1} \alpha_{1}\right)^{2}}{\left(1-D_{1}\right)^{2}}\right]
$$

Assim, se o critério não for satisfeito então não há evolução do dano e o valor calculado para $Y_{l}$ está correto. Porém, se o critério for satisfeito, isto é, se houver evolução de dano, então o seguinte sistema não-linear de duas equações deve ser resolvido: 


$$
\left\{\begin{array}{c}
Y_{1}-\frac{1}{2 E}\left[\left(E \varepsilon+\beta_{1} \alpha_{1}-\frac{\beta_{2} D_{2}}{1-D_{2}}\right)^{2}-\frac{\left(\beta_{l} \alpha_{1}\right)^{2}}{\left(1-D_{1}\right)^{2}}\right]=0 \\
D_{1}-1+\frac{1}{1+A_{l}\left(Y_{1}-Y_{0 I}\right)^{B_{l}}}=0
\end{array}\right.
$$

\section{Caso 2 (compressão com $\sigma>-\sigma_{f}$ )}

Assumindo-se que o critério de danificação é fixo então a variável $D_{2}$ não é alterada para $\sigma=\sigma_{f}$, e portanto o valor de $f^{\prime}(\sigma)$ precisa ser calculado:

$$
f^{\prime}(\sigma)=\frac{E \varepsilon\left(1-D_{2}\right)-\beta_{2} D_{2}+\sigma_{f}}{\sigma_{f}+\frac{\beta_{1} D_{1}\left(1-D_{2}\right)}{1-D_{1}}}
$$

Usualmente a tensão $\sigma_{f}$ é da ordem da tensão de tração e não existe evolução nas variáveis de dano no modelo em estudo.

\section{Caso 3 (compressão com $\sigma \leq-\sigma_{f}$ )}

Este caso, é similar ao caso 1, ou seja $D_{2}$ e $Y_{2}$ aumentam e a outra variável de dano, $D_{1}$, permanece constante, não aparecendo explicitamente na relação constitutiva. $\mathrm{O}$ primeiro cálculo de $Y_{2}$ é efetuado para testar o critério adotado para a evolução do dano, equação (3.52).

$$
Y_{2}=\frac{1}{2 E}\left[\left(E \varepsilon+\beta_{2} \alpha_{2}\right)^{2}-\frac{\left(\beta_{2} \alpha_{2}\right)^{2}}{\left(1-D_{2}\right)^{2}}\right]
$$

Assim, se o critério não for satisfeito então não há evolução do dano e o valor calculado para $Y_{2}$ está correto. Porém, se o critério for satisfeito, isto é, se houver evolução de dano, então o seguinte sistema não-linear de duas equações deve ser resolvido: 


$$
\left\{\begin{array}{c}
Y_{2}-\frac{1}{2 E}\left[\left(E \varepsilon+\beta_{2} \alpha_{2}-\right)^{2}-\frac{\left(\beta_{2} \alpha_{2}\right)^{2}}{\left(1-D_{2}\right)^{2}}\right]=0 \\
D_{2}-1+\frac{1}{1+A_{2}\left(Y_{2}-Y_{02}\right)^{B_{2}}}=0
\end{array}\right.
$$

Os sistemas não-lineares que aparecem nos casos 1 e 3 podem ser resolvidos empregando-se o método do tipo Newton, opção utilizada neste trabalho.

Nos 3 casos apresentados anteriormente as expressões resultantes para as tensões, os módulos de rigidez do material e as deformações anelásticas são resumidas na tabela 3.1 .

Tabela 3.1- Expressões das tensões, módulo de rigidez e deformações anelásticas LA BORDERIE (1991)

\begin{tabular}{|l|c|c|c|}
\hline & Caso 1 & Caso 2 & Caso 3 \\
\hline$\sigma$ & $\begin{array}{c}E \varepsilon\left(1-D_{1}\right)-\beta_{1} D_{1}- \\
+\frac{\beta_{2} D_{2}\left(1-D_{1}\right)}{1-D_{2}}\end{array}$ & $\begin{array}{c}E \varepsilon\left(1-D_{2}\right)-\beta_{2} D_{2}- \\
+\frac{\beta_{1} D_{1}\left(1-D_{2}\right)}{1-D_{1}} f^{\prime}(\sigma)\end{array}$ & $E \varepsilon\left(1-D_{2}\right)-\beta_{2} D_{2}$ \\
\hline$E_{D}$ & $E\left(1-D_{1}\right)$ & $E\left(1-D_{2}\right)$ & $E\left(1-D_{2}\right)$ \\
\hline$\varepsilon_{a n}$ & $-\frac{\beta_{1} D_{1}}{E\left(1-D_{1}\right)}-\frac{\beta_{2} D_{2}}{E\left(1-D_{2}\right)}$ & $-\frac{\beta_{1} D_{1}}{E\left(1-D_{1}\right)} f^{\prime}(\sigma)-\frac{\beta_{2} D_{2}}{E\left(1-D_{2}\right)}$ & $-\frac{\beta_{2} D_{2}}{E\left(1-D_{2}\right)}$ \\
\hline
\end{tabular}

É interessante ilustrar, para este modelo, o gráfico tensão/deformação do concreto que resulta de um processo de solicitação uniaxial que parte da tração e inverte-se para compressão. A representação está ilustrada na Figura 3.5: 


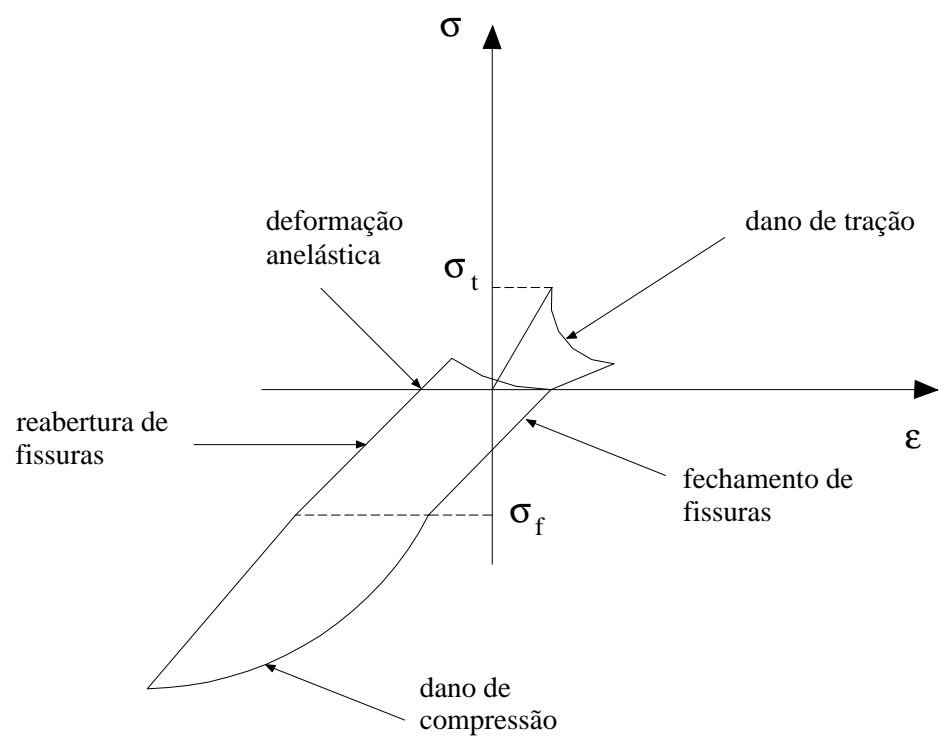

Figura 3.5- Relação tensão/deformação - MAZARS et al (2000)

\subsection{COMBINAÇÃO DOS MODELOS DE DANO COM A NÃO-LINEARIDADE GEOMÉTRICA}

\subsubsection{Modelo de Mazars combinado com não-linearidade geométrica}

Seja o elemento finito de pórtico plano apresentado no capítulo 2, deste trabalho, e considerem-se as expressões para a deformação axial, $\varepsilon_{X X}$ e $\varepsilon_{X}$, dadas pelas equações (2.64) e (2.65). Inicialmente, segundo o modelo de Mazars, as deformações equivalentes para estados de tração uniaxial e de compressão uniaxial ficam dadas, respectivamente, por:

$$
\tilde{\varepsilon}=\varepsilon \text { se } \varepsilon>0 \quad \text { e } \quad \tilde{\varepsilon}=-\vee \sqrt{2} \varepsilon \text { se } \varepsilon<0
$$

onde $v$ é o coeficiente de Poisson.

Neste caso, $\varepsilon=\varepsilon_{X}$ ou $\varepsilon=\varepsilon_{X X}$, dependendo da escolha da aproximação empregada para a deformação, conforme apresentado no capítulo2.

Tendo-se em vista a combinação com a não-linearidade geométrica e fazendo-se novamente uso da hipótese de pequenas deformações, para o caso unidimensional a equação (2.53a) assume a forma: 


$$
S=(1-D) E \varepsilon
$$

Como visto no capítulo 2, a matriz de rigidez tangente do elemento de pórtico plano resulta do desenvolvimento da seguinte expressão:

$$
\frac{d}{d t} \int_{V_{0}} r_{0} . \delta u d V_{o}=\int_{V_{0}} \dot{S} . \delta \varepsilon d V_{o}+\int_{V_{0}} S . \delta \dot{\varepsilon} d V_{o}
$$

sendo $\dot{\varepsilon}$ e $\delta \dot{\varepsilon}$ dadas pelas expressões (2.75), (2.76), (2.77) e (2.78).

Nesse caso, da relação (3.64) tem-se que:

$$
\dot{S}=(1-D) E \dot{\varepsilon}+(-\dot{D}) E \varepsilon
$$

Por sua vez:

$$
\dot{D}=\frac{\partial D}{\partial \widetilde{\varepsilon}} \frac{\partial \widetilde{\varepsilon}}{\partial \varepsilon} \frac{\partial \varepsilon}{\partial t}=F(\widetilde{\varepsilon}) \frac{\partial \widetilde{\varepsilon}}{\partial \varepsilon} \dot{\varepsilon}
$$

onde a função $F(\widetilde{\varepsilon})$, de acordo com o caso, tração ou compressão, pode assumir as formas dadas pelas expressões (3.20) e (3.21), respectivamente.

A derivada da deformação equivalente em relação à deformação longitudinal, dependendo do sinal de $\varepsilon$, resulta:

$$
\frac{\partial \tilde{\varepsilon}}{\partial \varepsilon}=1 \text { se } \varepsilon>0 \text { e } \frac{\partial \tilde{\varepsilon}}{\partial \varepsilon}=-v \sqrt{2} \text { se } \varepsilon<0
$$

Portanto, a matriz de rigidez tangente para o elemento de pórtico plano, considerando-se dano e não-linearidade geométrica, fica definida por:

$$
K_{T}=\int_{V_{0}} \underline{B}^{T}(1-D) E \underline{B} d V_{0}+\int_{V_{0}} \underline{B}^{T} \eta E \varepsilon \underline{B} d V_{0}+\int_{V_{0}} \underline{G} S d V_{0}
$$

ou 


$$
K_{T}=\int_{V_{0}} \underline{B}_{a}^{T}(1-D) E \underline{B}_{a} d V_{0}+\int_{V_{0}} \underline{B}_{a}^{T} \eta E \varepsilon \underline{B}_{a} d V_{0}+\int_{V_{0}} \underline{G}_{a} S d V_{0}
$$

sendo: $\eta=-F_{T}(\tilde{\varepsilon})$ e $D=D_{T}$ se $\varepsilon>0 ; \eta=\nu \sqrt{2} F_{C}(\tilde{\varepsilon})$ e $D=D_{C}$ se $\varepsilon<0$ e $\eta=0$ caso não haja evolução do dano.

O vetor dos esforços internos é expresso por:

$$
F^{i n t}=\int_{V_{0}} \underline{B}^{T} S d V_{0}
$$

ou

$$
F^{i n t}=\int_{V_{0}} \underline{B}_{a}{ }^{T} S d V_{0}
$$

sendo $S$ dado pela relação (3.64), $\underline{B}, \underline{B}_{a}, \underline{G}$ e $\underline{G}_{a}$ pelas (2.73), (2.74), (2.79) e (2.80), respectivamente.

\subsubsection{Modelo de La Borderie combinado com não-linearidade geométrica}

Neste caso, como não é possível explicitar a expressão do dano em função da deformação axial $\varepsilon$, as expressões da matriz de rigidez tangente e do vetor dos esforços internos são dados, respectivamente, por:

$$
\begin{gathered}
K_{T}=\int_{V_{0}} \underline{B}^{T} E_{D} \underline{B} d V_{0}+\int_{V_{0}} \underline{G} S d V_{0} \\
K_{T}=\int_{V_{0}} \underline{B}_{a}^{T} E_{D} \underline{B}_{a} d V_{o}+\int_{V_{0}} \underline{G}_{a} S d V_{0} \\
F^{i n t}=\int_{V_{0}} \underline{B}^{T} S d V_{0} \\
F^{i n t}=\int_{V_{0}} \underline{B}_{a}{ }^{T} S d V_{0}
\end{gathered}
$$


Nas expressões acima, $E_{D}$ e $S$ são dados pela tabela 3.1, lembrando-se que, em pequenas deformações; $S \cong \sigma$.

\subsection{MODELO CONSTITUTIVO PARA O AÇO}

Existem na literatura vários modelos elastoplásticos, $C H E N$ (1982), no entanto, neste trabalho utiliza-se o modelo elastoplástico com endurecimento linear cinemático ou misto (por opção) para simular o comportamento não-linear físico do aço, cujo diagrama tensão/deformação na tração está ilustrado na Figura 3.6.

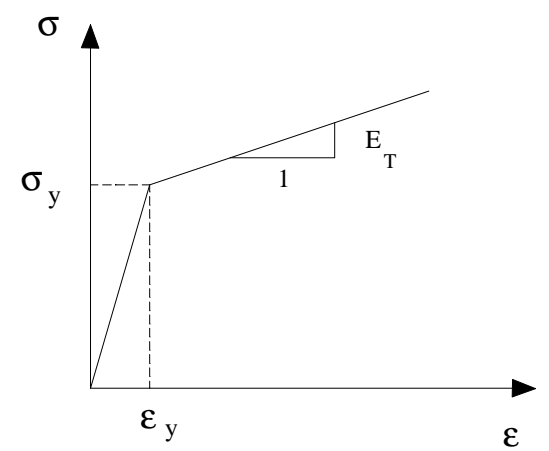

Figura 3.6- Diagrama tensão/deformação para aço com encruamento linear

Neste caso, utiliza-se o modelo elastoplástico com encruamento cinemático por ser mais adequado para carregamento cíclico ou com inversão de sinal, pois permite levar em conta o efeito Bauschinger; o modelo elastoplástico com encruamento isótropo aplica-se principalmente a carregamento monotônico crescente. O modelo de encruamento misto é mais adequado ao concreto.

$\mathrm{Na}$ implementação numérica do modelo cinemático ou misto para o caso unidimensional, os dados que devem ser fornecidos para a análise numérica são: o módulo rigidez elástico, E, a tensão de escoamento, o módulo elastoplástico tangente, $\mathrm{E}_{\mathrm{T}}$, e a razão entre o módulo plástico e o módulo de encruamento cinemático. Cabe lembrar que sendo nula tal razão o modelo com encruamento misto passa a se comportar como o de encruamento cinemático, mais adequado para a análise dinâmica, abordada no capítulo 4 deste trabalho. 


\subsection{DISCRETIZAÇÃO DA SEÇÃO DE CONCRETO ARMADO E INTEGRAÇÃO NUMÉRICA}

Como se trata da consideração da danificação do concreto e da plastificação do aço, a distribuição das tensões ao longo da altura da seção transversal não é linear. Como estratégia de cálculo das integrais que definem a matriz de rigidez tangente e o vetor de esforços internos, na seção transversal de concreto armado individualizam-se dois materiais distintos: o concreto e o aço, conforme ilustra a Figura 3.7, considerando-se uma perfeita aderência entre eles.

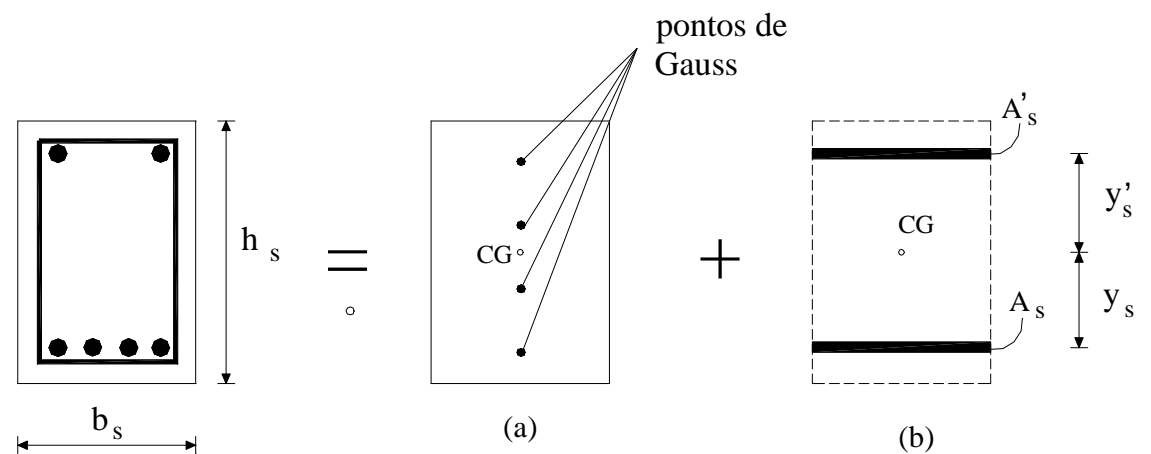

Figura 3.7- Discretização da seção de concreto armado - (a)- seção de concreto

(b)- seção de aço equivalente

As integrações são realizadas numericamente empregando-se ora a técnica de discretização do concreto em estratos de iguais espessuras ora as quadraturas de Gauss e de Gauss-Lobatto. A regra de Gauss-Lobatto é semelhante à de Gauss, exceto que os pontos extremos do intervalo de integração são sempre incluídos, permitindo-se assim considerar os pontos situados na superfície da seção onde se encontram os pontos com maior danificação. Nesse caso, define-se em cada elemento finito, no plano longitudinal que contém o eixo de simetria da seção, um número arbitrário de pontos ou estratos a eles associados, calculando-se para cada um desses pontos ou estratos, os vetores $\underline{B}$ ou $\underline{B}_{a}$, as matrizes $\underline{G}$ ou $\underline{G}_{a}$ e posteriormente a tensão $S$. Segundo esse procedimento, pode-se usar um número qualquer de pontos de Gauss ou de estratos. Porém, para os exemplos de aplicação aqui apresentados recomenda-se um número superior a 10 , de modo a garantir-se a qualidade da resposta mesmo em casos de danificação intensa, ver Anexo B. 
As armaduras, com comportamento elastoplástico caracterizado por encruamento linear, são discretizadas por tantos estratos quantos forem as camadas de barras. Cada estrato possui a mesma largura da seção e espessura tal que a área resultante seja igual área da camada de aço correspondente, como indicado na Figura 3.7b. A contribuição dessas camadas para as integrações é direta, isto é multiplica-se a área de cada camada de aço pelo fator peso normalizado associado à sua posição ao longo do comprimento do elemento.

Na Figura 3.8 apresenta-se a discretização da seção de concreto para o procedimento de integração por estratos. A distância do CG (centro geométrico) do estrato i ao CG (centro geométrico) da seção transversal, $y_{i}$, é dada por:

$$
y_{i}=-\frac{\left(n_{e}-2 i+1\right) h_{e}}{2}
$$

sendo $n_{e}$ o número total de estratos e $h_{e}$ a altura de cada estrato dada por:

$$
h_{e}=\frac{h_{s}}{n_{e}}
$$

onde $h_{s}$ é a altura da seção transversal.

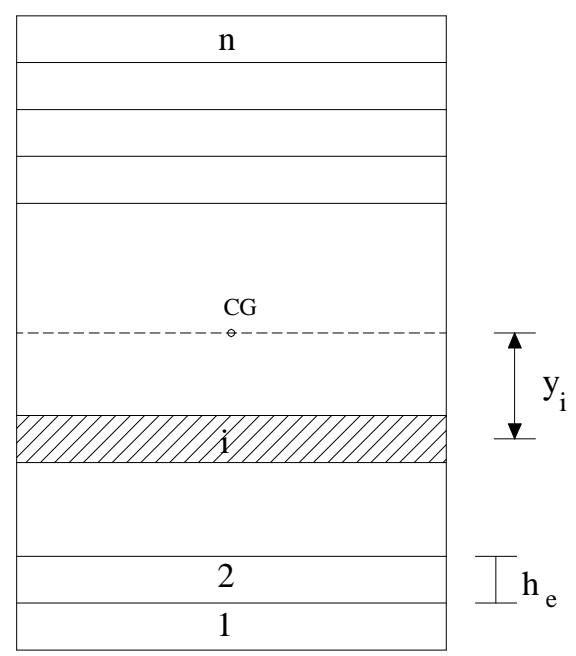

Figura 3.8- Divisão da seção transversal de concreto em estratos 
Uma vez discretizada a seção transversal, para complementar os dados para a integração numérica definem-se, neste trabalho, um número qualquer de pontos de Gauss ou de Gauss-Lobatto ao longo do comprimento do elemento da barra, porém, este número deve ser superior ou igual a 6.

\subsection{EXEMPLOS NUMÉRICOS}

Apresentam-se nesta seção alguns exemplos de análise estática, que ilustram a influência do comportamento não-linear do material, utilizando-se os modelos de dano de Mazars e de La Borderie, combinados ou não com o efeito não-linear geométrico.

Para simular o comportamento elastoplástico do aço emprega-se o modelo com encruamento cinemático.

A tolerância com a qual se comparam as normas euclidianas dos deslocamentos e de forças é fixada em $10^{-6}$.

\subsubsection{Exemplo 1 - Vigas bi-apoiadas}

Neste exemplo apresentam-se os resultados de análises experimental e numérica realizadas sobre as vigas apresentadas em ÁLVARES (1993) empregando-se os modelos de dano de Mazars e La Borderie, sem a consideração da não-linearidade geométrica. As vigas diferem entre si pelas taxas de armaduras e foram, por aquele autor ensaiadas e simuladas numericamente com o modelo de dano de Mazars, empregando-se uma discretização em elementos finitos diferente daquela aqui adotada. Os dados geométricos e a distribuição das armaduras estão apresentados na Figura 3.9.

Propriedades do concreto: $E=29200 \mathrm{MPa} ; \mathrm{v}=0.2$

Propriedades do aço: $E=196000 \mathrm{MPa} ; f_{Y}=420 \mathrm{MPa} ; E_{T}=19600 \mathrm{MPa}$ 
Parâmetros do modelo de Mazars: $A_{T}=0.995 ; B_{T}=8000 ; A_{C}=0.85 ; B_{C}=1050$ e $\varepsilon_{d 0}=0.00007$.

Parâmetros do modelo de La Borderie: $\quad \beta_{1}=1 \mathrm{MPa} ; \quad \beta_{2}=-10 \mathrm{MPa}$; $y_{01}=3.05 \times 10^{-4} \mathrm{MPa}, y_{02}=5 \times 10^{-3} \mathrm{MPa} ; A_{1}=3.5 \times 10^{3} \mathrm{MPa}^{-1} ; A_{2}=6.8 \mathrm{MPa}^{-1}$, $B_{1}=0.95 ; B_{2}=0.7705$ e $\sigma_{f}=2.6 \mathrm{MPa}$.
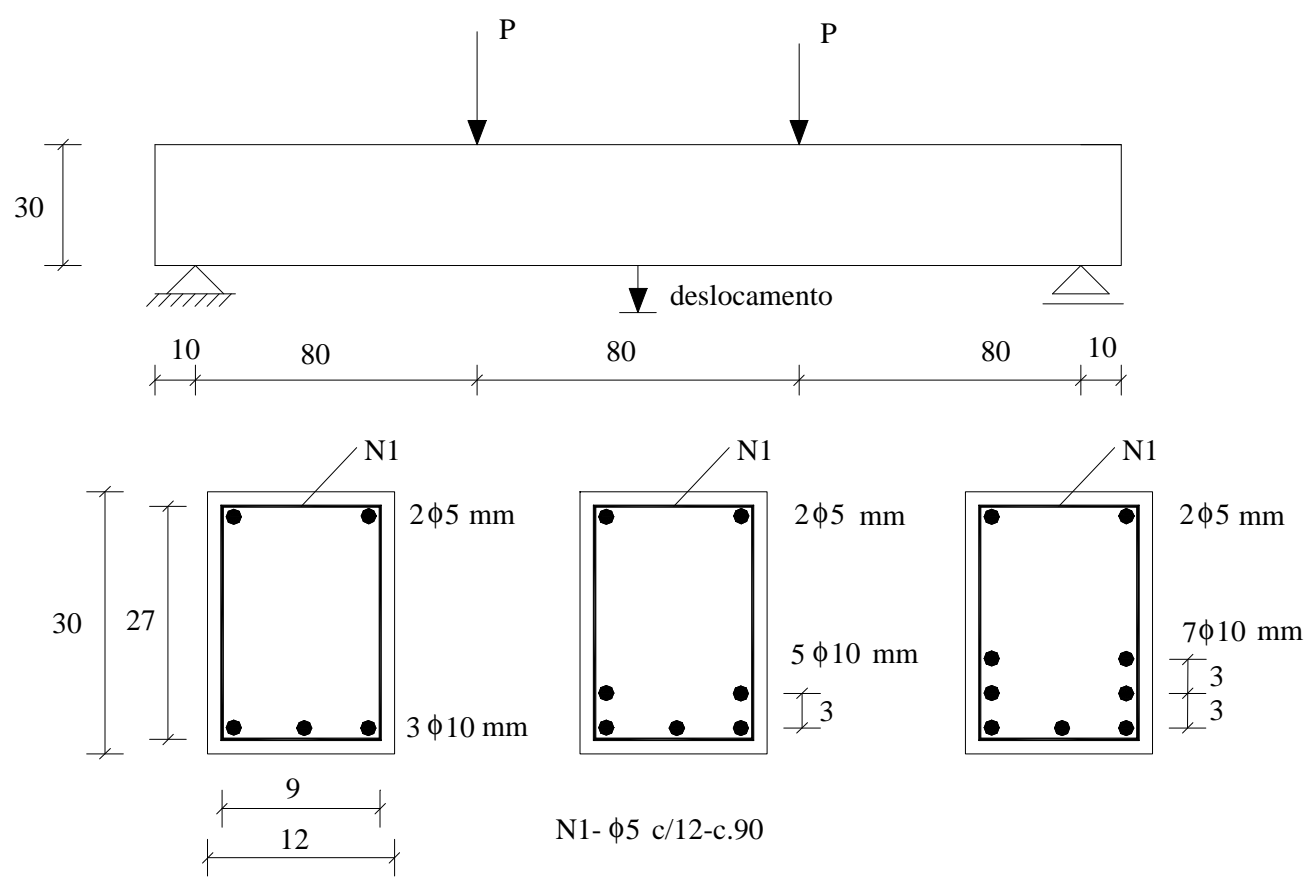

Figura 3.9- Geometria e armação das vigas - dimensões em cm

Alguns dos parâmetros acima foram obtidos a partir de identificação sobre resultados experimentais uniaxiais de compressão com deformação controlada e compressão diametral.

A estrutura foi discretizada em 12 elementos finitos iguais, sem consideração de simetria.

Para a integração numérica utilizou-se exclusivamente a quadratura de GaussLobatto considerando-se 20 de pontos ao longo da altura da seção e 6 ao longo do comprimento do elemento. 
Nos gráficos das Figuras 3.10, 3.11 e 3.12 comparam-se os resultados experimentais (distribuídos na faixa contida entre as curvas pretas pontilhadas) e os numéricos, observando-se uma boa concordância entre as repostas.

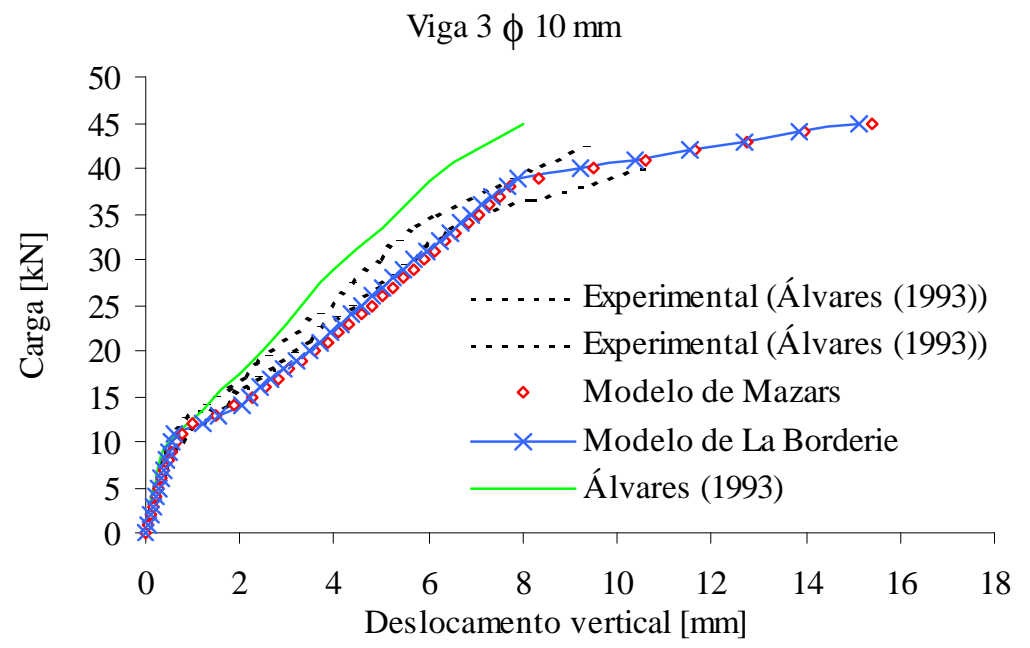

Figura 3.10- Curva carga/deslocamento - Viga $3 \phi 10 \mathrm{~mm}$

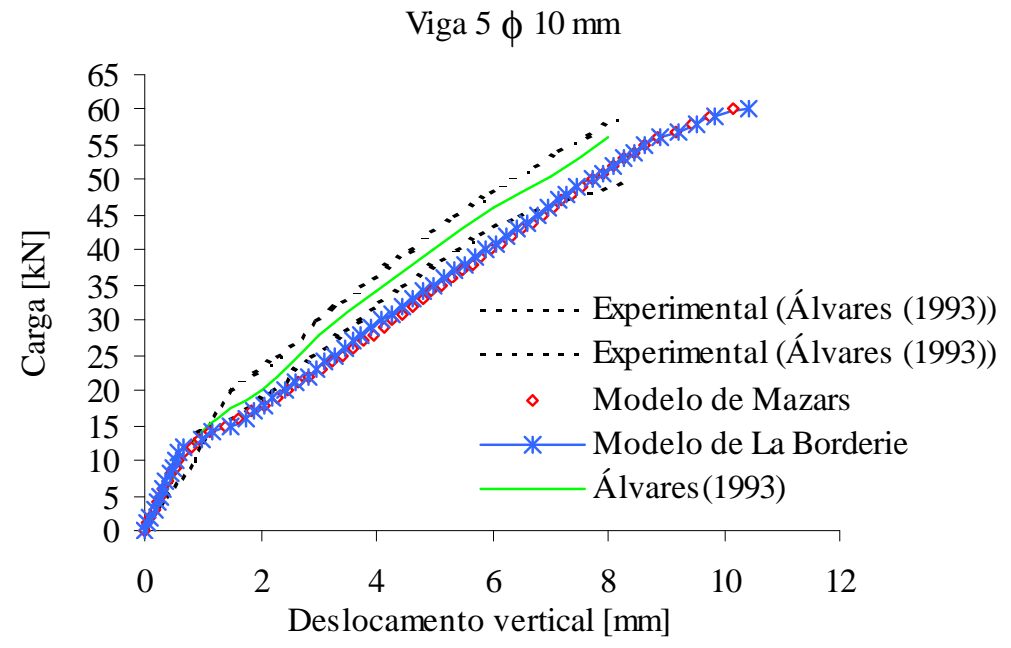

Figura 3.11- Curva carga/deslocamento - Viga $5 \phi 10 \mathrm{~mm}$ 


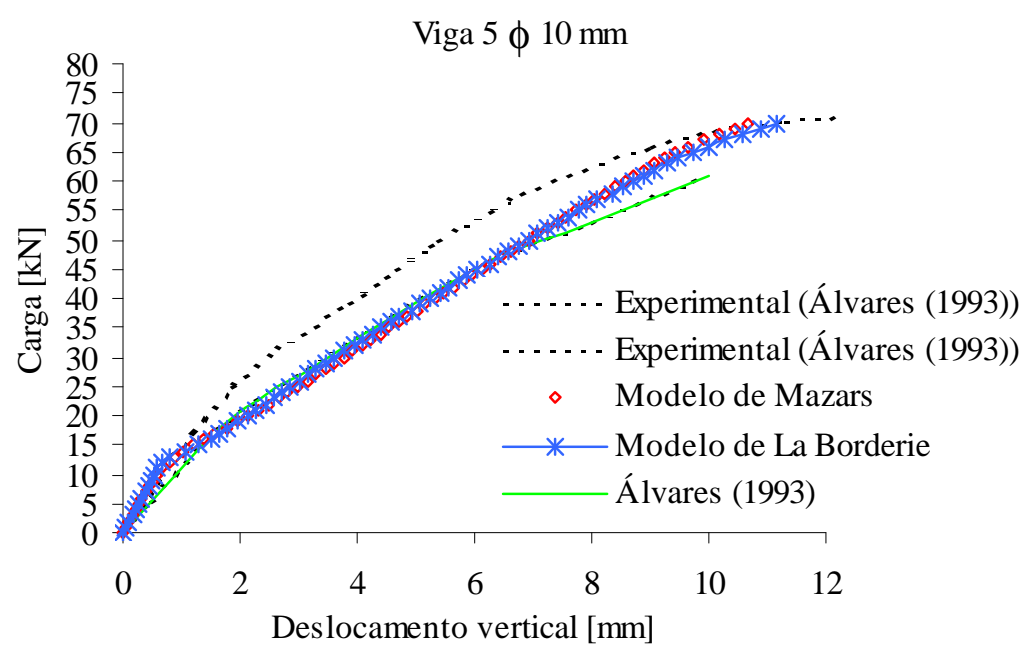

Figura 3.12- Curva carga/deslocamento - Viga $7 \phi 10 \mathrm{~mm}$

\subsubsection{Exemplo 2 - Viga simplesmente apoiada carregada por força axial excêntrica}

Neste exemplo apresentam-se os resultados das análises estáticas não-lineares física (modelo de dano de Mazars) e geométrica da estrutura proposta em EL-METWALLY et al (1990). O esquema estrutural está ilustrado na Figura 3.13.

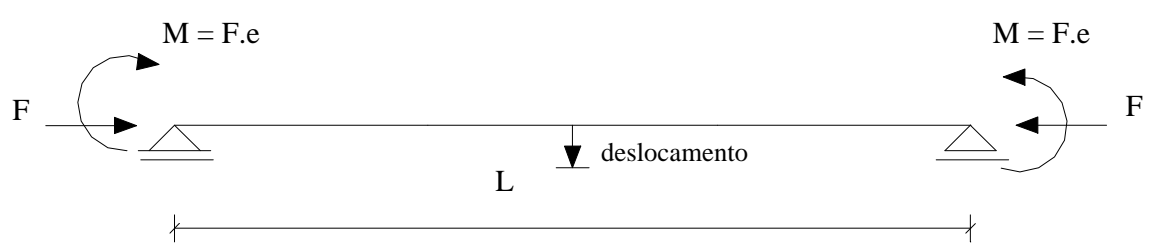

Figura 3.13- Viga biapoiada

Propriedades geométricas: comprimento $L=3403 \mathrm{~mm}$, seção quadrada de lado $150 \mathrm{~mm}$; armaduras positiva e negativa iguais formadas por $2 \phi 10 \mathrm{~mm}$ com cobrimento de $15 \mathrm{~mm}$ e excentricidade da carga aplicada $e=127 \mathrm{~mm}$.

Adotou-se para o concreto um módulo de elasticidade igual a $15000 \mathrm{MPa}$, uma vez que valor exato desse parâmetro não é fornecido naquela referência. $\mathrm{O}$ valor adotado permite recuperar a mesma rigidez inicial correspondente aos resultados numéricos apresentados naquele trabalho.

A não-linearidade geométrica é simulada segundo uma descrição lagrangiana total com a matriz de rigidez aproximada. O método utilizado na integração numérica foi 
a quadratura de Gauss-Lobatto, empregando-se 6 pontos ao longo do comprimento do elemento e 20 ao longo da altura da seção transversal.

Para a análise não-linear física são necessários os seguintes dados complementares:

Propriedades do concreto: $f_{c}^{\prime}=26.5 \mathrm{MPa} ; \mathrm{v}=0.2$

Propriedades do aço: $E=210000 \mathrm{MPa} ; f_{Y}=400 \mathrm{MPa} ; E_{T}=21000 \mathrm{MPa}$

Como não se dispõem de dados sobre o concreto utilizado, que permitam uma conveniente identificação, foram assumidos os seguintes valores (próximos dos empregados no exemplo anterior) para os parâmetros do modelo de Mazars: $A_{T}=0.995 ; B_{T}=8000 ; A_{C}=0.85 ; B_{C}=1050 ; \varepsilon_{d 0}=0.00018$.

A estrutura foi discretizada em 20 elementos finitos iguais.

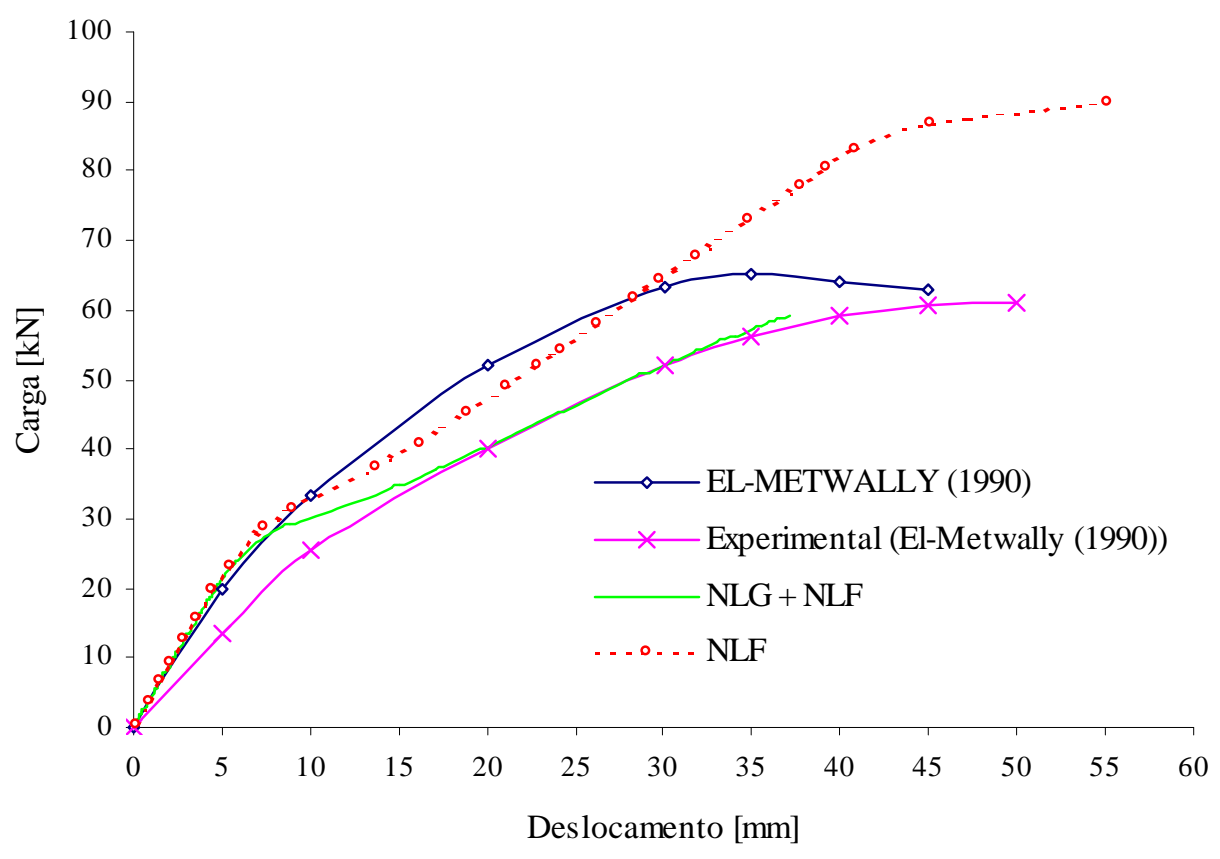

Figura 3.14- Curva carga/deslocamento

A Figura 3.14 mostra as curvas carga/deslocamento obtidas, destacando-se os casos de uma resposta não-linear física (NLF) isolada e a combinação desta com o efeito não-linear geométrico (NLF+NLG). Para confronto, incluem-se também os resultados experimentais apresentados por EL-METWALLY et al (1990). Ao 
contrário das respostas propostas por aquele autor, obtidas levando-se em conta as não-linearidades física (modelo hipoelástico baseado em relações momentocurvatura) e geométrica, pode-se observar que os resultados obtidos com a formulação desenvolvida, considerando-se as duas não-linearidades, encontram-se mais próximos dos experimentais. Esses resultados constituem um indicativo positivo sobre o desempenho e a eficiência da modelagem apresentada.

\subsubsection{Exemplo 3 - Pórtico simples em concreto armado}

Neste exemplo apresentam-se as análises não-lineares física isolada e física combinada com a geométrica de um pórtico em concreto armado, Figura 3.15.

Propriedades do concreto: $f_{c}^{\prime}=17.5 \mathrm{MPa} ; \mathrm{v}=0.2$

Propriedades do aço: $E=210000 \mathrm{MPa} ; f_{Y}=420 \mathrm{MPa} ; E_{T}=2100 \mathrm{MPa}$

Essa estrutura foi analisada por SILVA (1996), análise física e geométrica, empregando-se uma discretização composta por 10 elementos finitos iguais por barra e modelo elastoplástico considerando-se ou não a resistência à tração do concreto. As carga últimas encontradas foram $1400 \mathrm{kN}$ e $1300 \mathrm{kN}$, respectivamente.

Como não se dispõem de dados sobre o concreto utilizado que permitam uma conveniente identificação paramétrica, foram assumidos os seguintes valores médios para os parâmetros do modelo de Mazars: $A_{T}=0.995 ; B_{T}=8000 ; A_{C}=0.85$; $B_{C}=1050 ; \varepsilon_{d 0}=0.00007$.

$\mathrm{Na}$ análise aqui conduzida, a estrutura foi discretizada em 30 elementos finitos iguais, 10 por barra, considerando-se 6 pontos de Gauss-Lobatto ao longo do comprimento do elemento e 20 pontos na altura da seção transversal. 


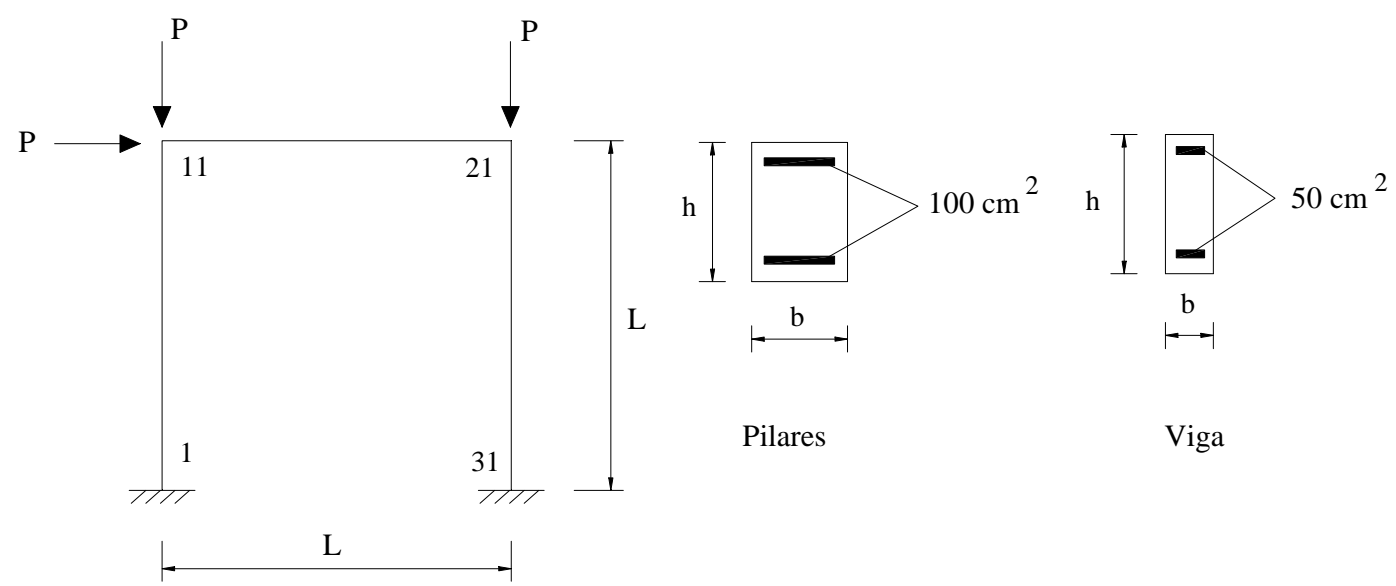

Figura 3.15 - Pórtico de concreto armado

Dados geométricos: $L=1000 \mathrm{~cm}$; pilares: $b=80 \mathrm{~cm}$ e $h=100 \mathrm{~cm}$; viga: $b=40 \mathrm{~cm}$ e $h=100 \mathrm{~cm}$.

Na Figura 3.16 estão apresentadas as curvas carga/deslocamento obtidas nas análises realizadas considerando-se o efeito não-linear físico e o mesmo combinado com o não-linear geométrico.

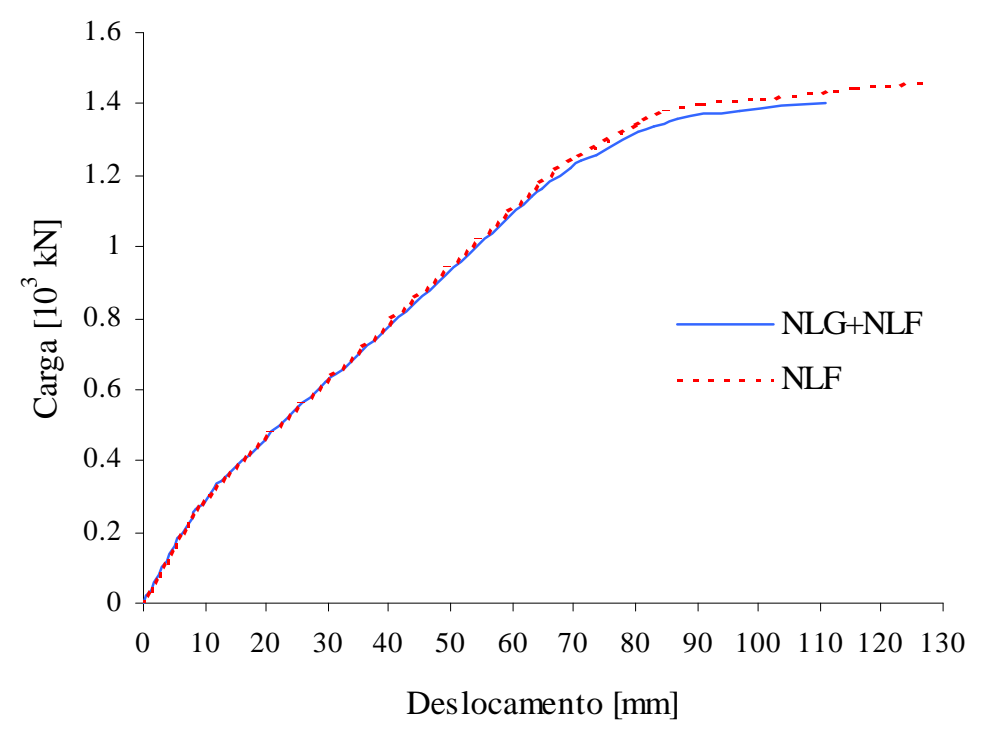

Figura 3.16- Curva carga horizontal/deslocamento horizontal

A carga última encontrada para a análise não-linear física isolada foi de $1460 \mathrm{kN}$ com correspondente deslocamento horizontal do nó 11 de $127.54 \mathrm{~mm}$; para a análise considerando-se as não-linearidades física e geométrica encontra-se uma carga 
máxima de $1400 \mathrm{kN}$ com correspondente deslocamento horizontal do nó 11 de $110.78 \mathrm{~mm}$.

Observa-se que o resultado obtido empregando-se o modelo de dano de Mazars foi idêntico ao obtido por SILVA (1996) com um modelo elastoplástico considerando-se a resistência à tração. Isto aponta para o fato de que parâmetros médios do modelo de Mazars, para concretos usuais, podem propiciar bons resultados. 


\section{4}

\section{CONSIDERAÇÃO DO EFEITO DINÂMICO}

"Não existem soluções prontas. Existem forças em marcha."

Henry Ford

\subsection{INTRODUÇÃO}

Sob um ponto de vista conceitual a análise dinâmica é mais geral e complexa do que a estática, apresentando a vantagem de permitir quantificar a magnitude dos esforços internos, das velocidades, das acelerações e dos deslocamentos que surgem num sistema estrutural quando o mesmo é submetido a um carregamento arbitrário cuja intensidade, direção e sentido variam com o tempo.

Neste trabalho, o objetivo de se realizar uma análise dinâmica limita-se a verificar a influência das forças inerciais e dissipativas sobre a evolução da danificação e o seu efeito conjunto na resposta estrutural.

De acordo com ARGYRIS \& MLEJNEK (1991) as forças inerciais por unidade de volume, num sistema de coordenadas cartesianas $\mathrm{x}$, y e $\mathrm{z}$, podem ser localmente representadas por: 


$$
f_{m}=\rho(x, y, z)\left\{\begin{array}{c}
\ddot{u} \\
\ddot{v} \\
\ddot{w}
\end{array}\right\}=\rho(\underline{X}) \ddot{d}
$$

onde $\rho(x, y, z)$ é a densidade específica do material, $\ddot{d}$ o vetor aceleração do ponto material e $\underline{X}$ o vetor posição.

A consideração de processos de amortecimento na análise estrutural é um tanto difícil, visto que tais processos podem ter origem localizada e provocada pela fricção interna nas ligações entre os componentes da estrutura. Uma maneira de se levar em conta tais efeitos consiste em se admitir que os elementos do sistema estrutural estejam submetidos aos efeitos de um amortecimento viscoso linear distribuído, que dão origem às forças dissipativas por unidade de volume, definidas num sistema de coordenadas cartesianas de forma análoga à equação (4.1) por:

$$
f_{d}=\mu(x, y, z)\left\{\begin{array}{c}
\dot{u} \\
\dot{v} \\
\dot{w}
\end{array}\right\}=\mu(\underline{X}) \dot{d}
$$

onde $\mu(x, y, z)$ é o parâmetro de amortecimento viscoso do material e $\dot{d}$ o vetor velocidade do ponto material.

Vale lembrar que as forças inerciais e as dissipativas se opõem ao movimento.

\subsection{EQUAÇÃO DE MOVIMENTO VIA PRINCÍPIO DOS TRABALHOS VIRTUAIS}

Levando-se em consideração o princípio de D'Alembert, ARGYRIS \& MLEJNEK (1991), num certo intervalo de tempo, pelo Princípio dos Trabalhos Virtuais, a equação de equilíbrio segundo uma descrição lagrangiana total, pode ser escrita na forma: 


$$
\begin{gathered}
\int_{V_{o}} r_{0} . \delta d d V_{o}=\int_{V_{0}} \underline{S} . \delta \underline{\varepsilon} d V_{o}+\int_{V_{o}}(\rho(\underline{X}) \ddot{d}) \cdot \delta d d V_{o}+\int_{V_{0}}(\mu(\underline{X}) \dot{d}) \cdot \delta d d V_{o}+ \\
-\int_{V_{0}} b_{o}(t) \cdot \delta d d V_{o}-\int_{A_{0}} \bar{t}_{0}(t) \cdot \delta d d A_{0}-\sum_{i}^{n c} \delta q_{i} \cdot f_{i}(t)=0
\end{gathered}
$$

Numa interpretação alternativa, normalmente usada quando se empregam estratégias iterativas de busca do equilíbrio, a equação (4.3) fornece o resíduo ou diferença entre o trabalho virtual interno acrescentado do trabalho virtual das forças inerciais e dissipativas, e o trabalho virtual externo. O trabalho virtual interno é dado pela soma dos produtos das tensões pelas deformações virtuais. O trabalho virtual externo é dado pelo produto entre as forças externas aplicadas e os respectivos deslocamentos virtuais. Na equação (4.3) $\delta q_{i}$ é o vetor de deslocamentos virtuais correspondentes aos pontos onde o vetor de forças concentradas, $f_{i}(t)$, é aplicado; $n c$ é o número desses vetores.

Uma forma aproximada para a relação (4.3), já considerando-se o caso de estruturas reticulares planas, pode ser obtida, como visto no capítulo2, empregando-se o método dos elementos finitos. Assim sendo, o vetor deslocamento de um ponto genérico de um elemento finito de barra, distante $y$ do seu eixo, pode ser escrito em função dos deslocamentos nodais por meio da seguinte forma matricial:

$$
d=\underline{\phi}_{M} q
$$

onde $q$ é o vetor dos graus de liberdade nodais e $\underline{\phi}_{M}$ é a matriz que contém as funções de forma e suas derivadas com relação a x, sendo dada por:

$$
\begin{aligned}
\underline{\phi}_{M} & =\left[\begin{array}{cccccc}
N_{1} & 0 & 0 & N_{4} & 0 & 0 \\
0 & N_{2} & N_{3} & 0 & N_{5} & N_{6}
\end{array}\right]+ \\
& +y\left[\begin{array}{cccccc}
0 & -N_{2}^{\prime} & -N_{3}^{\prime} & 0 & -N_{5}^{\prime} & -N_{6}^{\prime} \\
N_{1}^{\prime} & 0 & 0 & N_{4} & 0 & 0
\end{array}\right]
\end{aligned}
$$

De maneira análoga os vetores velocidade e aceleração são dados, respectivamente, por: 


$$
\begin{aligned}
& \dot{d}=\underline{\phi}_{M} \dot{q} \\
& \ddot{d}=\underline{\phi}_{M} \ddot{q}
\end{aligned}
$$

Por sua vez, o vetor dos deslocamentos virtuais pode ser interpolado por:

$$
\delta d=\underline{\phi}_{M} \delta q
$$

A deformação virtual, empregando-se a expressão aproximada para a deformação axial, é dada por:

$$
\delta \varepsilon=\underline{B}_{a} \delta q
$$

Nota-se que, em função da hipótese cinemática adotada para descrever o campo de deslocamentos, e descrito no capítulo 2, os tensores de deformação e de tensão possuem uma única componente não nula, podendo ser considerados grandezas escalares.

Substituindo-se as equações (4.6) a (4.9) na equação (4.3), obtém-se:

$$
\begin{aligned}
& \int_{V_{0}} \delta q^{T} \underline{B}_{a}^{T} S d V_{0}+\int_{V_{0}} \delta q^{T} \underline{\phi}_{M}^{T} \rho(\underline{X}) \underline{\phi}_{M} \ddot{q} d V_{0}+\int_{V_{0}} \delta q^{T} \underline{\phi}_{M}^{T} \mu(\underline{X}) \underline{\phi}_{M} \dot{q} d V_{o}+ \\
& -\int_{V_{0}} \delta q^{T} \underline{\phi}_{M}^{T} b(t) d V-\int_{V_{0}} \delta q^{T} \underline{\phi}_{M}^{T} \bar{t}_{0}(t) d A_{0}-\sum_{i}^{n c} \delta q^{T} f_{i}(t)=0
\end{aligned}
$$

Visto que os deslocamentos virtuais nodais são arbitrários, a nulidade expressa pela equação (4.10) pode ser verificada a partir da seguinte condição:

$$
\begin{aligned}
\int_{V_{0}} \underline{B}_{a}^{T} S d V_{0}+\int_{V_{0}} \underline{\phi}_{M}^{T} \rho(\underline{X}) \underline{\phi}_{M} \ddot{q} d V_{o}+\int_{V_{o}} \underline{\phi}_{M}^{T} \mu(\underline{X}) \underline{\phi}_{M} \dot{q} d V_{o}+ \\
-\int_{V_{o}} \underline{\phi}_{M}^{T} b(t) d V-\int_{V_{o}} \underline{\phi}_{M}^{T} \bar{t}_{0}(t) d A_{0}-\sum_{i}^{n c} f_{i}(t)=0
\end{aligned}
$$

A relação anterior pode ser expressa segundo o arranjo proposto por ARGYRIS \& MLEJNEK (1991) e DESAI \& ABEL (1972): 


$$
\underline{M} \ddot{q}+\underline{C} \dot{q}+F^{i n t}=F^{e x t}(t)
$$

onde:

$$
\begin{gathered}
F^{i n t}=\int_{V_{0}} \underline{B}_{a}^{T} S d V_{0} \\
\underline{M}=\int_{V_{0}} \underline{\phi}_{M}^{T} \rho(\underline{X}) \underline{\phi}_{M} d V_{0} \\
\underline{C}=\int_{V_{0}} \underline{\phi}_{M}^{T} \mu(\underline{X}) \underline{\phi}_{M} d V_{0} \\
F^{e x t}(t)=\int_{V_{0}} \underline{\phi}_{M}^{T} b(t) d V+\int_{V_{0}} \underline{\phi}_{M}^{T} \bar{t}_{0}(t) d A_{0}+\sum_{i}^{n c} f_{i}(t)
\end{gathered}
$$

Observa-se na equação (4.12) que os esforços externos dependem diretamente do tempo; já as matrizes de massa $\underline{M}$ e de amortecimento $\underline{C}$ podem ser consideradas constantes durante toda a análise. Por outro lado, as forças restauradoras $F^{\text {int }}$ dependem dos deslocamentos globais e da relação tensão/deformação, podendo-se incluir na análise as respostas não-lineares física e geométrica.

Neste estudo as forças externas são consideradas concentradas nos nós da estrutura, admitindo-se tipos de solicitações com as seguintes variações no tempo:

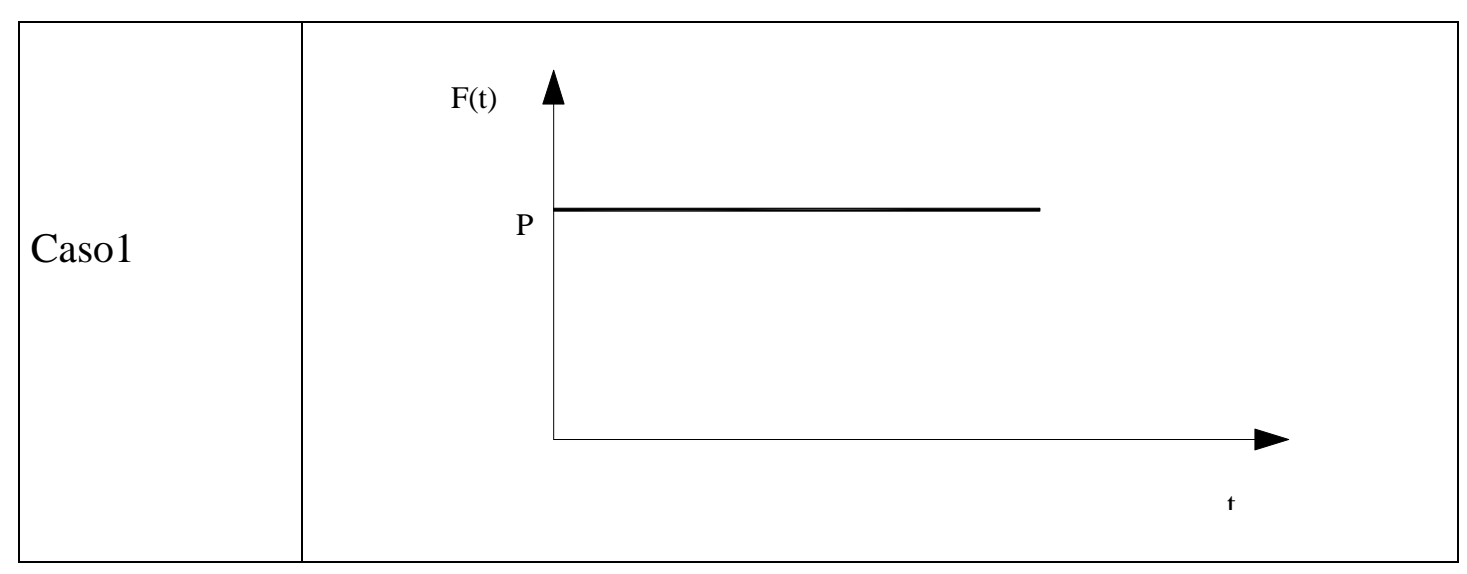

Quadro 4.1- Solicitação constante ao longo do tempo 


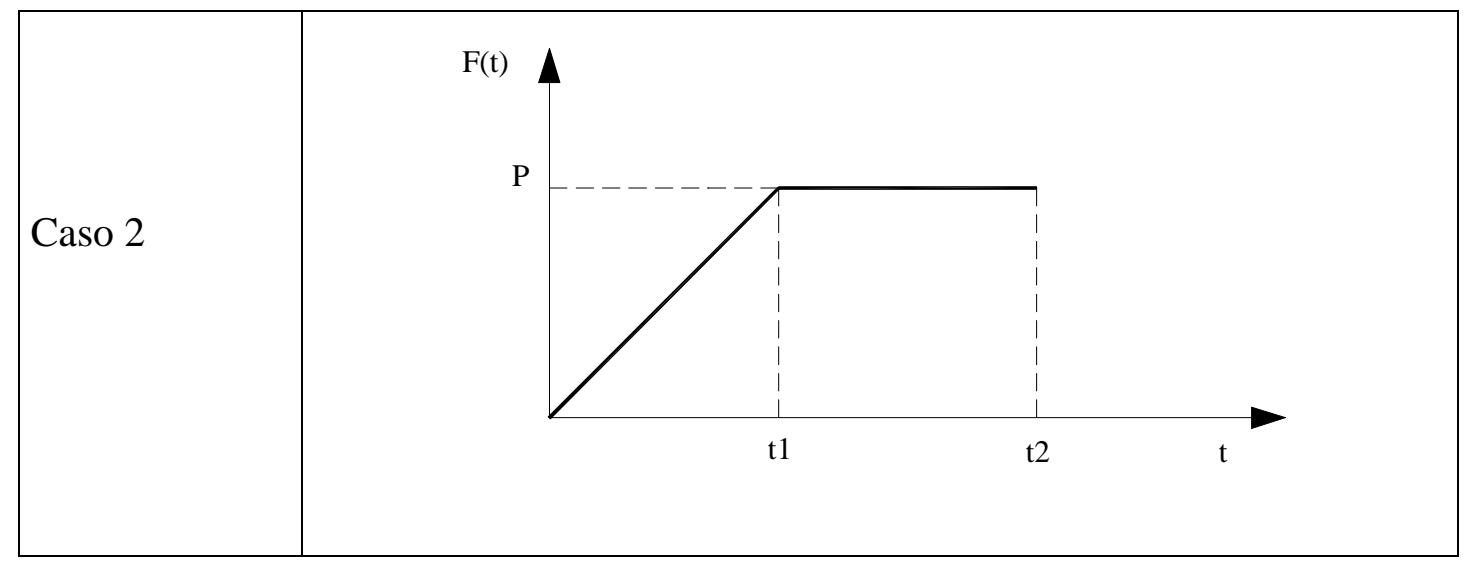

Quadro 4.2- Solicitação variável no tempo

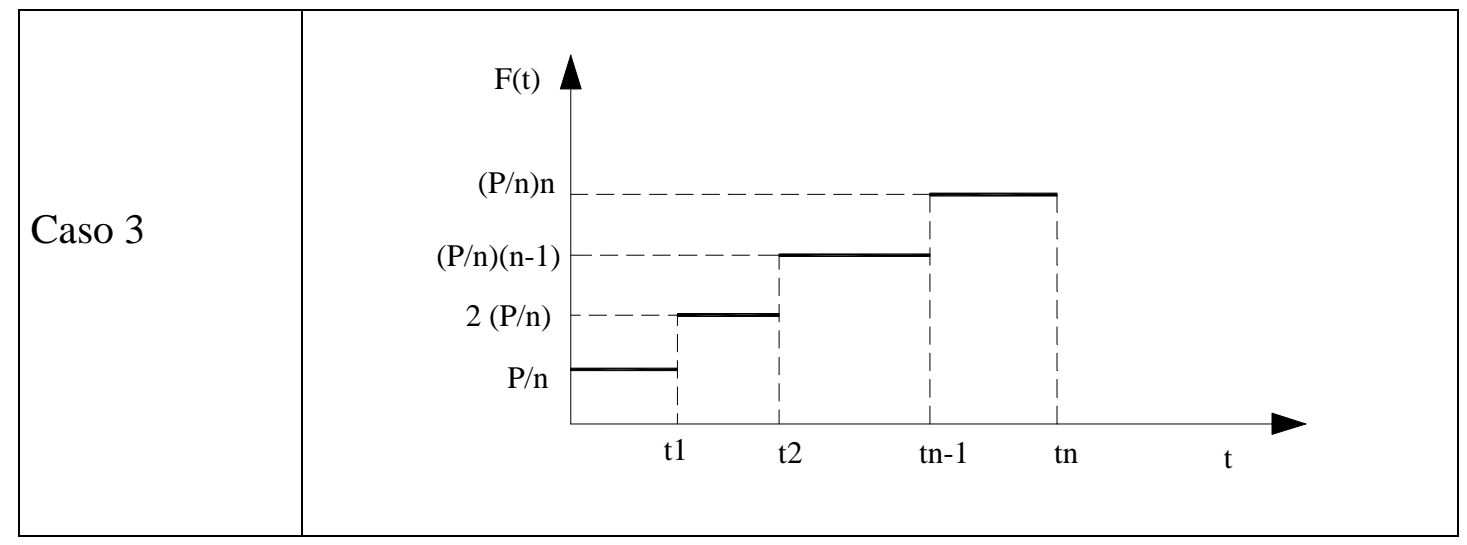

Quadro 4.3- Solicitação incremental constante no tempo

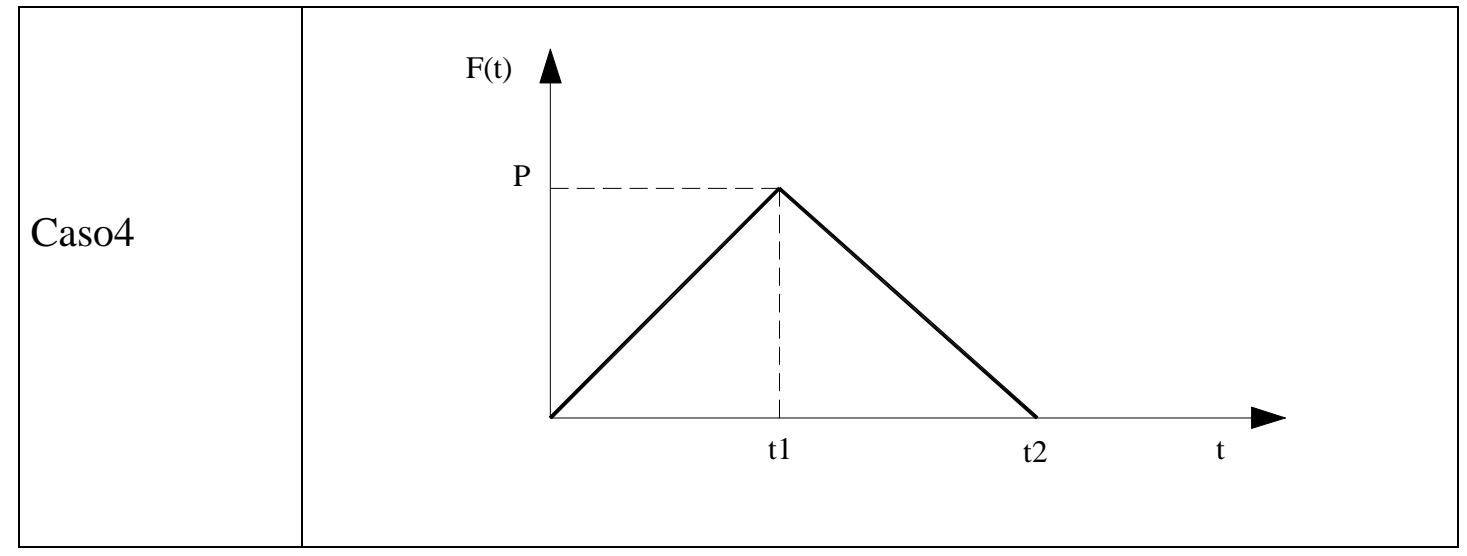

Quadro 4.4- Solicitação em forma de pulso 


\begin{tabular}{|l|l|}
\hline Caso5 & $\mathrm{F}(\mathrm{t})=\mathrm{Psen}\left(\omega_{\mathrm{e}} \mathrm{t}\right)$ \\
\hline Caso6 & $\mathrm{F}(\mathrm{t})=\mathrm{P} \cos \left(\omega_{\mathrm{e}} \mathrm{t}\right)$ \\
& \\
\hline
\end{tabular}

Quadro 4.5- Solicitações harmônicas

\subsection{MATRIZ DE MASSA}

A matriz de massa para o elemento finito de pórtico plano é obtida através da integração numérica da equação (4.14), utilizando-se a quadratura de Gauss. Na matriz de massa aparece a matriz $\underline{\phi}_{M}$, dada pela expressão (4.6), a qual foi obtida utilizando-se a expressão completa do campo de deslocamento dadas pelas equações (2.39) e (2.40).

$\mathrm{Na}$ existência de massas concentradas que possam gerar qualquer tipo de perturbação na estrutura, tais como as provenientes de maquinário industrial, as mesmas devem ser introduzidas na matriz de massa global da estrutura. Nesse sentido é importante observar que consideram-se neste trabalho apenas as massas concentradas que possuam deslocabilidade nas direções globais x e y, desconsiderando-se, portanto, o efeito rotacional das mesmas. Desse modo, cada massa concentrada deve estar associada à um ponto nodal, possibilitando-se computar a sua contribuição mediante a adição aos termos da diagonal principal da matriz de massa do sistema estrutural.

\subsection{MATRIZ DE AMORTECIMENTO}

Em princípio, a matriz de amortecimento do elemento de barra pode ser obtida pela integração da equação (4.15), porém a determinação da magnitude do parâmetro de amortecimento viscoso do material é um tanto difícil. Uma alternativa, muito usual, para contornar essa dificuldade, consiste na utilização do método de amortecimento de Rayleigh, onde a matriz de amortecimento viscoso é introduzida envolvendo 
frações específicas do amortecimento crítico. De acordo com COOK et al (1989) o amortecimento Rayleigh pode ser definido pela combinação linear entre as matrizes de rigidez e de massa da seguinte forma:

$$
\underline{C}=\lambda_{m} \underline{M}+\lambda_{k} \underline{K}_{0}
$$

sendo $\lambda_{m}$ e $\lambda_{k}$ as constantes da matriz de que ponderam as contribuições das matrizes de massa $\underline{M}$ e de rigidez inicial elástica $\underline{K}_{0}$, respectivamente.

A relação existente entre as constantes de amortecimento, $\lambda_{m}$ e $\lambda_{k}$, e a fração de amortecimento crítico $\xi$ para uma dada freqüência natural de vibração $\omega$, COOK et al (1989), expressa-se na forma:

$$
\xi_{i}=\frac{1}{2}\left(\lambda_{k} \omega_{i}+\frac{\lambda_{m}}{\omega_{i}}\right)
$$

As constantes de amortecimento podem, então, ser determinadas utilizando-se frações de amortecimento crítico para duas freqüências naturais de vibração:

$$
\begin{gathered}
\lambda_{k}=\frac{2\left(\xi_{2} \omega_{2}-\xi_{1} \omega_{1}\right)}{\left(\omega_{2}^{2}-\omega_{1}^{2}\right)} \\
\lambda_{m}=\frac{2 \omega_{1} \omega_{2}\left(\xi_{1} \omega_{2}-\xi_{2} \omega_{1}\right)}{\left(\omega_{2}^{2}-\omega_{1}^{2}\right)}
\end{gathered}
$$

Por sua vez, as frequiências naturais de vibração podem ser obtidas através dos autovalores da equação de equilíbrio do sistema estrutural, livre de carregamento e de amortecimento, dada por:

$$
\underline{M} \ddot{q}+\underline{K}_{o} q=0
$$

Assim, as frequiências naturais de vibração da estrutura são dadas por:

$$
\omega_{i}=\sqrt{\frac{1}{\Lambda_{i}}}
$$


sendo $\Lambda_{i}$ os autovalores da equação (4.21).

De acordo com COOK et al (1989) os valores usuais para as frequiências naturais podem ser tomados como sendo: $\omega_{1}$ a menor freqüência natural de vibração da estrutura e $\omega_{2}$ a freqüência relacionada com o carregamento externo de maior importância ou a freqüência subsequente à $\omega_{l}$. Esta opção foi utilizada neste trabalho para os casos de solicitação 1, 2, 3 e 4 (Quadros 4.1 a 4.4), enquanto que adotou-se $\omega_{2}=\omega_{e}$ para os casos 5 e 6 (Quadro 4.5).

Com relação às frações do amortecimento crítico, as mesmas são dadas em função do tipo de material e do tipo de sistema estrutural empregado, observando-se que o amortecimento crítico é representado pela unidade. Para estruturas convencionais o valor de $\xi$ é sempre menor que a unidade, sendo que para estruturas de aço adota-se $0.5 \%<\xi_{i}<5.0 \%$ e para estruturas em concreto $2.0 \%<\xi_{i}<15.0 \%$.

Neste trabalho pode-se, ainda, por opção, utilizar a seguinte expressão para a matriz de amortecimento $\underline{C}$ :

$$
\underline{C}=\lambda_{m} \underline{M}+\lambda_{k} \underline{K}
$$

neste caso, $\underline{K}$ igual à matriz de rigidez inicial elástica afetada pelo dano através do fator (1-D). As constantes de amortecimento $\lambda_{m}$ e $\lambda_{k}$ são calculadas conforme as equações (4.19) e (4.20), porém, as freqüências que aparecem naquelas relações são obtidas através dos autovalores da seguinte equação:

$$
\underline{M} \ddot{q}+\underline{K}[D(t)] q=0
$$

\subsection{MÉTODO DE INTEGRAÇÃO NUMÉRICA NO DOMÍNIO DO TEMPO}

Para a resolução numérica de problemas estruturais em dinâmica não-linear têm-se as mesmas questões referentes à análise estática, ou seja, escolha do procedimento de resolução do sistema não-linear somada à especificação do critério de tolerância para 
o equilíbrio dinâmico, escolha do procedimento de integração no domínio do tempo e especificação do passo de tempo.

Neste trabalho, para integração numérica no domínio do tempo, adota-se o método implícito de Newmark. Neste método, como se mostra em seguida, os deslocamentos ' $q_{n}$ ' ao final do intervalo de tempo ' $\Delta t_{n}$ ' podem ser expressos em função das derivadas com relação ao tempo dos próprios deslocamentos ' $q_{n}$ ', desconhecidos 'a priori', e dos deslocamentos e suas derivadas conhecidos ao final do intervalo de tempo anterior.

\subsubsection{Procedimento implícito de Newmark}

Os vetores aceleração e velocidade podem ser obtidos em função de um procedimento de discretização no tempo, do tipo Newmark por exemplo, BATHE (1996), cujas equações são dadas a seguir.

De início admite-se que a aceleração num certo instante $\tau$ do intervalo de tempo $0 \leq \tau \leq \Delta t$ possa ser expressa em função dos valores de aceleração nos extremos do intervalo. Desse modo, tem-se:

$$
\ddot{q}(\tau)=(1-\gamma) \ddot{q}_{n-1}+\gamma \ddot{q}_{n} \quad \text { com } \quad 0 \leq \gamma \leq 1
$$

onde:

$$
\begin{aligned}
& \ddot{q}_{n}=\ddot{q}(\Delta t) \\
& \ddot{q}_{n-1}=\ddot{q}(0)
\end{aligned}
$$

Integrando-se sucessivamente a equação (4.25) em relação a $\tau$, de modo a eliminar as ordens de derivação, e impondo-se as condições inicial e de contorno: $\dot{q}(0)=\dot{q}_{n-1}$ e $q(0)=q_{n-1}$, obtém-se:

$$
\dot{q}(\tau)=\dot{q}_{n-1}+(1-\gamma) \ddot{q}_{n-1} \tau+\gamma \ddot{q}_{n} \tau
$$




$$
q(\tau)=q_{n-1}+\dot{q}_{n-1} \tau+\frac{(1-\gamma)}{2} \ddot{q}_{n-1} \tau^{2}+\frac{\gamma}{2} \ddot{q}_{n} \tau^{2}
$$

Fazendo-se $\tau=\Delta t$ nas equações (4.28) e (4.29) e introduzindo-se $\beta=\gamma / 2$, obtémse a forma puramente implícita, dependente da aceleração ao final do intervalo $\ddot{q}_{n}$ :

$$
\begin{gathered}
\dot{q}_{n}=\dot{q}_{n-1}+(1-\gamma) \ddot{q}_{n-1} \Delta t+\gamma \ddot{q}_{n} \Delta t \\
q_{n}=q_{n-1}+\dot{q}_{n-1} \Delta t+\left(\frac{1}{2}-\beta\right) \ddot{q}_{n-1} \Delta t^{2}+\beta \ddot{q}_{n} \Delta t^{2}
\end{gathered}
$$

sendo $\gamma$ e $\beta$ parâmetros que no procedimento de Newmark são iguais a $1 / 2$ e $1 / 4$, respectivamente.

\subsubsection{Método de Newmark combinado com o procedimento incremental iterativo de Newton-Raphson - algoritmo}

A idéia básica do método consiste em adotar uma previsão do valor das acelerações no final do intervalo de tempo em que se deseja conhecer a resposta. Com isso, aplicando-se as equações generalizadas de Newmark (4.30) e (4.31), pode-se obter, também, uma previsão para os valores dos deslocamentos e das velocidades no final do mesmo intervalo de tempo. Na sequência, utiliza-se um processo iterativo que, ao final de cada iteração, realiza uma correção sobre os valores dos deslocamentos e suas derivadas no domínio do tempo. O critério de controle sobre o número de iterações é realizado através do resíduo das forças dinâmicas. Quando a norma euclidiana do resíduo atingir uma determinada tolerância, prefixada, assume-se que os últimos valores estão corretos e passa-se ao processo de integração para o próximo intervalo de tempo.

Objetivando-se apresentar as equações que compõem o método acima descrito, escreve-se a equação (4.12) da seguinte forma:

$$
R\left(q_{n+1}\right)=F^{e x t}-\left(\underline{M} \ddot{q}_{n+1}+\underline{C}_{n+1}+F^{i n t}\right)=0
$$


Da linearização da equação (4.32), obtida a partir do truncamento em $1^{\text {a }}$ ordem do seu desenvolvimento em série em torno do deslocamento $q_{n}$, tem-se:

$$
R\left(q_{n}+\Delta q_{n}\right)=R\left(q_{n}\right)+\frac{\partial R\left(q_{n}\right)}{\partial q_{n}} \Delta q_{n}=0
$$

de modo que:

$$
\Delta q_{n}=-\left[\frac{\partial R\left(q_{n}\right)}{\partial q_{n}}\right]^{-1} R\left(q_{n}\right)
$$

Por sua vez a derivada do resíduo, dado pela equação (4.32), em relação ao deslocamento, resulta:

$$
\frac{\partial R\left(q_{n}\right)}{\partial q_{n}}=\frac{\partial F^{e x t}}{\partial q_{n}}-\left(\underline{M} \frac{\partial \ddot{q}_{n}}{\partial q_{n}}+\underline{C} \frac{\partial \dot{q}_{n}}{\partial q_{n}}+\frac{\partial F^{i n t}}{\partial q_{n}}\right)
$$

Neste caso, como os esforços externos são dependentes apenas do tempo, tem-se que sua derivada em relação ao deslocamento é nula. Do gradiente do vetor dos esforços internos resulta a matriz de rigidez da estrutura, explicitada no capítulo 2.

Por outro lado, derivando-se as equação (4.31) em relação à aceleração, obtém-se:

$$
\frac{\partial q_{n}}{\partial \ddot{q}_{n}} \approx \beta \Delta t^{2}
$$

de onde segue que:

$$
\frac{\partial \ddot{q}_{n}}{\partial q_{n}}=\frac{1}{\beta \Delta t^{2}}
$$

Por sua vez, derivando-se a equação (4.30) em relação à aceleração, obtém-se:

$$
\frac{\partial \dot{q}_{n}}{\partial \ddot{q}_{n}} \approx \gamma \Delta t
$$

Portanto, a derivada da velocidade com relação ao deslocamento pode ser dada por: 


$$
\frac{\partial \dot{q}_{n}}{\partial q_{n}}=\frac{\partial \dot{q}_{n}}{\partial \ddot{q}_{n}} \frac{\partial \ddot{q}_{n}}{\partial q_{n}}=\frac{\gamma}{\beta \Delta t}
$$

Assim, substituindo-se as equações (4.37) e (4.39) na equação (4.35) tem-se:

$$
\frac{\partial R\left(q_{n}\right)}{\partial q_{n}}=-\left\{\underline{M} \frac{1}{\beta \Delta t^{2}}+\underline{C} \frac{\gamma}{\beta \Delta t}+\frac{\partial F^{\text {int }}\left(q_{n}\right)}{\partial q_{n}}\right\}
$$

Cabe lembrar que $\frac{\partial F^{i n t}\left(q_{n}\right)}{\partial q_{n}}=\underline{K}_{T}$, sendo $\underline{K}_{T}$ deduzida na seção 2.4 e dada pela equação (2.84).

Finalmente, substituindo-se a expressão (4.40) na equação (4.34) obtém-se a equação que fornece o acréscimo de deslocamentos, $\Delta q_{n}$, a qual se utiliza para a correção dos deslocamentos ao longo do processo iterativo:

$$
\left[\underline{M} \frac{1}{\beta \Delta t^{2}}+\underline{C} \frac{\gamma}{\beta \Delta t}+\underline{K}_{T}\right] \Delta q_{n}=R\left(q_{n}\right)
$$

O algoritmo mostrado no Quadro 4.6 combina o procedimento implícito de Newmark com o procedimento incremental iterativo de Newton-Raphson para o tratamento de problemas não-lineares, ARGYRIS \& MLEJNEK (1991) e RODRIGUES (1997). Sendo $\underline{K}_{T}$ a matriz de rigidez tangente da estrutura, dada pelas expressões (2.84), (3.65) e (3.69) de acordo com o comportamento adotado para o material, $\underline{M}$ a matriz de massa, considerada constante durante toda a análise. $\underline{C}$ é a matriz de amortecimento considerada constante ou atualizada, a cada incremento de tempo, durante toda a análise. A sequência descrita no Quadro 4.6 refere-se ao caso de vibração forçada, a qual pode ser facilmente adaptada para vibração livre. 
Passo inicial: $\mathrm{t}=0$ calculam-se:

$$
\begin{aligned}
& \text { a força externa } \rightarrow F^{e x t}(0) \\
& \text { a aceleração inicial } \rightarrow \ddot{q}_{0}=\underline{M}^{-1}\left\{F^{\text {ext }}(0)\right\}
\end{aligned}
$$

Passo 1: "Loop" incremental do tempo $\rightarrow t_{n}=t_{n-1}+\Delta t$

Passo 2: etapa de previsão:

$$
\begin{gathered}
\ddot{q}_{n}=\ddot{q}_{n-1} ; \\
\dot{q}_{n}=\dot{q}_{n-1}+\Delta t(1-\gamma) \ddot{q}_{n-1}+\Delta t \gamma \ddot{q}_{n} \\
q_{n}=q_{n-1}+\Delta t \dot{q}_{n-1}+\left(\frac{1}{2}-\beta\right) \Delta t^{2} \ddot{q}_{n-1}+\beta \Delta t^{2} \ddot{q}_{n}
\end{gathered}
$$

Passo 3: Cálculo do vetor resíduo: $\psi=F^{e x t}-\left(M \ddot{q}_{n}+\underline{C}_{n}+F^{i n t}\right)$

onde $F^{\text {int }}$ resulta de uma distribuição de tensão compatível com o modelo constitutivo.

Passo 4: Teste de convergência: $\|\psi\| \leq T O L ? \quad$ sim $\rightarrow \quad$ ir ao passo 1

$$
\text { não } \rightarrow \text { ir ao passo } 5
$$

Passo 5: Cálculo do acréscimo de deslocamento: $\left[\underline{M} \frac{1}{\beta \Delta t^{2}}+\underline{C} \frac{\gamma}{\beta \Delta t}+\underline{K}_{T}\right] \Delta q_{n}=\psi$

Passo 6: Incrementar: o deslocamento $\rightarrow q_{n}=q_{n}+\Delta q_{n}$

$$
\begin{aligned}
& \text { a velocidade } \rightarrow \dot{q}_{n}=\dot{q}_{n}+\frac{\gamma}{\beta \Delta t} \Delta q_{n} \\
& \text { a aceleração } \rightarrow \ddot{q}_{n}=\ddot{q}_{n}+\frac{1}{\beta \Delta t^{2}} \Delta q_{n}
\end{aligned}
$$

Passo 9: Ir ao passo 3

Quadro 4.6- Algoritmo de Newmark combinado com o método de Newton-Raphson

\subsection{EXEMPLOS NUMÉRICOS}

Nesta seção, para todos os exemplos apresentados utiliza-se a quadratura de Gauss-

Lobatto para as integrações numéricas. 


\subsubsection{Viga biengastada de material homogêneo com massa concentrada no meio do vão}

Neste exemplo apresentam-se os resultados da análise dinâmica, considerando-se apenas a não-linearidade geométrica, realizada sobre a estrutura sugerida em ORAN \& KASSIMALI (1976), Figura 4.1. A estrutura foi discretizada em seis elementos finitos e o incremento de tempo $\Delta t=5 \times 10^{-5} \mathrm{~s}$.

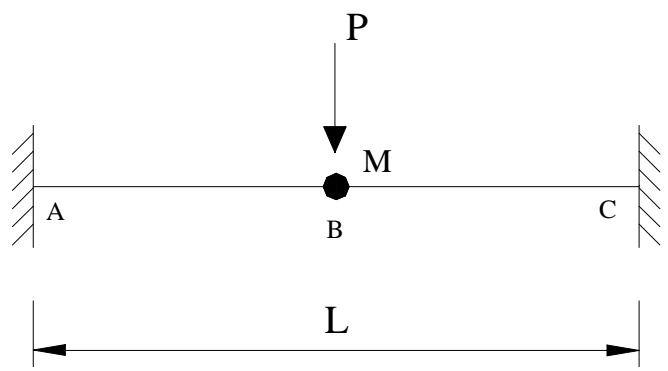

Figure 4.1- Viga biengastada com massa concentrada no meio do vão

Dados:

Seção transversal retangular com base igual a $2.54 \mathrm{~cm}$ e altura de $0.508 \mathrm{~cm}$;

$L=50.8 \mathrm{~cm} ; E=6894.757 \mathrm{kN} / \mathrm{cm}^{2} ; \rho=1.10^{-15} \mathrm{~kg} / \mathrm{cm}^{3} ;$

$M=7.55176 \times 10^{-7} \mathrm{~kg} ; P=2.846862 \mathrm{kN}$

Na Figura 4.2 estão apresentados os resultados das análises dinâmicas linear e nãolinear geométrica e também os apresentados por ORAN \& KASSIMALI (1976). Podese observar que o efeito da não-linearidade, neste caso, provoca uma diminuição da amplitude e do período de vibração, isso devido à movimentação de forças normais de tração na estrutura deslocada. 


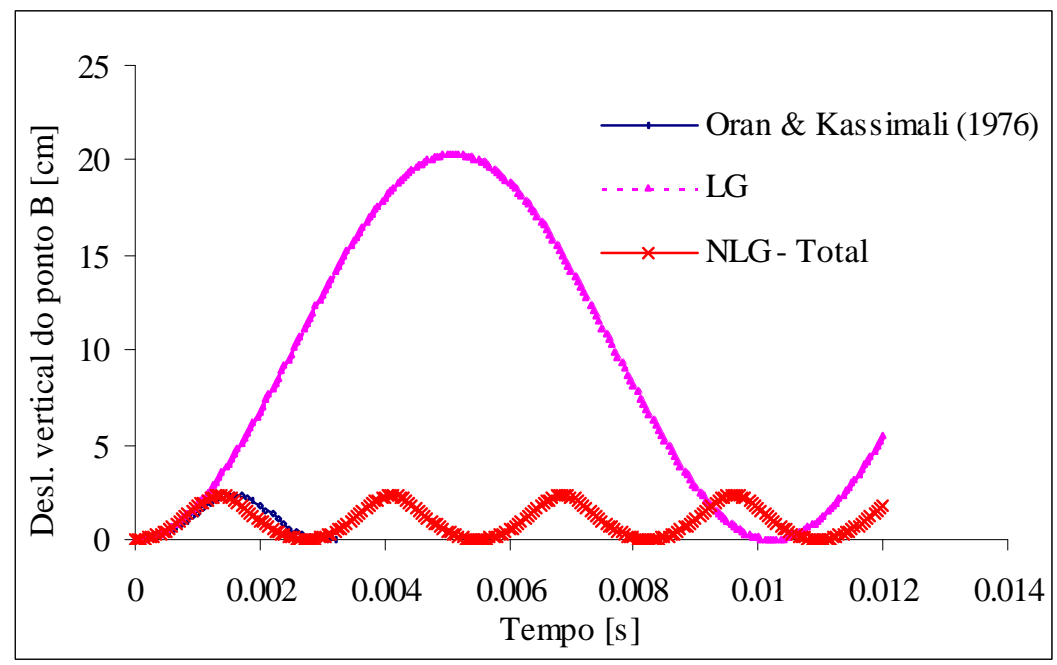

Figure 4.2- Curva deslocamento vertical do ponto B versus tempo

A Figura 4.3 confronta os resultados da análise dinâmica realizada considerando-se a não-linearidade geométrica, empregando-se tanto a formulação lagrangiana total como a atualizada, com os apresentados em ORAN \& KASSIMALI (1976), formulação euleriana; e de WEEKS (1972) $)^{3}$ apud ORAN \& KASSIMALI (1976). Apesar das descrições adotadas para a formulação do equilíbrio serem diferentes os resultados mostram boa concordância.

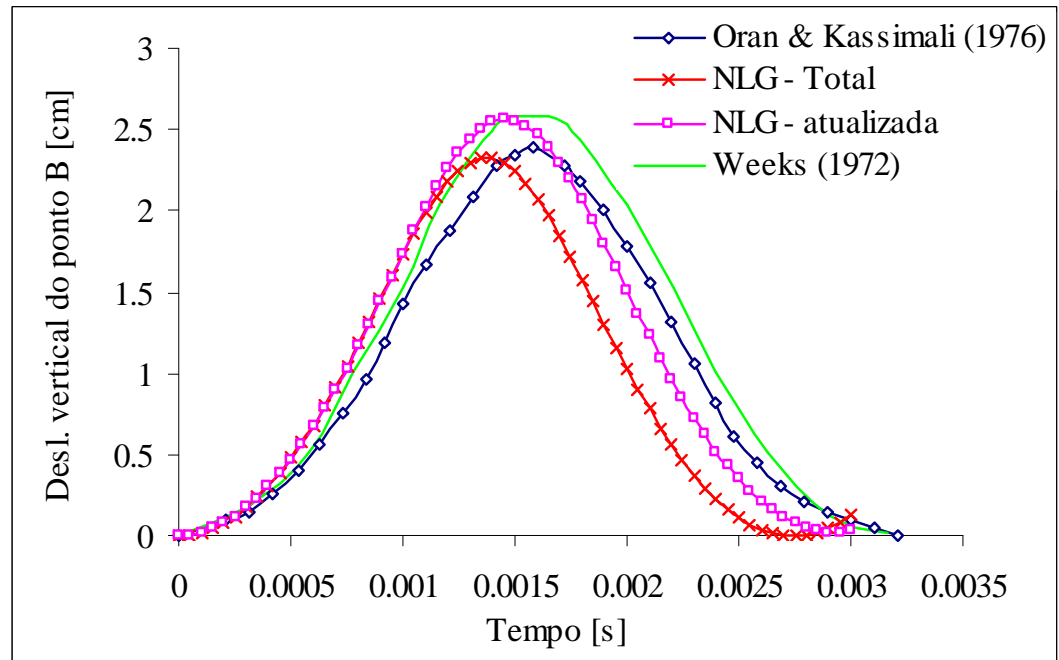

Figure 4.3- Curva deslocamento vertical do ponto B versus tempo

\footnotetext{
${ }^{3}$ WEEKS, G. (1972). Temporal operators for nonlinear structural dynamics problems. J. E. M. Div., ASCE 98, p.1087-1104.
} 


\subsubsection{Pórtico em concreto armado}

Este exemplo consiste de um pórtico biengastado em concreto armado, apresentado em RODRIGUES (1997).

A discretização adotada foi 12 elementos finitos iguais e ilustrado na Figura 4.4.

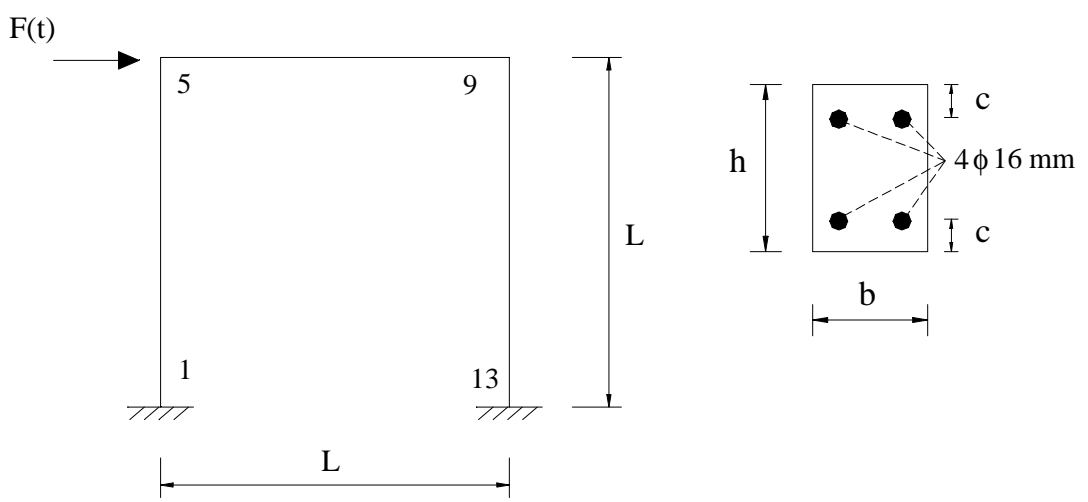

Figura 4.4- Pórtico simples em concreto armado

As características físicas e geométricas de todos os elementos são:

$L=200 \mathrm{~cm} ; \quad b=15 \mathrm{~cm} ; \quad h=30 \mathrm{~cm} ; \quad c=2.5 \mathrm{~cm} ; \quad f c k=26 \mathrm{MPa}$;

$E_{c}=28554.509 \mathrm{MPa} ; \quad E_{S}=210000 \mathrm{MPa} ; \quad f_{y}=510 \mathrm{MPa} ; \quad E_{T}=2100 \mathrm{MPa} ;$

$\gamma_{c}=2500 \mathrm{~kg} / \mathrm{m}^{3}$ e $\gamma_{s}=7850 \mathrm{~kg} / \mathrm{m}^{3}$.

Para os parâmetros do modelo de dano de Mazars adotaram-se os seguintes valores:

$A_{T}=0.995 ; B_{T}=8000 ; A_{C}=0.85 ; B_{C}=1050$ e $\varepsilon_{d 0}=0.00007$.

Os valores dos parâmetros do modelo de La Borderie adotados são: $\beta_{1}=1 \mathrm{MPa}$; $\beta_{2}=-10 \mathrm{MPa} ; y_{01}=3.05 \times 10^{-4} \mathrm{MPa} ; y_{02}=5 \times 10^{-3} \mathrm{MPa} ; A_{1}=3.5 \times 10^{3} \mathrm{MPa}^{-1} ;$ $A_{2}=6.8 \mathrm{MPa}^{-1}, B_{1}=0.95 ; B_{2}=0.7705$ e $\sigma_{f}=2.6 \mathrm{MPa}$.

O carregamento aplicado à estrutura é uma única força concentrada cuja variação com o tempo está representada na Figura 4.5. O incremento de tempo considerado é $\Delta t=4 \cdot 10^{-4} \mathrm{~s}$. 


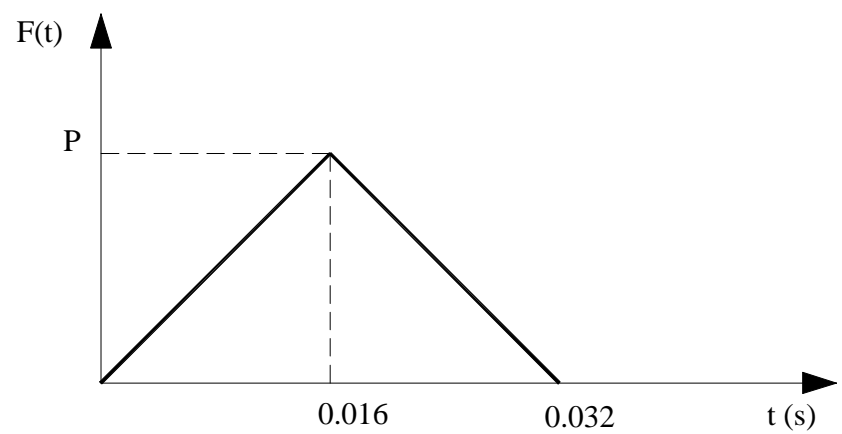

Figura 4.5- Variação da força $\mathrm{F}(\mathrm{t})$ com o tempo

As frações do amortecimento crítico utilizado foram $\xi_{1}=\xi_{2}=30 \%$, cabe lembrar que estas taxas são propositadamente altas, de modo a se ter um efeito de amortecimento mais forte.

A tabela 4.1 reúne os resultados obtidos efetuando-se as análises lineares e nãolineares (modelos de dano de Mazars e de La Borderie) estática e dinâmica e também os apresentados por RODRIGUES (1997), modelo elastoplástico.

Cabe ressaltar que em RODRIGUES (1997) os resultados das análises lineares foram obtidos utilizando-se o momento de inércia da seção bruta de concreto e das nãolineares o da seção homegeneizada.

Utilizando-se a tabela 4.1 pode-se observar que para a carga $\mathrm{P}=8 \mathrm{kN}$, empregando-se os dois modelos de dano, não houve danificação da estrutura nas análises estática e dinâmica, o mesmo não acontece para as cargas $\mathrm{P}=16 \mathrm{kN}$ e $\mathrm{P}=24 \mathrm{kN}$. Para a carga $\mathrm{P}=16 \mathrm{kN}$, utilizando-se o modelo de dano de La Borderie, não houve danificação na análise estática porém, na resposta dinâmica devido à influência das forças inerciais ocorre danificação. Observa-se também que na análise dinâmica a presença do dano aumenta os deslocamentos máximos com relação à análise elástica para todos os modelos de dano empregados. Como era de se esperar, verifica-se que o amortecimento provoca uma diminuição nos valores dos deslocamentos em relação à análise dinâmica não amortecida. No entanto, os deslocamentos máximos obtidos empregando-se o modelo de La Borderie são um pouco menores do que os obtidos com o modelo de Mazars. 
Tabela 4.1- Deslocamentos máximos, em $\mathrm{cm}$, obtidos no nó ' 5 ' na direção global $\mathrm{x}$, para $0 \leq t \leq 0.064 s$

\begin{tabular}{|c|c|c|c|c|c|}
\hline & \multirow{3}{*}{$\begin{array}{l}\mathrm{P}=8 \mathrm{kN} \\
0.03171\end{array}$} & & \\
\hline & & & & \multirow{2}{*}{$\begin{array}{c}\mathrm{P}=16 \mathrm{kN} \\
0.06341\end{array}$} & \multirow{2}{*}{$\begin{array}{l}\mathrm{P}=24 \mathrm{kN} \\
0.09512\end{array}$} \\
\hline \multirow[t]{5}{*}{ Estática } & \multirow[t]{2}{*}{ LF } & Presente Trabalho & & & \\
\hline & & Rodrigues (1997) & 0.0377 & 0.0754 & 0.1131 \\
\hline & \multirow[t]{3}{*}{ NLF } & Modelo de Mazars & 0.03171 & 0.06434 & 0.10485 \\
\hline & & Modelo de La Borderie & 0.03171 & 0.06341 & 0.09725 \\
\hline & & Rodrigues (1997) & 0.0310 & 0.0656 & 0.1229 \\
\hline \multirow{10}{*}{$\begin{array}{r}\text { Dinâmica sem } \\
\text { amortecimento }\end{array}$} & \multirow[t]{4}{*}{ LF } & \multirow[t]{2}{*}{ Presente Trabalho } & 0.04409 & 0.08817 & 0.1323 \\
\hline & & & -0.02423 & -.04848 & -0.07272 \\
\hline & & \multirow[t]{2}{*}{ Rodrigues (1997) } & 0.0539 & 0.1078 & 0.1617 \\
\hline & & & -0.0347 & -0.0694 & -0.1041 \\
\hline & \multirow[t]{6}{*}{ NLF } & Presente Trabalho & 0.04409 & 0.09055 & 0.1498 \\
\hline & & (Modelo de Mazars) & -0.02425 & -0.05401 & -0.1086 \\
\hline & & Presente Trabalho & 0.04409 & 0.08822 & 0.1408 \\
\hline & & (Modelo de La Borderie) & -0.02424 & -0.04826 & -0.0787 \\
\hline & & Rodrigues (1997) & 0.0425 & 0.0904 & 0.1580 \\
\hline & & & -0.0216 & -0.0339 & -0.0369 \\
\hline \multirow{10}{*}{$\begin{array}{l}\text { Dinâmica com } \\
\text { amortecimento }\end{array}$} & \multirow[t]{4}{*}{ LF } & \multirow[t]{2}{*}{ Presente Trabalho } & 0.03428 & 0.06855 & 0.1028 \\
\hline & & & -0.007105 & -0.01421 & -0.02131 \\
\hline & & \multirow[t]{2}{*}{ Rodrigues (1997) } & 0.0397 & 0.0794 & 0.1191 \\
\hline & & & -0.0081 & -0.0162 & -0.0243 \\
\hline & \multirow[t]{6}{*}{ NLF } & Presente Trabalho & 0.03428 & 0.06894 & 0.1070 \\
\hline & & (Modelo de Mazars) & -0.007105 & -0.01455 & -0.02380 \\
\hline & & Presente Trabalho & 0.03428 & 0.06855 & 0.1034 \\
\hline & & (Modelo de La Borderie) & -0.007105 & -0.01421 & -0.02057 \\
\hline & & \multirow[t]{2}{*}{ Rodrigues (1997) } & 0.0330 & 0.0671 & 0.1079 \\
\hline & & & -0.0060 & -0.0089 & -0.0033 \\
\hline
\end{tabular}


Vale lembrar que embora, neste trabalho, tenha sido utilizado um modelo diferente para a simulação do comportamento não-linear físico da estrutura, os resultados obtidos comparados com os de RODRIGUES (1997) apresentaram-se concordantes.

Finalizando, observa-se que neste exemplo o efeito do comportamento não-linear geométrico não é significativo em função da magnitude do carregamento aplicado.

\subsubsection{Viga bi-apoiada em concreto armado}

Neste exemplo apresentam-se os resultados de uma análise dinâmica, realizada sobre a estrutura (viga) apresentada em ÁLVARES (1993), empregando-se os modelos de dano de Mazars e La Borderie, sem a consideração da não-linearidade geométrica. Os dados geométricos e a distribuição das armaduras estão apresentados na Figura 4.6.
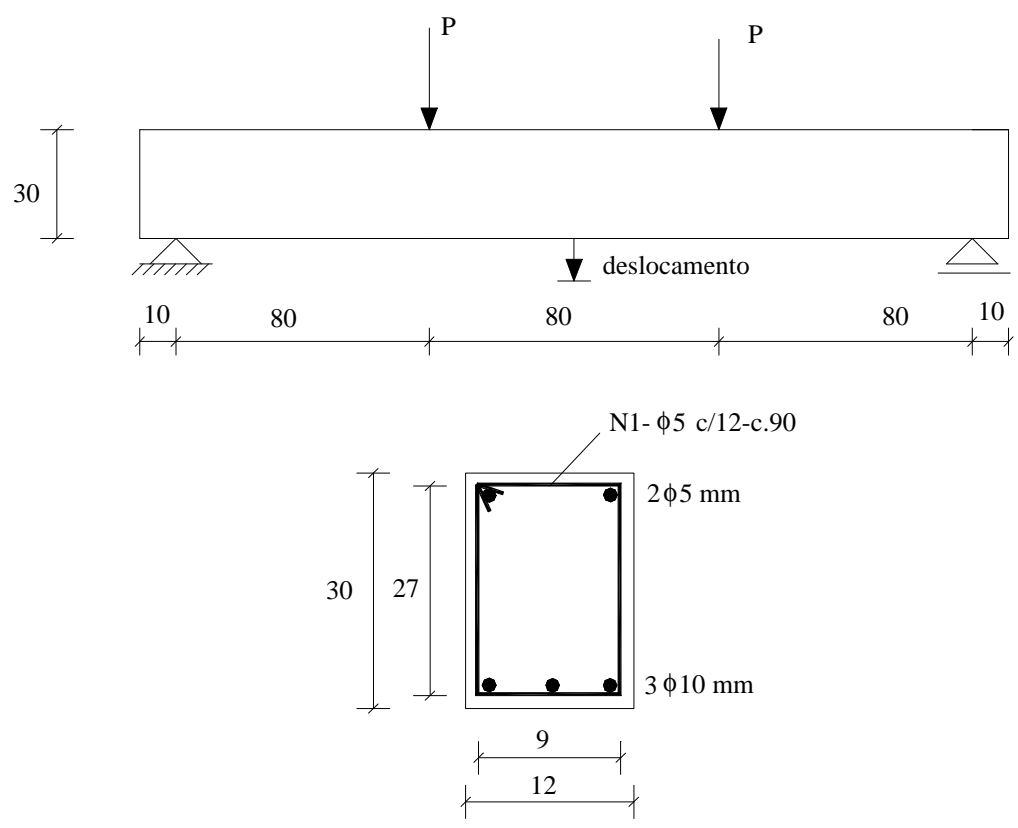

Figura 4.6- Geometria e armação da viga - dimensões em cm

Propriedades do concreto: $E=29200 \mathrm{MPa} ; \mathrm{v}=0.2 ; \gamma_{c}=2500 \mathrm{~kg} / \mathrm{m}^{3}$

Propriedades do aço: $E=196000 \mathrm{MPa} ; \quad f_{y}=420 \mathrm{MPa} ; \quad E_{T}=19600 \mathrm{MPa}$; $\gamma_{c}=7850 \mathrm{~kg} / \mathrm{m}^{3}$ 
Parâmetros do modelo de Mazars: $A_{T}=0.995 ; B_{T}=8000 ; A_{C}=0.85 ; B_{C}=1050$ e $\varepsilon_{d 0}=0.00007$.

Parâmetros do modelo de La Borderie: $\beta_{1}=1 \mathrm{MPa} ; \quad \beta_{2}=-10 \mathrm{MPa}$; $y_{01}=3.05 \times 10^{-4} \mathrm{MPa}, y_{02}=5 \times 10^{-3} \mathrm{MPa} ; A_{1}=3.5 \times 10^{3} \mathrm{MPa}^{-1} ; A_{2}=6.8 \mathrm{MPa}^{-1}$, $B_{1}=0.95 ; B_{2}=0.7705$ e $\sigma_{f}=2.6 \mathrm{MPa}$.

O parâmetro $\sigma_{f}$ tem influência direta na resposta numérica, pois implica em fechamento de fissuras que pode ocorrer em correspondência a diferentes níveis de resposta. O objetivo da análise, no entanto, não foi o de reproduzir de modo rigoroso o fechamento de fissuras, mas, sobretudo, o de avaliar seu efeito na resposta dinâmica estrutural.

A estrutura foi discretizada em 12 elementos finitos iguais, tendo sido adotado o seguinte passo de tempo: $\Delta t=1.10^{-5} \mathrm{~s}$.

Nesta análise consideraram-se quatro situações de solicitação. A primeira corresponde à vibração forçada provocada por cargas de $10 \mathrm{kN}$ e $25 \mathrm{kN}$, aplicadas subitamente e mantidas constantes ao longo do tempo (caso1, indicado no Quadro 4.1). A segunda corresponde à vibração livre a partir de deslocamentos iniciais de 2 $\mathrm{mm}$ e $4 \mathrm{~mm}$ impostos ao centro do vão. A terceira e a quarta correspondem à vibração forçada provocada por cargas com variação harmônica cossenoidal e senoidal, respectivamente (casos 6 e 5 indicados no Quadro 4.5). As duas primeiras análises foram feitas com e sem a consideração de amortecimento e a última sem amortecimento.

Para efeito de ilustração, na Tabela 4.2 estão apresentados os deslocamentos da seção situada no meio do vão da viga, obtidos realizando-se análises estáticas linear e nãolinear física. Verifica-se que empregando-se o modelo de dano de La Borderie a carga de 10 kN não é suficiente para provocar danificação da estrutura. 
Tabela 4.2- Valores do deslocamento vertical do meio do vão - análise estática

\begin{tabular}{|c|c|c|}
\cline { 2 - 3 } \multicolumn{1}{c|}{} & $\mathrm{P}=10 \mathrm{kN}$ & $\mathrm{P}=25 \mathrm{kN}$ \\
\hline Modelo elástico & $0.55868 \mathrm{~mm}$ & $1.3967 \mathrm{~mm}$ \\
\hline Modelo de Mazars & $0.64854 \mathrm{~mm}$ & $4.7842 \mathrm{~mm}$ \\
\hline Modelo de La Borderie & $0.55868 \mathrm{~mm}$ & $4.5670 \mathrm{~mm}$ \\
\hline
\end{tabular}

Nas Figuras 4.7 e 4.8 estão apresentadas as respostas das análises dinâmicas linear e não-linear física com cargas de 10 e $25 \mathrm{kN}$, respectivamente, correspondentes ao caso 1 de vibração forçada.

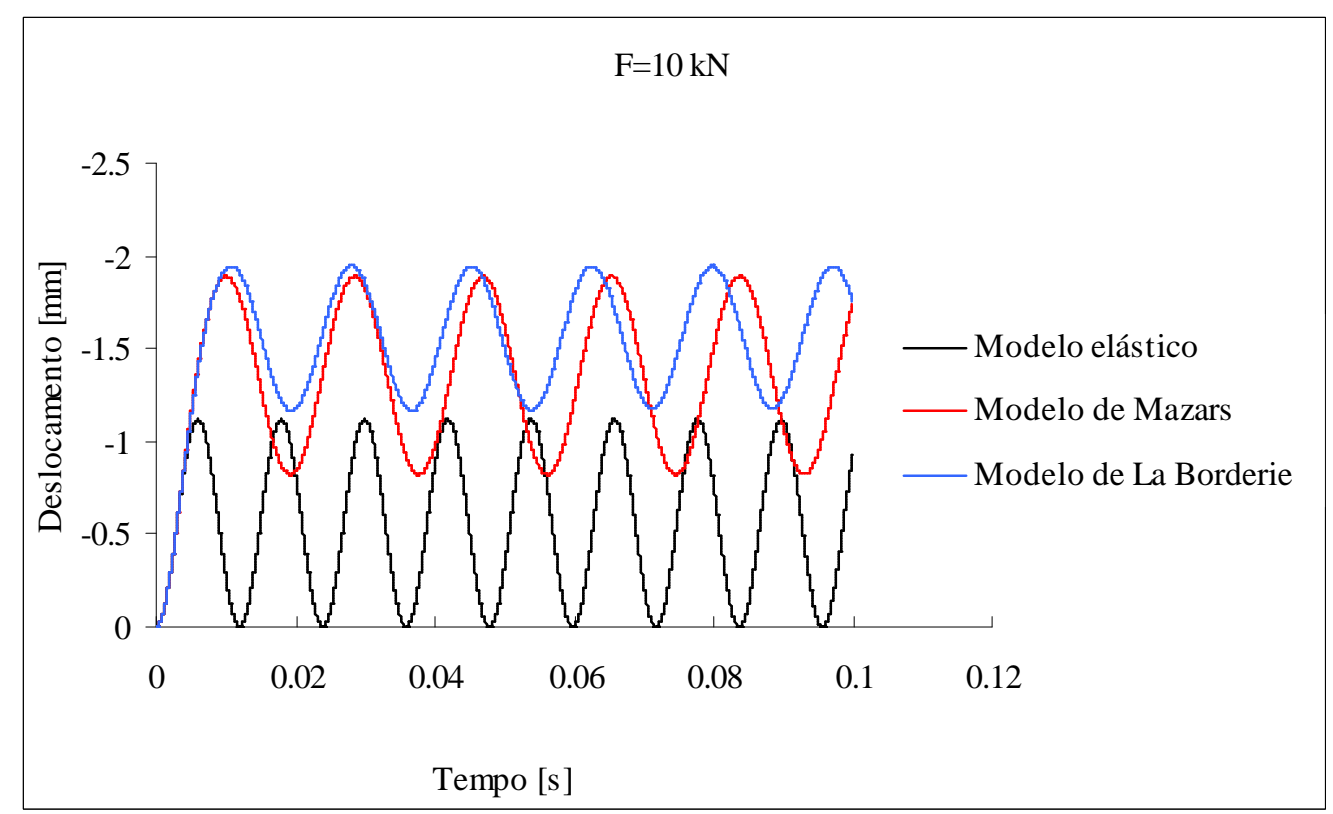

Figura 4.7- Curva deslocamento versus tempo- vibração forçada não amortecida 


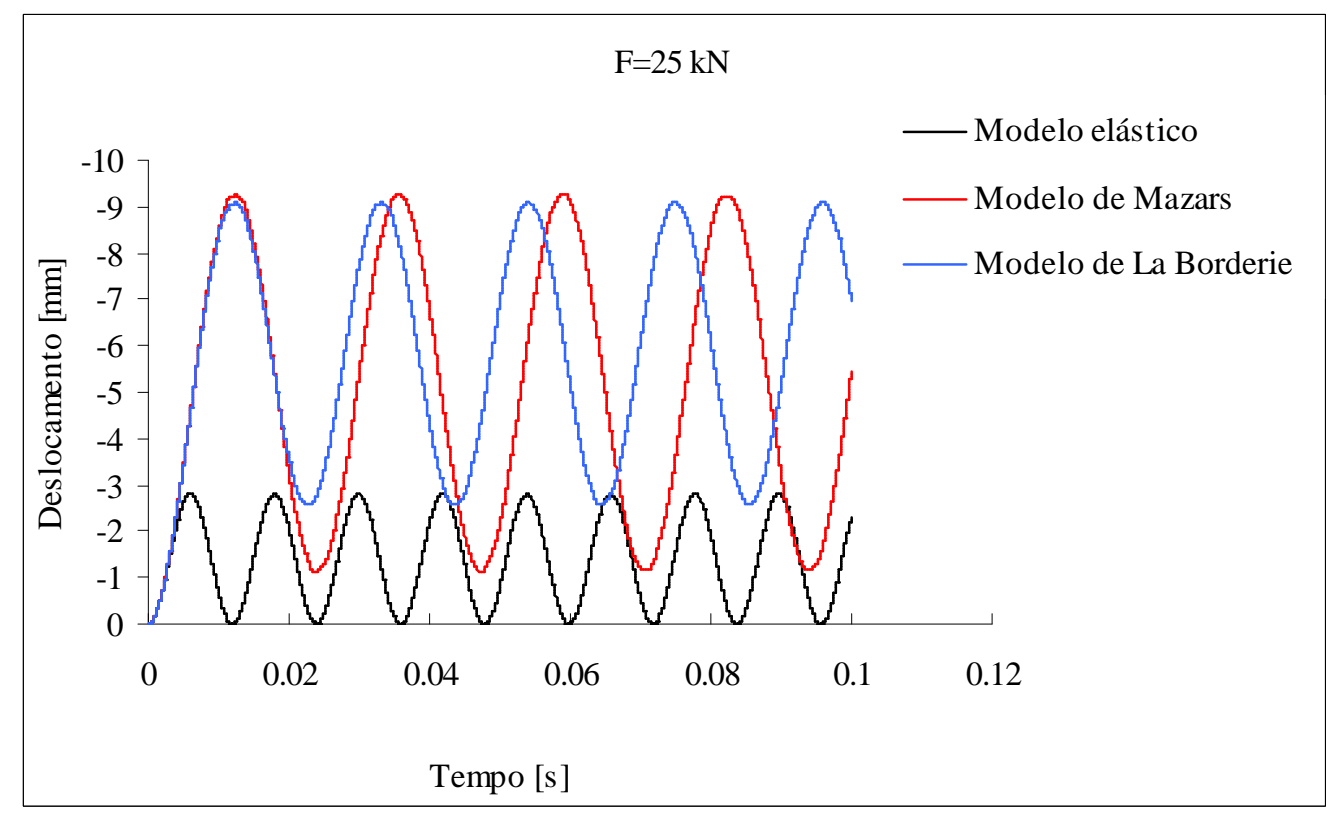

Figura 4.8- Curva deslocamento versus tempo - vibração forçada não amortecida

Observando-se as curvas apresentadas nas Figuras 4.7 e 4.8 verifica-se que a danificação provoca uma mudança na amplitude e no período de vibração em relação à resposta puramente elástica; quanto maior o nível de danificação maior a amplitude de vibração, no entanto no período essa mudança é pequena de um nível de carga para outro. Observa-se também que as respostas obtidas empregando-se os modelos de dano de Mazars e La Borderie são diferentes a partir de um certo intervalo de tempo. Isso se deve ao fato do modelo de dano de La Borderie computar a plastificação do concreto devido ao processo de danificação e também considerar o fechamento das fissuras.

Na Figura 4.9 estão confrontadas as respostas para o caso de vibração forçada $F=25$ $\mathrm{kN}$ considerando-se ou não o efeito da plastificação do aço combinado com a danificação do concreto. 


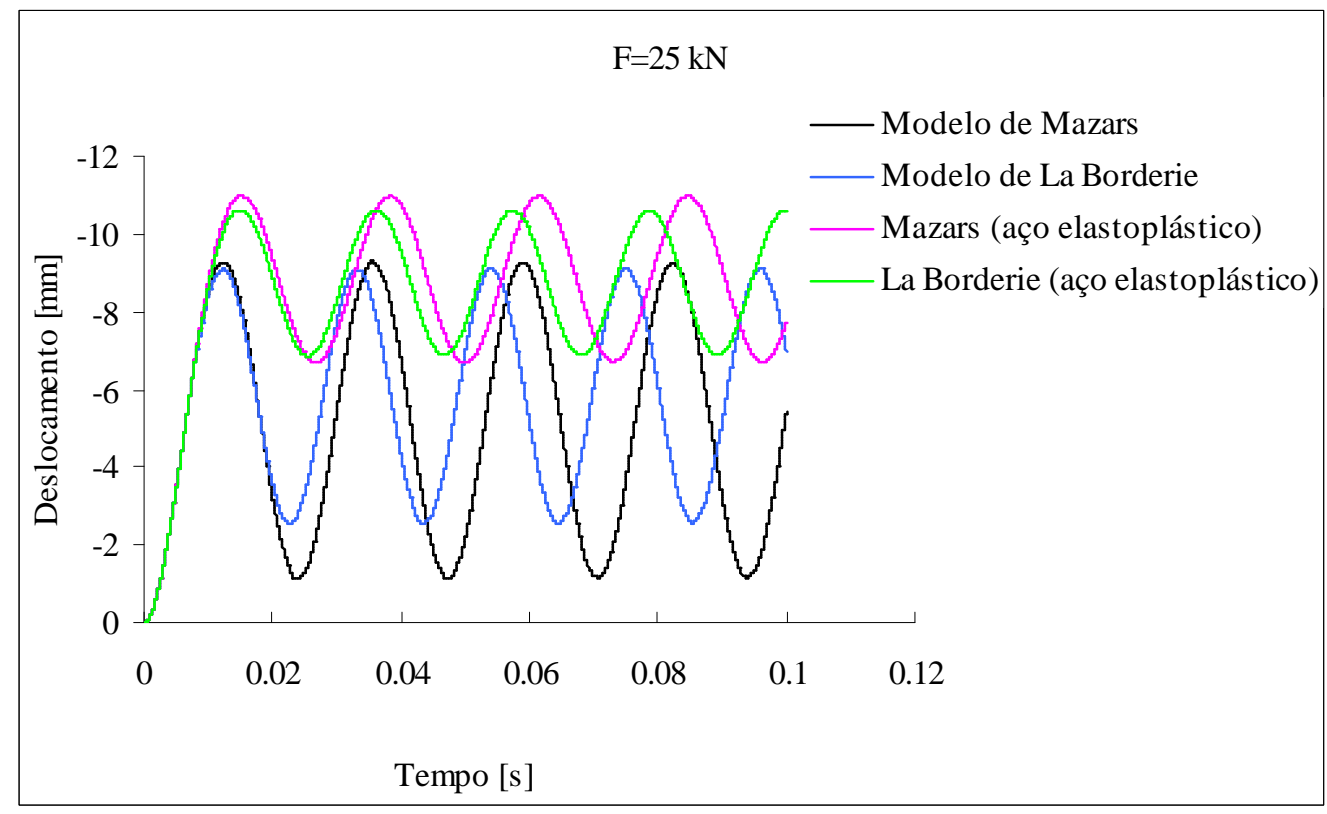

Figura 4.9- Curva deslocamento versus tempo- vibração forçada não amortecida

Observa-se na Figura 4.9 que o efeito da plastificação do aço diminui a amplitude do deslocamento e aumenta o período de vibração com relação ao aço elástico, efeito provocado por uma maior dissipação de energia nos processos de danificação e plastificação.

Nas Figuras 4.10, 4.11, 4.12 e 4.13 estão apresentadas as respostas da análise dinâmica para vibração forçada com amortecimento, considerando-se as nãolinearidades do concreto e do aço.

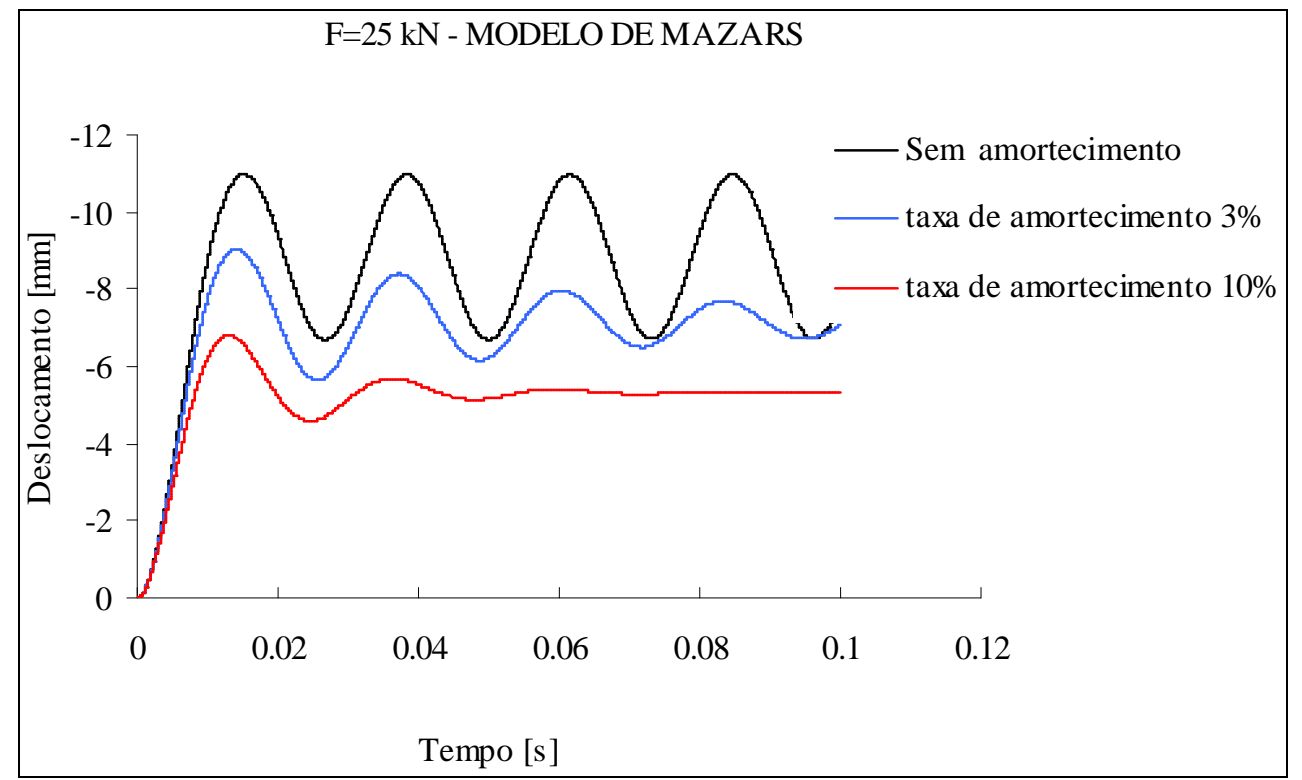

Figura 4.10- Curva deslocamento versus tempo - vibração forçada amortecida 


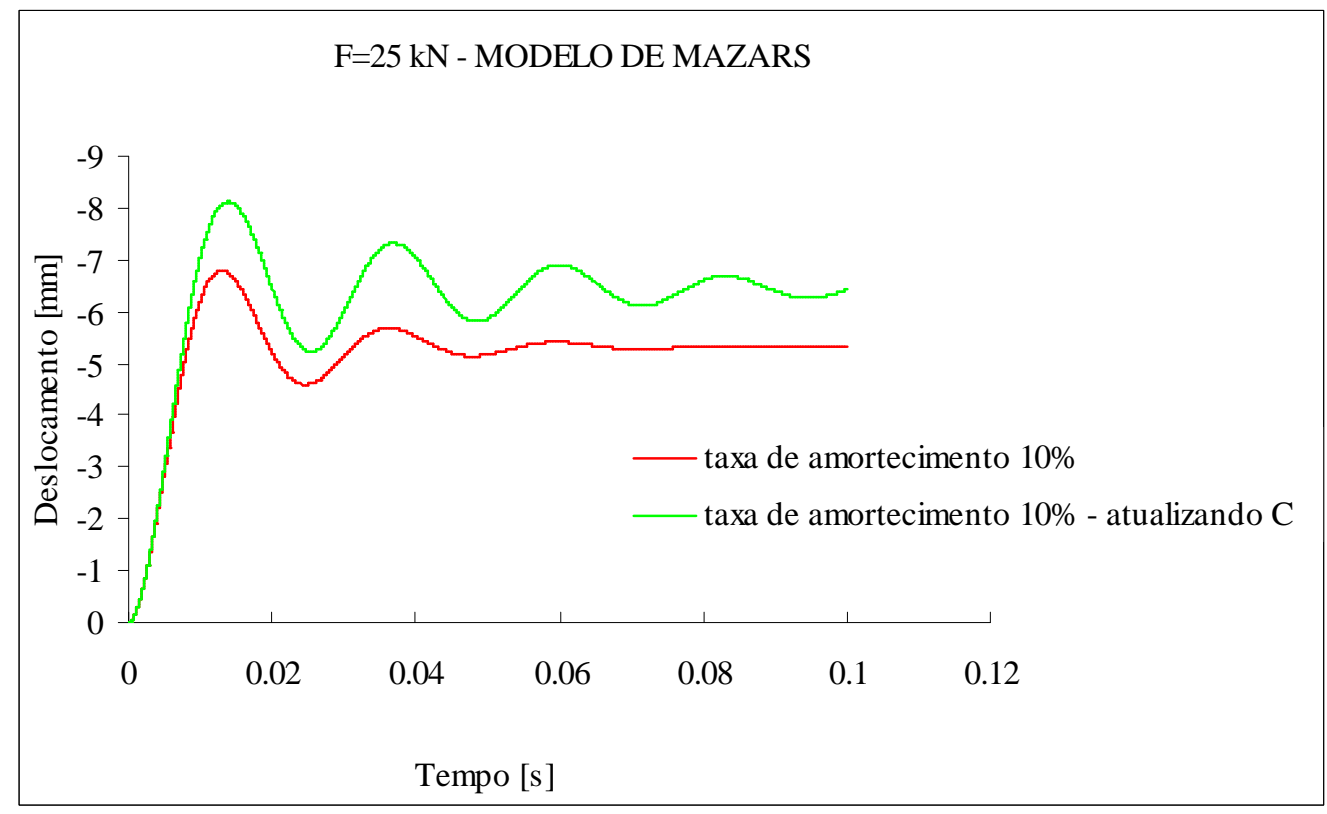

Figura 4.11- Curva deslocamento versus tempo - vibração forçada amortecida

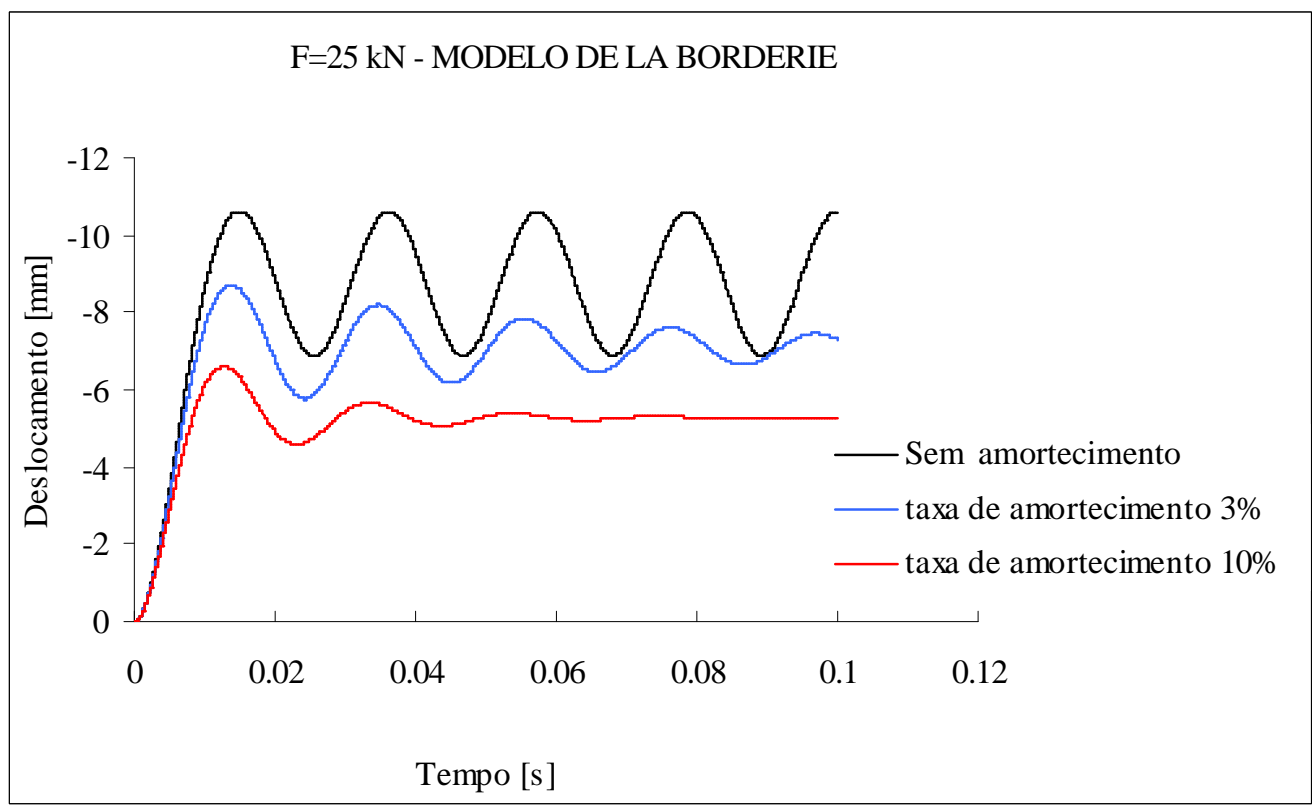

Figura 4.12- Curva deslocamento versus tempo - vibração forçada amortecida 


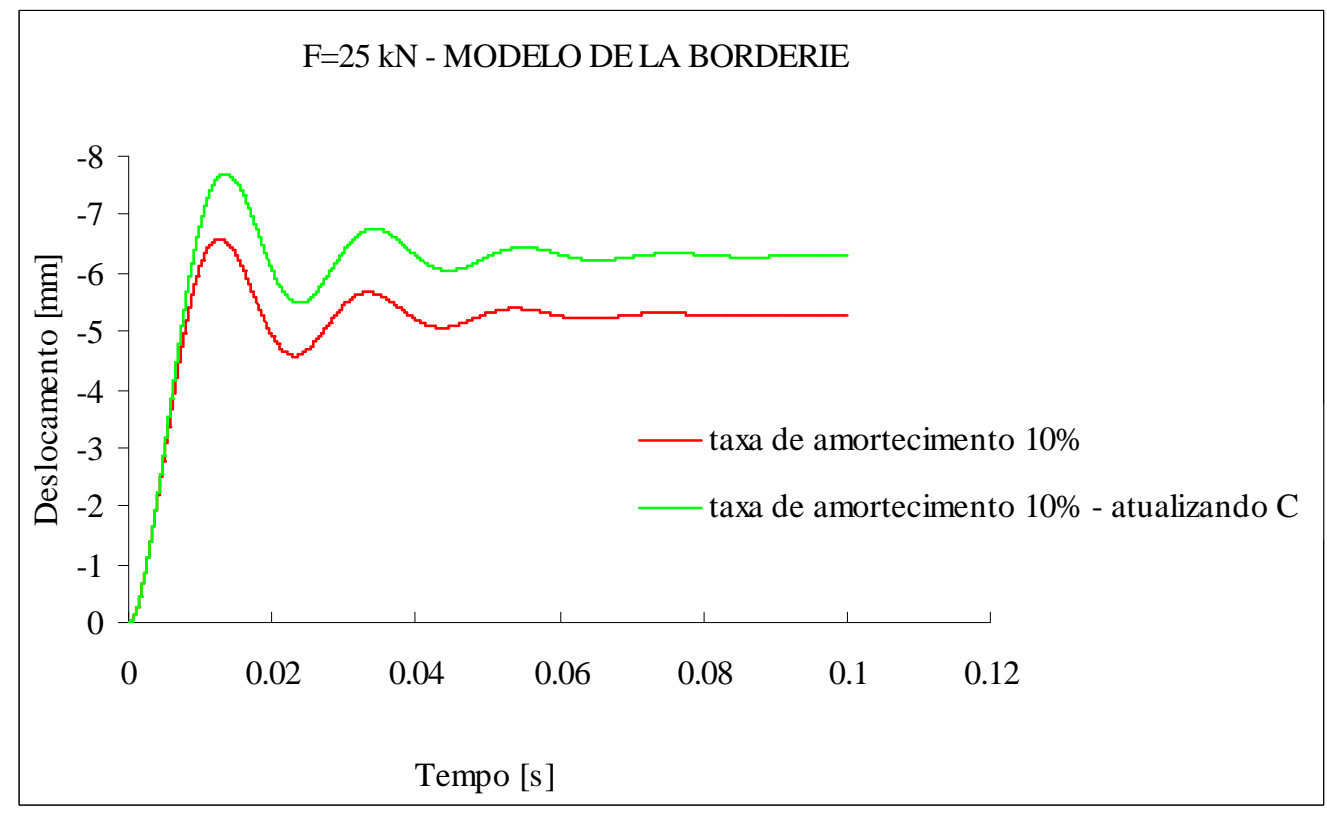

Figura 4.13- Curva deslocamento versus tempo - vibração forçada amortecida

As Figuras 4.10 e 4.12 mostram, considerando-se os dois modelos de dano, o efeito do amortecimento de Rayleigh na resposta dinâmica. Verifica-se que quanto maior a taxa de amortecimento menor é o nível do deslocamento final em virtude, certamente, do efeito inibidor do amortecimento sobre a danificação. Nas Figuras 4.11 e 4.13 , observa-se a influência de se atualizar a matriz de amortecimento a cada incremento de tempo. Em ambos os casos, a atualização da matriz de amortecimento permite uma maior danificação e consequentemente um deslocamento final maior. Naturalmente esse efeito é maior no Modelo de Mazars, pois não se levam em conta os mecanismos de fechamento de fissuras.

Nas Figuras 4.14 e 4.15 estão apresentadas as respostas de análises dinâmicas lineares e não-lineares para vibração livre, sem amortecimento, com deslocamentos iniciais de $2 \mathrm{~mm}$ e $4 \mathrm{~mm}$, respectivamente, impostos à seção central da viga. Nas análises o aço apresenta um comportamento elástico. 


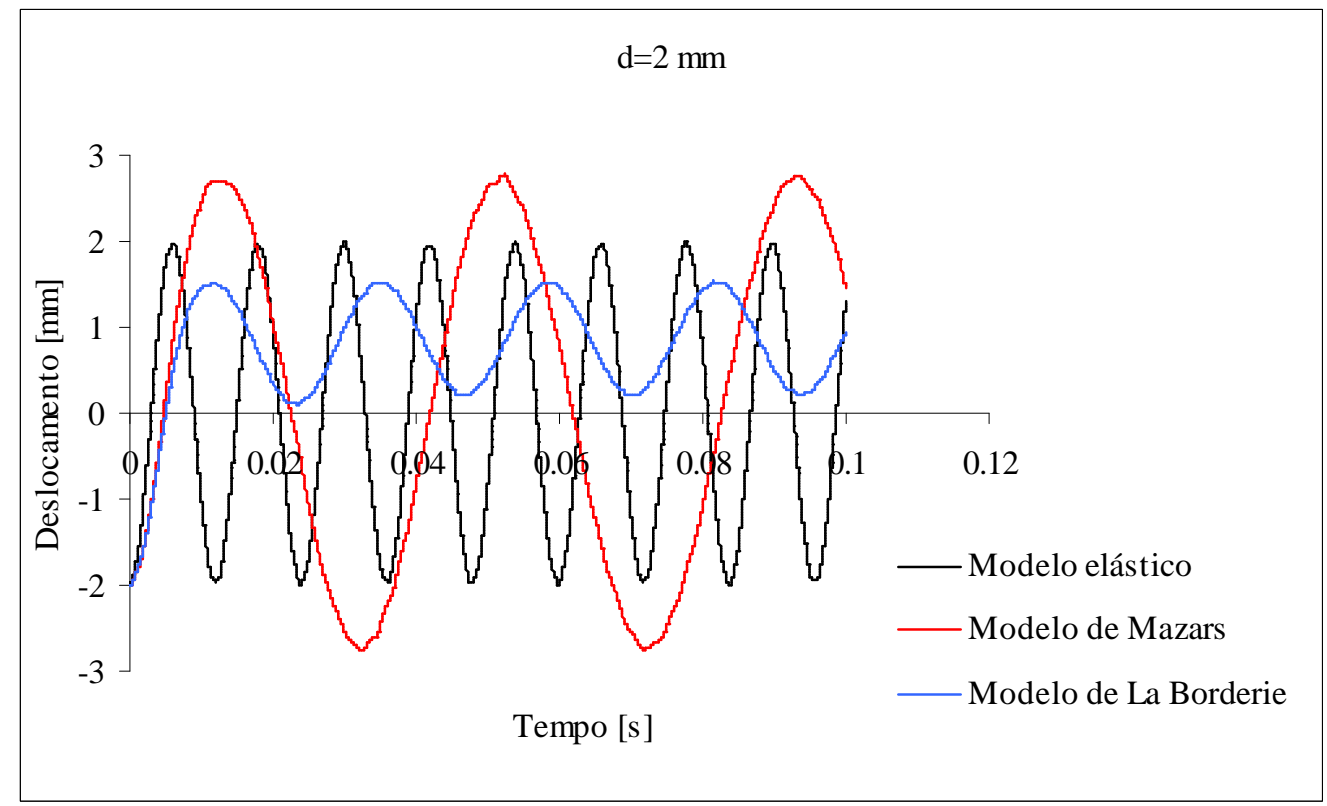

Figura 4.14- Curva deslocamento versus tempo - vibração livre não amortecida



Figura 4.15- Curva deslocamento versus tempo - vibração livre não amortecida

Observa-se nas Figuras 4.14 e 4.15 que empregando-se o modelo de Mazars obtémse uma danificação cujo efeito é o de aumentar a amplitude e o período de vibração do deslocamento. Com o modelo de La Borderie a danificação induz um aumento do período porém diminuição da amplitude de vibração. Provavelmente isso se deve ao fato de que nesse modelo consideram-se as deformações permanentes (plastificação 
do concreto) e também a recuperação da rigidez com o fechamento de fissuras, aspectos que não são considerados no modelo de Mazars.

Nas Figuras 4.16 e 4.17 são mostradas as comparações entre as respostas dinâmicas para os mesmos casos anteriores, porém considerando-se o aço com comportamento elastoplástico.

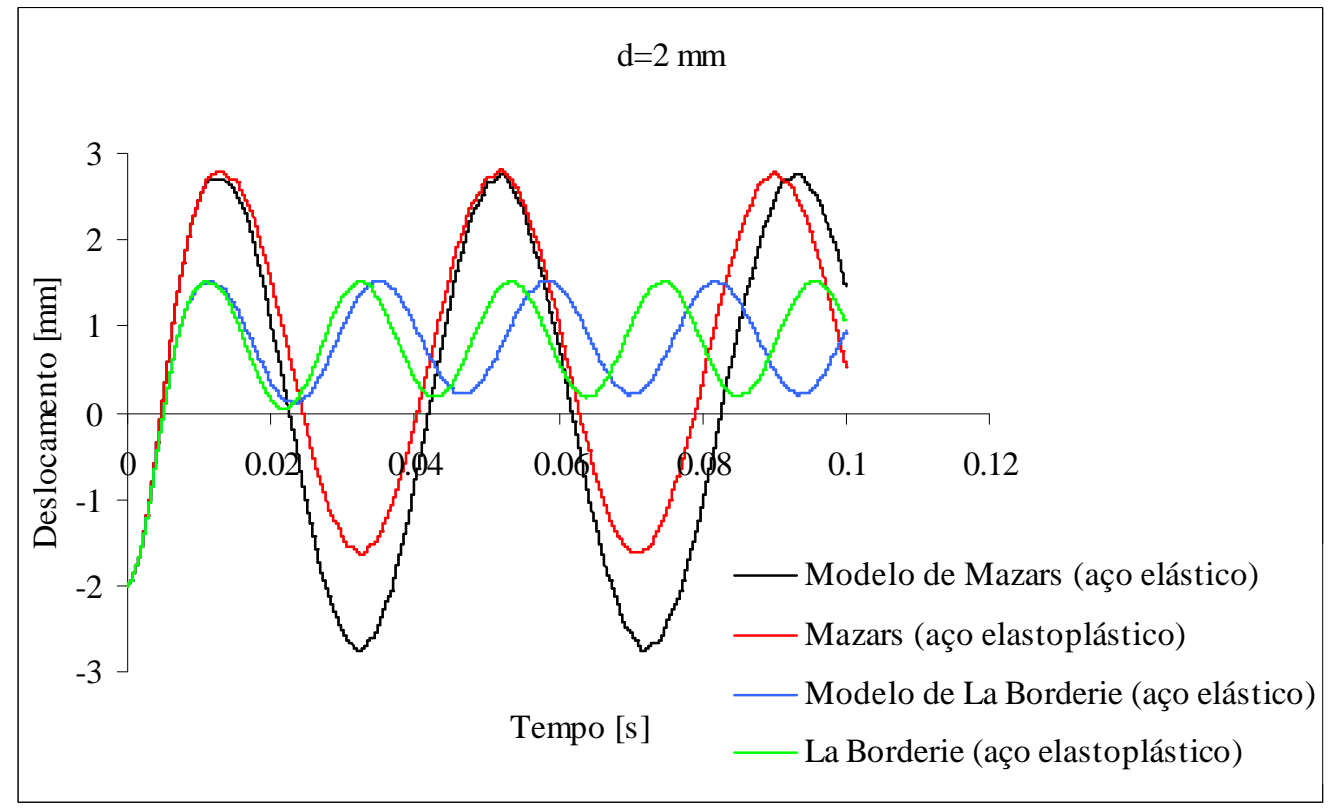

Figura 4.16- Curva deslocamento versus tempo - vibração livre não amortecida

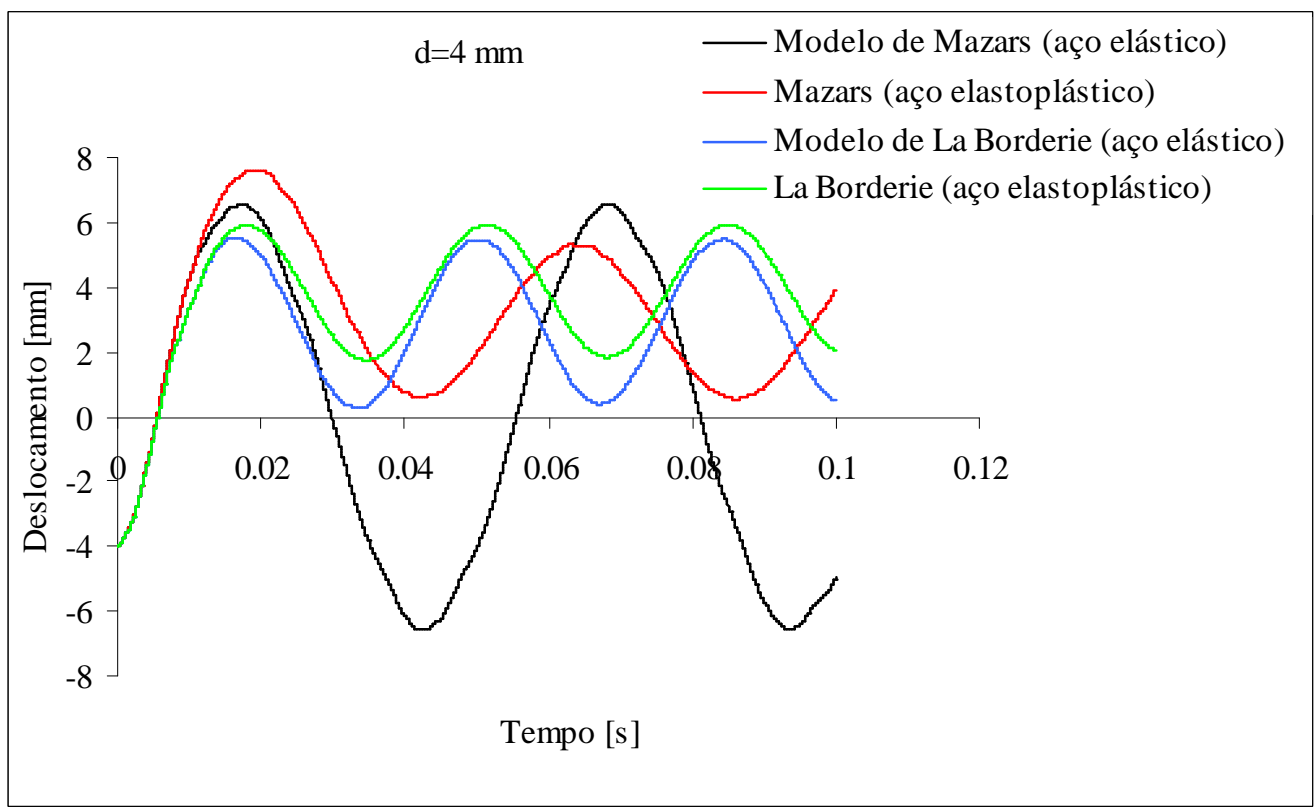

Figura 4.17- Curva deslocamento versus tempo - vibração livre não amortecida 
Observa-se, Figura 4.16, que a plastificação do aço diminui a amplitude e o período de vibração, isto se deve ao fato de que neste nível de solicitação ainda se ter uma evolução do processo de danificação associado ao de plastificação. Para o deslocamento de $4 \mathrm{~mm}$, devido ao fato de se ter um nível de danificação mais intenso e consequentemente maior nível de plastificação, na Figura 4.18 pode-se observar que a plastificação do aço diminui a amplitude e aumenta o período de vibração, HATZIGEORGIOU \& BESKOS (2000). Deste modo, a resposta obtida utilizando-se o modelo de Mazars e considerando-se o aço elastoplástico a partir de um certo intervalo de tempo apresenta uma redução ainda maior na amplitude.

Nas Figuras 4.18 e 4.19 estão apresentadas as respostas não-lineares dinâmicas com vibração livre amortecida, deslocamento de $4 \mathrm{~mm}$, modelos de dano de Mazars e de La Borderie, considerando-se o comportamento elastoplástico para o aço e a matriz de amortecimento constante durante todas as análises.

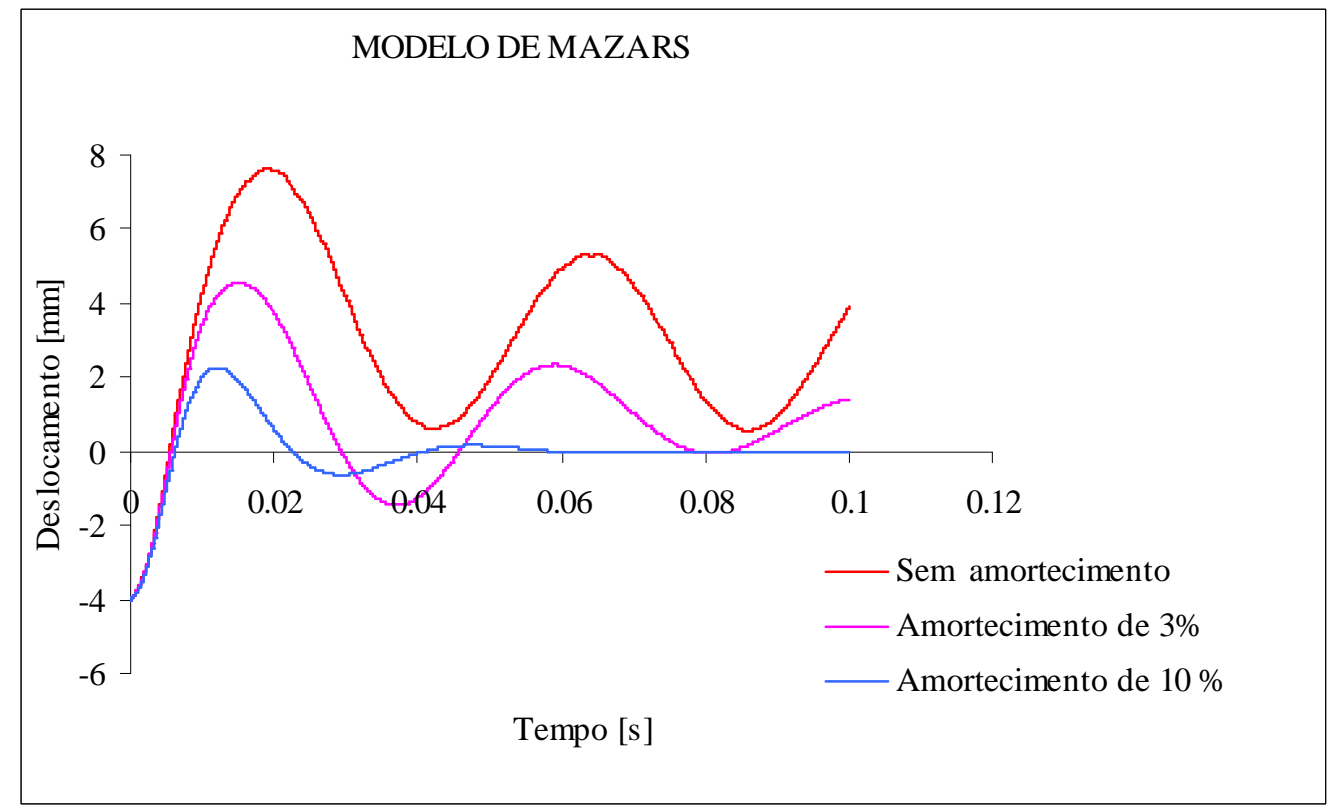

Figura 4.18- Curva deslocamento versus tempo - vibração livre amortecida 


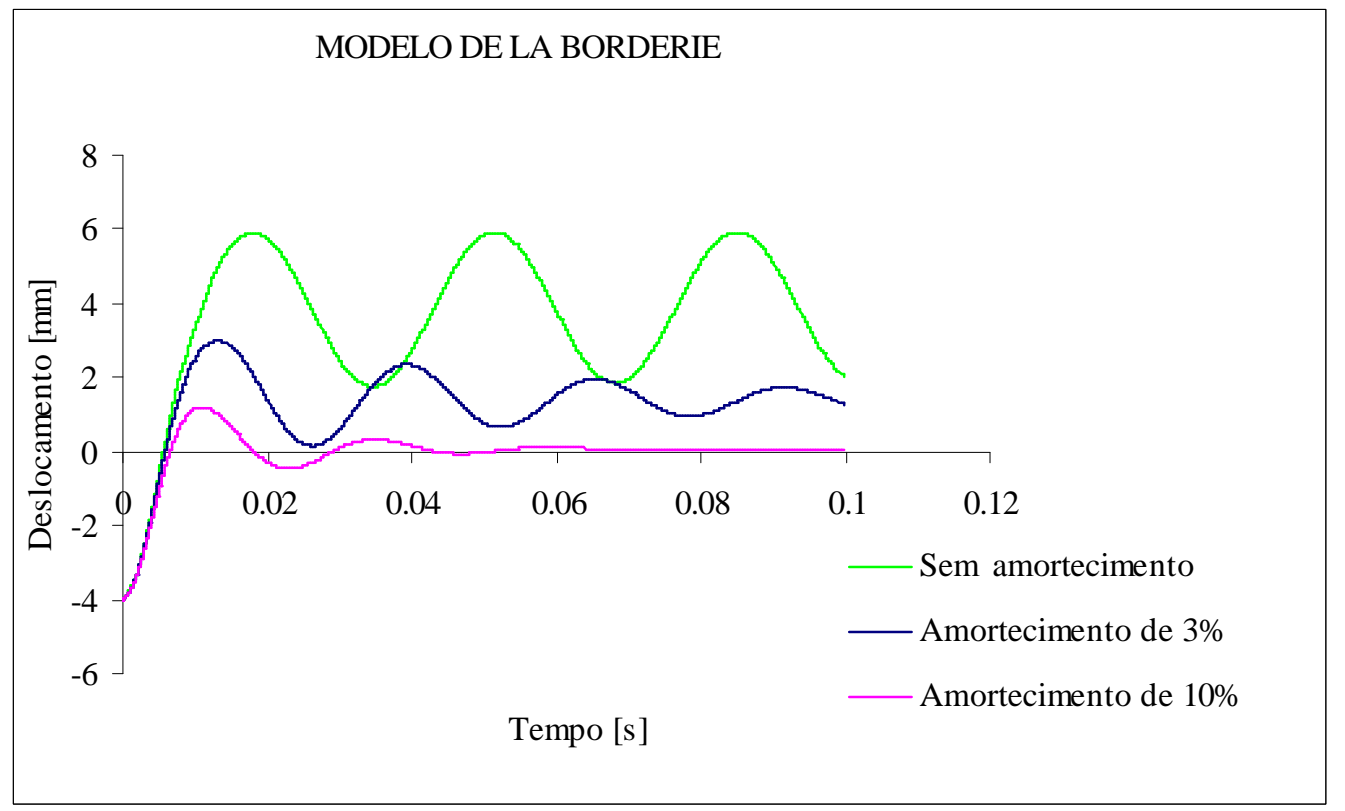

Figura 4.19- Curva deslocamento versus tempo - vibração livre amortecida

Observa-se nas Figuras 4.18 e 4.19 que quanto maior a taxa de amortecimento menor a amplitude e o período de vibração, resposta análoga à da vibração forçada.

Nas Figuras 4.20 e 4.21 estão confrontadas as respostas não-lineares dinâmicas para vibração livre amortecida, com deslocamento inicial de $4 \mathrm{~mm}$, segundo os modelos de dano de Mazars e de La Borderie, considerando-se a atualização da matriz de amortecimento devido ao dano.

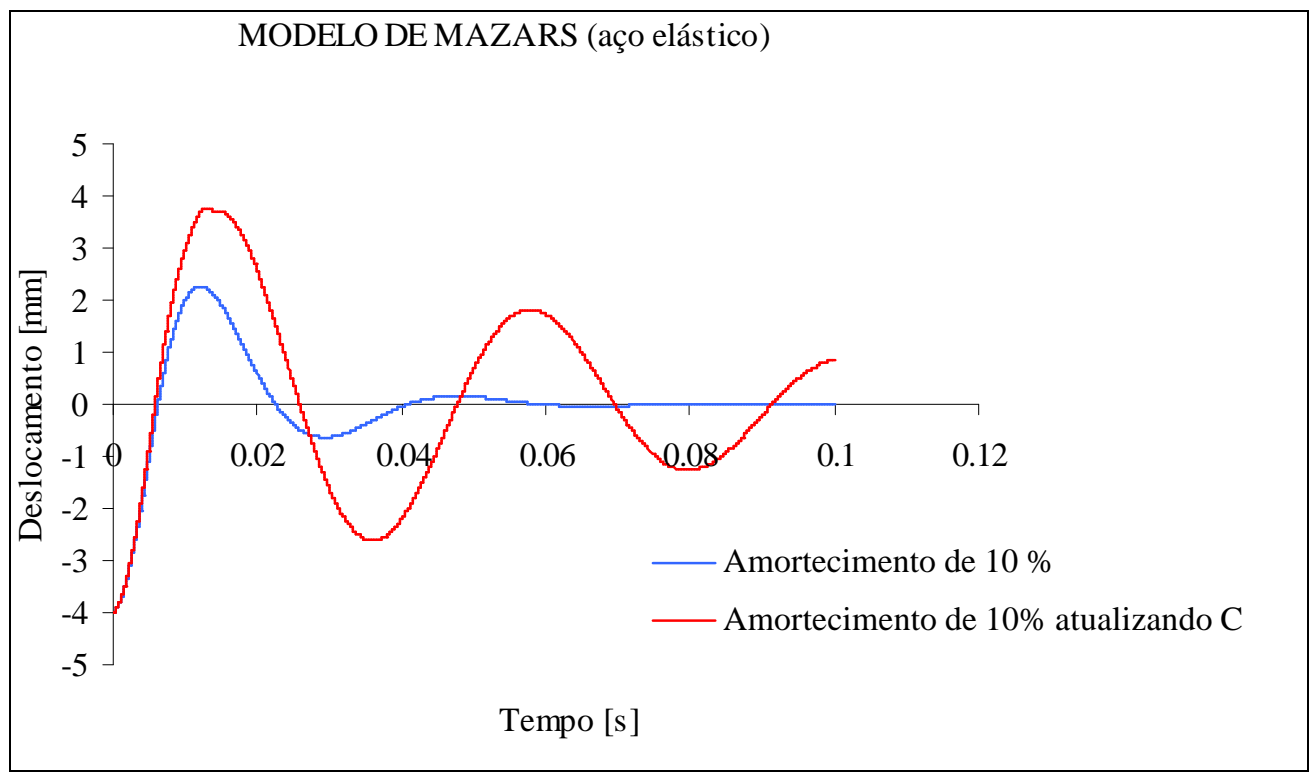

Figura 4.20- Curva deslocamento versus tempo - vibração livre amortecida 


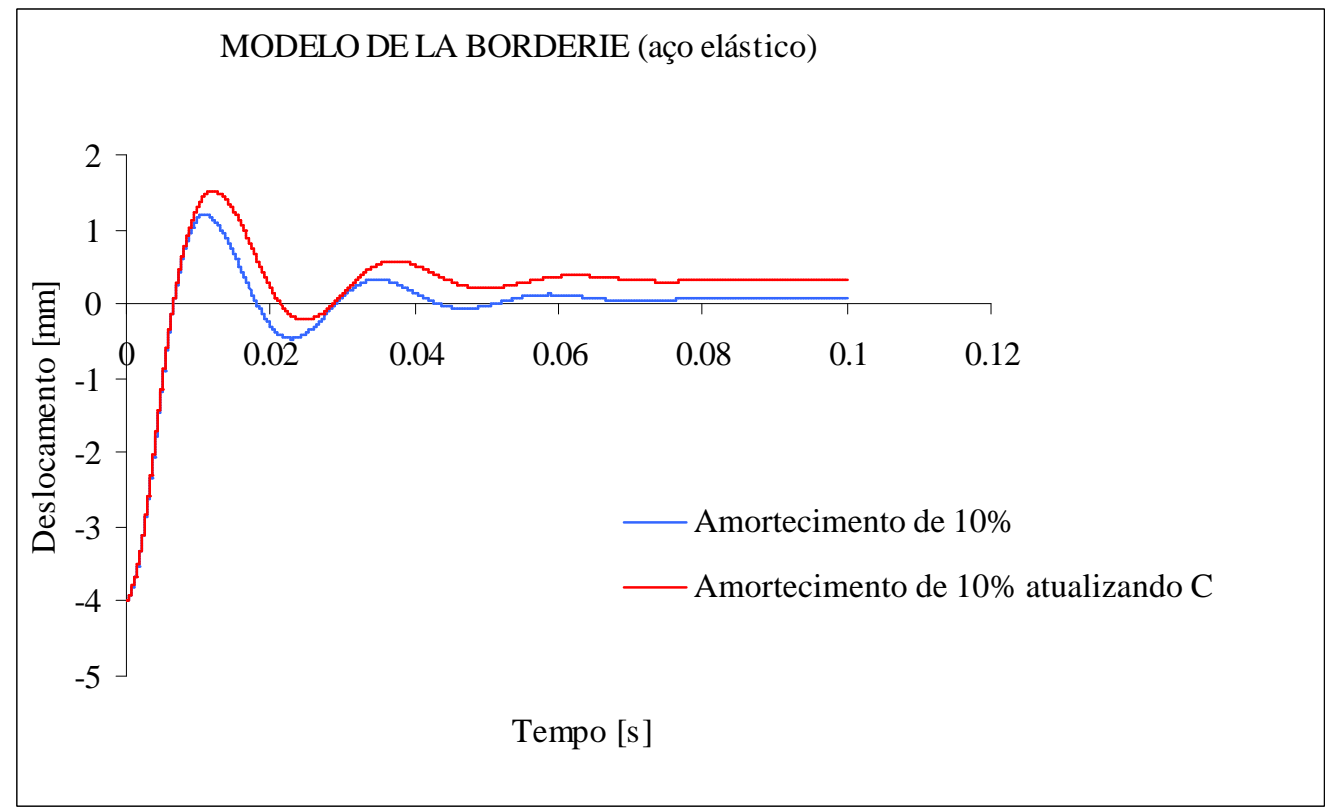

Figura 4.21- Curva deslocamento versus tempo - vibração livre amortecida

Pode-se notar que o efeito da atualização da matriz de amortecimento é análogo ao apresentado na análise de vibração forçada ou seja: com a atualização da rigidez aumenta a danificação e diminui o amortecimento. Essa diminuição do amortecimento é comparativamente menor no modelo de La Borderie devido ao fechamento de fissuras.

Nas Figuras 4.22 e 4.23 estão apresentadas, ainda para deslocamento inicial imposto de $4 \mathrm{~mm}$, as respostas obtidas para uma taxa de amortecimento de $10 \%$. No caso do modelo de Mazars, leva-se em conta na atualização da matriz de amortecimento o dano no concreto e a plastificação do aço. No modelo de La Borderie consideram-se naquela atualização o dano e a plastificação do concreto, e também a plastificação do aço. 




Figura 4.22- Curva deslocamento versus tempo - vibração livre amortecida

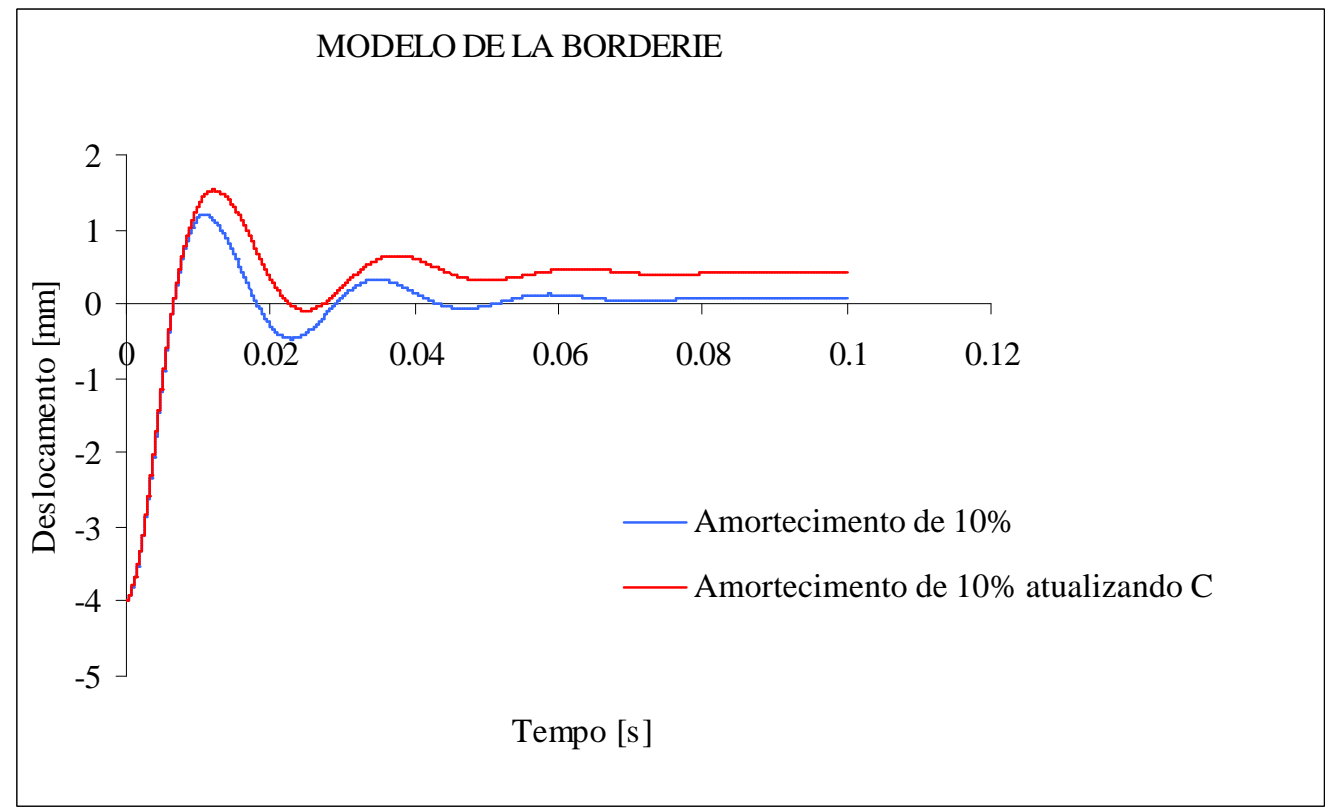

Figura 4.23- Curva deslocamento versus tempo - vibração livre amortecida

Comparando-se as Figuras 4.20 e 4.22, do modelo de Mazars, observa-se claramente o aparecimento do deslocamento residual e o aumento do amortecimento por efeito da plastificação do aço. No entanto, a resposta apresentada na Figura 4.23, modelo de La Borderie, a atualização da matriz de amortecimento essa redução no amortecimento é comparativamente bem menor; isso se deve ao fato deste modelo 
permitir a recuperação da rigidez com o fechamento de fissuras e também levar em conta as deformações anelásticas no concreto.

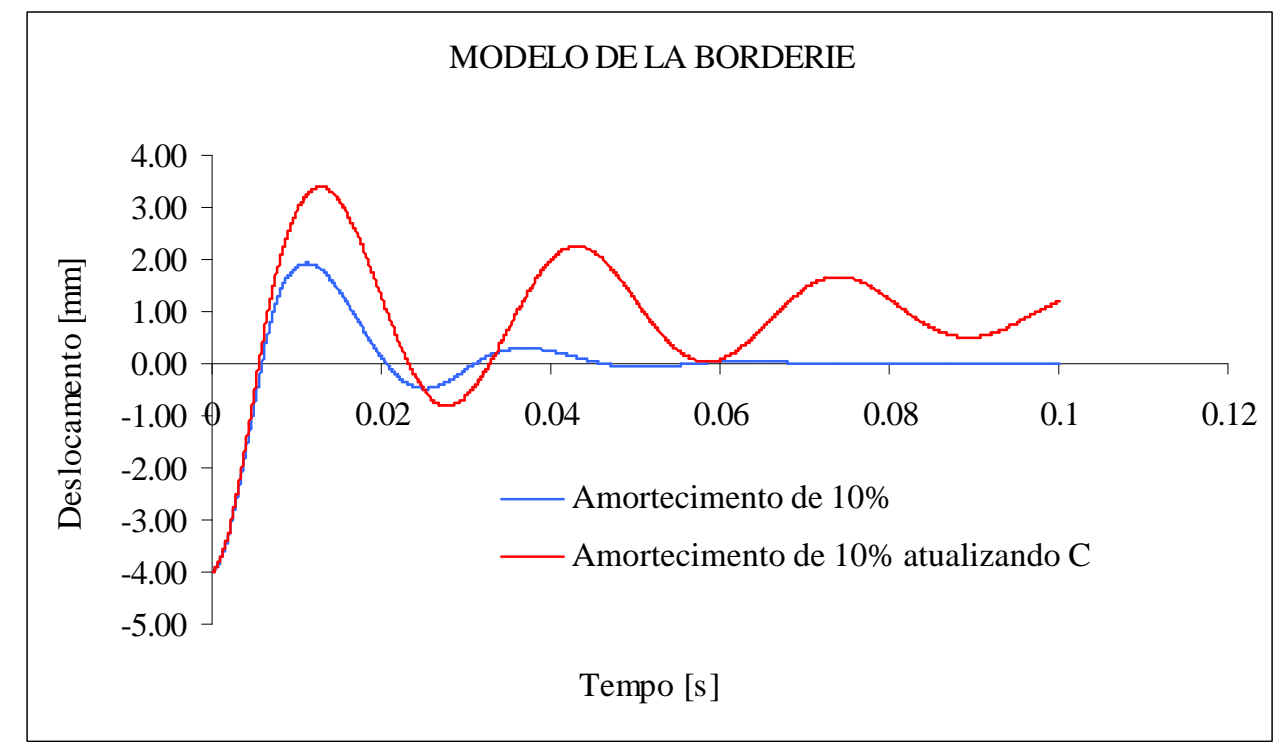

Figura 4.23a- Curva deslocamento versus tempo - vibração livre amortecida

$\mathrm{Na}$ Figura 4.23a apresentam-se as respostas empregando-se o modelo de dano de La Borderie sem a consideração de deformações anélasticas no concreto. Verifica-se que a diminuição do amortecimento com a atualização da matriz de amortecimento é análoga à resposta apresentada pelo modelo de dano de Mazars, ou seja, a estrutura apresentando um certo nível de danificação possui uma menor capacidade de amortecimento.

Objetivando-se ilustrar o efeito dos diferentes processos dissipativos sobre as respostas em velocidade e aceleração, nas Figuras 4.24 e 4.25 estão apresentadas as velocidades e acelerações, respectivamente, para um ponto situado na seção do meio do vão da viga, para o caso de vibração livre não amortecida, $\mathrm{d}=4 \mathrm{~mm}$; o aço é considerado elástico. 


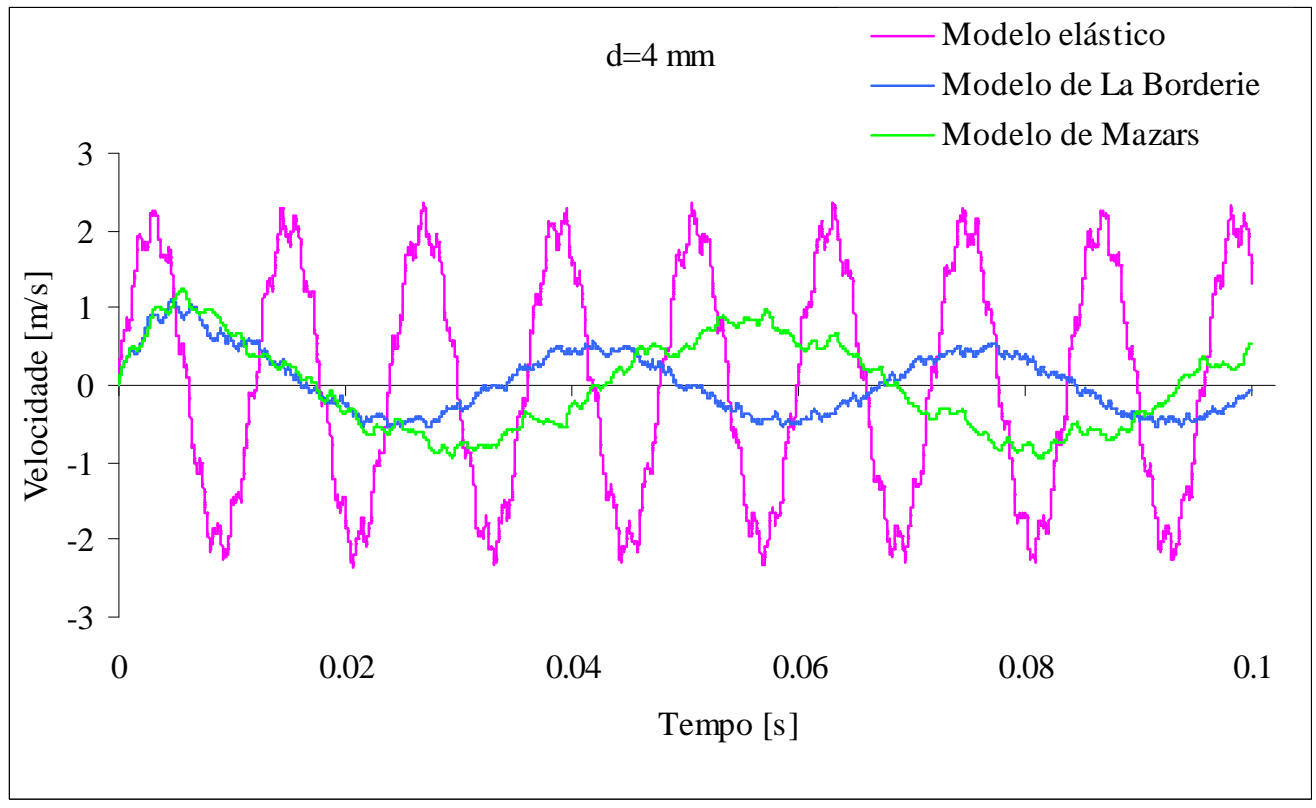

Figura 4.24- Curva velocidade do meio da viga versus tempo - vibração livre não amortecida

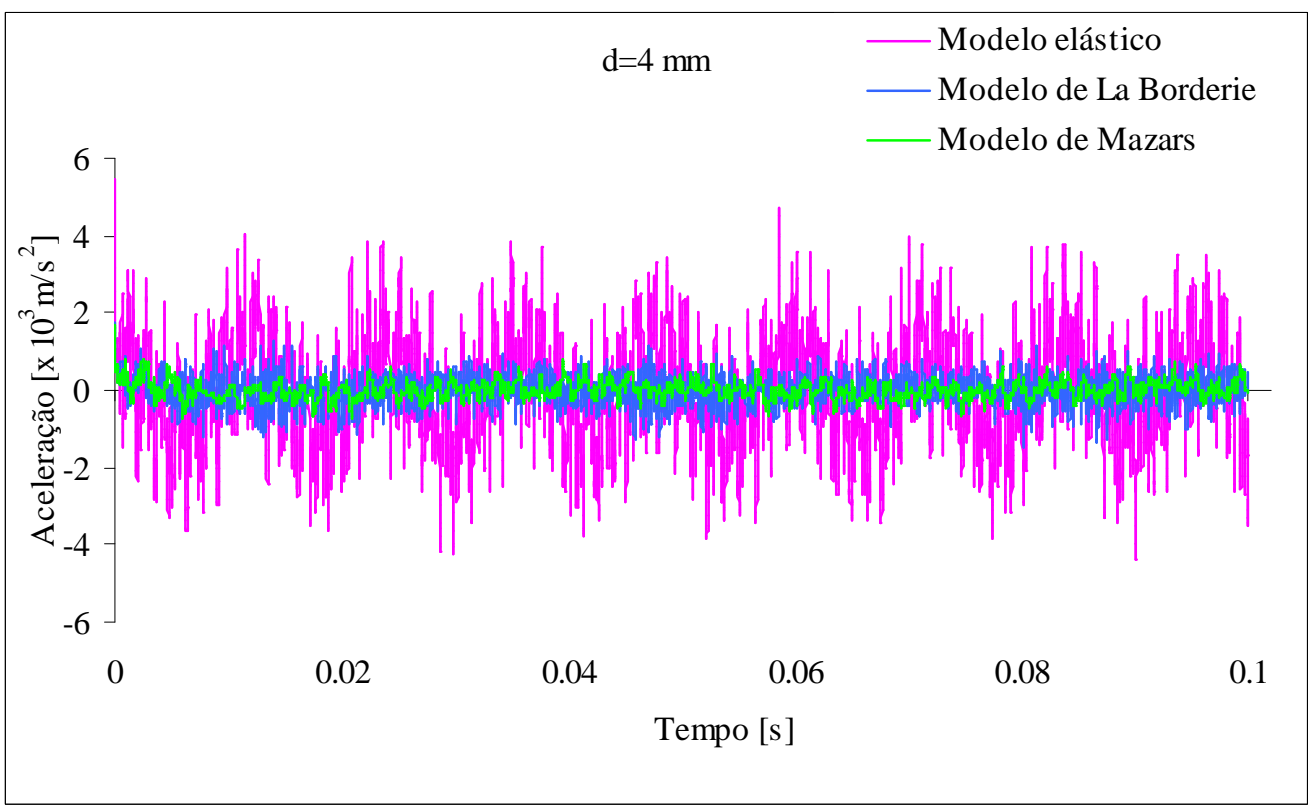

Figura 4.25- Curva aceleração do meio da viga versus tempo - vibração livre não amortecida

Pode-se observar que a danificação e conseqüente perda de rigidez diminuem a velocidade e a aceleração do ponto analisado.

Nas Figuras 4.26, 4.27 e 4.28 estão ilustrados os efeitos da danificação do concreto sobre as variações no tempo das frequências de vibração associadas ao primeiro modo de vibração da estrutura. Consideram-se os casos de vibrações forçada (caso 1 
do Quadro 4.1) e livre, sem amortecimento. Em todas as análises o aço tem comportamento elástico.

No caso da vibração forçada, pode-se interpretar que em cada instante a frequência relativa ao primeiro modo de vibração representa a resposta que a viga apresentaria se passasse vibrar livremente e, portanto, regida pela relação (4.24), com um certo nível de dano, produzido pela carga de $25 \mathrm{kN}$.

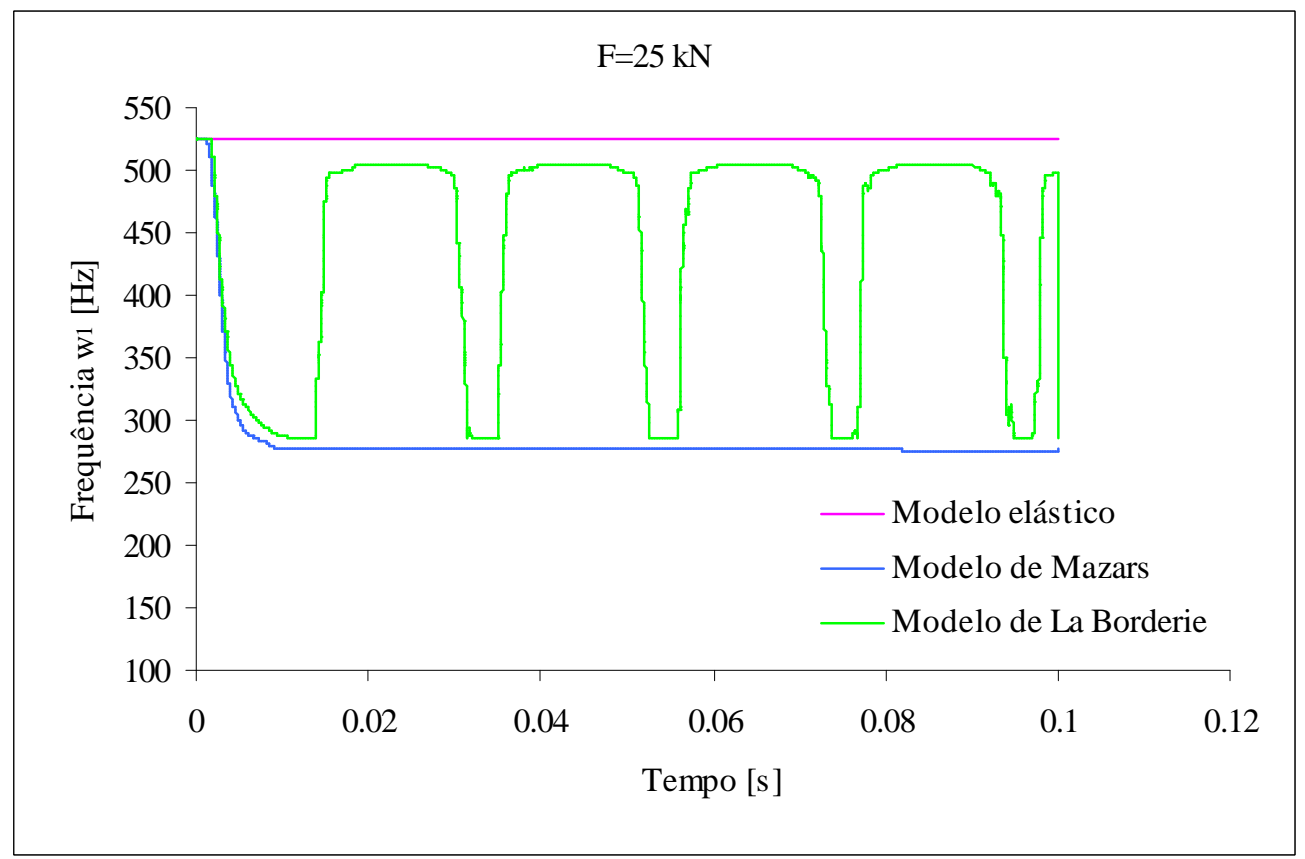

Figura 4.26- Curva primeiro modo de vibração livre versus tempo - vibração forçada

Observando-se a Figura 4.26, empregando-se o modelo de Mazars, verifica-se que a evolução do dano diminui o valor da frequiência correspondente ao primeiro modo de vibração livre da estrutura, tal fenômeno pode ser observado no intervalo de $0 \mathrm{~s}$ a aproximadamente $0.01 \mathrm{~s}$. A partir do instante $0.01 \mathrm{~s}$ o valor da freqüência passa a se manter constante devido ao fato de não se ter mais evolução do dano. Com o modelo de La Borderie resultam ciclos de aumento e decréscimo da freqüência devidos ao processo de fechamento e abertura de fissuras. Nesses ciclos há intervalos nos quais freqüência se mantém praticamente constante, porque nesses intervalos não se tem evolução no processo de danificação. 


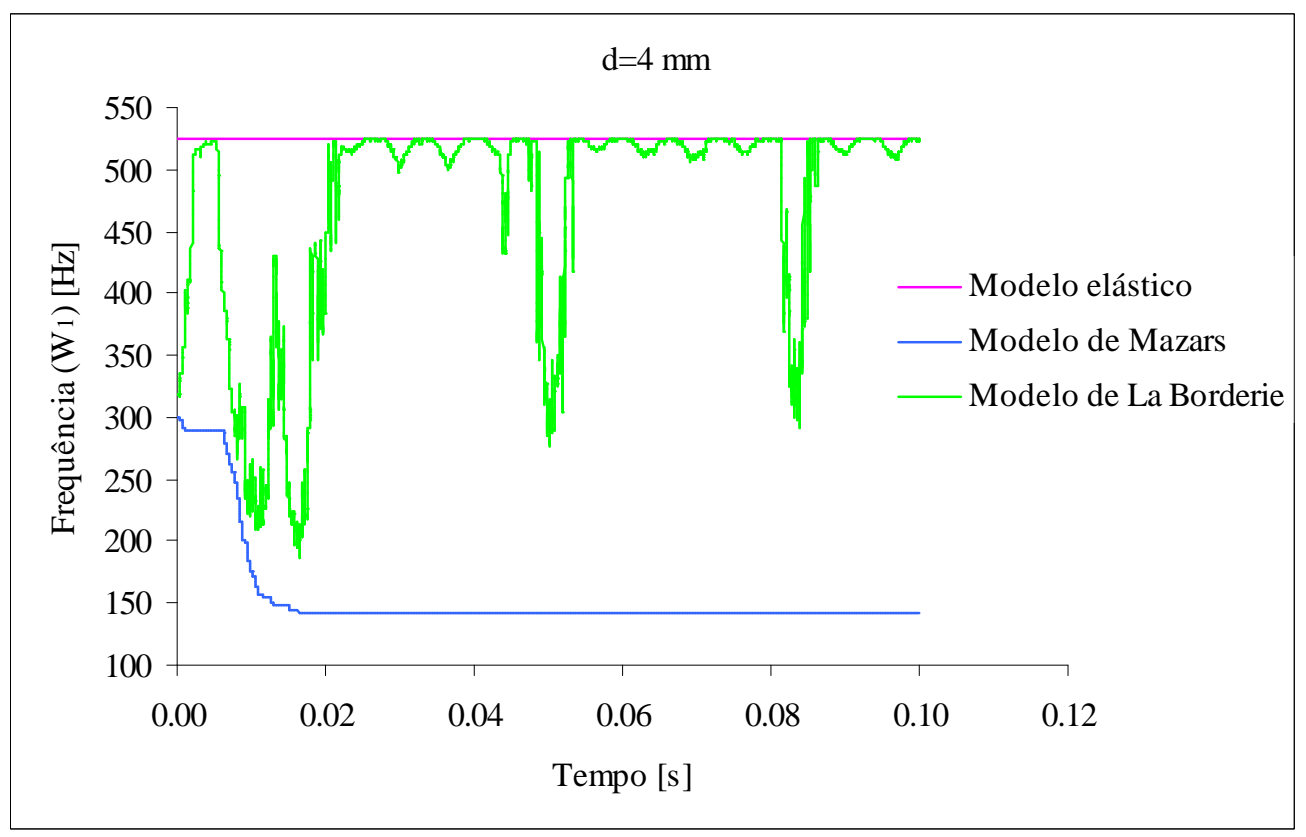

Figura 4.27- Curva primeiro modo de vibração livre versus tempo - vibração livre

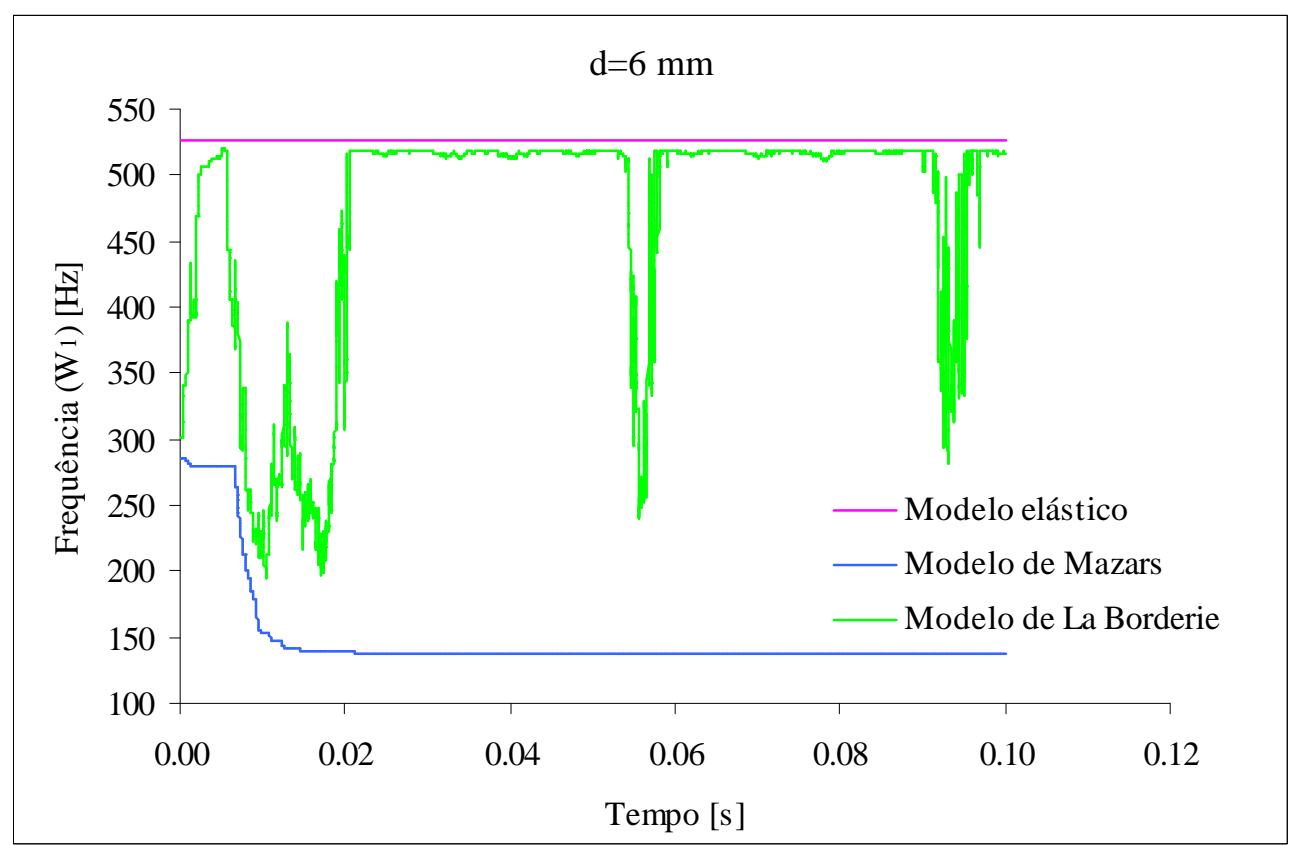

Figura 4.28- Curva primeiro modo de vibração livre versus tempo - vibração livre

Observando-se as Figuras 4.27 e 4.28 verifica-se uma diminuição no valor da freqüência correspondente ao primeiro de vibração livre da estrutura com o aumento do dano. Observa-se que para ambos os modelos de dano empregados a estrutura no 
instante $\mathrm{t}=0 \mathrm{~s}$ apresenta uma frequiência menor do que a do modelo elástico; tal fato ocorre porque a análise dinâmica se inicia com a estrutura já danificada.

$\mathrm{Na}$ resposta obtida empregando-se o modelo de Mazars a freqüência diminui enquanto o dano evolui. Porém, para o modelo de La Borderie a alteração apresentada pela freqüência reflete o efeito do fechamento das fissuras e das deformações permanentes do concreto devido à danificação. De fato durante alguns períodos o valor da freqüência aproxima-se do valor obtido para a estrutura sem dano. Por exemplo, no intervalo de 0.001 a mais ou menos $0.008 \mathrm{~s}$ tem-se um aumento considerável no valor da freqüência, este aumento reflete o ganho de rigidez pelo processo de fechamento de fissuras. A variação na freqüência no intervalo de 0.01 a mais ou menos $0.02 \mathrm{~s}$ se deve ao processo de danificação e plastificação do concreto. Na Figura 4.28 no intervalo de $0.028 \mathrm{~s}$ a mais ou menos $0.055 \mathrm{~s}$ a freqüência se mantém praticamente constante isso porque nesse intervalo não se tem uma evolução forte nos processos de danificação.

Vale ressaltar, que no gráfico da Figura 4.27 os valores máximos das freqüências para os modelos elástico e de La Borderie são $525.4836 \mathrm{~Hz}$ e $524.4801 \mathrm{~Hz}$, respectivamente.

Com o objetivo de observar o que acontece quando a carga imposta apresenta variação de sentido, seguem abaixo os resultados obtidos considerando-se a mesma viga com carga $\mathrm{P}(\mathrm{t})$ apresentando a variação harmônica com o tempo ilustrada na Figura 4.29.

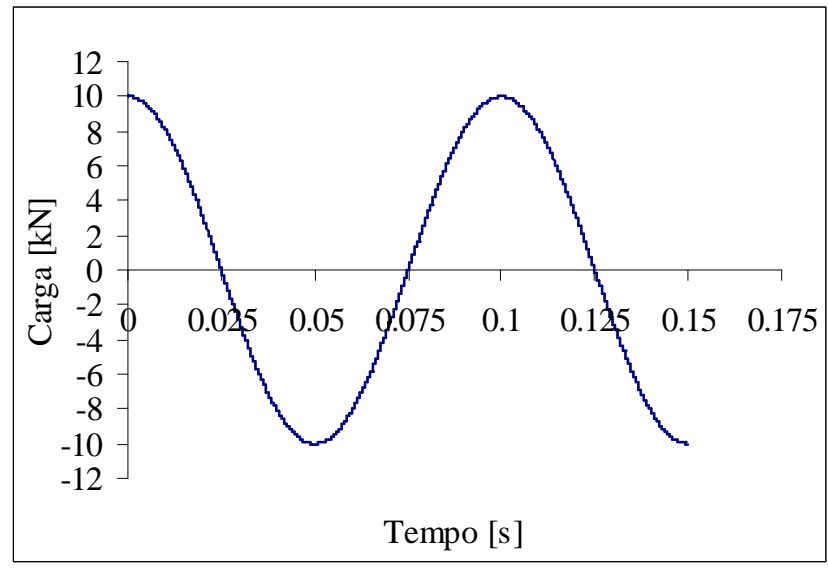

Figura 4.29- Variação da força $\mathrm{P}(\mathrm{t})=10 \cos \left(\omega_{\mathrm{e}} \mathrm{t}\right) \operatorname{com}$ o tempo $-\omega_{\mathrm{e}}=62.832 \mathrm{~Hz}$ 
Em primeiro lugar, na Figura 4.30 apresenta-se o resultado considerando-se a linearidade física.

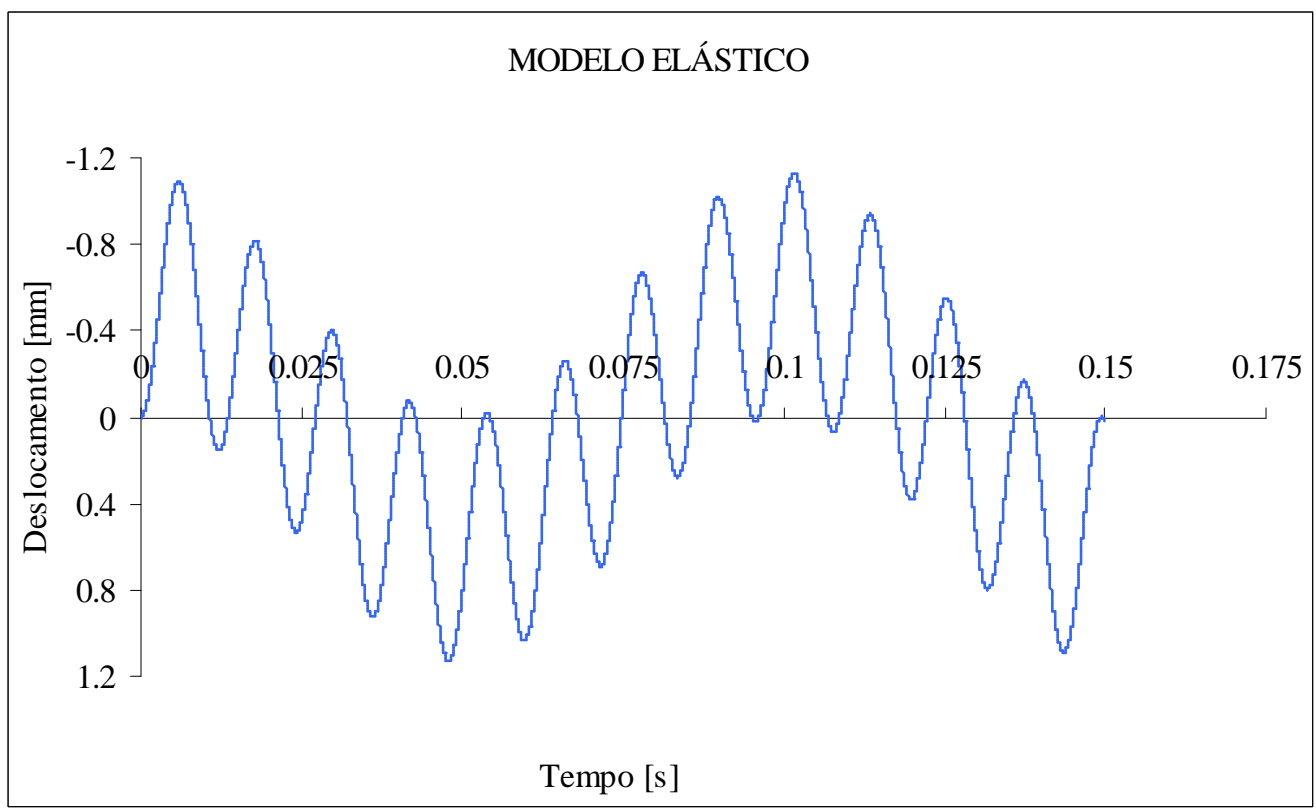

Figura 4.30- Curva deslocamento vertical versus tempo - vibração forçada não amortecida

Na Figura 4.31 apresentam-se os resultados obtidos considerando-se somente a nãolinearidade física do concreto segundo os modelos de dano de Mazars e de La Borderie.

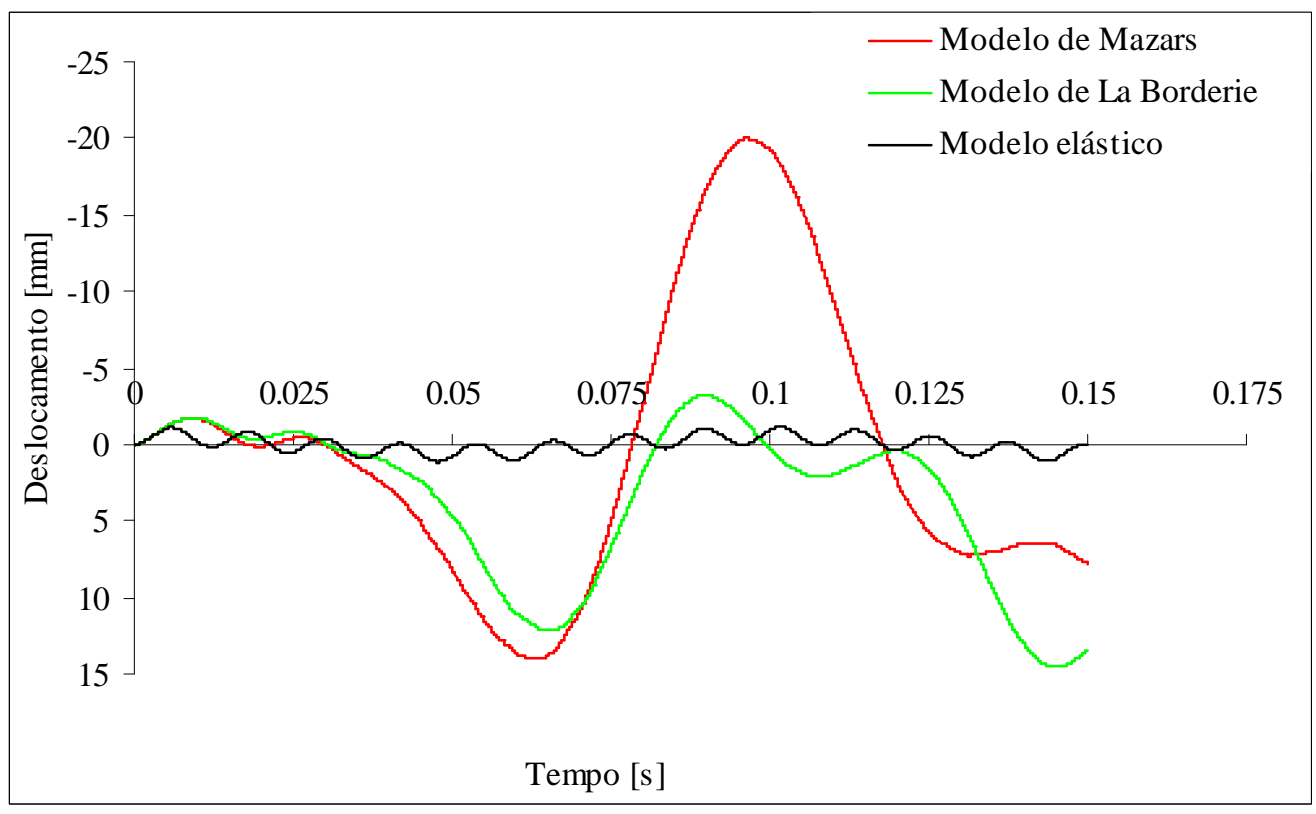

Figura 4.31- Curva deslocamento vertical versus tempo - vibração forçada não amortecida 
Na Figura 4.31 observa-se que o efeito da danificação aumenta a amplitude e modifica o período de vibração da estrutura. Neste caso, observa-se também a diferença das respostas obtidas considerando-se os dois modelos de dano, para o modelo de Mazars, ou seja, quando ocorre a inversão do carregamento os deslocamentos tornam-se bem maiores do que os obtidos com o modelo de La Borderie.

Na Figura 4.32 apresentam-se os resultados obtidos considerando-se as nãolinearidades físicas do concreto e do aço.

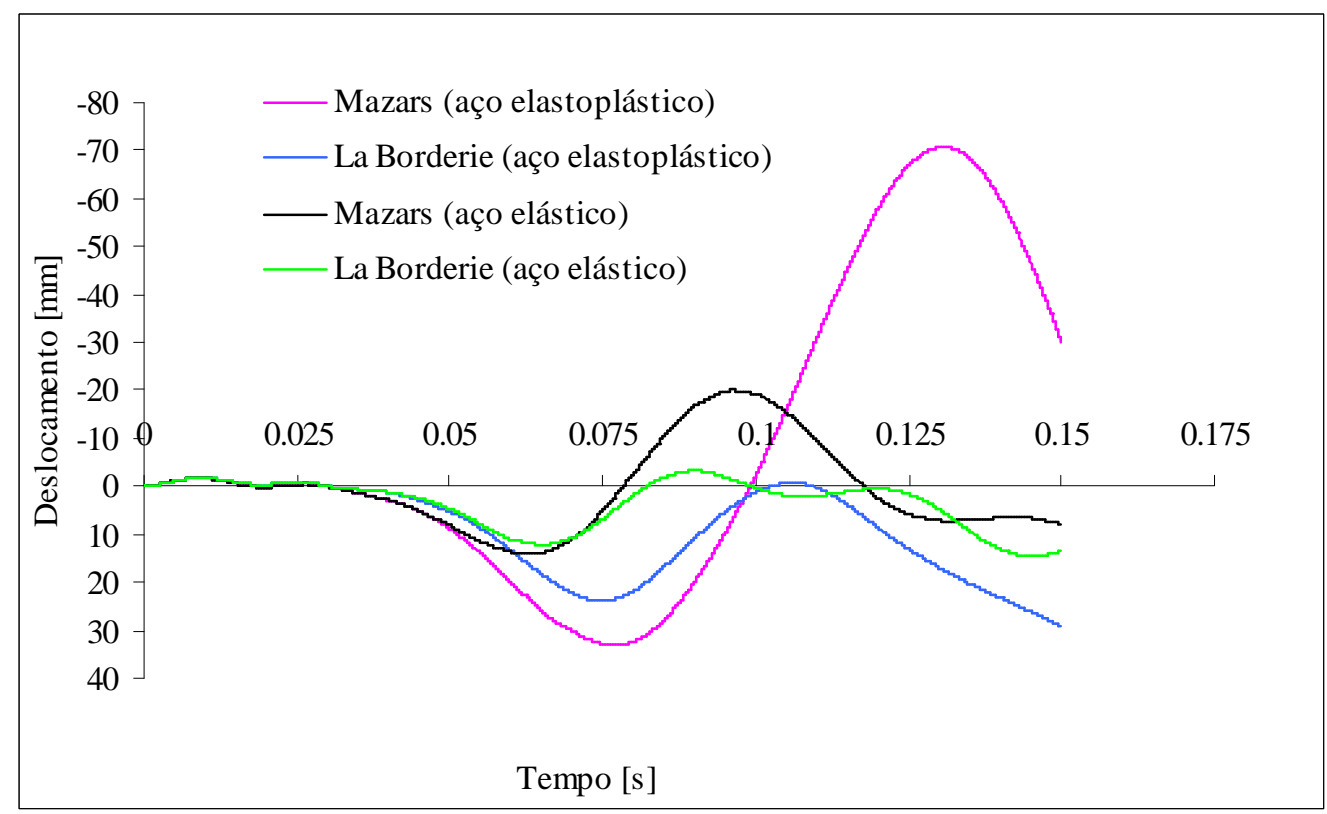

Figura 4.32- Curva deslocamento vertical versus tempo - vibração forçada não amortecida

Observando-se a Figura 4.32 verifica-se que a resposta obtida considerando-se o comportamento elastoplástico do aço, a partir de um certo instante de tempo, apresenta deslocamentos muito maiores do que quando o aço é considerado elástico. Neste caso, em que há uma inversão de carregamento e um maior efeito da nãolinearidade dos materiais, apesar de não se poder afirmar de modo definitivo, o modelo de Mazars parece levar a resultados exagerados em termos de deslocamentos.

Com o objetivo de observar o que acontece quando a carga imposta apresenta uma outra variação harmônica de sentido, seguem abaixo os resultados obtidos 
considerando-se a mesma viga com carga $\mathrm{P}(\mathrm{t})$ apresentando a variação com o tempo ilustrada na Figura 4.33.

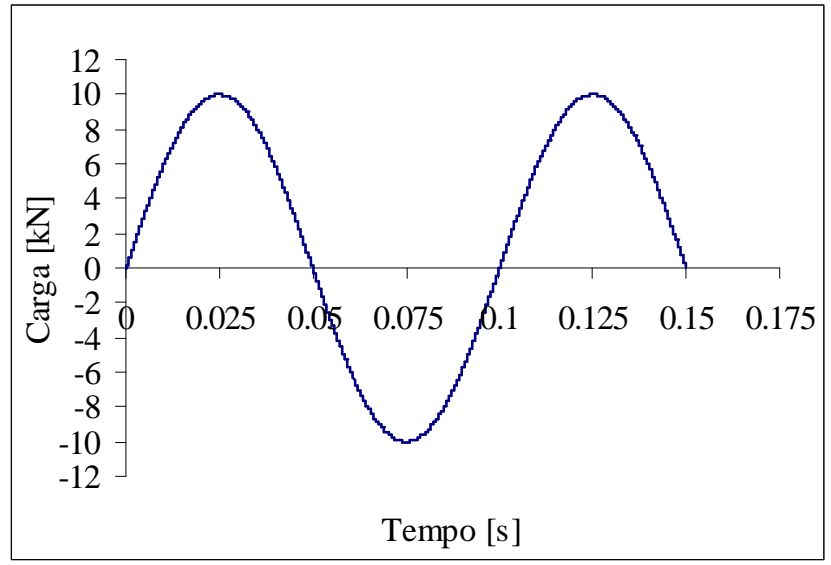

Figura 4.33- Variação da força $\mathrm{P}(\mathrm{t})=10 \operatorname{sen}\left(\omega_{\mathrm{e}} \mathrm{t}\right)$ com o tempo $-\omega_{\mathrm{e}}=62.832 \mathrm{~Hz}$

Em primeiro lugar, na Figura 4.34 apresenta-se o resultado considerando-se a linearidade física.

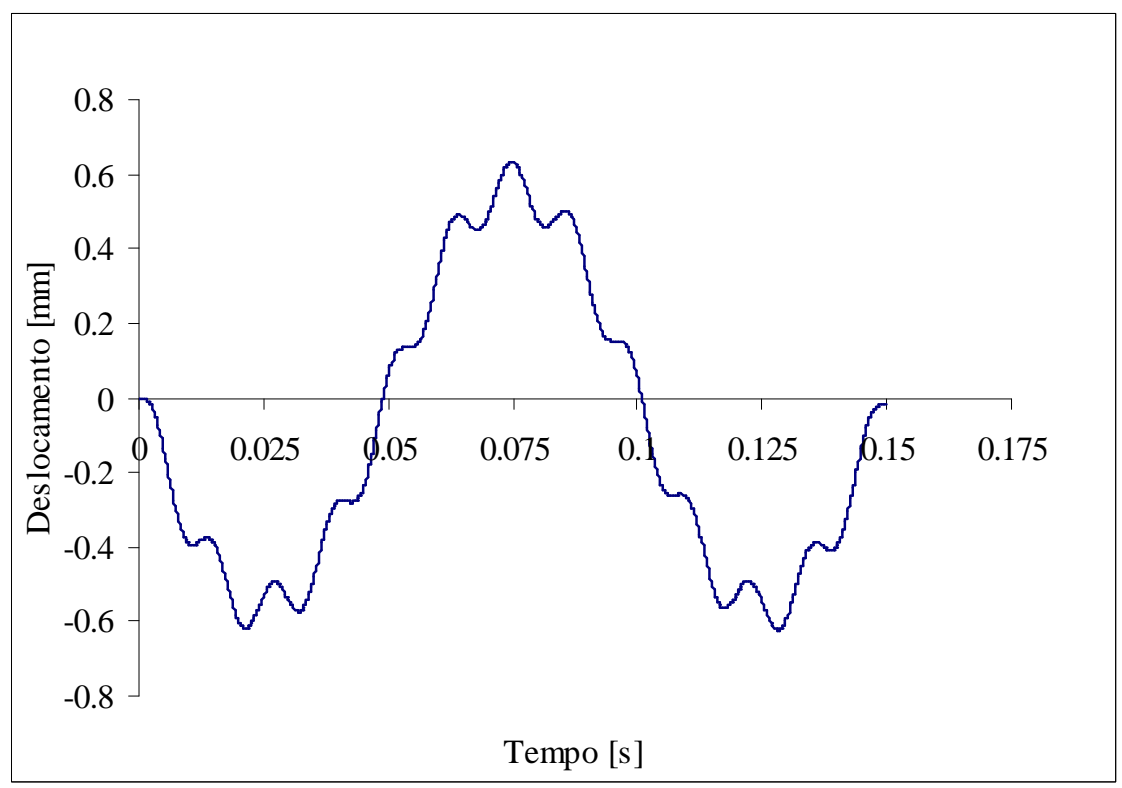

Figura 4.34- Curva deslocamento vertical versus tempo - vibração forçada não amortecida

Na Figura 4.35 apresentam-se os resultados obtidos considerando-se somente a nãolinearidade física do concreto segundo os modelos de dano de Mazars e de La Borderie. 


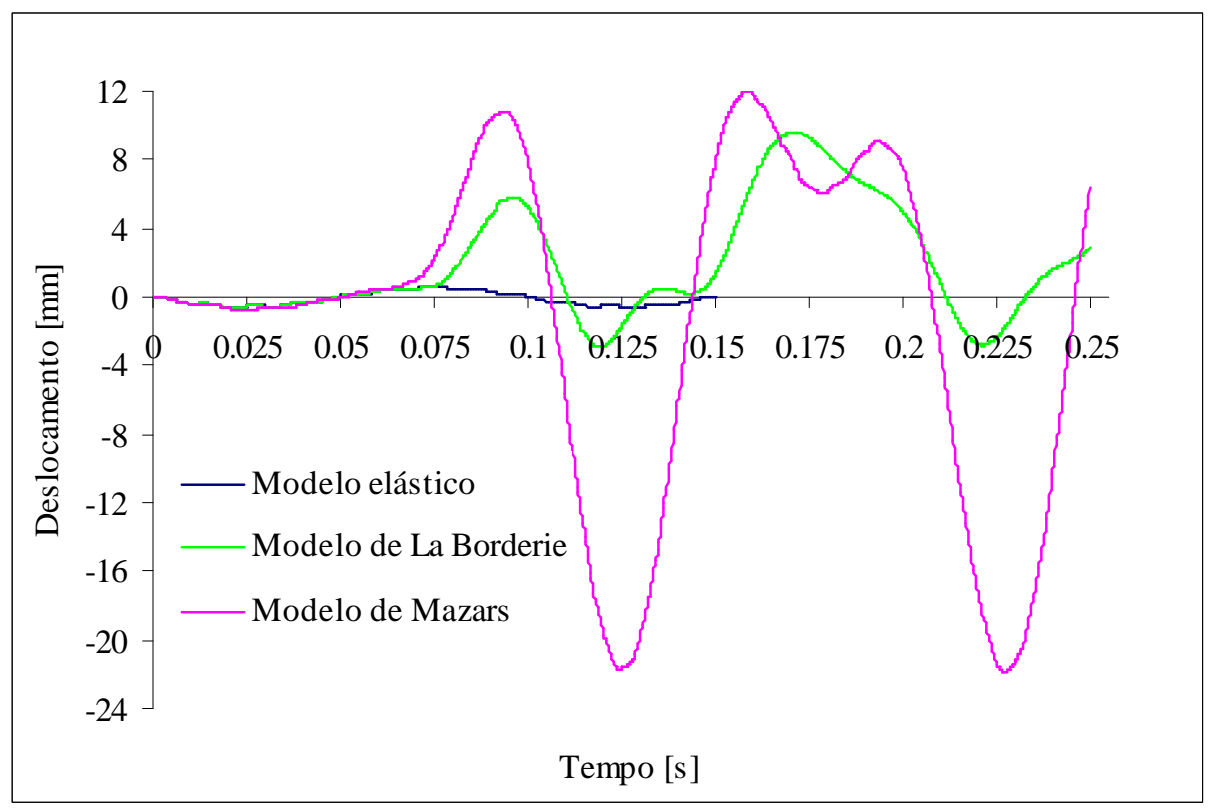

Figura 4.35- Curva deslocamento vertical versus tempo - vibração forçada não amortecida

Na Figura 4.36 apresentam-se os resultados obtidos considerando-se as nãolinearidades físicas do concreto e do aço.

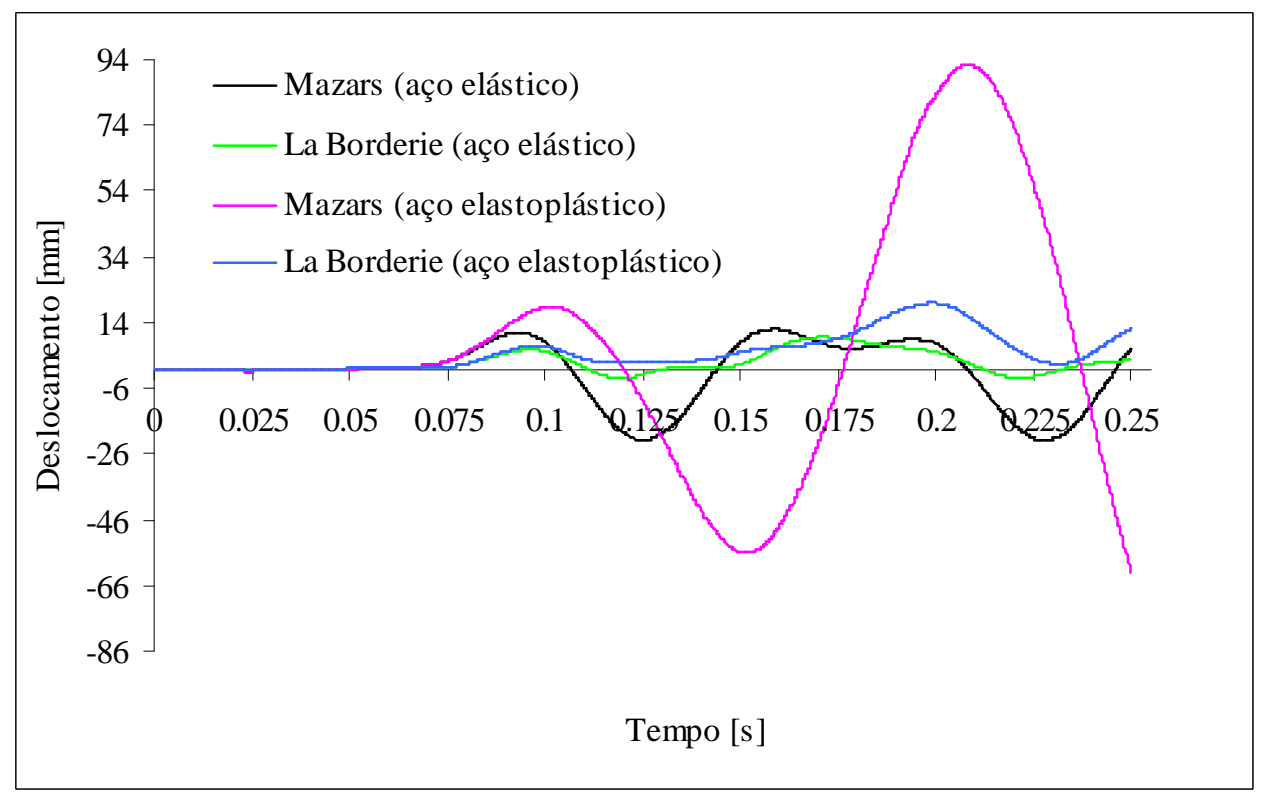

Figura 4.36- Curva deslocamento vertical versus tempo - vibração forçada não amortecida

As observações sobre os resultados são análogos às feitas para o carregamento harmônico cossenoidal.

Em princípio, pode-se concluir que entre os modelos de dano apresentados, o mais adequado para uma análise dinâmica é o modelo de dano de La Borderie. 


\section{SÍNTESE DO TRABALHO E CONCLUSÕES}

"Não conseguimos encontrar respostas para todos os nossos problemas. As que encontramos apenas nos levaram a formular novas questões. Sentimo-nos hoje tão confusos como antes. Acreditamos, entretanto, que estamos confusos num nível mais alto e sobre coisas mais importantes."

Autor desconhecido

\subsection{CONSIDERAÇÕES FINAIS E CONCLUSÕES}

No trabalho apresentou-se um estudo sobre os comportamentos não-lineares nas respostas de estruturas reticulares planas. As formulações do equilíbrio estático e dinâmico fundamentaram-se na aplicação do Princípio dos Trabalhos Virtuais segundo as descrições lagrangianas total e atualizada.

Primeiramente apresentou-se a não-linearidade geométrica em treliças planas, utilizando-se uma formulação lagrangiana total e empregando-se as medidas de deformações de Green e linear. Nesse caso, o principal objetivo foi mostrar a importância de medidas de deformação e tensão conjugadas numa abordagem consistente; quando esta consistência é verificada os resultados são independentes da escolha dos pares de tensão e deformação.

Restringindo-se ainda à não-linearidade geométrica, a eficiência das descrições lagrangianas total e atualizada foi verificada em exemplos clássicos de vigas, cujas respostas analíticas são conhecidas. 
A mecânica do dano foi empregada para a consideração da não-linearidade física nas estruturas em concreto. Particularmente, a equação constitutiva utilizada para a análise do comportamento do concreto na tração e na compressão uniaxial baseou-se nos modelos de danificação apresentados originalmente por MAZARS (1984) e LA BORDERIE (1991).

Nas integrações numéricas relativas à determinação da matriz de rigidez tangente e do vetor de esforços nodais internos aplicaram-se as quadraturas de Gauss, GaussLobatto e o método de integração por estratos, os quais se mostraram bastante eficientes no caso de elementos em concreto armado.

Os exemplos de aplicação consistindo de análises estáticas, empregando-se os dois modelos de dano para a consideração da não-linearidade física, apresentaram boa concordância com resultados experimentais disponíveis. As aplicações realizadas indicaram que a modelagem adotada é potencialmente interessante para a análise de estruturas planas em concreto armado em regimes de serviço (fissuração difusa), nos quais a consideração da não-linearidade física é, de fato, necessária. Verificou-se também que a combinação das não-linearidades física e geométrica em alguns casos é absolutamente necessária para a obtenção de uma resposta numérica de boa qualidade.

Vale ressaltar que a boa qualidade da resposta numérica com modelos de dano depende fortemente de uma conveniente identificação paramétrica. Nos casos estudados, os valores médios adotados conduziram a bons resultados, o que nem sempre poderá ocorrer.

$\mathrm{Na}$ análise dinâmica, para integração no domínio do tempo, utilizou-se o procedimento implícito de Newmark combinado com o procedimento incremental e iterativo de Newton-Raphson, porém outros métodos poderiam ter sido empregados. Observou-se, como era de se esperar, que a resposta dinâmica da estrutura sofre a influência do acréscimo de danificação induzido pelas forças inerciais. Apesar de não ter sido possível realizar um confronto com resultados experimentais, as respostas obtidas nos diferentes exemplos analisados mostraram-se bastante coerentes. 
Sobre a análise dinâmica, vale detalhar algumas conclusões específicas:

Observando-se as respostas das análises dinâmicas considerando-se a não-linearidade do concreto, verifica-se que elas são diferentes empregando-se os modelos de dano de Mazars e de La Borderie.

Os resultados obtidos em geral, evidenciam que os seguintes aspectos devem ser levados em conta para a simulação numérica:

- diminuição da rigidez do material com a danificação;

- recuperação da rigidez quando ocorre fechamento de fissuras;

- deformações anelásticas provocadas pela danificação.

Diante destas considerações, pelas suas características e sobretudo pelos resultados obtidos nas simulações numéricas, o modelo de dano de La Borderie é mais adequado que o modelo de dano de Mazars nas análises dinâmicas.

Para os estudos sobre amortecimento e frequiência de vibração utilizou-se, neste trabalho, para a matriz de amortecimento as expressões (4.17) ou (4.21), ou seja considerou-se uma matriz de amortecimento constante ou variável em função do nível de dano durante toda a análise. Um resultado importante obtido da simulação numérica é que a danificação diminui o amortecimento e a freqüência de vibração livre da estrutura. Essa conclusão está de acordo com os resultados experimentais de ensaios realizados em vigas de concreto armado, apresentados por RIERA \& RIOS (2000).

Apesar da concordância dos resultados numéricos com os experimentais, essa conclusão ainda não deve ser tomada como definitiva pois, existem, na literatura, algumas divergências quanto a se utilizar o modelo de Hayleigh para a consideração do amortecimento. MAZARS et al (2000), por exemplo, propõem um modelo de dano incluindo o comportamento histerético residual alegando que isto evita, em certos casos, uma representação fisicamente não coerente da dissipação por danificação que pode acontecer quando se usa amortecimento viscoso. 


\subsection{SUGESTÕES PARA TRABALHOS FUTUROS}

Obviamente, do ponto de vista das aplicações a outros tipos de elementos estruturais, sugere-se a extensão da formulação apresentada para o caso de placas e cascas, por exemplo.

Sob o ponto de vista da avaliação e confirmação numérica do efeito da danificação, sugere-se a implementação de outros modelos de dano.

Quanto à análise dinâmica pode-se aprofundar os estudos no domínio da freqüência.

Finalmente, talvez de maior interesse, sugere-se o desenvolvimento de um programa experimental em laboratório para gerar resultados para confronto e verificação das análises dinâmicas. 


\section{REFERÊNCIAS BIBLIOGRÁFICAS}

ÁLVARES, M.S. (1999). Contribuição ao estudo e emprego de modelos simplificados de dano e plasticidade para a análise de estruturas de barras em concreto armado. São Carlos. Tese (Doutorado) - Escola de Engenharia de São Carlos, Universidade de São Paulo.

ÁLVARES, M.S. (1993). Estudo de um modelo de dano para o concreto: formulação, identificação paramétrica e aplicação com o emprego do método dos elementos finitos. 123p. São Carlos. Dissertação (Mestrado) - Escola de Engenharia de São Carlos, Universidade de São Paulo.

ARGYRIS, J.; MLEJNEK, H. P. (1991). Dynamics of structures. Noth-Holland. v.5

BALBO, A.R. (1998). Contribuição à formulação matemática de modelos constitutivos para materiais com dano contínuo. São Carlos. 222p. Tese (Doutorado) - Escola de Engenharia de São Carlos, Universidade de São Paulo.

BATHE, K.-J. (1996). Finite element procedures. New Jersey, Prentice Hall.

BOTTA, A.S. (1998). Cálculo de esforços e deslocamentos em estruturas reticuladas considerando-se a mecânica do dano para a modelagem do concreto armado. São Carlos. 98p. Dissertação (Mestrado) - Escola de Engenharia de São Carlos, Universidade de São Paulo.

BRASIL, R.M.L.R.F.; MAZZILLI, C.E.N. (1993). A general FEM formulation of nonlinear dynamics applied to accessing the statical loading effect upon the dynamic response of planar frames. Appl Mech Rev, v.46, n.11, part 2, p.110-117.

BRASIL, R.M.L.R.F. (1990). Não-linearidade geométrica na dinâmica de estruturas aporticadas planas: um tratamento pelo método dos elementos finitos. São Paulo. Tese (Doutorado) - Escola Politécnica, Universidade de São Paulo.

CHEN, W.F. (1982). Plasticity in reinforced concrete. New York, McGraw-Hill.

CLOUGH, R.W.; PENZIEN, J. (1993). Dynamics of structures. 2.ed. New York, McGraw-Hill.

COOK, R. D.; MALKUS, D. S. ; PLESHA, M. E. (1989). Concepts and applications of finite element analysis. New York, John Wiley. 
CORRÊA, M.R.S. (1991). Aperfeiçoamento de modelos usualmente empregados no projeto de sistemas estruturais de edifícios. São Carlos. 331p. Tese (Doutorado) Escola de Engenharia de São Carlos, Universidade de São Paulo.

CRISFIELD, M.A. (1991). Non-linear finite element analysis of solids and structures. New York, John Wiley. v.1.

DESAI, C.S.; ABEL, J.F. (1972). Introduction to the finite element methods. New York, Van Nostrand Reinhold Company.

DRIEMEIER, L. (1999). Contribuição ao estudo da localização de deformações com modelos constitutivos de dano e plasticidade. São Carlos. 101p. Tese (Doutorado) - Escola de Engenharia de São Carlos, Universidade de São Paulo.

DRIEMEIER, L. (1995). Considerações sobre a fadiga em metais e o comportamento do concreto sob solicitação cíclica. São Carlos. 120p. Dissertação (Mestrado) - Escola de Engenharia de São Carlos, Universidade de São Paulo.

ELIAS, Z.M. (1986). Theory and methods of structural analysis. John Wiley \& Sons.

EL-METWALLY, S.E.; EL-SHAHHAT, A.M.; CHEN, W.F. (1990). 3-D nonlinear analysis of R/C slender columns. Computers and Structures, v.37, n.5, p.863-872.

GARCIA, L.F.T.; VILLAÇA, S.F. (1999). Introdução à elasticidade não linear. COPPE/UFRJ. $3^{\mathrm{a}}$ ed.

HATZIGEORGIOU, G.D.; BESKOS, D.E. (2000). Dynamic response of 3-D elastoplastic or damaged structures by BEM [CD-Rom]. In: ECCOMAS 2000, Barcelona, 2000. Proceedings. 9p.

HINTON, E. (1993). Introduction to nonlinear finite element. Glasgow, UK, NAFEMS.

HUGHES, T.J.R. (1987). The finite element method - linear static and dynamic finite element analysis. Englewood Cliffs, Prentice-Hall International.

KATTAN, P.I.; VOYIADJIS, G.Z. (1990). A coupled theory of damage mechanics and finite strain elasto-plasticity-I. Damage and elastic deformations. International Journal Engineering Science, v.28, n.5, p.421-435.

LA BORDERIE, C. (1991). Phenomenes unilateraux dans un materiau endommageable: modelisation et application a l'analyse de structures en beton. These de Doctorat de l'Universite Paris.

LAVALL, A.C.C. (1996). Uma formulação consistente para análise não-linear de pórticos planos de aço considerando imperfeições iniciais e tensões residuais. São Carlos. 265p. Tese (Doutorado) - Escola de Engenharia de São Carlos, Universidade de São Paulo. 
LEMAITRE, J. (2000). Some open problems in damage mechanics. In: BENALLAL, A. ed. Continuous damage and fracture. Elsevier. p.1-5.

LEMAITRE, J. (1992). A course on damage mechanics. Springer-Verlag.

LEMAITRE, J.; CHABOCHE, J-L. (1990). Mechanics of solid materials. Cambridge University Press.

MATTIASSON, K. (1981). Numerical results from large deflection beam and frame problems analysed by means of elliptic integrals. International Journal for Numerical Methods in Engineering, v.17, n.1, p.145-153.

MAZARS, J.; RAGUENEAU, F.; PIJAUDIER-CABOT, G. (2000). Continuum damage modelling for concrete structures in dynamic situations. In: CONTINUUM DAMAGE MECHANICS OF MATERIALS, Cachan, France, oct.2000. Damage mechanics of materials and structures. Cachan, CNRS. 36p. (Lectures series)

MAZARS, J. (1984). Application de la mécanique de l'endommagement au compotaement non lineaire et à la rupture du béton de structure. $\mathrm{PhD}$ thesis, Université Paris 6.

MAZZILLI, C.E.N. (1988). Considerações sobre não-linearidade geométrica em estruturas reticuladas planas. Anais EPUSP, Engenharia Civil, Engenharia de Estruturas e Fundações, v.1, série A. pt.2, p.653-676.

NEVES, R.A. (2000). Cálculo de esforços e deslocamentos em estruturas de pisos de edifícios, considerando-se a influência das tensões cisalhantes. São Carlos. 113p. Dissertação (Mestrado) - Escola de Engenharia de São Carlos, Universidade de São Paulo.

NOVOTNY, A.A.; LUERSEN, M.A.; PEREIRA, J.T.; SELKE, C.A.C. (1994). Análise comparativa entre alguns procedimentos de integração na espessura para problemas elastoplásticos em placas semi-espessas. In: CONGRESSO LATINOAMERICANO SOBRE MÉTODOS COMPUTACIONAIS EM ENGENHARIA, 15., Belo Horizonte. Anais. v.2, p.1569-1578.

ORAN, C.; KASSIMALI, A. (1976). Large deformations of framed structures under static and dynamic loads. Computers and Structures, v.6, p.539-547.

PAULA, C.F. (1997). Estudo das descrições lagrangiana e euleriana na análise não-linear geométrica com o emprego do método dos elementos finitos. São Carlos. 112p. Dissertação (Mestrado) - Escola de Engenharia de São Carlos, Universidade de São Paulo.

PAZ, M. (1991). Structural dynamics: theory and computation. New York, VNR.

PEREGO, M.A. (1990). Danneggiamento dei materiali lapidei: leggi costitutive, analisis per elementi finiti ed applicazioni. Tese (Laurea) - Politecnico de Milano. 
PETERSON, A.; PETERSSON, H. (1985). On finite element analysis of geometrically nonlinear problems. Computer Methods in Applied Mechanics and Engineering, v.51, p.277-286.

PIMENTA, P.M. (1988). Análise não-linear de pórticos planos. Anais EPUSP, Engenharia Civil, Engenharia de Estruturas e Fundações, v.1, série A, pt.1, p.561-582.

PIMENTA, P.M. (1996). Análise não-linear de pórticos planos: teoria exata vs teoria de segunda ordem. Anais EPUSP, Engenharia Civil, Engenharia de Estruturas e Fundações. 17p.

PITUBA, J.J.C.; PROENÇA, S.P.B.; ÀlVARES, M.S. (1999). Estudo do desempenho de modelos de dano para estruturas reticulares em concreto armado [CD-Rom]. In: XX CILAMCE, São Paulo, 1999.

PITUBA, J.J.C. (1998). Estudo e aplicação de modelos constitutivos para o concreto fundamentados na mecânica do dano contínuo. São Carlos. 130p. Dissertação (Mestrado) - Escola de Engenharia de São Carlos, Universidade de São Paulo.

RIERA, J.D.; RIOS, R.D. (2000). Evolução do amortecimento com o nível de dano em estruturas de concreto armado. [CD-Rom]. In: JORNADAS SUDAMERICANAS DE INGENIERIA ESTRUCTURAL, 29., Punta Del Este, 2000. 10p.

RODRIGUES, R.O. (1997). Análise dinâmica bidimensional não-linear física e geométrica de treliças de aço e pórticos de concreto armado. São Carlos. 275p. Tese (Doutorado) - Escola de Engenharia de São Carlos, Universidade de São Paulo.

RUBERT, J.B. (1993) Estudo do desempenho de algoritmos numéricos na solução de sistemas não-lineares de estruturas formadas por barras de treliça. São Carlos. 97p. Dissertação (Mestrado) - Escola de Engenharia de São Carlos, Universidade de São Paulo.

SILVA, R.M. (1996). Análise não-linear de pórticos planos de concreto armado: modelagem numérica e avaliação dos métodos aproximados. São Carlos. 263p. Tese (Doutorado) - Escola de Engenharia de São Carlos, Universidade de São Paulo.

SOUZA LIMA, V.M.; VENÂNCIO FILHO, F. (1992) Considerações sobre a nãolinearidade geométrica de estruturas reticuladas. In: ESCOLA DE MATEMÁTICA APLICADA, 3., Laboratório de Computação Científica (CNPq), Rio de Janeiro, p.1-38.

VEIZAGA, J.E.F. (1993). Identificação de dano em estruturas pela variação das características modais. Porto Alegre. 77p. Dissertação (Mestrado) - Escola de Engenharia da Universidade Federal do Rio Grande do Sul. 
WONG, M.B.; TIN-LOI, F. (1990). Geometrically nonlinear analysis of elastic framed structures. Computers and structures, v.34, n.4, p.633-640. 


\section{BIBLIOGRAFIA CONSULTADA}

ALTENBACH, H.; MORACHKOVSKY, O; NAUMENKO, K.; SYCHOV, A. (1997). Geometrically nonlinear bending of thin-walled shells and plates under creep-damage conditions. Archieve of applied mechanics, v.67, p.339-352.

BERGAN, P.G. (1980). Solution algorithms for nonlinear structural problems. Computers and Structures, v.12, p.497-509.

BONET, J.; WOOD, R.D. (1999). Nonlinear continuum mechanics for finite element analysis. Cambridge University Press.

CARDONA, A.; HUESPE, A. (1999). Evaluation of simple bifurcation points and post-critical path in large finite rotation problems. Comput. Methods Appl. Mech. Engrg., v. 175, p.137-156.

CARDONA, A.; GERADIN, M. (1988). A beam finite element non-linear theory with finite rotations. International Journal for Numerical Methods in Engineering, v.26, p.2403-2438.

CAUVIN, A.; TESTA, R.B. (1999). Elastoplastic material with isotropic damage. International Journal of Solids and Structures, v.36, p.727-746.

CESCOTTO, S.; FREY, F.; FONDER, G. (1979). Total and updated lagrangian descriptions in nonlinear structural analysis: a unified approach. In: GLOWINSKI, R.; RODIN, E.Y.; ZIENKIEWICS, O.C., eds. Energy methods in finite element analysis. Chichester, John Wiley., p.283-296.

CHABOCHE, J.L. (1988a). Continuum damage mechanics: part I - general concepts. Journal of Applied Mechanics, v.55, p.59-64.

CHABOCHE, J.L. (1988b). Continuum damage mechanics: part II - damage growth, crack initiation, and crack growth. Journal of Applied Mechanics, v.55, p.65-72.

CILONI, A.D. (1993). Sobre o comportamento em seviço de estruturas planas de concreto armado. São Carlos. Tese (Doutorado) - Escola de Engenharia de São Carlos, Universidade de São Paulo.

COIMBRA, A.L. (1981). Novas lições de mecânica do contínuo. São Paulo, Edgard Blücher. 
DVORKIN, E.N. (1988). On a non-linear formulation for curved Timoshenko beam elements considering large displacement/rotation increments. International Journal for Numerical Methods in Engineering, v.26, p.1597-1613.

GADALA, M.S.; ORAVAS, G.AE. (1984). Survey of formulation methods and solution techniques. Computers and Structures, v.19, n.5/6, p.865-877.

GATASS, M.; ABEL, J.F. (1987). Equilibrium considerations of the updated lagrangian formulation of beam-columns with natural concepts. International Journal for Numerical Methods in Engineering, v.24, p.2119-2141.

JOHNSON, G.C.; BAMMANN, D.J. (1984). A discussion of stress rates in finite deformation problems. International Journal Solids Structures, v.20, n.8, p.725737.

JUBRAN, J.S.; COFER, W.F. (1991). Ultimate strength analysis of structural componentes using the continuum damage mechanics approach. Computers and Structures, v.39, n.6, p.741-752.

KATTAN, P.I.; VOYIADJIS, G.Z. (1990b). A coupled theory of damage mechanics and finite strain elasto-plasticity-II. Damage and finite strain plasticity. International Journal Engineering Science, v.28, n.6, p.505-524.

KOUHIA, R.; MIKKOLA, M. (1989). Tracing the equilibrium path beyond simple critical points. International Journal for Numerical Methods in Engineering, v.28, p.2923-2941.

KRAJCINOVIC, D. (1984). Continuum damage mechanics. Journal of Applied Mechanics, v.37, n.1, p.1-6.

KRAJCINOVIC, D. (1983). Constitutive equations for damaging materials. Journal of Applied Mechanics, v.50, p.355-360.

LEMAITRE, J. (1985). Coupled elasto-plasticity and damage constitutive equations. Computer Methods in Applied Mechanics and Engineering, v.51, p.31-49.

LEMAITRE, J. (1984). How to use damage mechanics. Nuclear Engineering and Design, v.80, p.233-245.

LEMAITRE, J. (1983). A continuous damage mechanics model for ductile fracture. Journal of Engineering Materials and Technology, v.107, p.83-89

LEMAITRE, J.; DUFAILLY, J. (1987). Damage measurements. Engineering Fracture Mechanics, v.28, n.5/6, p.643-661.

LO, S.H. (1992). Geometrically nonlinear formulation of 3D finite strain beam element with large rotations. Computers and Structures, v.44, n.1/2, p.147-157.

LOLAND, K.E. (1980). Continuous damage model for load-response estimation of concrete. Cement and Concrete Research, v.10, p.395-402. 
LUBLINER, J.; OLIVER, J.; OLLER, S.; OÑATE, E. (1989). A plastic-damage model for concrete. International Journal of Solids and Structures, v.25, p.299326.

LUCCIONI, B.; OLLER,S.; DANESI, R. (1996). Coupled plastic-damage model. Computer Methods in Applied Mechanics and Engineering, v.129, p.81-89.

MALVERN, L.E. (1969). Introduction to the mechanics of a continuous medium. Englewood Cliffs, Prentice Hall.

MAZZILLI, C.E.N. (1986). Comportamento não-linear de pórticos planos em regime elástico linear. In: CONGRESSO LATINO-AMERICANO SOBRE MÉTODOS COMPUTACIONAIS EM ENGENHARIA, 7. São Carlos. Anais. v.1, p.381-395

MEEK, J.L.; LOGANATHAN, S. (1990). Geometric and material non-linear behaviour of beam-columns. Computers and Structures, v.34, n.1, p.87-100.

MESCHKE, G.; LACKNER, R.; MANG, H.A. (1998). An anisotropic elastoplasticdamage model for plain concrete. International Journal for Numerical Methods in Engineering, v.42, p.703-727.

MOJIA, H.; BUFLER, H. (1999). Updated lagrangian polar decomposition method in non-linear elastoplasticity and its shell element implementation. Communications in Numerical Methods in Engineering, v.15, p.167-181.

MOITA, G.F.; CRISFIELD, M.A. (1996). A finite element formulation for 3-D continua using the co-rotational technique. International Journal for Numerical Methods in Engineering, v.39, p.3775-3792.

MURAKAMI, S. (1988). Mechanical modeling of material damage. Journal of Applied Mechanics, v.55, p.280-286.

NOGUCHI, H.; HISADA, T. (1995). Integrated FEM formutation for total/ updated lagrangian method in geometrically nonlinear problems. JSME International Journal, v.38, série A, n.1, p.23-29.

OLIVER, J.; OÑATE, E. (1986). A total lagrangian formulation for the geometrically nonlinear analysis of structures using finite elements. Part II: arches, frames and axisymmetric shells. International Journal for Numerical Methods in Engineering, v.23, p.253-274.

ONAT, E.T.; LECKIE, F.A. (1988). Representation of mechanical behavior in the presence of changing internal structure. Journal of Applied Mechanics, v.55, p.110.

PAI, P.F.; NAYFEH, A. H. (1994). A new method for the modeling of geometric nonlinearities in structures. Computers and Structures, v.53, p.877-895. 
PIMENTA, P.M. (1986). Aspectos da análise não-linear de estruturas reticuladas. In: CONGRESSO LATINO-AMERICANO SOBRE MÉTODOS COMPUTACIONAIS EM ENGENHARIA, 7., São Carlos. Anais.v.1, p.449-464.

PITANGUEIRAS, R.L.; SILVA, R.R. (2000). Investigação de um modelo constitutivo para estruturas de concreto [CD-Rom]. In: XX CILAMCE, Rio de Janeiro, 2000. 21p.

PROENÇA, S.P.B. (1997). Análise não-linear de estruturas - notas de aula. São Carlos. 127p.

PROENÇA, S.P.B. (1988). Sobre modelos matemáticos do comportamento nãolinear do concreto: análise crítica e contribuições. São Carlos. 330p. Tese (Doutorado) - Escola de Engenharia de São Carlos, Universidade de São Paulo.

RIERA, J.D.; TORELLY, E. (1985). Sobre as propriedades dinâmicas de vigas de concreto armado submetidas a vibrações de flexão. Porto Alegre, CPGEC, Universidade Federal do Rio Grande do Sul. (Relatório Técnico)

RIOS, R.D. (1994). Determinação das propriedades dinâmicas das estruturas mediante o emprego de modelos em escala reduzida. Porto Alegre. 105p. Dissertação (Mestrado) - Escola de Engenharia da Universidade Federal do Rio Grande do Sul.

SAETTA, A.V.; SCOTTA, R.; VITALIANI, R.V. (2000). Shear behaviour of R.C. structures analyzed by means of a two parameters damage model [CD-Rom]. In: XX CILAMCE, Rio de Janeiro, 2000. 20p.

SAVASSI, W. (1996). Introdução ao método dos elementos finitos: em análise linear de estruturas. São Carlos, EESC-USP. 260p.

SIMO, J.C.; FOX, D.D.; RIFAI, M.S. (1990). On a stress resultant geometrically exact shell model. Part III: Computational aspects of the nonlinear theory. Computer Methods in Applied Mechanics and Engineering, v.79, p.21-70.

SIMO, J.C.; JU, J.W. (1987). Strain- and stress-based continuum damage models - I. Formulation. International Journal of Solids and Structures, v.23, n.7, p.821-840.

SIMO, J.C.; JU, J.W. (1987). Strain- and stress-based continuum damage models II. Computational aspects. International Journal of Solids and Structures, v.23, n.7, p.841-869.

SOUZA LIMA, V.M.; PIMENTA, P.M.; BRASIL, R.M.L.R.F. (1996). On the analysis of planar framed structures of geometrically nonlinear behavior. In: TAROCO, E.; VENÂNCIO FILHO, F.; BEVILACQUA, L., eds. Recent developments in solids mechanics. Rio de Janeiro, LNCC/CNPq. p.93-97. 
SOUZA LIMA, V.M.; VENÂNCIO FILHO, F. (1984). A noção de rigidez tangente no estudo da não-linearidade geométrica de estruturas reticuladas. In: CONGRESSO LATINO-AMERICANO SOBRE MÉTODOS COMPUTACIONAIS EM ENGENHARIA, 5., Salvador. p.1-24

STEINMANN, P.; CAROL, I. (1998). A framework for geometrically nonlinear continuum damage mechanics. International Journal of Engineering Science, v.36, p.1793-1814.

SURANA, K.S.; SOREM, R.M. (1989). Geometrically non-linear formulation for three dimensional curved beam elements with large rotations. International Journal for Numerical Methods in Engineering, v.28, p.43-73.

VECCHIO, F.J.; EMARA, M.B. (1992). Shear deformations in reinforced concrete frames. ACI Structural Journal, v.89, n.1, p.46-56.

VOYIADJS, G.Z.; KIOUSIS, P.D. (1987). Stress rate and the lagrangian formulation of the finite-strain plasticity for a von mises kinematic hardening model. International Journal Solids Structures, v.23, n.1, p.95-109.

ZIENKIEWICZ, O.C.; TAYLOR, R.L. (1989). The finite element method. 4.ed. London, McGraw-Hill.

YAGHMAI, S.; POPOV, E.P. (1971). Incremental analysis of large deflections of shells of revolution. International Journal Solids Structures, v.7, p.1375-1393.

YAZDANI, S.; SCHREYER, H.L. (1990). Combined plasticity and damage mechanics model for plain concrete. Journal of Engineering Mechanics, v.116, n.7, p.1435-1450.

WANG, Z.; LIN, R.M.; LIM, M.K. (1997). Structural damage detection using measured FRF data. Computer Methods in Applied Mechanics and Engineering, v.147, p.187-197.

WASZCZYSZYN, Z. (1983). Numerical problems of nonlinear stability analysis of elastic structures. Computers and Structures, v.17, n.1, p.13-24.

WEN, R.K.; RAHIMZADEH, J. (1983). Nonlinear elastic frame analysis by finite element. Journal of Structural Engineering, v.109, n.8, p.1952-1971.

WRIGGERS, P. (1990). Lectures on continuum mechanics, nonlinear finite element techniques and computacional stability. Udine, Italy, CISM. (Notas do curso de análise não-linear). 


\section{ANEXO A}

\section{MÉTODO DO DESLOCAMENTO CONTROLADO}

O método incremental iterativo de Newton-Raphson, clássico, utilizado para obtenção da solução numérica de problemas não-lineares é aplicado quase sempre tendo a carga como parâmetro controlador. Porém, com esse tipo de controle não é possível seguir toda a trajetória de equilíbrio, se esta incluir pontos limites. Uma alternativa, neste caso, constitui em utilizar o deslocamento como parâmetro controlador do processo incremental. No entanto, mesmo controlando os deslocamentos pode haver problemas quando a trajetória de equilíbrio implicar em redução de carga acompanhada de redução de deslocamento, numa resposta denominada "snap-back". Para problemas simples, que não envolvem tal fenômeno o controle de deslocamento constitui uma boa alternativa de solução. Neste caso, a estratégia consiste em estabelecer incrementos de deslocamentos, impostos à estrutura como deslocamentos prescritos, $\bar{d}_{i}$. Deste modo, o sistema de equações passa a ser dado por:

$$
\left[\begin{array}{cccccc}
K_{11} & K_{12} & \ldots & 0 & \ldots & K_{1 n} \\
K_{21} & K_{22} & \ldots & 0 & \ldots & K_{2 n} \\
\vdots & \vdots & \ddots & 0 & \ddots & \vdots \\
0 & 0 & \ldots & 1 & \ldots & 0 \\
\vdots & \vdots & \ddots & 0 & \ddots & \vdots \\
K_{n 1} & K_{n 2} & \ldots & 0 & \ldots & K_{n n}
\end{array}\right]\left\{\begin{array}{c}
d_{1} \\
d_{2} \\
\vdots \\
d_{i} \\
\vdots \\
d_{n}
\end{array}\right\}=\left\{\begin{array}{c}
f_{1}-K_{1 i} \bar{d}_{i} \\
f_{2}-K_{2 i} \bar{d}_{i} \\
\vdots \\
\bar{d}_{i} \\
\vdots \\
f_{n}-K_{n i} \bar{d}_{i}
\end{array}\right\}
$$

Na realidade o sistema de equações é reduzido à ordem de $n-m$, sendo $n$ o número total de equações e $m$ o número de deslocamentos prescritos. O sistema de equações apresentado em (A.1) é empregado na primeira iteração de cada incremento de deslocamento, podendo-se notar que os deslocamentos prescritos são transformados em forças. No processo iterativo de correção, calcula-se um resíduo dado por:

$$
\psi=F^{e x t}-F^{i n t}
$$


sendo:

$F^{e x t}$ o vetor de forças externas aplicadas, nulo na primeira iteração, uma vez que nenhum carregamento é aplicado; $F^{\text {int }}$ o vetor de forças internas, resultante do estado de tensão proviniente do campo de deslocamento presente.

É importante ressaltar que, a rigidez deve ser atualizada de acordo com a nãolinearidade envolvida no problema. Em particular na coordenada nodal i, cujo deslocamento é deslocamento prescrito, esse valor deve ser mantido constante ao longo de cada incremento, ou seja, a variação de deslocamento nessa coordenada é nulo para todas as iterações.

Cabe ressaltar que quando se considera a não-linearidade física (dano) a variável utilizada para verificação do processo de evolução do dano deve ser mantida constante durante o procedimento iterativo, sendo atualizada após cada incremento de deslocamento. Isso se deve ao fato deste procedimento não corresponder ao Método de Newton-Raphson e sim a um procedimento de previsão e correção. Deste modo, as variáveis $s(D)$, Modelo de Mazars, e $Y_{1}$ e $Y_{2}$ (modelo de La Borderie) são atualizadas somente após a convergência de cada passo. 


\section{ANEXO B}

ANÁLISE COMPARATIVA ENTRE OS MÉTODOS UTILIZADOS PARA A INTEGRAÇÃO DAS TENSÕES AO LONGO DA ALTURA DA SEÇÃO TRANSVERSAL

Nas Figuras B.1 e B.2 estão apresentados os resultados dos deslocamentos verticais do ponto situado no meio do vão, das vigas do exemplo 1 do capítulo 3, considerando-se 3 métodos diferentes para integração ao longo da altura da seção transversal. Para integração ao longo do comprimento emprega-se o método de Gauss-Lobatto, 6 pontos. O aço é considerado elastoplástico com encruamento cinemático.

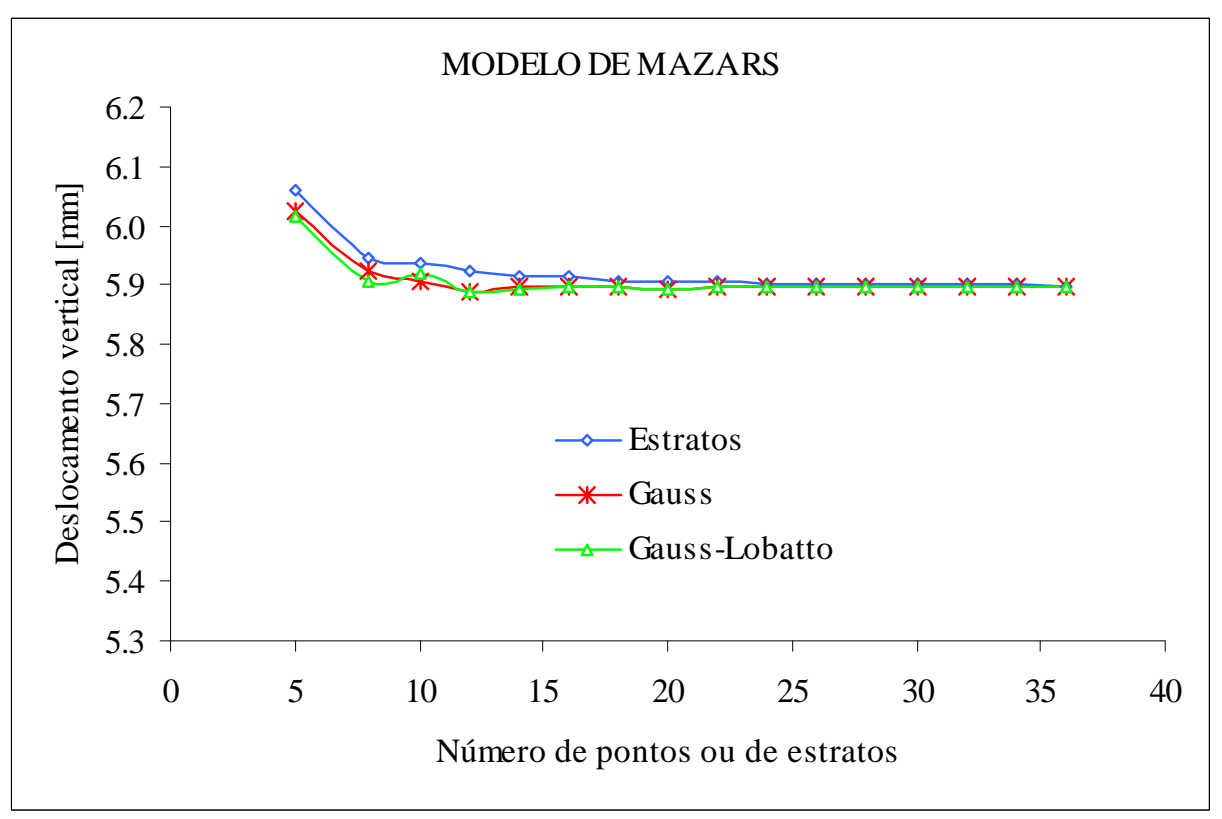

Figura B.1- Variação do deslocamento vertical em função do método empregado para a integração 


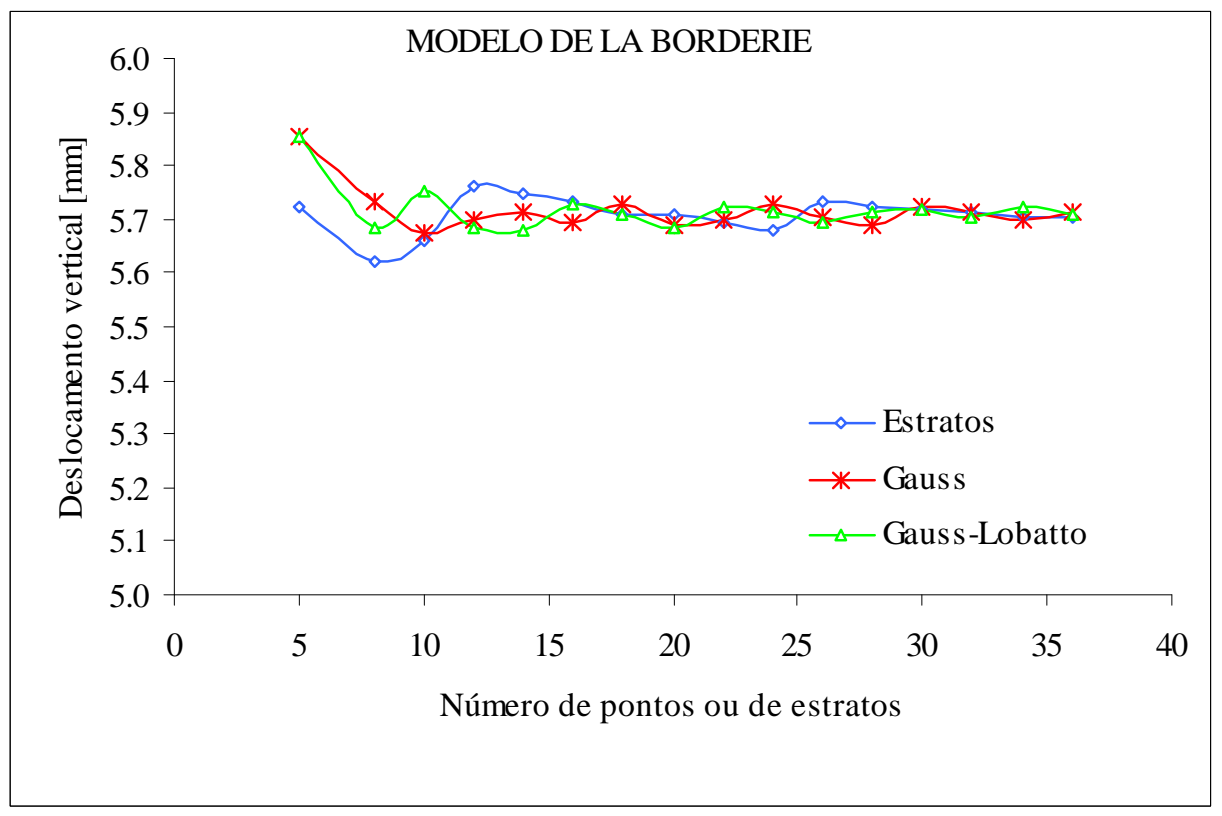

Figura B.2- Variação do deslocamento vertical em função do método empregado para a integração

Pode-se observar que a partir de $n=20$, o valor dos resultados obtidos, com os diferentes métodos, não apresentam grandes variações. Deste modo, na integração das tensões ao longo da altura da seção transversal, no trabalho, adotaram-se 20 pontos de Gauss-Lobatto.

Um estudo similar realizado em placas semi-espessas foi desenvolvido por NOVOTNY et al (1994). 